Université Paris-Diderot - Sorbonne Paris Cité

UFR d'Études Psychanalytiques

Centre de Recherches Psychanalyse, Médecine et Société (EA 3522)

École Doctorale Recherches en Psychanalyse et Psychopathologie (ED 450)

En cotutelle avec

Universidade de São Paulo

Instituto de Psicologia da Universidade de São Paulo - IPUSP

Departamento de Psicologia Clínica

\title{
Psychanalyse et génétique médicale : une rencontre possible à partir du syndrome du chromosome $X$ fragile
}

\author{
Thèse de Doctorat présentée par Andréa Sousa Varela \\ Thèse dirigée par le Professeur Karl-Leo Schwering \\ Thèse co-dirigée par la Professeure Maria Lívia Tourinho Moretto \\ Soutenue publiquement le 5 octobre 2017
}

Jury

Professeur Karl-Leo Schwering, Université Paris 13, Sorbonne Paris Cité, Directeur de thèse Professeure Maria Lívia Tourinho Moretto, Universidade de São Paulo, Co-Directrice de thèse Professeur François Villa, Université Paris - Diderot, Sorbonne Paris Cité, Président du jury Professeure Karla Patrícia Holanda Martins, Universidade Federal do Ceará, Rapporteuse Professeure Régine Scelles, Université Paris Nanterre, Rapporteuse

Professeur Daniel Kuppermann, Universidade de São Paulo, membre invité

(c) $\$ \bigoplus \begin{aligned} & \text { Except where otherwise noted, this work is licensed under } \\ & \text { http://creativecommons.org/licenses/by-nc-nd/3.0/ }\end{aligned}$ 
Titre : Psychanalyse et génétique médicale : une rencontre possible à partir du syndrome du chromosome $X$ fragile

Résumé : Cette thèse part de la proposition d'une rencontre possible entre psychanalyse et génétique médicale par le biais des soins offerts aux enfants porteurs de syndromes génétiques, notamment le syndrome de l'X fragile. Nous avons trouvé dans les recherches en épigénétique une voie de rapprochement de ces différents champs du savoir. L'idée selon laquelle l'environnement est capable de modifier l'expression des gènes représente la rupture d'un certain déterminisme génétique autrefois accepté, et ouvre un espace où penser la singularité. Notre travail propose d'élargir le concept d'environnement, en y considérant la relation de l'enfant avec l'Autre, lieu du langage, comme opérateur de marques sur son corps : marques symboliques, constituées dès le tout début de la rencontre de l'infans et de ceux qui s'occupent de lui. C'est justement dans cet espace d'échange avec l'Autre qu'a lieu l'émergence d'un sujet. Nous avons opté pour les concepts de sujet et de transfert pour soutenir l'articulation de la clinique psychanalytique et de la génétique médicale en ce qui concerne le traitement. Nous avons donc exposé trois cas cliniques issus de notre pratique, d'enfants traversés par le diagnostic de l'X fragile afin d'illustrer de quelle manière les conceptions de sujet et de transfert se reflètent dans la clinique. Tenant compte que la psychothérapie est également prise comme objet d'étude de l'épigénétique, et qu'elle est donc considérée comme un environnement capable de provoquer, voire de renverser des marques épigénétiques, l'enjeu de notre travail repose sur la proposition suivante: et pourquoi pas la psychanalyse également ? La psychothérapie psychanalytique, ancrée sur le transfert, ne peut-elle pas, elle aussi, laisser des marques sur le petit patient?

Mots clefs : Psychanalyse; Génétique Médicale ; Syndrome de l'X fragile ; Épigénétique; Clinique psychanalytique ; enfance.

Title : Psychoanalysis and medical genetics: a possible encounter from the fragile $X$ syndrome

Abstract : The current thesis assumes a possible encounter between psychoanalysis and medical genetics based on the treatment applied to children carrying genetic syndromes such as the Fragile $\mathrm{X}$ Syndrome. Epigenetic studies are a way to approximate different knowledge fields. The assumption that the environment is able to change gene expression strays from the genetic determinism we once believed and opens the way for us to reason about singularity. The proposition in the present study lies on expanding the concept of environment, by taking into consideration the relation between the child and the Other in the environment in question, as well as the place of language as the operator marking the child's body. These symbolic marks start emerging in the first encounter between the infans and caregivers. The subject emerges precisely 
within an environment of exchanges that is set with the Other. The concepts of subject and transference were chosen to support the treatment articulation between psychoanalytic clinic and medical genetics. Thus, the present study reports three clinical cases followed by the authors, which involved children diagnosed with fragile $\mathrm{X}$ syndrome. These cases illustrate how the aforementioned concepts affect the clinical practice. Since psychotherapy has also been taken as the object of epigenetic studies, and as it is considered an environment able to cause, and even reverse, epigenetic marks, the current study relies on the following proposition: why not psychoanalysis as well? Can the psychoanalytic psychotherapy, anchored in the concept of transference, leave marks on the little patient too?

Keywords : psychoanalysis medical genetics; fragile X syndrome; epigenetics; psychoanalytic clinic; childwood.

Título: Psicanálise e genética médica: um encontro possível a partir da síndrome do cromossomo X frágil.

Resumo: Esta tese parte da proposição de um encontro possível entre psicanálise e genética médica através do tratamento oferecido às crianças com síndromes genéticas, notadamente a Síndrome do X Frágil. Encontramos nas pesquisas em epigenética uma via de aproximação entre os distintos campos de saber. A ideia de que o ambiente é capaz de alterar a expressão dos genes quebra com um certo determinismo genético outrora acreditado, abrindo espaço para se pensar a singularidade. Nosso trabalho propõe a ampliação do conceito de ambiente, considerando nele a relação da criança com o Outro, lugar da linguagem, como operadora de marcas no seu corpo: marcas simbólicas, constituídas desde os primórdios do encontro do infans com seus cuidadores. É justamente nesse ambiente de trocas com o Outro que se dá a emergência de um sujeito. Os conceitos de sujeito e transferência foram escolhidos para sustentarmos a articulação da clínica psicanalítica com a genética médica no que concerne o tratamento. Assim, expusemos três casos clínicos oriundos de nossa prática, de crianças atravessadas pelo diagnóstico de $\mathrm{X}$ frágil no intuito de ilustrar de que forma as concepções de sujeito e transferência incidem na clínica. Levando-se em conta que a psicoterapia tem sido igualmente tomada como objeto de estudo da epigenética, sendo, desta forma, considerada como ambiente capaz de provocar e até mesmo reverter marcas epigenéticas, a aposta de nosso trabalho repousa na seguinte proposição: $e$ por que não a psicanálise também? Será que a psicoterapia psicanalítica, ancorada na transferência, não pode ela também provocar marcas no pequeno paciente?

Palavras-chave: psicanálise; genética médica; síndrome do cromossomo X frágil; epigenética; clínica psicanalítica; infância. 
À Paulo Varela

En mon nom, pour mon nom. 
O correr da vida embrulha tudo. A vida é assim: esquenta e esfria, Aperta e dai afrouxa, Sossega e depois desinquieta. O que ela quer da gente é coragem.

Le passage de la vie enveloppe tout. Ainsi est la vie : elle réchauffe et refroidit, serre et relâche. Elle se calme et puis s'agite. Ce qu'elle attend de nous, c'est du courage.

Guimarães Rosa Grande Sertão Veredas 


\section{Remerciements}

C'est dans la rencontre avec l'Autre qu'émerge le sujet. Notre insuffisance primordiale exige que le sens de notre existence soit traversé par les relations qui nous composent. Et au fil des rencontres, nos vies se tissent. Ainsi, le parcours d'élaboration et de rédaction de cette thèse n'aurait pas été possible sans les marques laissées par les rencontres avec mes pairs.

«As distâncias somam a gente para menos [Les distances nous somment à l'envers] $»^{1}$, disait le poète Manoel de Barros. Je remercie Maria de Fátima Sousa Lima et Cleovonsóstenes Varela pour m'avoir donné la possibilité, également psychique, de m'aventurer sur d'autres terres, alors même qu'on savait l'agonie et le poids contenu dans le mot saudade. Je remercie également la présence, même distante, de mes frères Eduardo et Thiago, piliers de ma Fortaleza.

Paris m'a permis la rencontre de Manoel Madeira, dont le sens dépasse tous les mots d'amour et de reconnaissance. Je te remercie d'avoir partagé si généreusement ta force dans les moments les plus ardus du parcours de cette thèse. Ta force : matière-première non seulement de cette thèse mais de ce que je suis devenue et de mon constant devenir.

Je remercie le professeur Karl-Leo Schwering pour avoir accepté de diriger cette thèse, élaborée par une étrangère qui ne dominait alors pas la langue française. Merci pour votre patience, pour vos contributions et pour avoir été le miroir d'un chercheur sérieux, dévoué et responsable quant à son travail et à celui de ses étudiants. Votre posture éthique et respectueuse restera une référence pour ma formation professionnelle.

Un remerciement sincère à ma chère professeure Maria Lívia Moretto pour l'accueil si chaleureux fait à ma recherche depuis ses premiers pas, et pour son engagement dans la réalisation de ma cotutelle. Sans son courage et sa détermination, mon projet de rencontre entre l'Université Paris-Diderot et l'Université de Sao Paulo n'aurait pas été possible. Merci également pour l'écoute attentive et pour les orientations précises qui m'ont aidée à diriger cette recherche.

Je remercie Régine Scelles pour la disponibilité et la générosité dont elle a fait preuve en acceptant d'être rapporteuse de cette thèse. Ma sincère reconnaissance à une chère professeure, Karla Patrícia Martins, non seulement pour la disponibilité d'être rapporteuse de ma recherche, mais aussi pour avoir donné consistance, et ce, depuis mes premières années

\footnotetext{
${ }^{1}$ BARROS Manoel (2010). Poesia Completa.
} 
d'université, à ma rencontre avec la psychanalyse. L'admiration que j'éprouve pour son travail et pour son application dans la transmission de la psychanalyse a constitué et constitue encore ce que je suis devenue aujourd'hui.

Je remercie la Dr. Têmis Félix pour avoir accepté de dialoguer avec un savoir aussi opposé au sien, rendant ainsi réalisable la proposition de ce travail. Mon remerciement à la professeure Simone Moschen qui m'a prêté son écoute alors que cette recherche n'était encore qu'à l'état d'embryon. Merci pour votre disponibilité et pour m'avoir accompagnée dans la trajectoire de soumission du projet de recherche à l'Hospital de Clínicas de Porto Alegre.

Merci à mes collègues de la Fadem, en particulier Laura Corso, Lívia Dávalos, Amanda da Costa, Luciana Loureiro et Nina Kloss, pour partager le désir de faire une clinique si difficile mais tellement possible. Pour les conversations qui, d'une certaine manière, permettent l'écoulement des angoisses qui traversent la confrontation à des questions organiques chez des enfants et/ou au développement de ceux-ci ; mais aussi pour le partage des satisfactions liées à l'évolution de chaque cas. Je remercie l'équipe du CAMSP, en particulier Sabine Lewartowski et Patricia Rochut pour avoir orienté vers moi les cas cliniques travaillés dans cette thèse. Merci pour votre accueil et pour votre générosité dans le partage d'expériences, d'inquiétudes et d'espérances.

Mes remerciements aux très chères Marieta Madeira, Antônia Rodrigues et Flora Rodrigues, pour leur accueil fondamental à Porto Alegre : pour le soin, pour la tendresse, pour les rires, mais aussi pour leur maîtrise de la langue anglaise. Un grand merci à Charlotte Dafol et Annie Cambe pour leur attention, leur application et leur disponibilité au moment du passage d'une langue à l'autre. À ma chère Léa, merci pour ton amitié construite à Paris et pour ton affection chaleureuse qui fait tellement défaut à ceux qui sont loin des leurs.

Les rencontres parisiennes ont également produit des liens d'amitié sans lesquels mon aventure aurait été infiniment plus pénible. Leidiana Martins - souffle de vent natif en terre étrangère -, Marina Mafra, Niely Pontes, Lucas Bloc - compagnon de BnF -, Thomas Lepoutre et Nicolas Rabin : merci pour m'avoir accompagnée sur ce chemin. Lia Ciarlini et Luciana Oliveira, rencontres d'enfance ayant produit des liens fraternels; Eliziane Vasconcelos, merci pour l'appui et pour le soutien sans faille.

Parce que la vie est l'art de la rencontre. 


\section{Table des matières}

$\begin{array}{ll}\text { Remerciements } & 06\end{array}$

$\begin{array}{ll}\text { Avant-propos } & 11\end{array}$

$\begin{array}{ll}\text { Introduction } & 15\end{array}$

\section{Chapitre I}

Articulation clinique entre la génétique médicale et la psychanalyse : ouverture d'un champ de recherches possibles

1.1. Ouverture 25

1.2. Note sur une rencontre : Freud et la médecine 26

1.3. Psychanalyse et Médecine 32

1.4. La psychanalyse et les neurosciences 37

1.5. La psychanalyse et la génétique 45

1.6. Conclusion $\quad 54$

Chapitre II

Considérations sur le syndrome de l'X fragile - un saut entre deux savoirs

2.1. Ouverture 55

2.2. Présentation du syndrome 56

2.3. Causes génétiques 60

2.4. Symptomatologie 65

2.5. Diagnostic 69

2.6. Traitement 71

2.7. Autisme versus X fragile 77

2.8. Autisme et DSM 82

2.9. Conclusion 87 


\section{Chapitre III}

\section{L’épigénétique : l'indétermination génétique}

3.1. Ouverture $\quad 89$

3.2. Le concept d'épigénétique 91

3.3. L'environnement et son influence 95

3.4. Le modèle animal 97

3.5. Les marques épigénétiques chez les humains 99

3.6. L'environnement et la psychanalyse 106

3.7. La psychothérapie comme environnement 109

3.8. Conclusion 115

\section{Chapitre IV}

Le dispositif clinique de la psychanalyse : quelques considérations sur les concepts de sujet et de transfert

4.1. Ouverture 117

4.2. L'autisme comme point historique de tension entre génétique 119 médicale et psychanalyse

4.3. Le concept de sujet 129

4.4. Le concept de transfert 138

4.5. Conclusion 143

\section{Chapitre V}

La clinique psychanalytique en acte : présentation des cas cliniques

5.1. Ouverture 146

5.2. Le cas Maria 148

5.3. Le cas Flora 162

5.4. Le cas Benjamin 173

5.5. Note sur une proposition de recherche théorico-clinique 181

$\begin{array}{lll}\text { 5.6. Conclusion } & 184\end{array}$ 
Considérations finales

185

Références bibliographiques

192

Annexe

208 


\section{Avant-Propos}

Cette thèse, à cheval entre la psychanalyse et la génétique médicale, est le fruit d'une cotutelle entre 1'Université Paris-Diderot et l'Universidade de São Paulo. Notre parcours s'est divisé en deux temps : la première moitié du doctorat, financée par le gouvernement brésilien par le biais de la CAPES ${ }^{1}$, s'est déroulée en France, et la seconde moitié, au Brésil. C'est ainsi que s'est construit ce travail : à la croisée de deux pays, de deux langues, de deux cultures, de deux champs de savoir différents. L'enjeu d'écrire une thèse dans une autre langue n'a pas été moindre que celui auquel elle se propose : permettre une rencontre entre la psychanalyse et la génétique médicale. Enjeu poursuivi tant en théorie qu'en pratique clinique dans des institutions françaises et brésiliennes.

Dès l'époque des premiers cycles universitaires, nous avons pris contact pour la première fois avec ce sur quoi nous avons décidé de continuer à travailler : la clinique d'enfants présentant des complications organiques. Nous connaissons, grâce à la psychanalyse, la rencontre primordiale et cruciale du petit individu avec ceux qui s'occupent de lui au début de sa vie, et nous savons que c'est à partir de ce lien que se constituera un sujet. Cette rencontre n'est pas naturelle ni donnée au départ : elle est parsemée de minuties qui la composent, y compris de possibles entraves. Qu'en est-il de l'enfant lorsque son insuffisance primordiale est aggravée par des questions organiques qui gênent sa reconnaissance à la place qui lui était destinée chez l'Autre, avant même sa naissance ?

Attentif à cette impasse et en vue d'en signaler les risques pour le développement du petit individu, notre parcours est, depuis le début, consacré à cette clinique d'enfants porteurs d'affections organiques. Tout d'abord, lors de notre formation de base, nous avons participé au projet d'Intervenção Precoce, dans le cadre d'un stage hors programme. Le projet était destiné à des bébés de 0 à 3 ans présentant des limitations organiques et des retards du développement, pris en charge par le service de Estimulação Precoce da Terapia Ocupacional, au sein de l'Universidade de Fortaleza. Nous faisions partie d'une équipe interdisciplinaire composée de professionnels de physiothérapie, d'orthophonie, de psychologie et de thérapie occupationnelle. Lors du stage obligatoire en Clinique, encore à l'université, nous avons reçu Maria, l'enfant qui, affectée par le syndrome du chromosome

\footnotetext{
${ }^{1}$ Nous avons obtenu une bourse, dans le cadre du programme Bourse de doctorat plein à l'étranger, de juillet 2014 à décembre 2015. Numéro du dossier : 0447/14-5
} 
de l'X fragile, a fait surgir de nombreuses remises en question qui sont devenues notre force de travail. Dans notre cabinet particulier, nous avons donné suite au travail avec le même public. Toutefois, les énigmes autour de l'histoire de Maria n'ont pas cessé de s'imposer : nous avons alors décidé d'accorder la place qu'elles méritaient à ces questions dans nos études de master.

Nous avons commencé en France notre mastère au Centre de Recherches Psychanalyse, Médecine et Société, à l'Université Paris-Diderot, sous la direction de la professeure Drina Candilis, qui a abouti à notre dissertation intitulée : Psychanalyse et Médecine génétique : essai d'articulation entre les différents champs du savoir à partir d'un travail sur le syndrome du chromosome X fragile. Durant notre investigation sur l'X fragile, nous avons été confronté à quatre questions qui, dans un certain sens, ont été surprenantes pour nous: 1) l'attribution au syndrome d'une diversité de symptômes dits comportementaux; 2) la considération de l'X fragile comme cause génétique la plus fréquente de l'autisme; 3) l'absence de référence au savoir psy dans les recherches consultées, abordant des catégories diagnostiques n'appartenant pas à leur champ théorique ; et 4) l'indication d'un passage direct entre mécanisme organique et symptôme psychique. Bien que ces questions indiquent, d'une certaine manière, des critiques au savoir médical sur le syndrome, il fallait prendre une position éthique en ce qui concerne les petits patients. Nous avons donc décidé d'essayer par le biais du traitement un rapprochement de cette médecine, afin de faire également une place aux questions psychiques qui font partie de l'histoire de l'enfant. Ainsi, la rencontre avec le discours médical sur le syndrome de l'X fragile, d'où ont surgi les questions ci-dessus énumérées, nous a encouragée à poursuivre dans le cadre d'une recherche doctorale.

Parallèlement aux recherches théoriques, nous avons exercé en France une activité clinique au CAMSP - Centre d'action médico-sociale précoce, institution qui prend en charge des enfants de 0 à 6 ans, souffrant également de problèmes organiques et/ou au développement. Nous y avons réalisé le suivi psychothérapique de la petite Flora et de Benjamin, deux enfants également affectés par le syndrome de l'X fragile. Nous avons publié un article dans la revue Topique sur les cas en question, article intitulé L'émergence de la parole chez l'enfant à la croisée de la médecine génétique et de la psychanalyse, dans lequel nous avons réfléchi aux effets du discours médical sur les difficultés de langage présentées par Flora et Benjamin. Nous avons aussi proposé un projet de recherche au Service de génétique et de cytogénétique du groupe hospitalier la Pitié Salpêtrière, en vue de 
mettre en relief les représentations psychiques de l'expérience d'avoir un enfant porteur du syndrome de l'X fragile. Bien qu'autorisée au départ par le chef de service, l'exécution de ce projet n'a pas abouti, car le retour au Brésil s'approchait.

Une fois sur le sol brésilien, nous avons donné suite à notre pratique clinique à la FADEM - Fundação de Atendimento de Deficiência Múltipla. Cette institution, de caractère interdisciplinaire, prend en charge des enfants et des adolescents présentant des déficiences organiques et/ou des retards du développement. Nous y avons réalisé la prise en charge psychothérapeutique des patients et de leurs familles. Nous entretenons encore un dialogue constant avec d'autres champs de savoir (thérapie occupationnelle, orthophonie, physiothérapie, pédagogie, éducation physique, psychologie et service social) qui composent le traitement offert à cette population pour laquelle nous nourrissons un intérêt tout particulier. Nous avons publié dans la Revista Brasileira de Psicologia Hospitalar un article intitulé Síndrome do Cromossomo X frágil: uma articulação possível entre psicanálise $e$ genética médica?, dans lequel nous nous penchons sur les possibilités de rapprochement entre ces deux champs par les recherches en épigénétique.

Nous entamons actuellement l'exécution d'un projet de recherche au Service de génétique médicale de l'Hospital de Clínicas de Porto Alegre. L'objectif de ce projet est d'évaluer quels seraient les effets (si tant est qu'il y en ait) de la psychothérapie psychanalytique pour les enfants porteurs du syndrome de l'X fragile. Il convient de noter qu'il ne sera pas possible d'en présenter les résultats dans cette thèse. En effet, à l'instar de ce qui s'est passé en France, l'approbation finale du projet par le Comité d'éthique de l'hôpital a pris un temps assez significatif et il n'a été approuvé que peu avant la finalisation de la rédaction de notre thèse. Quoi qu'il en soit, vu l'importance de ce projet dans notre parcours, nous avons décidé d'y donner suite et de mettre en pratique ce que nous avons proposé à l'hôpital.

Nous reconnaissons les limites de la portée et de la faisabilité de notre proposition. Toutefois, nous pouvons aussi souligner le potentiel de ce travail. Il s'agit d'une thèse moins classique, s'ouvrant au champ médical et qui se met en outre à disposition pour une rencontre avec l'autre savoir. Nous ne visons absolument pas à ce que le médecin devienne psychanalyste ou s'occupe de la subjectivité des patients. Nous pensons que la psychanalyse peut contribuer à la génétique médicale, aussi bien en ce qui concerne le traitement que les 
recherches de l'épigénétique qui s'intéressent à la relation de l'enfant à son environnement. $\mathrm{Si}$ certaines recherches contemporaines se penchent sur les effets de la psychothérapie produisant des modifications épigénétiques, notre question - et notre pari - est la suivante : et pourquoi pas la psychanalyse? 


\section{Introduction}

L'environnement est capable de modifier l'expression génique, affirment depuis quelques décennies les études de l'épigénétique ${ }^{1}$. C'est sur cette prémisse que se tisse notre thèse, en proposant une articulation entre psychanalyse et génétique médicale, par le biais du traitement d'enfants syndromiques et par l'élargissement de la notion d'environnement. C'est-à-dire un environnement qui considère la relation de l'enfant avec l'Autre, lieu du langage, comme opérateur de marques sur son corps. Il s'agit d'un objectif inhabituel dans les deux champs de savoir et c'est d'ailleurs pour cela que le caractère de cette thèse est clairement de proposer un appel à des dialogues possibles. Cette proposition s'inscrit ici par divers biais : par la recherche des possibilités de lien entre les deux disciplines et par la recherche bibliographique à cette intersection de savoirs (chapitre un) ; par l'étude de la génétique médicale (chapitres deux et trois); par une transmission de la psychanalyse qui converse avec elle (chapitre quatre) ; par les interventions - et les projets d'interventions cliniques en psychanalyse avec des enfants syndromiques (chapitre cinq et annexe).

De plus, nous visons à étayer ce dialogue par la forme même d'écriture et d'adresse du texte. Dans Lector in fabula, Umberto Eco travaille sur la notion du lecteur modèle, lecteur qui organise le texte comme toile de fond : « un texte postule son propre destinataire comme condition indispensable non pas seulement de sa capacité concrète de communication, mais aussi de sa potentialité significative. Dans d'autres termes, un texte est émis à quelqu'un qui l'actualise - bien qu'il n'existe pas concrète ou empiriquement $»^{2}$. C'est pour un lecteur abstrait que le texte se tisse, s'oriente : c'est avec lui que l'écrit vise à dialoguer. Dans ce sens, si une thèse en psychanalyse vise un public averti, notre lecteur modèle peut aussi être tourné vers le champ médical - professionnels, chercheurs, étudiants. On suppose évidemment que ces deux lecteurs modèles imaginaires, pour ainsi dire, se retrouvent avec ce texte imbus d'une certaine envie de conversation - et c'est la tenant toujours dans son horizon, que cet écrit se tisse.

Cette thèse est née à partir de la clinique psychanalytique. La rencontre avec la petite Maria, une enfant de six ans dont l'histoire a été traversée par le diagnostic du syndrome de

\footnotetext{
${ }^{1}$ Voir HEARD Edith (2013). Épigénétique et mémoire cellulaire.

${ }^{2}$ Voir ECO Umberto (1979). Lector in Fabula, 37. Traduction libre de l'auteure.
} 
l'X fragile a été le moteur de notre investigation sur cette modification génétique. Nous avons découvert des brèches dans le discours de la littérature médicale sur ce syndrome qui ont suscité en nous l'envie de passer outre à la critique historique - et limitante - de la psychanalyse à la médecine et de proposer un dialogue possible en ce qui concerne le traitement d'enfants syndromiques.

La proposition de rencontre entre psychanalyse et génétique médicale peut paraître étrange tant aux psychanalystes qu'aux médecins généticistes. Dans la littérature psychanalytique étudiée, rares sont les œuvres se proposant au dialogue entre les champs. Nous avons trouvé dans le champ de l'épigénétique des recherches qui s'ouvrent, pour nous, au savoir de la psychanalyse, permettant ainsi une intersection de savoirs autour des données obtenues par la génétique. L'assertion selon laquelle l'environnement est capable de modifier l'activité génétique et que ces modifications peuvent être transmises aux prochaines générations n'est peut-être plus une nouveauté ${ }^{1}$. Pourquoi ne pas parier que l'environnement conçu par la psychanalyse - les échanges avec le semblable, la rencontre avec l'Autre du langage, le lien social, la relation transférentielle - engendrerait aussi des changements dans les fonctions corporelles?

«On n'est pas meilleur médecin pour être mauvais psychanalyste [...] et on n'est pas plus instruit en psychanalyse pour être ignorant en médecine $»^{2}$, indiquait Jacques Lacan au début de son enseignement. Bien que Lacan soit également reconnu par les critiques qu'il a adressées au discours médical de son temps, cette simple indication peut nous servir d'adage épistémologique, vu qu'alimenter les divergences entre psychanalyse et médecine appauvrit la thérapeutique de ces deux disciplines. Ainsi, la construction de cette thèse a visé à trouver un chemin par où cette intersection entre savoirs aussi divergents puisse se concrétiser. Le défi que nous proposons est d'indiquer des tissages possibles entre les pratiques médicales et psychanalytiques par la voie de la clinique de la petite enfance, notamment pour les enfants porteurs du syndrome de l'X fragile.

La critique récurrente adressée à la médecine semble être, dans le champ psychanalytique, une tentation intellectuelle qui se fonde justement sur les différences de ces deux champs du savoir. Notre proposition, comme nous tenterons sans cesse de le soutenir, est de promouvoir l'articulation entre psychanalyse et médecine par la génétique médicale, cet ancrage se faisant sur tout le déroulement de ce travail. Notre objectif est ainsi

\footnotetext{
${ }^{1}$ Voir GONON François (2011). La psychiatrie biologique : une bulle spéculative?

${ }^{2}$ LACAN Jacques (1954). Introduction au commentaire de Jean Hyppolite, 369.
} 
de transiter dans ces deux champs de savoir, en tentant de mettre en évidence les possibilités de ce terrain de recherche encore peu exploré. Considérant que le discours médical tend à privilégier une certaine objectivité de la maladie, nous nous demandons comment la psychanalyse peut introduire dans ce contexte la dimension de la subjectivité. Avant d'investir contre le discours médical par un fondement non prioritaire de ce champ de savoir (celui de la subjectivité), nous avons conçu une initiative de recherche qui s'appuie sur l'articulation de cette dimension tissée avec le savoir de la médecine. Telle est la question qui nous meut et qui alimente le déroulement de notre thèse.

Nous utiliserons dans ce travail deux conceptions de méthodologie : l'exposition de trois cas cliniques et la recherche bibliographique. L'écriture de cas est un outil essentiel de la méthodologie psychanalytique par laquelle Freud a pu construire sa théorie et la rendre consistante. Car, comme nous l'avons indiqué plus haut, c'est de la clinique que naît cette thèse. En 1913, dans son texte Sur la psychanalyse, Freud souligne que « la psychanalyse est une discipline d'un genre inhabituel, dans laquelle une nouvelle forme de recherche sur les névroses coïncide avec une nouvelle thérapie des névroses édifiée sur les résultats de la première. Elle ne repose pas [...] sur la spéculation, mais sur l'expérience et, conformément à cette provenance, elle est inachevée en tant que théorie $»^{1}$. Freud y indique, nous semblet-il, trois temps schématiques, celui de la clinique, celui de la formalisation théorique de la recherche et, enfin, la conséquence de cette construction sur la pratique analytique : clinique et recherche se nourrissent réciproquement, demeurant ainsi toujours inachevées.

Comme nous comprenons qu'il s'agit, d'une certaine manière, d'une proposition peu fréquente dans les champs étudiés, la révision bibliographique de la littérature est aussi un outil méthodologique important pour étayer notre thèse. Ainsi, de notre point de vue, il sera nécessaire de préparer le terrain, de le rendre plus solide, afin que puisse s'y instaurer le dialogue souhaité sur le traitement des enfants syndromiques. La recherche bibliographique permet de localiser les facettes sous lesquelles se présente l'objet dans le discours et la façon dont nous pouvons l'aborder et le découper en fonction de notre intérêt. Ainsi, en articulant théorie et pratique, nous fonderons notre travail, le rendant possible dans le cadre de son propos.

\footnotetext{
${ }^{1}$ FREUD Sigmund (1913). Sur la psychanalyse, 29.
} 
Pour commencer notre parcours, nous présenterons donc, dans le premier chapitre, un bref historique de la rencontre entre la psychanalyse et la médecine, au-delà de la simple indication que Freud était lui-même un médecin neurologue. La psychanalyse naît avec la clinique médicale, lors de la rencontre de Freud et du corps de l'hystérique, ce dernier étant étranger aux pratiques médicales de l'époque et marquant les limites d'un abordage purement anatomique. Depuis lors, bien des textes ont été produits à la rencontre entre ces deux champs. En vue de construire une voie plus accessible, nous exposerons dans ce premier chapitre des travaux d'auteurs venant corroborer notre idée selon laquelle il est possible d'inclure la psychanalyse dans la thérapeutique des services en médecine, notamment en ce qui concerne les soins destinés aux enfants.

Outre la référence aux travaux indiquant la faisabilité de la psychanalyse dans les institutions de santé, nous présenterons également des débats du point de vue théorique cherchant à rapprocher le savoir psychanalytique du savoir médical, notamment des neurosciences. Tout en gardant leurs épistémologies respectives, psychanalyse et neurosciences se retrouvent dans la recherche de la compréhension de la façon dont se construit et se constitue le psychisme humain. C'est autour de la conception de plasticité cérébrale qu'a pu être rompue une divergence historique entre ces deux champs ${ }^{1}$. La preuve apportée par le concept selon lequel le cerveau peut être modifié par l'expérience (inscrite en forme de traces ${ }^{2}$ ), ouvre la possibilité d'émergence du sujet, en introduisant une certaine discontinuité. Certes, la notion de trace en psychanalyse n'équivaut pas à la notion de trace pour les neurosciences. Pour cette dernière, la trace (ensemble de synapses facilitées) serait le correspondant neuronal d'une expérience ou d'un objet de la réalité externe, alors que, pour la théorie freudienne, la trace (trace mnésique) est le signe de la perception et correspond à l'inscription du représentant de l'expérience dans l'appareil psychique ${ }^{3}$. Les différents domaines se rencontrent et dialoguent donc autour des énigmes traversant l'émergence du sujet.

Toujours dans le premier chapitre, nous avons mené une recherche bibliographique dans la littérature psychanalytique en vue de connaître la production portant sur la psychanalyse et la génétique médicale. Nous verrons qu'il s'agit d'une articulation encore peu fréquente, et la nouveauté de ce terrain se fait visible dans notre parcours. Nous

\footnotetext{
${ }^{1}$ Voir ANSERMET François et MAGISTRETTI Pierre (2004). À chacun son cerveau : plasticité neuronale...

${ }^{2}$ Voir MAGISTRETTI Pierre et ANSERMET François (2010). Neurosciences et psychanalyse, 17.

${ }^{3}$ Voir FREUD Sigmund (1900). L'interprétation du rêve, 620.
} 
détacherons surtout l'intervention de psychanalystes dans les services de génétique médicale, en mettant en évidence la fonction du savoir psychanalytique auprès de la population atteinte de maladies génétiques. Nous n'avons pas trouvé de trace, dans la littérature (ni médicale ni psychanalytique), de travaux menés sur les enfants porteurs du syndrome de l'X fragile qui articule les deux champs.

Ainsi, si l'idée principale de cette thèse a trait au traitement des enfants porteurs d'X fragile, nous entendons qu'une connaissance de cette maladie est nécessaire pour étayer notre proposition, à savoir chercher à en comprendre l'origine, les causes, les symptômes, la thérapeutique. Dans notre second chapitre, nous présenterons le syndrome de l'X fragile qui, transmis aussi bien par le père que par la mère à leurs descendants, est considéré comme la principale cause génétique héritée de la déficience intellectuelle et du trouble du spectre autiste ${ }^{1}$.

Ce syndrome est causé par la mutation du gène FMR1, présent dans le chromosome $\mathrm{X}$ et responsable de la synthèse de la protéine FMRP. Cette protéine agit sur le fonctionnement des synapses et sur les structures des cellules neuronales, empêchant également que d'autres protéines soient synthétisées en excès ${ }^{2}$. Avec sa mutation, le gène cesse de la synthétiser, occasionnant un dérèglement de la plasticité synaptique en raison de la forte production d'autres protéines neuronales. Nous soulignons que la mise en sourdine de la FMRP est considérée comme un effet de mécanismes épigénétiques, c'est-à-dire que l'activité du gène FMR1 a été modifiée par l'environnement (encore inconnu) et que cette modification a été transmise entre générations ${ }^{3}$.

Ce qui a attiré notre attention, et qui fera l'objet de débat dans ce deuxième chapitre, c'est le saut observé dans les recherches consultées entre le mécanisme organique et les symptômes qui en dérivent. Or, le mauvais fonctionnement cérébral est considéré, dans ces études, comme cause de symptômes psychiques variés ${ }^{4}$ qui indiqueraient différentes positions de la relation du sujet face à l'Autre du langage. Dans notre recherche bibliographique sur le syndrome, nous n'avons pas trouver d'explication sur la manière dont le manque d'une protéine cérébrale serait, à la fois, à l'origine de l'autisme chez un enfant ou du «trouble obsessionnel-compulsif » chez un autre, par exemple. Nous verrons à quel

\footnotetext{
${ }^{1}$ Voir BERRY-KRAVIS Elizabeth (2014). Mechanism Based Treatments in Neurodevelopmental Disorders...

${ }^{2}$ Voir CHONCHAIYA Weerasak et al. (2009). Fragile X: A family of Disorders.

${ }^{3}$ Voir TABOLACCI Elisabetta et al. (2016). Transcriptional reactivation of the FMR1 gene. A possible...

${ }^{4}$ Parmi les symptômes, citons notamment l'hyperactivité, l'autisme, la phobie sociale, la névrose obsessive, les troubles du langage, l'anxiété sociale, la timidité.
} 
point il est problématique de situer des catégories diagnostiques assez distinctes, sans même considérer l'incidence d'autres facteurs - psychiques et sociaux - dans la composition de son cadre clinique. Nous prendrons comme exemple l'association fréquente du diagnostic d'autisme à l'X fragile pour signaler les brèches dans le discours qui nous permettent d'y tisser une discontinuité, pour proposer non pas une séparation, mais une articulation entre le syndrome et l'autisme où il soit possible d'y inclure la dimension du sujet.

Ainsi, en cherchant à renforcer notre proposition d'intersection de savoirs, nous avons trouvé dans les recherches en épigénétique une voie possible qui rende viable notre démarche visant le dialogue entre des champs aussi différents. Nous présenterons donc, dans le troisième chapitre, une révision bibliographique sur l'épigénétique, en prenant soin d'indiquer ce que les chercheurs entendent par environnement. Nous nous intéresserons notamment aux recherches qui, utilisant le modèle animal, indiquent les soins maternels pendant la première enfance comme environnement capable de produire des marques épigénétiques pouvant être transmises entre générations ${ }^{1}$. Si nous ne considérons pas qu'il soit convaincant d'assimiler les résultats des études sur les rats à la dimension humaine, il nous semble toutefois important que les expériences vécues au début de la vie soient prises comme objet d'investigation.

D'autres études ont observé des marques épigénétiques chez des humains, notamment chez ceux ayant vécu une expérience précoce considérée comme indésirable, c'est-à-dire ayant subi un type de violence ou de négligence durant la première enfance ${ }^{2}$. Nous savons que l'intérêt de la science de démontrer les possibles dommages de violences subies dans l'enfance n'est pas nouveau, et qu'il est même un objet de recherche récurrent dans le domaine de la génétique médicale ${ }^{3}$. Nous mettrons également l'accent sur les recherches faisant de la psychothérapie un objet d'étude épigénétique. Jusqu'à présent, quatre études se sont penchées sur les effets épigénétiques provoqués par la psychothérapie chez des patients diagnostiqués comme porteurs de troubles mentaux. La psychothérapie est donc considérée comme environnement capable de provoquer, voire de renverser des modifications épigénétiques. Il faut toutefois observer que ces recherches sont considérées comme pionnières et demandent à être approfondies.

\footnotetext{
${ }^{1}$ Voir TATA Despina et al. (2015). Effects of maternal separation on behavior and brain damage...

${ }^{2}$ Voir LUTZ P.-E. \& TURECKI G. (2014). DNA methylation and childhood maltreatment: from ...

${ }^{3}$ Voir MOYLAN et al. (2010). The effects of child abuse and exposure to domestic violence on...
} 
La première étude a été menée par Perroud et $a l$., sur des patients diagnostiqués de trouble de la personnalité borderline (BPD - borderline personality disorder). Les chercheurs ont trouvé une modification dans la méthylation de l'ADN d'une protéine cérébrale, la BNDF (Brain-Derived Neurotrophic Factor), importante pour le neurodéveloppement. Cette protéine est associée au trouble borderline et sa modification considérée comme une conséquence de mécanismes épigénétiques provoqués par une maltraitance durant l'enfance ${ }^{1}$. Les objectifs de l'étude en question étaient de vérifier si la haute méthylation de la BNDF chez les patients BPD était associée à la maltraitance pendant l'enfance et si les mécanismes épigénétiques pourraient être modifiés par une psychothérapie. Les résultats préliminaires après l'intervention psychothérapique ont indiqué que ceux ayant le mieux répondu au traitement avaient atteint des niveaux de méthylation équivalents à ceux du groupe de contrôle. Ceci indique que la psychothérapie a été capable de renverser les modifications épigénétiques provoquées par l'environnement hostile pendant l'enfance ${ }^{2}$.

La seconde recherche, ayant pour objet les mécanismes épigénétiques et la psychothérapie, est celle menée par Yehuda et ses collaborateurs ${ }^{3}$. La population étudiée était composée d'anciens combattants diagnostiqués porteurs de Trouble du stress posttraumatique (PTSD Post-Traumatic Disorder). L'objectif était d'évaluer la méthylation de deux gènes : le GR (gène qui n'est actif que dans des situations de stress) et le FKBP5 (dont l'influence porte justement sur le gène GR). Ces gènes sont également associés aux adversités vécues durant la première enfance. Après douze semaines de psychothérapie, on a observé chez ceux ayant répondu au traitement, outre une diminution des symptômes du PTSD, une diminution de la méthylation du gène FKBP5, ce qui indique une régulation de l'activité de ce gène. En d'autres termes, la psychothérapie mise en œuvre dans l'étude s'est révélée capable de renverser les modifications des mécanismes épigénétiques des gènes en question, modifications provoquées par les événements traumatiques.

La troisième étude a associé les troubles d'anxiété chez les enfants et les effets de la psychothérapie. Roberts et $a l$. ont évalué des mécanismes épigénétiques dans le gène SERT (transporteur de sérotonine) qui est couramment associé à divers types d'expériences négatives au cours de la vie ${ }^{4}$. Dans cette recherche, les enfants ont été soumis à deux

\footnotetext{
${ }^{1}$ Voir PERROUD et al. (2013). Response to psychotherapy in borderline personality disorders and...

${ }^{2}$ Ibidem

${ }^{3}$ Voir YEHUDA Rachel et al. (2013). Epigenetic biomarkers as predictors and correlates of symptom..

${ }^{4}$ Voir ROBERTS et al. (2014). Serotonin transporter methylation and response to cognitive behavior...
} 
semaines de psychothérapie et suivis durant six mois après le traitement. On a observé une modification de la méthylation du gène SERT chez ceux ayant répondu au traitement, c'està-dire chez ceux qui ont vu diminuer leurs symptômes initiaux d'anxiété.

La quatrième et dernière étude est celle menée par Ziegler et ses collaborateurs, cette fois-ci sur des patients ayant un diagnostic de trouble panique. Les chercheurs ont évalué la méthylation du gène MAOA (monoamine-oxydase), considéré comme une enzyme-clé dans la dégradation de neurotransmetteurs et donc tenue comme l'une des principales candidates aux facteurs de risque de ce trouble ${ }^{1}$. Il a été observé, après exposition à la psychothérapie, une diminution des attaques de panique chez les patients ayant répondu au traitement et les échantillons de l'ADN indiquaient, par rapport au groupe de contrôle, une augmentation significative de la méthylation du gène MAOA indiquant la régulation de son fonctionnement.

Bien que les psychothérapies auxquelles ces études se réfèrent adoptent un abordage cognitivo-comportemental, nous reconnaissons qu'elles ouvrent un espace de débat sur les effets de diverses autres approches théoriques, parmi lesquelles la psychothérapie psychanalytique. La conclusion selon laquelle «la psychothérapie menant à des changements symptomatiques substantiels constitue une forme de 'régulation environnementale' qui peut modifier l'état épigénétique $»^{2}$ est pour nous une porte ouverte sur l'articulation que nous proposons. Et pourquoi pas la psychanalyse également ? Cette thèse pourrait bien être le premier pas d'une recherche future et conjointe de la psychanalyse et de la génétique médicale, aspirant à mettre également en évidence les effets corporels provoqués par la psychothérapie psychanalytique.

Dans le but d'introduire la psychothérapie psychanalytique parmi les soins offerts aux enfants syndromiques, nous parions, dans le quatrième chapitre, sur le développement de deux concepts qui peuvent étayer l'articulation de la clinique psychanalytique et de la génétique médicale : les concepts de sujet et de transfert. Or, si l'épigénétique indique que l'environnement est capable d'influencer l'activité génique, nous pensons que la dimension d'environnement apportée par la psychanalyse doit être étendue et prise en compte par les savoirs s'occupant de l'enfance. C'est dans la rencontre avec l'Autre du langage que l'enfant

\footnotetext{
${ }^{1}$ Voir ZIEGLER Christiane et al. (2016). MAOA gene hypomethylation in panic disorder - reversibility of...

2 YEHUDA Rachel et al. (2013). Epigenetic biomarkers as predictors and correlates of symptom..., 2. Traduction libre de l'auteure. C'est nous qui soulignons.
} 
se constitue et s'approprie de son corps. C'est justement par ce pari que nous introduirons ce que la psychanalyse, à la lumière de Freud et de Lacan, entend par environnement. L'émergence du sujet a lieu dans cet environnement d'échange avec l'Autre, incarné par ceux qui s'occupent de l'enfant. L'un des principaux piliers de la psychanalyse, que nous aimerions détacher dans notre dialogue avec les disciplines, est l'idée de la singularité, du cas par cas, de l'enfant pensé aussi par rapport à ceux qui l'entourent. Ainsi, toute prétention psychanalytique de traitement doit tenir compte de la dimension du transfert, autrement dit de la relation qui s'établit entre le patient et le thérapeute. Car, nous verrons avec Freud qu' «une analyse sans transfert est une impossibilité » ${ }^{1}$.

Nous présenterons donc, dans notre dernier chapitre, trois cas cliniques issus de notre pratique. Il s'agit d'enfants dont les histoires ont été traversées par le diagnostic du syndrome de l'X fragile. La conduite du traitement de Maria, Flora et Benjamin illustre de quelle manière les conceptions de sujet et de transfert ont une incidence sur la clinique. Nous verrons, ainsi, comment ces cas cliniques s'articulent les uns aux autres, tous les trois étant des cas, disons, classiques de la clinique psychanalytique avec des enfants. Plutôt que des modèles des parcours spécifiques et inhabituels, nous chercherons à y mettre en relief justement ce caractère classique, ordinaire, voire attendu de ces histoires de transfert pour y marquer une possible répétition. Celle-ci se repose sur la possible fréquence de l'influence qu'une psychothérapie psychanalytique peut avoir sur la production de ses effets dans les trois cas en question. C'est-à-dire le développement de la symbolisation, marqué par la complexification de l'acquisition du langage et du tissu fantasmatique. Dans les trois cas exposés dans le dernier chapitre, les possibilités d'énonciation vont fonctionner, pour l'enfant, comme l'un des moteurs du travail clinique, possibilités intrinsèquement tissées sous le transfert, et donc indissociables du support des jeux et de la couture fantasmatique.

C'est sur le pari sur le devenir d'un sujet que nous fondons notre pratique et, dans l'intention de l'élargir, nous avons élaboré deux projets de recherche, dans deux services différents de génétique, prenant en charge des enfants atteints du syndrome de l'X fragile. Nous y avons rendu viable notre proposition de travail avec la génétique médicale, visant à inclure la psychanalyse comme traitement possible. Les différences entre les deux champs, comme l'indique notre révision bibliographique, ne seront et ne devront pas être supprimées. C'est aussi dans le travail avec la différence que nous pourrons offrir un lieu,

\footnotetext{
${ }^{1}$ FREUD Sigmund (1925). Autoprésentation, 89.
} 
si exigu soit-il, d'où un sujet puisse émerger. Au-delà ou en-deçà d'une défense de la psychanalyse, si nous défendons quelque chose dans notre thèse, c'est bien le sujet et sa singularité. 


\title{
Chapitre I
}

\section{Articulation entre la génétique médicale et la psychanalyse - ouverture d'un champ de recherches possibles}

\author{
Le corps humain constitue, par droit de \\ nature, l'espace d'origine et de répartition de \\ la maladie: espace dont les lignes, les \\ volumes, les surfaces et les chemins sont fixés, \\ selon une géographie maintenant familière, \\ par l'atlas anatomique ${ }^{1}$.
}

Michel Foucault

\subsection{Ouverture}

Dans ce premier chapitre, nous chercherons à constituer un ensemble d'études qui ouvrent un champ de recherches possibles à l'intersection de la psychanalyse et de la génétique médicale. D’une manière générale, nous y présenterons des travaux qui dialoguent avec notre objectif central: l'articulation des savoirs entre psychanalyse et génétique médicale dans le cadre du traitement de maladies génétiques chez l'enfant, et en particulier du syndrome de l'X fragile. Il est important de signaler que le défi d'établir un dialogue entre la psychanalyse et la médecine, praxis des sciences biologiques, est pour le moins délicat. D'un point de vue épistémologique, les deux disciplines ne partagent pas les mêmes références et la délimitation de leurs champs de recherche diverge tout autant. Toutefois ce défi constitue précisément le fondement de notre recherche.

Nous commencerons avec une note historique sur la rencontre entre la psychanalyse et la médecine, afin de mieux visualiser son contexte d'origine. Cette partie montrera succinctement l'importance du paradigme médical dans les écrits de Freud et sa croyance en la biologie, telle qu'elle se reflète au travers de son œuvre. Nous réunirons ensuite des travaux de psychanalystes qui exercent dans le milieu médical, notamment en milieu hospitalier, et qui sont pour nous des références dans la mesure où ils nous montrent

\footnotetext{
${ }^{1}$ FOUCAULT Michel (1963). Naissance de la clinique, 19.
} 
comment il est possible de travailler avec les divergences entre les différents savoirs. En outre, les débats avec les neurosciences ont également mis en évidence les possibles rencontres entre savoir psychanalytique et savoir médical, et c'est ce que nous aborderons dans une troisième partie. Enfin, le dialogue spécifique entre psychanalyse et génétique sera présenté par le biais de recherches contemporaines qui inspirent l'étude réalisée ici. Le présent chapitre a ainsi pour objectif de dessiner l'état des lieux spécifique d'un champ qui nous semble être d'intersection. Il ne s'agit pas ici d'être exhaustif ni historique, mais de bien délimiter cet état des lieux par un critère particulier qui l'oriente directement vers l'articulation entre les champs médical et psychanalytique.

\subsection{Note sur une rencontre: Freud et la médecine}

Pour en revenir brièvement sur l'origine des possibles divergences entre la psychanalyse et la médecine, il est nécessaire de partir de l'épistémologie de ces deux disciplines. La science moderne, inaugurée par René Descartes, rompt le dogmatisme religieux et pose la rationalité au centre du discours. Avec cette nouvelle logique, selon Alberti \& Fulco, «l'homme existe parce qu'il peut être inscrit dans le symbolique, dans la pensée qui lui donne une place au sein du cogito $»^{1}$. L'homme qui, au Moyen-Âge, servait la religion, passe à servir la science à l'âge de la modernité. À partir de Michel Foucault, nous savons que le passage de la médecine classique vers la médecine moderne scientifique - passage qui a fait de la science un synonyme de vérité ${ }^{2}$ - a impliqué un changement de paradigme en ce qui concerne la spatialisation de la maladie, déplaçant l'objet au sein du discours :

«le regard n'est plus réducteur, mais fondateur de l'individu dans sa qualité irréductible. Et par là, il devient possible d'organiser autour de lui un langage rationnel. L'objet du discours peut aussi bien être un sujet, sans que les figures de l'objectivité en soient pour autant altérées » ${ }^{3}$.

\footnotetext{
${ }^{1}$ ALBERTI Sonia \& FULCO Ana Paula (2005). Um estudo, uma denúncia e uma proposta: a psicanálise ... 722. Traduction libre de l'auteure.

${ }^{2}$ Voir CLAVREUL Jean (1978) L'ordre médical.

${ }^{3}$ FOUCAULT Michel (1963). Naissance de la clinique, 11.
} 
Ce changement surgit, selon Foucault, à partir de la naissance de la clinique moderne, dans laquelle la vie de chacun assumera une condition scientifique. Jusqu'à la fin du XVIII ${ }^{\mathrm{e}}$ siècle, le dialogue entre médecin et patient était entamé par la question suivante : «qu'estce que vous avez? » Cette phrase est alors remplacée par «où avez-vous mal ? La discontinuité structurale n'est pas seulement due aux nouveaux savoirs et concepts médicaux, mais aussi à la possibilité d'un discours sur la maladie : c'est ce que Foucault appelle la discrétion du discours clinique, c'est-à-dire la structure commune qui recoupe et articule ce qui se voit et ce qui se dit.

D'un point de vue historique, la psychanalyse s'est toujours positionnée, d'une certaine manière, comme une pratique subversive par rapport à la pratique médicale, qui est par ailleurs la représentante du discours scientifique. Toutefois on peut aussi dire que la psychanalyse naît au travers de la clinique médicale, à partir de la rencontre entre Sigmund Freud et Jean-Marie Charcot. La subversion psychanalytique survient quand Freud, constatant l'impuissance de la médecine face à l'hystérie, déplace un regard centré sur l'anatomie du corps hystérique et propose une écoute des représentations psychiques qui échappaient au savoir médical. Dans son article intitulé Quelques considérations pour une étude comparative des paralysies motrices organiques et hystériques, Freud affirme que «dans tous les cas de paralysie hystérique, on trouve que l'organe paralysé ou la fonction abolie est engagé dans une association subconsciente qui est munie d'une grande valeur affective, et l'on peut montrer que le bras devient libre aussitôt que cette valeur affective est effacée $»^{1}$, montrant ainsi qu'au-delà de l'anatomie, la souffrance hystérique serait le fruit d'une lésion du corps vivant. La rupture épistémologique opérée par la psychanalyse dans le traitement des hystéries a provoqué un glissement du voir vers l'écouter, faisant de l'écoute un outil d'intervention clinique ${ }^{2}$.

En revanche, les pratiques médicales ont tendance à rechercher une cause exclusivement organique aux maux de la condition humaine. Afin d'obtenir un statut scientifique, tout ce qui est d'ordre psychique se voit rattaché à l'organique et à l'expérimentable, marquant par là un des principes de divergence entre le discours psychanalytique et le discours médical. On peut citer en exemple les études sur le syndrome de l’X fragile, où sont associés de manière biunivoque des diagnostics de phobie ou

\footnotetext{
${ }^{1}$ FREUD Sigmund (1893). Quelques considérations pour une étude comparative des paralysies motrices...,13.

${ }^{2}$ Voir RICKES Simone \& GLEICH Paulo (2009). Letras em oficina: a afirmação retumbante do « não ».
} 
d'autisme, entre autres, au dérèglement neurophysiologique provoqué par l'absence de protéine FMRP (voir chapitre 2).

Au sujet de ces divergences, Christophe Dejours nous met en garde sur le fait que la description du corps étudié par la biologie renvoie à des questions du monde objectif tandis que le corps étudié par la psychanalyse dépasse la dimension physiologique. Pour cette dernière, selon l'auteur, les questions soulevées évoquent le « rêve, le fantasme, le désir, la souffrance, le plaisir, l'amour et, plus largement, les affects ${ }^{1}$ qui passent par le corps et le mobilisent. Tandis que la psychanalyse s'intéresse au contenu onirique, par exemple, la biologie s'intéresse au sommeil et à ses troubles.

Il convient de souligner que le psychanalyste, ancré dans le concept freudien de la pulsion, se doit de considérer le corps comme non séparé du psychique. En d'autres termes, « les phénomènes du corps ne sont pas libres d'une représentation psychique, même si le sujet ne sait pas quelle est cette représentation $»^{2}$. En effet, les regards et la constitution même de l'objet sont différents pour chacun des champs de savoir, une différence qui peut éveiller - et éveille de fait - des débats théoriques entre les disciplines. Ce conflit a été principalement relevé par certains psychanalystes qui avertissent sur la possibilité d'une pratique médicale qui méprise l'existence d'une dimension psychique dans les phénomènes étudiés.

Jacques Lacan, dans une critique plus acerbe au discours médical de son temps, a indiqué la manière dont la médecine, en devenant scientifique, avait laissé de côté sa dimension philosophique, pour fixer son regard sur le corps, sur le cadavre. Selon lui, le médecin a perdu alors sa position traditionnelle, devenant une espèce d'agent distributeur au service du monde scientifique, dont le devoir serait de mettre à l'essai les nouveaux agents thérapeutiques, chimiques ou biologiques ${ }^{3}$. Lacan signale également une faille dans la relation de la médecine avec le corps, une «faille épistémo-somatique », selon ses propres termes, qui serait conséquence du progrès même de la science. Le corps, selon l'auteur, « est quelque chose qui est fait pour jouir, jouir de soi-même. La dimension de la jouissance est complètement exclue de ce que j'ai appelé le rapport épistémo-somatique » ${ }^{4}$. Lacan montre

\footnotetext{
${ }^{1}$ DEJOURS Christophe (2001) Le corps, d'abord, 10.

${ }^{2}$ MORETTO Maria Lívia (2001). O que pode um analista no hospital?, 79. Traduction libre de l'auteure.

${ }^{3}$ Voir LACAN Jacques (1966) La place de la psychanalyse dans la médecine.

${ }^{4}$ Ibidem, 08 .
} 
que le corps est, de cette manière, considéré en son état pur et n'intéresse essentiellement la médecine que pour être le lieu où s'installe la maladie ${ }^{1}$.

Sur les pas de la pensée lacanienne, Jean Clavreul a aussi mis en évidence ce conflit en les différents champs de savoir. En mettant en relief un supposé Ordre médical, l'auteur affirme que ce dernier « est plus puissant que le plus puissant dictateur, et parfois aussi cruel. On ne peut lui résister parce qu'on n'a aucune "raison" à lui opposer $»^{2}$. Pour Clavreul, le discours médical, en plus de rendre le malade muet face à sa propre maladie, étouffe le médecin en tant que personne dans sa relation avec le patient : «[le médecin est] appelé à faire taire ses sentiments parce que l'exige le discours médical. [...] À la relation médecinmalade, se substitue la relation institution médicale-maladie $»^{3}$, ajoute l'auteur.

D'autres auteurs ont également mis en garde sur une potentielle «santé totalitaire ${ }^{4}$ et apportèrent par là une importante contribution à la réflexion sur les pratiques de soin médicales. Selon Roland Gori, la médecine a acquis sa supposée rationalité scientifique au détriment de la valeur éthique et symbolique des discours de la souffrance et du soin qui lui étaient adressé. La médecine scientifique, toujours selon Gori, s'empêche de penser la maladie dans son inscription singulière au sein d'un drame intérieur, comme traversée par une historicité et rattachée à une trame imaginaire et symbolique.

Cependant, si elle reconnaît la valeur des travaux cités ci-dessus, notre thèse ne s'insère pas, dans l'absolu, au sein d'une logique d'attaques et de critiques à la médecine depuis le discours psychanalytique ${ }^{5}$. Car il semblerait qu'il s'agisse, dans le champ psychanalytique, d'une tentation intellectuelle qui s'enracine précisément dans la différence entre les deux champs de savoir. Notre projet, comme nous tâcherons de le soutenir avec insistance, est bien de fomenter l'articulation et le dialogue entre la psychanalyse et la médecine, à travers la génétique médicale : c'est là même le pilier central de tout le développement de ce travail. Notre objectif est en effet de transiter entre ces deux champs de savoir en cherchant à mettre en évidence les possibilités d'un terrain de recherche encore peu exploité. Sachant que le discours médical a tendance à privilégier une certaine objectivité de la maladie, nous nous demandons comment la psychanalyse pourrait introduire dans ce

\footnotetext{
${ }^{1}$ Voir QUEIROZ \& CORREIA (2002). Algumas considerações sobre a falha épistémo-somática...

${ }^{2}$ CLAVREUL Jean (1978) L'ordre médical, 29.

${ }^{3}$ Ibidem, 31.

${ }^{4}$ Voir GORI Roland \& DEL VOLGO, Marie-José (2005). La santé totalitaire : Essai sur la ...

${ }^{5}$ Voir MADEIRA Manoel \& VARELA Andrea (2016) L'émergence de la parole chez l'enfant à la ...
} 
contexte la dimension de la subjectivité. Avant d'attaquer le discours médical sur cette dimension non prioritaire de son champ de savoir (la subjectivité), nous avons pensé une initiative de recherche qui se fonde sur l'articulation d'une telle dimension, soudain greffée au savoir de la médecine.

Il est essentiel de rappeler que la psychanalyse elle-même provient de la rationalité scientifique de la médecine et du développement de la neuro-anatomo-pathologie pour ce qui fait précisément référence à ses modes de connaissance. On sait que dès le début, Freud s'est soucié de défendre le caractère scientifique de sa découverte, faisant de lourds efforts pour maintenir l'objectivité de sa théorie. Comme nous l'avons indiqué dans un autre travail $1^{1}, l^{\prime}$ histoire nous montre que la place de la neurologie dans l'œuvre de Freud est à la fois limpide et singulière. Dans son Esquisse d'une psychologie scientifique ${ }^{2}$, Freud se montre particulièrement soucieux de l'articulation entre ses conceptions neurologiques et la constitution de concepts fondamentaux pour la psychanalyse - en particulier celui du refoulement. Si Freud finit par abandonner son entreprise, ce n'est pas faute de croyance théorique mais plutôt en raison d'apories épistémologiques et thérapeutiques. Ainsi écrit-il à Fliess, en 1898 :

«Je suis loin de penser que le psychologique flotte dans les airs et n'a pas de fondements organiques. Néanmoins, tout en étant convaincu de l'existence de ces fondements, mais n'en sachant davantage ni en théorie, ni en thérapeutique, je me vois contraint de me comporter comme si je n'avais affaire qu'à des facteurs psychologiques $»^{3}$.

Autrement dit, l'abandon des minuties neurologiques de Freud est davantage dû au choix de son objet d'étude, les «facteurs psychologiques », qu'au doute que ces derniers puissent être liés à des facteurs neurologiques. La neurologie obtient ainsi une place privilégiée dans l'œuvre de Freud, car même s'il ne s'y réfère pas directement, il semble que son origine de neurologiste soit intimement impliquée dans l'invention de l'appareil psychique et, plus amplement, dans la conception freudienne de la structure psychique. On

\footnotetext{
${ }^{1}$ Voir VARELA Andrea et al. (2015). Síndrome do cromossomo X frágil : uma possível articulação...

${ }^{2}$ Voir FREUD Sigmund (1895) Esquisse d'une psychologie.

${ }^{3}$ FREUD Sigmund (1887-1902). La naissance de la psychanalyse, 235.
} 
sait que Freud ne cessera pas de croire en l'existence de bases biologiques de l'organisation de l'inconscient. Il dira, par exemple, dans Analyse terminable et interminable, que «pour le psychique, le biologique joue véritablement le rôle de roc d'origine sous-jacent $»^{1}$.

De ce point de vue, la tentative d'articulation entre psychanalyse et médecine constitue même un certain retour à Freud. Peut-être pas au neurologiste du Projet qui voulait faire coïncider avec précision des symptômes psychiques et localités cérébrales, mais au Freud qui reconnaît aussi bien les limites que les potentialités de chaque champ de savoir. Un retour au Freud qui, dans Métapsychologie, soutient qu'il existe entre les processus psychiques et la neuroanatomie «une lacune manifeste, qu'il n'est pas possible, actuellement, de combler et qui, de plus, ne relève pas des tâches de la psychologie $»^{2}$.

Sur les pas de Freud, nous défendons la possibilité d'une articulation qui ne contrarie pas les principes de chacune des pratiques et qui, surtout, puisse travailler avec les différences. C'est pourquoi nous ne soutenons ni une psychanalyse qui prétend expliquer toutes les affections humaines au travers du psychisme et ni une médecine qui considère exclusivement une biunivocité organique dans le traitement de l'être humain. Il ne s'agit pas, selon Sylvie Tordjman, d'imposer à l'une des disciplines une pensée qui lui soit étrangère, mais bien de confronter différents points de vue. Cette confrontation, selon l'auteure, pourrait mener à une décentralisation à partir de laquelle on pourrait commencer à percevoir l'autre en tant que pratique distincte, tout en respectant les spécificités de chacun ${ }^{3}$.

Notre recherche nous rapproche donc de ceux qui, même devant les impasses irréductibles qui existent entre les deux disciplines, misent sur le travail interdisciplinaire. Nous avons ainsi accompagné de remarquables travaux sur l'insertion de la psychanalyse dans le milieu médical ${ }^{4}$, mais aussi des productions théoriques qui recherchent une telle articulation. Référence de poids pour notre projet, l'optimiste conjecture de Karl-Leo Schwering nous fait ainsi observer que «tout médecin n'est ni complètement, ni définitivement dominé par la division épistémologique exposée ci-dessus [l'auteur se réfère notamment aux travaux de Foucault et Gori], n'en déplaise aux déclarations si appuyées des collègues cités $»^{5}$.

\footnotetext{
${ }^{1}$ FREUD Sigmund (1937). L'analyse finie et l'analyse infinie, 55.

${ }^{2}$ FREUD Sigmund (1915). Métapsychologie, 78.

${ }^{3}$ Voir TORDJMAN Sylvie (2010). Regards croisés entre la psychanalyse et les neurosciences.

4 Voir MORETTO Maria Lívia (2001); SCHWERING Karl-Leo (2015) ANSERMET François \& MAGISTRETTI Pierre (2004).

${ }^{5}$ SCHWERING Karl-Leo (2015). Corps d'outrance : souffrance de la maladie grave à l'hôpital, 62.
} 


\subsection{Psychanalyse et médecine}

Il nous semble indispensable de rapporter ici les contributions de Danièle Brun au débat entre la psychanalyse et la médecine. En 2001, Brun a fondé, en étroite articulation avec l'Université Paris-Diderot, la Société Médecine et Psychanalyse, ce qui n'a été possible, selon elle, qu'à partir de la reconnaissance par les médecins de leur propre impuissance ${ }^{1}$. Il est important de rappeler que c'est autour de l'enfant qu'une première approximation s'est établie, en France, entre psychanalystes et pédiatres ${ }^{2}$. Selon Brun, «confrontés à l'impuissance de leurs moyens thérapeutiques, étonnés par les obstacles et les résistances qu'oppose le corps à la diversité des thérapeutiques, les médecins découvrent de plus en plus souvent la part psychique qui tente de se frayer un passage dans la maladie $»^{3}$.

Les psychanalystes se voient donc invités à collaborer avec la médecine lorsque cette dernière reconnaît, d'une part, le facteur psychique inhérent à l'ensemble de la maladie et, d'autre part, la limite de son intervention par le traitement proposé. Signalons toutefois, comme le suggère l'auteure elle-même, que les médecins ne sont pas toujours disposés à reconnaître leur limite, une limite à laquelle toute discipline et tout savoir se doit d'être confronté, y-compris le savoir psychanalytique.

Maria Lívia Moretto nous donne des pistes pour un possible exercice du psychanalyste en milieu médical, et notamment hospitalier. Selon elle, pour éviter un certain malaise provoqué par l'exclusion de la psychanalyse par «l'ordre médical ${ }^{4}$, le psychanalyste doit maintenir une extraterritorialité par rapport au médecin, dans la mesure où, si on traite le même patient, « on ne traite pas de la même chose $»^{5}$. Bien qu'elle considère antinomique la relation entre psychanalyse et médecine, Moretto met en évidence l'existence d'une dépendance entre les deux champs. Selon l'auteure, «à partir du moment où le discours médical exclut toute position subjective, il ouvre un espace pour le discours psychanalytique $»^{6}$. Autrement dit, c'est précisément ce qui n'intéresse pas le discours médical - l'étrange, le reste - qui constituerait l'angle de vue du travail du psychanalyste. Ce qui garantit l'espace de l'analyste au sein de l'hôpital est donc, selon Moretto, cet

\footnotetext{
${ }^{1}$ Voir BRUN Danièle (2015). L'expérience de la Société Médecine et Psychanalyse : hasard, besoin...

${ }^{2}$ En 1993, lors du premier colloque de « Pédiatrie et psychanalyse »

${ }^{3}$ Ibidem, 78.

${ }^{4}$ L'auteure se réfère à la définition de l'Ordre Médical donnée par Jean Clavreul.

${ }^{5}$ MORETTO Maria Lívia (2001). O que pode um analista no hospital?, 71. Traduction libre de l'auteure.

${ }^{6}$ Ibidem, 72. Traduction libre de l'auteure.
} 
intéressant paradoxe : la présence de l'analyste permet au médecin de continuer à exclure la subjectivité, de la même manière que l'exclusion de la subjectivité par le médecin permet la présence de l'analyste à l'hôpital. Serait-il possible de dépasser un tel constat ? Le travail que nous proposons dans cette thèse ose le pari d'aller au-delà de ces difficultés.

Toujours selon Moretto, il est tout à fait probable que le milieu médical fasse appel au psychanalyste pour mettre de l'ordre dans ce qui ne saurait être éliminé, mais qui a bien des effets et perturbe la thérapeutique médicale : le facteur psychique du malade. Répondre à la demande médicale serait alors problématique pour le psychanalyste, déplacé de son espace propre, au point de provoquer «la distorsion même du discours psychanalytique et la dénégation de la proposition freudienne ${ }^{1}{ }^{1}$. Toutefois si ces considérations peuvent constituer un certain piège pour le psychanalyste qui exerce en milieu médical, elles n'interdisent pas pour autant qu'un travail psychanalytique se fasse.

Dans ce sens, nous avons sélectionné quelques études qui constituent une référence et nous aident à penser de possibles contributions de la psychanalyse pour la médecine, en particulier en ce qui concerne les soins proposés aux enfants malades. La remarquable étude de cas publiée par Schwering démontre l'importance de l'écoute psychanalytique - cette écoute qui est l'instrument du traitement psychanalytique - auprès d'enfants qui ont passé par des techniques invasives, comme la transplantation d'organe. L'auteur rapporte le cas de Daniel, un enfant de huit ans interné à cause d'une atrésie des voies biliaires. Il s'agit là d'une maladie congénitale de cause encore inconnue, qui provoque un important dysfonctionnement du foie et, en l'absence d'intervention chirurgicale, peut mener le patient jusqu'à la mort. Or, la scène d'un enfant malade interné à l'hôpital en l'attente de son nouvel organe pourrait bien n'être qu'une situation anodine pour le milieu médical, où prévaut toujours le regard sur la maladie.

Néanmoins grâce au rapport de cas, on peut observer, au-delà de la maladie et de ses effets physiologiques, l'incidence des représentations psychiques qui accompagnent le processus de l'enfant dans sa rencontre avec la réalité de son corps. Une écoute psychanalytique attentive au chevet du lit d'hôpital a rendu possible au jeune malade un travail d'élaboration psychique autour de sa maladie, mais aussi l'incorporation psychique du nouvel organe reçu. Selon les mots de l'auteur,

\footnotetext{
${ }^{1}$ MORETTO Maria Lívia (2001). O que pode um analista no hospital?, 71. Traduction libre de l'auteure.
} 
«au-delà du nécessaire travail d'élaboration psychique exigé de tout sujet confronté à une atteinte corporelle grave entraînant un acte chirurgical lourdement invasif, une hospitalisation longue, l'incertitude du pronostic [...], se pose la question de la confrontation à un nouvel organe ; un intrus nécessaire et attendu, mais plus que probablement source de questionnement $»^{1}$.

Moretto, qui exerce également dans un service de transplantation du foie, a réalisé une écoute de patients adultes, qu'elle expose dans son ouvrage $O$ que pode um analista no hospital? [Que peut faire l'analyste à l'hôpital ?]. L'auteure y décrit, comme le titre l'indique, les difficultés et possibilités d'action du psychanalyste en milieu hospitalier. Au croisement des impasses qui cernent l'espace occupé par le psychanalyste à l'hôpital, elle parvient à faire émerger des questions qui sont cruciales pour le sujet-patient. Des questions comme celles du fantasme, des identifications, du délire, du transfert, de la demande, que la médecine, pourtant, peu instrumentalisée pour affronter une telle dimension, traite le plus souvent en disant au patient sur un ton que l'on peut considérer défensif : « vous n'avez rien d'anormal $»^{2}$. Il n'est pas rare, par exemple, qu'un patient refuse ce que la médecine peut lui offrir comme traitement d'une maladie, voire pour le prolongement d'une vie en risque imminent. D'une manière générale, ce refus est incompris par le médecin qui a alors recours à un psychanalyste. Moretto affirme qu'il n'appartient alors pas à l'analyste de répondre à l'ordre médical mais bien de permettre au patient de «faire valoir sa vérité, son désir $»^{3}$.

À propos de ce possible travail entre la psychanalyse et la médecine, il convient de rappeler aussi les contributions de la psychiatre et psychanalyste Claire Squires, qui réalise un travail notable sur les représentations psychiques traversant les pratiques médicales au moment de la naissance et de la procréation médicalement assistée (PMA). En exposant quatre cas cliniques de parentalités considérées tardives, à la limite « de ce que la société peut accepter $»^{4}$, Squires et ses collaborateurs présentent les coulisses de la demande de reproduction avec intervention médicale. On peut alors observer le rôle fondamental du psychanalyste au sein de l'équipe des soigneurs, en particulier lorsqu'il extrait des contenus psychiques qui sont aussi impliqués dans la demande de procréation, contenus que

\footnotetext{
${ }^{1}$ SCHWERING Karl-Leo (2001). Le traitement psychique de l'organe transplanté ... 153.

${ }^{2}$ MORETTO Maria Lívia (2001). O que pode um analista no hospital?, 140 Traduction libre de l'auteure.

${ }^{3}$ Ibidem, 140. Traduction libre de l'auteure.

${ }^{4}$ SQUIRES Claire et al. (2008). Psychopathologie et procréation médicalement assisté : comment ..., 144.
} 
l'assistance médicale « a tendance à occulter [...] dans leur dimension à la fois somatique et psychique $»^{1}$.

L'infertilité n'est plus un obstacle intransposable pour les couples désireux de vivre une parentalité. Actuellement, la médecine reproductive propose des techniques de fertilisation qui permettent que ces couples atteignent plus facilement leur objectif tant espéré : celui d'avoir un enfant. Cependant, ces pratiques ne viennent pas sans d'importantes conséquences psychiques. C'est sur ce point que l'auteure nous met en garde : «en dehors des fragilités individuelles, le parcours du traitement de la stérilité pourrait, en soi, être déstabilisant. [...] Les motivations avancées tiendraient à un découragement, des sentiments négatifs dans la série anxieuse $»^{2}$. Certaines questions liées à la demande d'avoir un enfant - vécue de manière singulière par chaque parent - ne sont pas toujours considérées par les médecins. Supposons que l'écoute du contenu inconscient qui traverse la demande de PMA et qui interfère dans le succès ou l'échec de la procédure, soit la place destinée au psychanalyste au sein de l'équipe. Toujours selon Squires et al.,

« au-delà des modèles sociaux, familiaux et médicaux, le désir d'enfant est aussi infiltré de significations inconscientes, d'identifications aux parents, mais aussi d'enjeux narcissiques. Il est lié aussi à l'expression du sentiment intime de n'avoir pas interrompu la chaîne des générations $»^{3}$.

Aussi évidente soit l'incidence des enjeux psychiques dans tout le processus de reproduction médicalement assistée, l'inscription de la place du psychanalyste dans ce processus reste encore complexe et à défendre ${ }^{4}$. Car l'exercice médical peut rapidement excéder la place destinée à l'écoute des patients et des représentations psychiques qui traversent la demande d'avoir un enfant. Cela dit, le travail de Squires fait preuve d'un pouvoir de fondement de la place du psychanalyste dans les services de PMA, malgré les difficultés qui s’interposent dans une telle insertion.

La psychanalyse montre également sa contribution dans la composition de l'équipe des soigneurs de bébés prématurés. Le travail réalisé par Catherine Vanier auprès d'un

\footnotetext{
${ }^{1}$ SQUIRES Claire et al. (2008). Psychopathologie et procréation médicalement assisté : comment les..., 148.

${ }^{2}$ Ibidem, 136.

${ }^{3}$ Ibidem, 144.

${ }^{4}$ Ibidem.
} 
service de réanimation néonatal révèle les facettes qui composent le décor de l'au-delà de la technique de réanimation des bébés en risque mortel. «La technique confronte aux limites et les réactions de certains enfants aux soins échappent à toute logique médicale ${ }^{1}$, affirmet-elle. Le rapport fait par Vanier du cas de la petite Anne illustre comment l'Autre - incarné par la mère et par l'équipe de soigneurs - joue un rôle fondamental dans le cadre clinique présenté par l'enfant. Le bébé en question, née après 26 semaines de gestation, était connecté à appareil lui permettant de respirer pendant que son corps acquérait la maturation interrompue par l'accouchement précoce. Quand la stabilité et la maturation ont atteint un niveau considérable, les médecins ont décidé de cesser la ventilation mécanique. Ils ont noté alors chez Anne une régression et des difficultés à respirer sans appareil. L'enfant, décrit Vanier, s'agrippait aux doigts de qui se trouvait à ses côtés, tandis qu'on lui parlait, qu'on lui expliquait ce qui était en train de se passer, qu'on la calmait. Il est impressionnant de constater que « le simple fait d'être près d'elle et de lui parler, sans aucune manœuvre de réanimation, faisait remonter sa fréquence cardiaque $»^{2}$. Ce qui suggère, comme l'indique l'auteure elle-même, qu'en ce qui concerne la survie d'Anne, les mots, la voix et le désir de vivre remplacèrent l'appareil ininterrompu et atemporel qui la maintenait en vie.

L'écoute de la mère angoissée et traumatisée par la fragilité de sa fille-l'équipe s'étant aperçue que la mère aussi méritait une attention particulière ${ }^{3}$ - a finalement permis qu'Anne stabilise peu à peu sa fréquence cardiaque. Une telle posture n'a été possible qu'à partir du moment où, dans le service où la psychanalyste était affectée, l'équipe de soigneurs a accepté de suivre ses indications. L'auteur souligne l'importance de la réalisation d'un travail systématique et individuel, non seulement avec les parents mais aussi avec l'équipe qui exerce autour des incubateurs. «Le souffle de la vie dont il est question dans l'étymologie du mot réanimation, n'est pas seulement l'oxygène que les machines apportent, mais aussi l'appel d'air de la demande qui ramènera le bébé à la vie »", indique Vanier. C'est la présence de l'Autre qui soutiendra la force de survie de l'enfant. «J'ai l'impression de tricoter des signifiants, j'essaie de tricoter des histoires qui sont les filets de sécurité pour un enfant et pour sa famille en même temps $»^{5}$, explique l'auteure à propos de son travail auprès des enfants internés et de leurs familles. Au milieu de tout un appareil médical de tubes à

\footnotetext{
${ }^{1}$ VANIER Cathèrine (2006). Le bébé et la pulsion. « Le sourire de la Joconde quelques années..., 72.

${ }^{2}$ Ibidem, 75.

${ }^{3}$ Rappelons-nous les mots de Winnicott : « un bébé, cela n'existe pas ». Voir Winnicott Donald (1943) De la Pédiatrie à la Psychanalyse.

${ }^{4}$ Ibidem, 74.

${ }^{5}$ VANIER Catherine (2015). Un psychanalyste en réanimation néonatale, 58.
} 
oxygène, de sondes gastriques, de moniteurs cardiaques, le mot, la voix, la supposition d'un sujet, existent soudain dans la lutte pour la survie.

La réalité des USI néonatales, où règne la pression d'un risque de décès, ne laisse peutêtre pas d'espace pour réfléchir aux questions si fondamentales soulevées par Vanier. Cela dit, l'attention apportée à l'équipe médicale est un facteur substantiel pour que celle-ci soit apte à renoncer au savoir scientifique tout entier et à ouvrir une brèche où seraient admises les limites et l'impuissance de la médecine. Serait-ce donc le rôle du psychanalyste de montrer et recevoir ces failles, tout aussi inhérentes à notre pratique ? C'est l'un des grands défis de la psychanalyse que nous rencontrons ici face à la pratique médicale. Catherine Vanier admet avoir eu de la «chance $»^{1}$ de se retrouver au milieu d'une équipe de soigneurs disposée, même si ce n'a été pas immédiat, à suivre sa posture et son acte de considérer les bébés comme des sujets ayant un nom, une histoire, une famille, un dire.

Bien d'autres psychanalystes ont également fait témoignage de leurs pratiques, que ce soit en milieu hospitalier ou dans des institutions de santé ${ }^{2}$. La lecture que nous faisons de ces témoignages nous laisse entendre que la rencontre de la psychanalyse et de la médecine est sans aucun doute complexe, mais qu'aucun obstacle ne peut rendre impossible un travail visant à atteindre et donner une place au sujet. Au-delà de la chance, nous pensons que la rencontre est possible lorsque, d'un côté comme de l'autre, les pratiques distinctes sont disposées à se reconnaître comme limitées et ne considèrent pas un autre savoir, différent, comme non-qualifié ou comme une menace.

\subsection{La psychanalyse et les neurosciences}

Les articulations théoriques sont tout aussi fécondes en ce qui concerne l'approximation de la psychanalyse avec le champ du vivant. C'est le cas des productions qui tentent la rencontre de la théorie freudienne avec les neurosciences. Il ne s'agit pas ici d'épuiser la littérature sur ce thème, mais d'apporter quelques contributions qui nous aident à penser un possible dialogue au sujet de ces pratiques historiquement opposées à la psychanalyse. Le débat entre théorie psychanalytique et neurosciences apparaît comme un champ fertile, d'où naissent accords et désaccords, et sans aucun doute parce que c'est

\footnotetext{
${ }^{1}$ VANIER Catherine (2015). Un psychanalyste en réanimation néonatale.

${ }^{2}$ Voir KAMERS Michele, MARCON Heloisa et MORETTO Maria Livia (2016) ; OPPENHEIM Daniel (2015) ; SAUSSE Simone (2006) ; OPPENHEIM Daniel et HARTMANN Olivier (2005) ; GOLSE Bernard (2012).
} 
précisément du système psychique que traitent les deux disciplines, chacune à sa manière. Si le dialogue entre les deux domaines peut encore susciter un certain malaise, il est nécessaire, selon Bernard Golse, de transformer le conflit de perspectives en un débat épistémologique ${ }^{1}$.

Pour nous aider à localiser d'un point de vue global le point où se trouvent actuellement les discussions entre neurosciences et psychanalyse, nous comptons sur les contributions du psychiatre et psychanalyste Nicolas Georgieff ${ }^{2}$. Ce dernier distingue quatre modèles d'articulation ou désarticulation, selon ses mots, pour situer la discussion : le premier modèle est celui de la rupture épistémologique. Ce qui est vu, dans le meilleur des cas, est la coexistence et la reconnaissance mutuelle des deux pratiques, qui se rencontrent, mais qui n'établissent pas d'échanges et ne collaborent pas à construire un parcours commun. La relation la plus nuisible - et peut-être la plus fréquente - décrite par l'auteur, apparaît lorsque les théories s'invalident entre elles par la contestation des méthodologies ou de l'existence des objets de travail de l'une et de l'autre. Il y a alors une impossibilité de dialogue.

Le deuxième modèle indiqué par Georgieff porte sur le parallélisme ou l'équivalence. Dans ce modèle, à l'opposé du premier, les deux pratiques ont un même langage et un même objet. Autrement dit, un phénomène est expliqué à la fois par la théorie psychanalytique et par les processus cognitifs, car «rien n'interdit de mettre sur un même plan processus biologiques et métapsychologie $»^{3}$. Dans ce cas-là, il s'agit d'expliquer scientifiquement la métapsychologie freudienne, ce qui, selon l'auteur, pose des problèmes et de confusions entre les différents langages. De notre point de vue, cette confusion de langage a été mise à l'épreuve par certains psychanalystes qui ont essayé de démontrer la psychanalyse à travers des données neuroscientifiques ${ }^{4}$.

Le troisième modèle saisit la complémentarité des champs d'observation. Selon Georgieff, dans ce modèle, les objets, les langages et les théories sont différents mais directement compatibles, complémentaires. La contradiction de ce modèle naît de l'indication que «les neurosciences prennent pour objet l'émotion, la subjectivité et l'intersubjectivité, autant que par le fait qu'il existe une théorie psychanalytique de la pensée et des fonctions dites 'cognitives' $»^{5}$.

\footnotetext{
${ }^{1}$ Voir GOLSE Bernard (2012). Entre neurosciences et psychanalyse : un dialogue enfin possible...

${ }^{2}$ Voir GEORGIEFF Nicolas (2010). Psychanalyse, neurosciences et subjectivités.

${ }^{3}$ Ibidem, 344.

4 Voir notamment l'ouvrage de Gérard POMMIER (2004). Comment les neurosciences démontrent la psychanalyse.

${ }^{5}$ GEORGIEFF Nicolas (2010). Psychanalyse, neurosciences et subjectivités, 345.
} 
Le quatrième et dernier modèle, celui qui a été choisi par l'auteur, est celui de la convergence entre points de vue irréductibles l'un à l'autre : regards croisés. Les langages, les points de vue et les méthodes sont absolument distinctes dans cette approche d'articulation. Il n'y existe pas d'équivalence, mais une compatibilité indirecte, c'est-à-dire qu'il faut une traduction des langages - d'ailleurs difficile à établir - prenant en considération l'irréductibilité de chaque concept et de chaque territoire. «La différence entre psychanalyse et neurosciences tient donc ici à une différence de regards plutôt que d'objets $»^{1}$ ajoute l'auteur. L'objet est le même, le psychisme, cependant il est appréhendé à partir de la manière dont chaque approche découpe cet objet dans le réel. Il ne s'agit pas de rapprocher les concepts par le principe de l'analogie, ou d'indiquer que l'un peut expliquer l'autre. Si l'objet est, donc, le même, les systèmes conceptuels sont radicalement différents.

Pour l'auteur, une voie qui s'est montrée fertile dans le dialogue entre les deux champs de savoir est celle qui s'intéresse aux processus subjacents de l'intersubjectivité : «la psychanalyse ne peut être insensible au fait que les neurosciences commencent à élaborer une théorie neurobiologique et cognitive de l'empathie et de l'identification, de l'intersubjectivité et de la cosubjectivité $»^{2}$, indique Georgieff. Autrement dit, ce qui fut pendant longtemps l'objet de critiques à la psychanalyse par la science, à savoir, l'existence des processus subjectifs, est aujourd'hui l'argument de convergence entre les savoirs.

Visant à pousser le débat entre ces différents domaines, Golse met en relief certains points de ce qui peut être considéré comme une convergence entre les neurosciences et la psychanalyse. Nous les rapportons ici à titre purement indicatif. Il s'agit d'études scientifiques sur la mémoire, et notamment sur une nouvelle modélisation qui indique que «les souvenirs ne correspondraient à aucune trace concrète fixée, mais au souvenir du frayage neuronal lié à l'expérience de l'événement considéré »³. Cette idée, selon Golse, montre une affinité avec la théorie psychanalytique de l'après-coup, du traumatisme en deux temps. En outre, l'auteur suggère que de nouvelles données neurophysiologiques du champ de l'audition - et également d'autres modalités sensorielles - viennent confirmer l'hypothèse freudienne du processus de la perception. Ces données indiquent que lorsque nous recevons un stimulus sonore, par exemple, ce qui est envoyé au cortex « est un stimulus d'origine endogène (cochléaire) mais reconstruit en référence au stimulus externe $»^{4}$. Ce stimulus

\footnotetext{
${ }^{1}$ GEORGIEFF Nicolas (2010). Psychanalyse, neurosciences et subjectivités.

${ }^{2}$ Ibidem, 348.

${ }^{3}$ GOLSE Bernard (2012). Entre neurosciences et psychanalyse : un dialogue enfin possible..., 270.

${ }^{4}$ Ibidem, 271. C'est nous qui soulignons.
} 
endogène, récrée au niveau de la cochlée, est isomorphe au stimulus externe et porte la même structure en ce que concerne son spectre de fréquences.

La théorie de l'esprit, que nous avons citée plus haut ${ }^{1}$, indique que le bébé atteint l'idée que l'autre possède un monde représentationnel - des pensées, des intentions, des désirs qui lui appartient, différent du sien. Bien que d'inspiration cognitive, ces données sont, toujours selon Bernard Golse, un point de convergence avec la théorie psychanalytique d'identification projective. Nous pouvons également nous référer à l'identification primaire chez Freud, ou encore au stade du miroir décrit par Lacan et qui a été repris par Winnicott ${ }^{2}$. Autrement dit, en suivant Golse, il s'agit pour l'enfant « de voir le monde à travers le regard de l'autre, fût-ce d'un autre encore indifférencié » ${ }^{3}$. C'est à partir de l'image reflétée par l'Autre - par le visage de la mère chez Winnicott - que l'enfant se voit et crée son image corporelle, commençant peu à peu une reconnaissance et intrinsèque articulation de ce qui est externe et de ce qui est interne ; de ce qu'il est et de ce qu'est l'Autre. Le stade du miroir et la théorie de l'esprit ne sont pas absolument équivalents, cependant présentent leur lecture sur un même objet. Après une possible traduction conceptuelle, indiquée dans le quatrième modèle de Georgieff, un dialogue entre le psychanalyste et le neuroscientifique intéressés par ce thème semble tout à fait possible.

\section{Sur la plasticité du cerveau}

Un autre concept clé pour la rencontre des deux théories est celui de la plasticité cérébrale. Selon Ansermet et Magistretti, c'est la découverte de ce phénomène qui a permis à la psychanalyse et la neuroscience de rompre enfin avec l'opposition historique entre les deux champs. Les auteurs proposent que « la psychanalyse soit nouée aux neurosciences par le concept de la plasticité. Celui-ci, bien qu'issu directement de la biologie, s'avère opérant dans le champ de la psychanalyse $»^{4}$. La philosophe Catherine Malabou, qui a beaucoup contribué au dialogue entre la psychanalyse et les neurosciences, propose une intéressante lecture du concept de plasticité. Entendu comme plasticité cérébrale, ce dernier est défini par les sciences biologiques comme la «capacité qu'ont les synapses de modifier leur efficacité sous l'effet de l'expérience, c'est-à-dire de l'apprentissage, de l'habitude et de

\footnotetext{
${ }^{1}$ Il s'agit là de ce que Georgieff indiquait sur la convergence à propos de l'intersubjectivité.

${ }^{2}$ Voir WINNICOTT Donald (1971) Le rôle de miroir de la mère et de la famille dans le développement...

${ }^{3}$ GOLSE Bernard (2012). Entre neurosciences et psychanalyse : un dialogue enfin possible..., 276.

${ }^{4}$ ANSERMET François \& MAGISTRETTI Pierre (2004). À chacun son cerveau : plasticité..., 25.
} 
l'environnement $»^{1}$. Cela signifie que les connexions neuronales sont organisées, réorganisées ou supprimées à partir de la convocation de l'activité cérébrale faite par l'expérience. Avec la découverte de la plasticité cérébrale, il est devenu possible d'observer que « le cerveau n'est pas une instance fixe et rigide, programmée une fois pour toutes, mais que sa forme, qui dépend de la taille et du volume des connexions entre neurones, est soumise à variation et à modification au cours de la vie $»^{2}$.

Pour Malabou, il existerait également une plasticité psychanalytique qui renvoie au concept de la libido. En d'autres termes, si l'investissement libidinal est normalement fixé à un objet, il peut aussi choisir un nouvel objet d'investissement : «la plasticité de la libido désigne alors la capacité de changer d'objet quand il le faut $»^{3}$. L'absence de la plasticité de la libido entraînerait, selon la philosophe, la fixation pathologique de l'objet ou une excessive fluidité libidinale, avec un rapide changement d'objet, également vue comme une entrave à la santé psychique. En ce qui concerne la plasticité cérébrale, toujours selon la philosophe, l'excès de réorganisation synaptique rendrait difficile l'établissement des mémoires; et, par ailleurs, l'absence de nouveaux réarrangements, équivalente à une certaine rigidité des connexions neuronales, rendrait difficile l'inscription de la trace, de l'empreinte. Au point de rencontre des deux concepts, on retrouve le même principe : une bonne mesure de la plasticité serait le résultat de l'équilibre entre excès de fluidité et excès de rigidité des connexions.

Définissant le concept de plasticité neuronale comme «la capacité qu'a le cerveau d'être modifié par l'expérience ${ }^{4}$, Magistretti et Ansermet, comme nous l'avons indiqué plus haut, situent également ce concept au sommet du dialogue possible entre neurosciences et psychanalyse, soulignant que la plasticité introduit la discontinuité et que celle-ci ouvre à son tour la possibilité de l'émergence du sujet. «L'expérience laisse une trace dans le réseau neuronal » : voilà donc une évidence prouvée par la neurobiologie expérimentale. Cette trace - vue sous la forme d'un ensemble de synapses facilitées - serait le correspondant neuronal d'une expérience ou d'un objet de la réalité externe.

\footnotetext{
${ }^{1}$ MALABOU Catherine (2011). Souffrance cérébrale, souffrance psychique et plasticité, 489. Dans cet article, l'auteure fait une intéressante réflexion au sujet de la plasticité pathologique, c'est-à-dire de la capacité destructrice et désorganisatrice de cette dernière par rapport à la formation de l'identité de l'individu. Nous avons cependant opté pour ne pas entrer dans ce débat dans le cadre de ce travail.

${ }^{2}$ Ibidem. C'est nous qui soulignons.

${ }^{3}$ Ibidem, 488.

${ }^{4}$ MAGISTRETTI Pierre \& ANSERMET François (2010). Neurosciences et psychanalyse, 17.
} 
La neuroscientifique Cristina Alberini présente des études récentes sur la mémoire à long terme, appelée "mémoire déclarative ». Selon elle, on sait déjà que «les épisodes d'apprentissage associatif, qui constituent la mémoire déclarative, provoquent des changements neuronaux et synaptiques durables dans des groupes de neurones distribués dans de nombreuses régions du cerveau. [...] ces changements représentent les traces mnésiques ${ }^{1}$. Autrefois, les chercheurs pensaient que c'était par la consolidation de la mémoire, autrement dit par un nécessaire processus de stabilisation, qu'un souvenir s'inscrivait de manière durable dans la mémoire. La trace du souvenir serait alors susceptible de changements pendant une période déterminée. Au cours du temps, selon Alberini, le souvenir deviendrait de plus en plus résistant au changement et finirait par se stabiliser. Des chercheurs ont récemment réévalué cette hypothèse de la consolidation de la mémoire, observant qu' " un souvenir établi, et devenu insensible à certains types d'interférences, peut redevenir transitoirement labile s'il est réactivé $»^{2}$. Les chercheurs ont constaté que le souvenir réactivé devra être de nouveau stabilisé au cours d'un processus que l'on appelle reconsolidation de la mémoire. À partir de ce nouvel entendement de la constitution de la mémoire déclarative, l'auteure aboutit à deux conclusions : 1) il est possible de supprimer un souvenir en utilisant un moyen efficace d'interférence ;2) la mémoire peut être modifiée et liée à de nouvelles associations ${ }^{3}$. Les scientifiques n'ont toujours pas trouvé d'explication à cette labilité de la mémoire, ni à sa réactivation. Toutefois pour Alberini, «cette connaissance contribuera grandement à une meilleure compréhension du potentiel thérapeutique de la réactivation des souvenirs dans la démarche psychanalytique $»^{4}$.

À partir du questionnement sur la manière dont se passerait la reconsolidation, Ansermet et Magistretti préparent le terrain pour une rencontre entre la psychanalyse et les neurosciences. Les théoriciens proposent que nous considérions l'inconscient comme un système de traces. Les expériences seraient inscrites à partir de l'association des traces primaires - représentantes de l'expérience - avec d'autres traces, formant de cette manière de nouvelles traces qui ne seraient plus directement liées avec l'expérience ni avec les perceptions initiales ${ }^{5}$. «La réassociation de traces introduit ainsi un degré de liberté qui est essentiel pour l'émergence de la singularité. [...] Or, la discontinuité introduite par la

\footnotetext{
${ }^{1}$ ALBERINI Cristina (2010). Consolidation de la mémoire, reconsolidation et intégration de ..., 31.

${ }^{2}$ Ibidem,31. C'est nous qui soulignons.

${ }^{3}$ Ibidem, 31.

${ }^{4}$ Ibidem, 47.

${ }^{5}$ Voir MAGISTRETTI Pierre \& ANSERMET François (2010). Neurosciences et psychanalyse.
} 
réassociation de traces ouvre à la possibilité de l'émergence du sujet, ouvre à son incontournable singularité $»^{1}$. La plasticité neuronale introduit, de cette manière, l'idée d'une discontinuité, dans la mesure où elle montre qu'il n'y aurait pas une structure cérébrale rigide et déterminée mais au contraire une structure tout à fait susceptible de subir des changements permanents. Cette discontinuité pourrait, selon les auteurs, contribuer à la constitution de l'inconscient proprement dit.

\section{Trace psychique, trace synaptique}

La notion de trace est centrale dans la théorie psychanalytique. $\mathrm{Si}$, pour les neurosciences, la trace est celle de l'expérience qui se voit inscrite sous la forme d'ensembles de synapses dans le réseau neuronal, pour Freud, comme nous le verrons au troisième chapitre, la trace est un signe de la perception. Rappelons ce qu'il écrit à propos de l'inscription de la première expérience de satisfaction :

«il apparaît une perception de cette expérience dont l'image mnésique reste désormais associée à la trace mémorielle de l'excitation de besoin. Dès que ce besoin survient une nouvelle fois, il se produira une motion psychique qui veut investir de nouveau l'image mnésique de cette perception et provoquer de nouveau la perception elle-même $»^{2}$.

Cela signifie que l'expérience laisse une première trace, définie par Freud comme signe de la perception, qui demeure dans l'appareil psychique et qui est réactivée quand émerge une tension. Freud ajoute «cette première activité psychique a donc pour but une identité de perception, à savoir la répétition de cette perception qui est connectée à la satisfaction du besoin $»^{3}$. Ces traces seront ultérieurement identifiées par Jacques Lacan comme les signifiants: «nous pouvons tout de suite leur donner, à ces Wahrnehmungszeichen, leur vrai nom de signifiants $»^{4}$. Ce qu'apporte la psychanalyse, à la lumière de Freud, est que les traces mnésiques ne s'inscrivent pas seules : elles ont besoin de l'intervention d'un autre, de l'aide étrangère. Autrement dit, la détresse primordiale est

\footnotetext{
${ }^{1}$ MAGISTRETTI Pierre \& ANSERMET François (2010). Neurosciences et psychanalyse, 19.

${ }^{2}$ FREUD Sigmund (1900). L'interprétation du rêve, 620.

${ }^{3}$ Ibidem, 640.

${ }^{4}$ LACAN Jacques (1964). Les quatre concepts fondamentaux de la psychanalyse, 46.
} 
déchargée par l'expérience de l'action spécifique de l'autre ${ }^{1}$. En s'appuyant sur les approches lacaniennes, Magistretti et Ansermet ajoutent les remarques suivantes : «au commencement est le cri : le cri du vivant est un cri hors sens, hors langage. Ce cri est transformé en appel, en demande, à travers la réponse de l'autre qui fait entrer le sujet dans le monde du langage qui lui préexiste $»^{2}$. Rappelons-nous également Lacan : cet échange avec cet Autre, c'est-à-dire, ce «lieu où se situe la chaîne du signifiant qui commande tout ce qui va pouvoir se présentifier du sujet » laissera des traces - des traces de langage, des signifiants qui s'inscrivent dans le corps du sujet et qui donnent le contour de son histoire.

Psychanalyse et neurosciences se rencontrent donc autour de l'émergence du sujet et de son psychisme. Toutefois cette rencontre n'est pas sans impasses, comme nous en avertissent Ansermet et Magistretti :

«Entre neurosciences et psychanalyse, il n’y a pas de syncrétisme, pas de réconciliation, pas de synthèse possible. Pas de salut pour la pensée sans reconnaître d'abord les différences essentielles qu'il y a entre les neurosciences et psychanalyse. Ces différences sont un facteur dynamique dont se déduit l'émergence du sujet, y compris à partir des lois de la biologie $»^{3}$

Il est certain que nous ne parlons pas la même langue et que la notion de trace, comme nous venons de le voir, n'est pas équivalente d'un domaine à l'autre. Cela dit, la découverte du concept de plasticité neuronale, tout comme de ceux de reconsolidation, de théorie de l'esprit, ou encore des études sur la mémoire que nous venons de passer en revue, ont permis l'ouverture d'une voie d'articulation, afin que les deux disciplines puissent se regarder mutuellement au cours d'une rencontre possible. C'est en suivant cette même logique, celle de rechercher une approximation en partant d'une découverte de la science elle-même, que nous proposons la rencontre de la psychanalyse avec la génétique médicale, à travers le concept d'épigénétique.

\footnotetext{
${ }^{1}$ Nous nous arrêterons plus longuement sur ce processus au quatrième chapitre, dans la partie « La constitution du sujet ».

${ }^{2}$ MAGISTRETTI Pierre \& ANSERMET François (2010). Neurosciences et psychanalyse, 24.

${ }^{3}$ ANSERMET François \& MAGISTRETTI Pierre (2004). À chacun son cerveau : plasticité neuronale ..., 25.
} 
La plasticité neuronale et l'épigénétique indiquent que l'être humain est loin d'être déterminé, que ce soit par ses gènes ou par son cerveau. Les connexions neuronales et l'activité génique sont en constante relation avec l'environnement, subissant des modifications - aussi bien structurelles que fonctionnelles - mais aussi modifiant celui-ci, par une activité réciproque qui aboutit à la production de la diversité, de la singularité, de la différence, si chère à la psychanalyse. Il est important de reconnaître aussi la nécessité pour la psychanalyse d'adopter une position moins obscurantiste et plus ouverte au dialogue avec le savoir médical. La possibilité de découvrir comment la machinerie humaine s'organise en termes de connexions neuronales et de processus physiologiques dans la dynamique de sa relation avec l'environnement, ne peut pas se permettre d'être sous-estimée par les psychanalystes.

«Pour la psychanalyse, ce serait d'aller dans la direction ouverte par Lacan lorsqu'il se demandait ce que serait une science qui inclurait la psychanalyse. Pour les neurosciences, ce serait trouver dans la psychanalyse les points d'appui nécessaires pour se repérer dans l'émergence de l'unique au sein même des mécanismes biologiques généraux qu'elle découvre ${ }^{1}$.

Le principe propre à la clinique psychanalytique qui dit que le sujet, son corps, son symptôme se constituent aussi dans sa relation avec l'Autre, mérite également de se faire connaître auprès la médecine. Nous proposons que l'ouverture au savoir médical se fasse en partant de la médecine elle-même, c'est-à-dire des découvertes scientifiques elles-mêmes, et en particulier de celles qui nous avons relatées ici : la plasticité neuronale et, dans notre cas, l'épigénétique (cf. troisième chapitre).

\subsection{La psychanalyse et la génétique}

Nous arrivons ici à l'un des points centraux de notre proposition : la rencontre de la génétique médicale avec la psychanalyse. Comme nous l'avons souligné en introduction et comme nous le développerons également au troisième chapitre, l'épigénétique se présente à nous comme un terrain privilégié pour cette articulation. La question que l'on soulève ici comme un véritable champ de recherche encore à explorer est celle de la mise en pratique

\footnotetext{
${ }^{1}$ ANSERMET François \& MAGISTRETTI Pierre (2004). À chacun son cerveau : plasticité neuronale ..., 25.
} 
d'une telle articulation. Plutôt que s'attaquer d'emblée à cette perspective, il nous semble nécessaire, dans un premier temps, de rechercher dans la littérature les études qui se rapprochent de notre proposition, c'est-à-dire qui impliquent par la pratique les deux savoirs en question. Dans les rares travaux disponibles, nous percevons que les psychanalystes, en ce qui concerne la génétique, ont tendance à s'interroger sur les effets de l'annonce du diagnostic de la maladie; sur le point de rencontre traumatique de l'enfant réel syndromique - et de l'enfant idéalisé par les parents ; sur le fait que l'hérédité puisse confronter le patient ou sa famille à des questions psychiques quant à la filiation et l'origine ${ }^{1}$. Les travaux qui, partant du point de vue de l'épigénétique, proposent une pratique qui combine psychanalyse et génétique médicale au niveau de la thérapeutique, sont encore plus rares. Notre recherche bibliographique n'a trouvé en effet qu'une seule recherche : elle fut menée par le brésilien Jorge Forbes, au Centre du Génome Humain de l'Université de São Paulo. Son travail, malgré sa simplicité clinique, a le mérite d'introduire ces deux champs de savoir à un débat pionnier (nous y reviendrons). En France, le travail de la psychanalyse en partenariat avec la génétique semble bien établi. À l'Université Paris Diderot, nous retiendrons le Labex Who am I?, laboratoire d'excellence qui travaille dans une perspective interdisciplinaire autour du concept d'identité. Le laboratoire réunit divers chercheurs issus des domaines de la biologie moléculaire, de la génétique, de la psychanalyse, de la philosophie, de la physique et de la sociologie. Le Centre de Recherches Psychanalyse, Médecine et Société (CRPMS), laboratoire de l'UFR d'Études Psychanalytique de Paris Diderot, en est l'un des partenaires et ses recherches y sont réalisées sous la direction du psychanalyste et Professeur François Villa.

Nous nous arrêterons ici sur les travaux de psychanalystes qui touchent, d'une manière ou d'une autre, à la psychanalyse et à la génétique médicale. Certes, la dimension travaillée par ces psychanalystes est principalement théorique. Toutefois, elle nous est fondamentale pour penser les particularités et les éléments psychiques qui sont partie intégrante de la maladie dans son ensemble, sans oublier pour autant qu'il s'agit là d'expériences vécues de manière singulière par chaque individu.

À l'Institut de Myologie de l'hôpital de la Pitié-Salpêtrière, la psychanalyste Marcela Gargiulo travaille sur les syndromes neurodégénératifs. Dans son ouvrage Vivre avec une

\footnotetext{
${ }^{1}$ Voir GARGIULO Marcela (2009), POTIER Rémy et al. (2016) ; MANNONI Maud (1964) ; CORIAT Elsa (1997) ; CRESPIN Graciela (2007) ; JERUSALINSKY Alfredo (2010) ; GODARD Anne (2005).
} 
maladie génétique l'auteure apporte un regard plus général sur les maladies génétiques, c'est-à-dire sur le vécu des acteurs impliqués dans tout le processus du devenir malade. Pour Gargiulo, l'une des grandes questions qui traversent le contexte de la maladie génétique est le moment de l'énonciation du diagnostic. L'annonce aux parents que leur fils est porteur d'une maladie génétique est, dans la plupart des cas, une expérience traumatique capable de faire s'écrouler les idéalisations initiales qui existent autour de l'enfant. Comme nous le verrons dans les paroles de la mère de Flora (cas clinique que nous présentons au cinquième chapitre), peu après l'annonce du diagnostic, « il a fallu faire le deuil ». Selon Gargiulo, la blessure narcissique provoquée par la rencontre avec l'enfant malade peut éveiller des diverses réactions chez les parents, comme le rejet de la réalité, la culpabilité, le désir de mort $^{1}$. «Les parents peuvent être submergés, dans un état de grande confusion, fait d'interrogations, de reproches, de culpabilité, mais aussi d'ambivalence vis-à-vis de l'enfant $»^{2}$, indique l'auteure. Elle ajoute que les prédictions médicales pourront même déterminer le futur de l'enfant, dans la mesure où elles le figent dans la maladie dont il est porteur : «toute prédiction sur l'évolution de la maladie a des effets potentiellement délétères sur le devenir de l'enfant $»^{3}$. Au sujet du pouvoir qu'aurait la génétique médicale de prévoir et prédire le futur d'un enfant, Arnold Munnich, pédiatre et médecin généticien à l'Hôpital Necker, se montre emphatique : «prédire rime avec médire. La prédiction est une forme de malédiction. Nous ne nous autorisons pas à prédire l'avenir ; nous ne sommes ni devins ni diseuses de bonne aventure $»^{4}$. Ainsi, prédéterminer le futur d'un enfant à partir de la maladie dont il est porteur peut impliquer une violence par laquelle son devenir, ses possibilités symboliques se montrent clairement menacées.

En outre, il est important de considérer que l'effet traumatique de l'annonce du diagnostic aux parents de l'enfant peut mettre en lumière d'autres événements refoulés dans

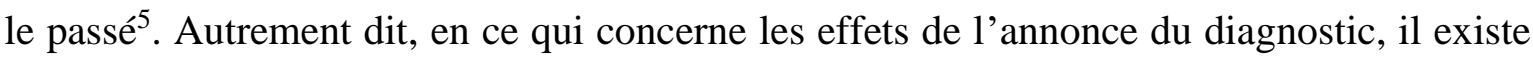
encore la possibilité du réveil d'un épisode vécu comme douloureux, qui aurait été mis sous silence à partir d'un refoulement, mais qui serait rendu actuel par la nouvelle de la maladie génétique, faisant de celle-ci une expérience encore plus dévastatrice.

\footnotetext{
${ }^{1}$ Voir GARGIULO Marcela (2009). Vivre avec une maladie génétique.

2 Ibidem, 17.

${ }^{3}$ Ibidem, 12.

${ }^{4}$ MUNNICH Arnold *Entretien avec (2014). La génétique est-elle inhumaine ?, 66.

${ }^{5}$ Voir GARGIULO Marcela et DÜRR Alexandra (2014). Anticiper le handicap. Les risques ..., 62.
} 
À propos du travail articulé avec la génétique, Gargiulo relate son expérience en tant que membre de l'équipe multidisciplinaire - composée par un généticien, un neurologiste et un psychologue clinique - responsable de la réalisation des tests pré-symptomatiques. Prenant en exemple le syndrome de Huntington, l'auteure cite des cas qui illustrent le poids psychique de la confirmation de ce syndrome neurodégénératif pour lequel il n'existe de mesures ni préventives ni curatives. Or, une telle confirmation se fait, le plus souvent, avant même le développement des symptômes : « quand on est porteur du gène, la maladie devient une crainte avec laquelle il faut apprendre à cohabiter. L'incertitude qui régnait avant le test est déplacée, se transformant en une autre incertitude qui taraude : à quelle moment la maladie va-t-elle apparaître ? » ${ }^{1}$, affirme Gargiulo.

La possibilité, grâce aux nouvelles technologies de cartographie génétique, de se savoir porteur d'un gène défectueux, avant même de développer quelconque symptôme, n'est pas sans conséquences psychiques : «Les suites de l'annonce d'un test génétique ne s'inscrivent pas sur une page blanche de vie mais sur un fond d'histoire et d'inconscient $»^{2}$. La présence du psychologue clinique, loin de toute pratique de conseil ou de suggestion, permet alors que le candidat à la maladie puisse élaborer et évaluer les conséquences de sa décision par rapport au résultat du test génétique, que celui-ci soit favorable ou défavorable 3 . En d'autres termes, l'écoute clinique permet que l'individu considère diverses questions : les motifs qui l'on amené à vouloir savoir ; ce qu'il y a derrière la réalité du possible héritage d'un gène défectueux; les possibles conséquences de se savoir malade (mais aussi de se savoir non-malade). En outre, au cas où le patient renonce à sa demande de réalisation de test, il ne faut pas négliger qu'il devra alors supporter l'angoisse du doute ${ }^{4}$.

Il convient de signaler ici le travail exemplaire que Marcela Gargiulo réalise avec la neurogénéticienne Alexandra Dürr et toute l'équipe multidisciplinaire de l'Hôpital la PitiéSalpêtrière. L'expérience de Gargiulo démontre la richesse du travail développé en partenariat avec la génétique médicale, et l'on ne saurait oublier de relever l'importance de l'écoute psychanalytique pour les patients porteurs - où candidats porteurs - d'une maladie génétique. Il ne serait en rien prétentieux, à nos yeux, que l'équipe de Gargiulo enquête sur les possibles effets de l'écoute psychanalytique régulière dans le développement de la

\footnotetext{
${ }^{1}$ GARGIULO Marcela (2009). Vivre avec une maladie génétique, 81.

${ }^{2}$ GARGIULO Marcela et DÜRR Alexandra (2014). Anticiper le handicap. Les risques ..., 54.

${ }^{3}$ Ibidem, 56.

${ }^{4}$ Ibidem, 60.
} 
maladie ou par rapport aux symptômes psychiques qui en découlent. Et c'est précisément là l'initiative menée au Brésil par le psychanalyste Jorge Forbes.

Anne Aubert-Godard est une autre référence importante quant à l'articulation du travail psychanalytique à la génétique médicale. Elle s'est notamment intéressée aux représentations psychiques qui se trouvent derrière les maladies génétiques, suggérant que « comme dans le processus d'adoption d'un enfant dont les parents ne sont pas géniteurs, ou celui de l'intégration psychique d'une transplantation d'un organe vital tel le cœur ${ }^{1}{ }^{1}$, il s'agit pour le porteur adulte d'une maladie génétique, de se placer différemment par rapport à l'autre, c'est-à-dire de fabriquer de nouveaux ensembles relationnels, de construire de nouvelles façons «d'être avec » l'autre. La découverte d'une mutation génétique, c'est-àdire d'une faille génétique, serait vécue comme une «faille narcissique primaire $»^{2}$, sans représentation psychique possible. Pour l'auteure, la mutation génétique provoquerait une perturbation de l'efficacité symbolique liée au sexe et à la génération. En ce qui concerne l'enfant porteur d'un syndrome génétique, Aubert-Godard souligne que «si l'anomalie ou la maladie, présentes, à venir ou risquées, qualifient l'être aux yeux de ses parents, l'identité de cet enfant est aliénée dans le regard du premier Autre à un trait, de maladie, de handicap, au détriment de sa personne globale $»^{3}$. Cela signifie, comme nous le verrons au cinquième chapitre avec les cas de Flora et de Benjamin, que l'enfant court le risque d'être prisonnier du signe de sa maladie, répondant alors avec son symptôme. Quand un espace est ouvert, par le biais de l'écoute psychanalytique en transfert, la maladie peut se défaire de son trait unique de reconnaissance et les manifestations de l'enfant peuvent s'amplifier et se diversifier.

Dans une étude sur le syndrome de microdélétion 22q11.2 menée sur des enfants, Potier et $a l$. ont mis en évidence la nécessité d'une méthodologie interdisciplinaire rigoureuse pour faire face aux progrès technoscientifiques, «tant pour garantir un accompagnement de qualité à ces enfants que pour prendre acte au niveau du débat interdisciplinaire des apports spécifiques liés aux épistémologies respectives $»^{4}$. Selon les auteurs, l'exercice, dans le contexte d'une clinique aussi complexe, requiert la considération

\footnotetext{
${ }^{1}$ AUBERT Anne (2005). Filiation en question : maladies génétiques, identités incertaines..., 40.

${ }^{2}$ Ibidem, 42.

${ }^{3}$ Ibidem, 32. C'est nous qui soulignons.

${ }^{4}$ POTIER Rémy et al. (2016). Regards croisés sur une pathologie développementale d'origine ... 103.
} 
des spécificités irréductibles de chaque champ de savoir, en particulier de la génétique médicale, de la psychopathologie psychanalytique et de la pédopsychiatrie. La dimension épistémologique, clinique et éthique de chaque domaine se doit d'être articulée, toujours selon les auteurs, pour le bien des enfants touchés par la mutation génétique : « c'est bien du génome à l'individu et à son insertion sociale que l'impact de ce type d'affection doit être appréhendé »1.

Pour Potier et $a l$., le psychanalyste se concentrerait sur la dimension psychique des pathologies d'origine génétique, sans ignorer l'incidence de l'impact organique sur ce qui serait de l'ordre du psychique, permettant ainsi «d'examiner le versant psychique de ces psychopathologies complexes sans préjuger de sa nature $»^{2}$. Il ne s'agirait donc pas de penser une continuité symptomatique, entre cause génétique et conséquence psychique sous une unique entité nosographique, mais bien de considérer le rôle d'autres facteurs, biologiques, psychiques et sociaux, dans la composition des symptômes présentés. Et c'est là aussi, d'une certaine manière, notre questionnement au sujet du syndrome de l'X fragile. Nous avons d'ailleurs trouvé des similitudes entre les deux syndromes en ce qui concerne les limitations imposées aux enfants porteurs. Le syndrome de l'X fragile, comme le syndrome de la microdélétion 22q11.2, génère des difficultés dans le domaine des compétences cognitives comme l'attention, la mémoire de travail, la planification, le raisonnement et l'exécution. Nous avons également observé que les difficultés d'apprentissage, le retard du langage, les troubles de l'anxiété et les troubles de l'humeur sont communs aux deux syndromes ${ }^{3}$.

Or, le trouble du spectre autistique est également associé au syndrome de la microdélétion 22q11.2. Citant l'étude de Angkustsiri et al., Potier et ses collaborateurs soulignent que le repli social identifié pour ce syndrome - et qui l'amènera à être associé à l'autisme - «apparaît comme un acquis, consécutif à l'atteinte développementale et sédimenté au cours d'interactions sociales ultérieures $»^{4}$. Cela signifie que la mutation génétique ne serait pas la cause organique du supposé autisme. Toutefois, l'impact psychique, chez l'enfant et chez son entourage, lié au fait de porter une maladie génétique, contribue à la manière dont il établit une relation avec ses pairs et avec sa famille. C'est par la considération et par le travail réalisé sur l'impact psychique provoqué par une maladie

\footnotetext{
${ }^{1}$ POTIER Rémy et al. (2016). Regards croisés sur une pathologie développementale ..., 104. Italique conforme à l'original

${ }^{2}$ Ibidem.

${ }^{3}$ Ibidem, 106.

${ }^{4}$ Ibidem, 107. Italique conforme à l'original.
} 
génétique, que la psychanalyse pourra être exercée en tant que partie intégrante des soins apportés à une enfant malade.

$\mathrm{Au}$ Brésil, comme nous l'avons dit précédemment, il convient de s'arrêter sur l'importante contribution du psychiatre et psychanalyste Jorge Forbes, idéalisateur et chef du Service de Psychanalyse du Centre de Génome Humain de l'Université de São Paulo. Ce service fut créé pour répondre à la demande des patients du Centre, porteurs de maladies neurodégénératives d'origine génétique et ayant sollicité un suivi psychanalytique. Dans le cadre de nos recherches côté brésilien, ce travail est celui qui se rapproche le plus de notre proposition, dans la mesure où la psychanalyse y est insérée dans un espace qui appartient à la génétique : celui du suivi de patients porteurs de maladies neurodégénératives, où règne le déterminisme de la faille corporelle dans la vie de l'individu. Une telle pratique démontre qu'il est possible de partager le champ des soins au patient porteur d'un syndrome génétique, tout en maintenant les différences qui constituent chaque domaine de savoir.

L'une des hypothèses de travail de Forbes, est que la psychanalyse «pourrait influencer l'expression des gènes qui modulent les neurotransmetteurs et avoir un effet sur la vitesse d'avancement de la maladie neuromusculaire ${ }^{1}$. L'auteur soutient qu'au-delà de l'évolution naturelle d'une maladie dégénérative, celle-ci peut aussi se développer à partir de la représentation donnée par l'individu, à condition d'avoir un destin tracé par l'annonce d'une maladie neurodégénérative. En d'autres termes, le cadre organique empire plus rapidement, dans la mesure où il y aurait une capitulation, une identification du sujet à ce qui s'est socialement établi comme un modèle de souffrance. «Par exemple, une personne reçoit le diagnostic d'une altération qui va affecter ses mouvements d'ici à une dizaine d'années. Il sort déjà de la salle en boitant et les bras tremblant. Face à l'inconnu, c'est une forme connue de réaction qui se précipite $»^{2}$, explique Forbes.

Être porteur d'une maladie génétique neurodégénérative signifie, selon l'auteur, que le sujet est exonéré de la responsabilité de ses actes, de son futur, dont la sentence est tombée avec le diagnostic. Dans une recherche intitulée «Refuser la souffrance $»^{3}$, Forbes et son équipe proposèrent un suivi psychanalytique à un groupe de 42 patients porteurs de maladies neuromusculaires diverses - d'origine génétique - pendant quinze semaines. L'objectif de

\footnotetext{
${ }^{1}$ FORBES Jorge (2007). Uma hipótese de trabalho: A influência da Psicanálise..., 30. Traduction libre de l'auteure.

${ }^{2}$ FORBES Jorge (2011). Desautorizando o sofrimento socialmente ..., 05-06. Traduction libre de l'auteure.

${ }^{3}$ Traduction libre de «Desautorizando o sofrimento ».
} 
la recherche était alors d'étudier les effets de la psychothérapie psychanalytique chez ces patients mais aussi chez certains de leurs proches qui ont fait appel au service $(n=22)$. L'hypothèse était que la psychanalyse puisse offrir au patient la possibilité d'une autre réponse, singulière, à sa condition, sans utilisation d'une souffrance socialement modelée. Après application d'une échelle d'évaluation adaptée, on a constaté des améliorations considérables des aspects sociaux et subjectifs et qui, selon l'auteur, ont contribué à retarder les effets de la maladie ${ }^{1}$.

La chercheuse Claudia Rosa Riolfi, membre de l'équipe de Forbes, a mené également une recherche au Centre d'Étude du Génome Humain de l’USP. Analysant sept fragments de cas cliniques, Riolfi a mis en évidence cinq principaux effets produits par le traitement psychanalytique proposé aux patients porteurs de maladies dégénératives :

«1) Altération de l'interprétation que le patient donne à sa maladie ;2) Convocation de la singularité de celui qui reçoit une réponse insolite en dépit de la banalité avec laquelle il faisait face à sa propre vie ; 3) Construction d'une étique autour du principe de la responsabilité ; 4) Établissement d'un statut étique au corps, comme résultat d'une manière singulière d'interpréter les contingences de la vie ; 5) Réinsertion de la dimension sexuelle, non normalisée, dans le quotidien du patient $»^{2}$.

Pour la chercheuse, les résultats du traitement psychanalytique peuvent être favorables quand l'analyste « réussit l'opération de séparer le sujet du signifiant auquel il était aliéné »33. Même sans identifier étroitement notre pratique psychanalytique à celle réalisée par Forbes et son groupe de recherche, signalons qu'une telle considération fait écho au cas de Maria, présenté et débattu au cinquième chapitre. Un cas pour lequel nous faisons l'hypothèse que, une fois ancré dans le transfert, le $\mathrm{X}$ du syndrome ( $X$ fragile) qui marquait l'enfant a pu se déplacer et devenir, au-delà d'un $\mathrm{X}$ fragile, le $\mathrm{X}$ de «Xuxa » (célèbre présentatrice de télévision au Brésil) ou le X de Maria. Le traitement a ainsi ouvert une voie de sortie pour la jeune fille, lui offrant de nouvelles possibilités pour qu'elle puisse se représenter au-delà de son syndrome.

\footnotetext{
${ }^{1}$ FORBES Jorge (2011). Desautorizando o sofrimento socialmente padronizado em ..., 05-06. Traduction libre de l'auteure.

${ }^{2}$ RIOLFI Claudia (2011). Corpo e responsabilidade: efeitos da psicanálise sobre portadores de..., 242. Traduction libre de l'auteure

${ }^{3}$ Ibidem, 241.
} 
Le travail de Forbes et Riolfi est, de fait, pionnier, principalement en ce qui concerne la rencontre de la psychanalyse avec la génétique médicale. Nous questionnons toutefois la thèse des auteurs qui défend que la psychanalyse n'aurait pas d'incidence sur la matière organique «dans la sphère des phénomènes passibles de preuve empirique » ${ }^{1}$. Les études que nous apportons ici en rapport à l'épigénétique et aux effets de la psychothérapie montrent pourtant bien qu'il existe une preuve empirique des modifications organiques à partir du traitement psychothérapique. Croire à cette non incidence organique du traitement psychanalytique serait croire, comme l'écrit Freud à Fliess, que «le psychologique flotte dans les airs et n'a pas de fondement organique $»^{2}$. La supposition que toute modification psychique implique une modification organique, même si on ne peut pas la détecter ni la démontrer de manière empirique nous semble évidente. Dans ce sens, la psychanalyse, tout comme les autres thérapeutiques et comme tout ce qui survient dans l'histoire du sujet, a toujours le potentiel de produire des marques organiques, certainement pas flottantes dans les airs au-dessus de l'organisme.

Ce que nous retiendrons des travaux cités ci-dessus et qui nous est extrêmement précieux est la suivante affirmation de Forbes : «entre l'altération du gène et l'expression génique, s'établit un territoire d'action clinique pour la psychanalyse » ${ }^{3}$. Une affirmation qui nous semble d'ailleurs être une contradiction avec son autre thèse que le traitement psychanalytique n'aurait pas d'incidence organique. C'est donc sur cette dernière citation que s'ancre notre proposition, encore renforcée par la contribution d'Ansermet \& Giacobino aux recherches sur l'autisme, et que nous suggérons d'élargir à d'autres affections de l'enfant :

« Ne pourrait-on pas, au contraire, aller jusqu'à imaginer que des interventions psychothérapeutiques puissent moduler l'épigénome ? Alors que la tendance est plutôt de réduire l'autisme à un déterminisme génétique considéré comme inéluctable, le passage du génomique à l'épigénétique ne permettrait-il pas de redonner une place aux prises en charge cliniques, psychothérapeutiques et psychanalytiques ? ${ }^{4}$.

\footnotetext{
${ }^{1}$ RIOLFI Claudia (2011). Corpo e responsabilidade: efeitos da psicanálise sobre portadores de..., 263. Traduction libre de l'auteure.

${ }^{2}$ FREUD Sigmund (1887-1902). La naissance de la psychanalyse, 235.

${ }^{3}$ FORBES Jorge (2011). Desautorizando o sofrimento socialmente padronizado em pacientes afetados..., 32. Traduction libre de l'auteure. C'est nous qui soulignons.

${ }^{4}$ ANSERMET François \& GIACOBINO Ariane (2012) Autisme, à chacun son génome, 64. C'est nous qui soulignons.
} 


\subsection{Conclusion}

Dans ce premier chapitre, nous avons parcouru le chemin qui semble nous introduire à une rencontre possible entre psychanalyse et génétique médicale. Nous sommes revenus, d'une certaine manière, aux origines de cette rencontre - faite de bien des contretemps - où la psychanalyse et la médecine se confrontent et, malgré toute la divergence qui les caractérise, se trouvent des points d'intérêt en commun. Nous avons choisi dépasser l'histoire critique dessinée à la médecine : face aux impasses, nous relevons l'existence de discontinuités, toutefois proposons à partir de celles-ci une articulation des savoirs. Nous comprenons que la critique pure de la médecine en soi ne contribue en rien à notre pratique, mais renforce au contraire la scission entre les deux champs et semble devenir un obstacle de la complexification des traitements conférés aux patients dans les institutions de soin.

C'est pourquoi nous avons réuni dans ce chapitre des auteurs qui nous motivent et nous inspirent dans notre initiative. La psychanalyse en milieu hospitalier, relatée dans les travaux abordés ici, montre comment un travail articulé est à la fois possible et nécessaire. Le dialogue entre les neurosciences et la psychanalyse pointe vers un futur de recherches qui rapprochent toujours plus les deux champs de savoir. Enfin, et c'est ce qui constitue notre principal intérêt de recherche, nous nous sommes exprimés sur les travaux rencontrés qui trament, d'une certaine manière, la psychanalyse avec la génétique médicale. De tels travaux nous donnent l'espérance qu'il soit admis que la psychanalyse puisse contribuer aux soins proposés aux enfants porteurs de syndromes génétiques - et c'est précisément cette espérance, cette croyance, ce désir qui soutiennent le développement de notre recherche. 


\section{Chapitre II}

\section{Considérations sur le syndrome de l'X fragile - un saut entre deux savoirs}

\subsection{Ouverture}

Le syndrome de l'X fragile (SXF) est notre point clef pour construire la proposition majeure de cette thèse : le dialogue entre la génétique médicale et la psychanalyse. C'est à partir de ce syndrome que nous nous sommes engagés à réaliser une articulation entre les différents champs de savoir impliqués. Il nous a fallu réaliser une recherche bibliographique $^{1}$ sur le syndrome pour légitimer et donner de la consistance à notre discussion. Le SXF est considéré par la littérature médicale comme « la cause génétique identifiable la plus fréquente de la déficience intellectuelle et du trouble du spectre autistique $»^{2}$. Les scientifiques attribuent au syndrome une série de symptômes dits comportementaux, dont l'hyperactivité, le trouble du langage, l'anxiété sociale, la névrose obsessionnelle, la phobie sociale, l'impulsivité, la labilité de l'humeur ${ }^{3}$.

Il semble indispensable, afin de pouvoir discuter avec la génétique, d'acquérir quelques connaissances sur ce sujet qui n'appartient pas au champ de la psychanalyse. Nous allons donc dans un premier temps éclaircir le syndrome de $1^{\prime} \mathrm{X}$ fragile, en cherchant à comprendre quelle est son origine et quels en sont les symptômes, le diagnostic et le traitement proposé. Pour cela, nous allons utiliser une approche historique de la construction de la connaissance du SXF, depuis sa découverte en 1969. Il est particulièrement intéressant d'observer le progrès des techniques scientifiques et les différentes facettes du discours de la science au cours des années, avec comme toile de fond le syndrome de l'X fragile.

\footnotetext{
${ }^{1}$ Nous avons consulté les ouvrages sur le syndrome disponibles à la Bibliothèque national de France et les articles ont été collectés durant l'écriture de cette thèse via la base de données PubMed avec le mot clé : fragile $X$ syndrome.

${ }^{2}$ BERRY-KRAVIS Elizabeth (2014) Mechanism Based Treatments in Neurodevelopmental Disorders: Fragile $X$ Syndrome, 01. Traduction libre de l'auteure.

${ }^{3}$ CORNISH Kimberly et al. (2007) ; HAGERMAN Randi et HAGERMAN (2002); MCLENNAN et al. (2011); BORODYANSKAYA Mariya et al. (2010) RESTIVO Leonardo et al. (2005); ROBERTS Jane et al. (2014);
} 
À la fin de ce chapitre, nous allons soulever une discussion sur le diagnostic de l'autisme qui est fortement associé aux porteurs de l'X fragile. Autrement dit, nous allons interroger l'utilisation du critère diagnostic basé sur les phénomènes, sur les signes du comportement présentés par les porteurs du syndrome qui, selon certaines recherches contraires à cette association courante, ne sont pas équivalentes aux signes de l'autisme. Au cours des années, les critères diagnostics psychopathologiques ont suivi la tendance des manuels psychiatriques, notamment le DSM (Diagnostic and Statistical Manuel of Mental Disorders - et ses diverses versions. Dans ce manuel, soit l'étiologie des psychopathologies est exclusivement d'origine organique, soit elle est escamotée de sorte que le critère diagnostic se retrouve exclusivement basé sur l'ensemble de signes du comportement, décrits par les propres auteurs du $D S M^{1}$.

\subsection{Présentation du syndrome}

L'espèce humaine possède 46 chromosomes, soit 23 hérités du père et 23 hérités de la mère. De ces chromosomes, 44 sont homologues, appelés autosomes, et 2 sont appelés chromosomes sexuels. La représentation du génotype du chromosome sexuel féminin est indiquée par la paire $\mathrm{XX}$, tandis que le masculin est représenté par la paire XY. Un chromosome est une longue séquence d'ADN responsable des caractéristiques des individus. L'ADN code divers gènes et séquences de nucléotides aux fonctions spécifiques dans les cellules des êtres vivants. Autrement dit, les gènes sont à la base des messages biologiques qui sont transmis d'une génération à l'autre. Selon Borodyanskaya, en principe, les gènes sont extrêmement stables et copiés de façon précise pendant la division cellulaire ${ }^{2}$. Chimiquement, les gènes sont composés d'un acide désoxyribonucléique (ADN), lui-même constitué d'une séquence de nucléotides.

L'ADN contient l'information de différents acides aminés produisant des protéines qui orientent les cellules dans la réalisation de diverses fonctions - croître, phagocyter, se partager - qui sont fondamentales au bon fonctionnement de l'organisme. Les nucléotides sont définis comme des complexes moléculaires qui contiennent du sucre, des groupes de phosphate et de l'acide nucléique. Nous trouvons dans l'ADN les nucléotides suivants : adénine, guanine, thymine et cytosine. Dykens et al. affirment que c'est l'ordonnance

\footnotetext{
${ }^{1}$ Voir LANE Christopher (2010). Comment la psychiatrie et l'industrie pharmaceutique ont médicalisée...

${ }^{2}$ Voir BORODYANSKAYA Mariya, (2010). Intergenerational effects of mutations in the fragile X...
} 
spécifique de ces quatre nucléotides qui transmet l'information génétique et qu'il faut, pour réaliser cette transmission, produire un ARN messager par transcription du code génétique, étant donné que la séquence des nucléotides ne fournit pas directement le modèle de synthèse des protéines ${ }^{1}$.

Les sciences biologiques appellent mutation génétique les modifications de la séquence des nucléotides du matériel génétique d'un organisme. Ces mutations peuvent se produire à partir d'erreurs de copie du matériel pendant la division cellulaire. Il existe plusieurs facteurs qui interfèrent dans les mutations génétiques et risquent de produire ces erreurs, telle l'exposition à la radiation ultraviolette ou ionisante, ou à des mutagènes chimiques, ou encore certaines infections virales.

Le syndrome de l’X fragile a été documenté la première fois par les scientifiques Martin et Bell, qui ont remarqué un trouble du développement hérité lié au chromosome $\mathrm{X}^{2}$. En 1969, Herbert Lubs découvre qu'une petite partie d'un gène présent dans le chromosome $\mathrm{X}$ était instable et il a rapporté un aspect fragile proche de la fin du bras du chromosome $\mathrm{X}^{3}$. Ce n'est qu'après cette découverte que l'existence du retard mental lié au chromosome $\mathrm{X}$ a été acceptée par le milieu scientifique ${ }^{4}$. Ce gène, le FMR1 - fragile mental retardation 1 gene - a été isolé en 1991 par la stratégie de clonage positionnel, devenant ainsi le premier gène cloné qui a été lié à l'intelligence humaine ${ }^{5}$.

En 1989, dans la préface de l'ouvrage The fragile X syndrome, le scientifique Kay Davies explique que l'X fragile a alors éveillé l'intérêt de la science pour avoir été reconnu, après le syndrome de Down - trisomie du chromosome 21 -, comme la plus fréquente cause génétique du retard mental ${ }^{6}$. Selon Fryns, c'est au cours de la période de 1977 à 1982 que la recherche sur le retard mental lié au chromosome X (X-linked) s'est focalisée pour la première fois au syndrome de l'X fragile. L'auteur ajoute que le développement de la connaissance des mécanismes biologiques impliqués dans la cause du retard mental a stimulé l'intérêt scientifique pour cette maladie?

\footnotetext{
${ }^{1}$ Voir DYKENS Elisabeth, HODAPP Robert et LECKMAN James, 1994. Behavior and development...

${ }^{2}$ Voir WIJETUNGE Lasani et al. (2013). Fragile X syndrome : From targets to treatments

${ }^{3}$ Voir HOGENBOOM Marga (2001); WIJETUNGE Lasani et al. (2013)

${ }^{4}$ FRYNS Jean-Pierre (1989). X-linked mental retardation and the fragile X syndrome: a clinical approach., 03. Traduction libre de l'auteure.

${ }^{5}$ Voir SABARATNAM Manga (2006). Fragile X syndrome.

${ }^{6}$ Voir DAVIES Kay (1989). The fragile X Syndrome, 05.

${ }^{7}$ Voir FRYNS Jean-Pierre (1989). X-linked mental retardation and the fragile X syndrome: a clinical...
} 
Les recherches de Dykens et $a l .{ }^{1}$, indiquent que le syndrome est le résultat d'une région instable dans l'ADN, qui a été trouvée dans le long bras du chromosome X. Après avoir réussi à isoler le gène FMR1 en 1991, les chercheurs ont concentré leur attention sur lui. Toujours selon Dykens et al., le syndrome de l'X fragile est le résultat d'une mutation complète au sein du FMR1 qui, à son tour, entraîne une amplification des séquences des nucléotides CGG. Cependant, «la structure de ce gène n'a pas encore été caractérisée complètement, il doit exister quelques éléments non habituels ${ }^{2}$ ont affirmé les auteurs. Autrement dit, à l'époque, la fonction du FMR1 et la protéine qu'il produisait étaient encore méconnues $^{3}$. En 1996 les études de Fridell et al. ont souligné que le syndrome de l’X fragile résultait du «manque d'expression d'une forme fonctionnelle de la fragile mental retardation protein (FMRP) $»^{4}$. Cette protéine, selon les auteurs cités, est présente dans les tissus humains, notamment dans le cerveau, mais sa fonction physiologique était méconnue.

Au début du XXI ${ }^{\text {ìme }}$ siècle, nous constatons un changement significatif du discours sur le syndrome. Si celui-ci se centralisait jusque-là sur les aspects physiques - les aspects visibles - liés au retard mental, le regard scientifique se focalise à partir des années 2000 sur l'invisible, c'est-à-dire sur les productions et les interactions chimiques du corps, qui sont petit à petit dévoilées par la science.

En 2002, dans la préface de la troisième édition de l'ouvrage Fragile X Syndrome : Diagnosis, Treatment and Research, Hagerman et Hagerman signalent les progrès de la connaissance sur les mécanismes d'expression du gène FMR1 et sur la neurobiologie du syndrome de l'X fragile. Dans le premier chapitre, Randi Hagerman affirme que «le manque ou la déficience de la FMRP cause les caractéristiques physiques, cognitives et du comportement que nous identifions dans le syndrome de l'X fragile $»^{5}$. La FMRP est considérée comme une protéine de liaison du RNA, cependant, ses fonctions, spécifiques et générales, restent des questions sans réponse ${ }^{6}$. Irwin et al., dans l'ouvrage déjà cité, ajoutent que la FMRP peut être spécifique pour le développement de la maturation et l'élagage des

\footnotetext{
${ }^{1}$ Voir DYKENS Elizabeth et al. (1994) Behavior and development in fragile X syndrome.

${ }^{2}$ Ibidem, 16. Traduction libre.

${ }^{3}$ Ibidem, 18. Traduction libre.

4 FRIDELL Robert et al. (1996). A nuclear role for the Fragile mental retardation protein, 5408. Traduction libre de l'auteure.

${ }^{5}$ HAGERMAN Randi \& HAGERMAN Paul (2002). Fragile X syndrome : Diagnosis, Treatment and Research, 06. Traduction libre de l'auteure.

${ }^{6}$ OOSTRA Ben \& HOOGEVEEN Andre (2002). FMR1 Protein Studies and Animal Model for Fragile X Syndrome, 183. Traduction libre de l'auteure.
} 
épines des dendritiques. Un long travail a été développé par Irwin et ses collaborateurs sur le rôle de la FMRP dans le cerveau. L'auteur soutien l'hypothèse qu' « il est probable que cette protéine [FRMP] soit impliquée dans le processus de la plasticité synaptique $»^{1}$.

Cornish et $a l$., cinq ans plus tard, indiquent que le SXF est considéré par la littérature médicale comme le désordre mental héréditaire le plus fréquent, étant la cause la plus connue et prédominante du retard génétiquement hérité dans le développement ${ }^{2}$. Le syndrome de l'X fragile peut être transmis par la mère comme par le père porteur. La mère peut transmettre ce gène aux enfants des deux sexes, tandis que le père ne peut le transmettre qu'à la fille, car c'est le chromosome Y transmis par le père qui définit le sexe masculin de l'enfant. L'auteur cité ajoute qu'il existe près de trente mille gènes dans le génome humain et environ mille dans le chromosome $\mathrm{X}$. Environ deux cents de ces gènes sont associés par les chercheurs au retard mental, ce qui fait du chromosome $\mathrm{X}$ celui qui est le plus lié à ce type de pathologie. Environ 20 à $25 \%$ des cas du trouble cognitif en question auraient un rapport avec le chromosome $\mathrm{X}^{3}$. N'ayant qu'un seul chromosome $\mathrm{X}$, les hommes seraient plus vulnérables aux effets d'une anomalie génétique.

$\mathrm{Au}$ sujet des effets du syndrome chez les hommes et chez les femmes, Borodyanskaya explique que les femmes, ayant deux chromosomes $\mathrm{X}$, auraient le pouvoir de pallier le dysfonctionnement du chromosome atteint par l'anomalie. En ce qui concerne le retard mental, l'auteur indique que les hommes sont, d'une manière générale, $20 \%$ plus affectés que les femmes. Autrement dit, les troubles provoqués par l'X fragile sont généralement plus graves chez les hommes. Cependant, bien que les femmes soient moins affectées au niveau cognitif, comme l'indiquent les études de Cordeiro et al., elles sont plus vulnérables aux «problèmes émotionnels et du comportement » ${ }^{4}$.

Dans un article publié en 2011, McLennan et al. affirment que le SXF est considéré comme la cause la plus courante de déficit intellectuel et que le FMR1 serait le gène le plus impliqué dans la cause de l'autisme ${ }^{5}$. Le SXF y est vu comme un trouble hétérogène comprenant des facteurs génétiques multiples et, peut-être, des facteurs environnementaux. Dans les recherches les plus actuelles, il est indiqué que «les anormalités

\footnotetext{
${ }^{1}$ IRWIN Scott et al. (2002) Brain Structure and the Functions of FMR1 ..., 200. Traduction libre de l'auteure.

${ }^{2}$ Voir CORNISH Kimberly, LEVITAS Andrew et SUDHALTER Vioki (2007). Fragile X syndrome: ...

${ }^{3}$ Voir BORODYANSKAYA Mariya (2010). Intergenerational effects of mutations in the fragile X...

${ }^{4}$ CORDEIRO Lisa, BALLINGER Elizabeth, HAGERMAN Randi and HESSL David (2011). Clinical assessment of DSM-IV anxiety disorders in fragile $X$ syndrome..., 58. Traduction libre de l'auteure.

${ }^{5}$ Dans l'originel : «the most common gene single cause of autism », 216.
} 
neurocomportementales de l'X fragile sont le résultat d'un dérèglement du parcours de la signalisation neuronale réalisé par les groupes mGluR1 et mGluR5 et d'une synthèse excessive de protéines des dendritiques $»^{1}$. Ces groupes - mGluR 1 et mGluR 5 - sont des grandes protéines réceptrices métabotropiques impliquées dans les processus de la plasticité neuronale, dans la neurodegénération et dans la neuroprotection ${ }^{2}$. Dans un article publié en 2013, Wijetunge et ses collaborateurs affirment que l'X fragile est une des causes monogénétiques les plus étudiées de la déficience intellectuelle, mais aussi de l'autisme ${ }^{3}$. Un an plus tard, le syndrome de l’X fragile est décrit comme « la cause génétique identifiée la plus courante du handicap mental et du trouble du spectre autiste $»^{4}$.

$\mathrm{Au}$ vu de la construction du savoir sur le syndrome de l'X fragile, depuis sa découverte en 1969, les avancées techniques de la dernière décennie sont donc remarquables. Le point de départ fut la découverte de l'association du retard mental au chromosome $\mathrm{X}$. Vingt ans plus tard, le gène impliqué dans la mutation a été isolé. Les chercheurs ont ensuite remarqué l'expansion du trinucléotide CGG dans ce gène. Le pas suivant a été d'identifier que la mutation génétique rendait silencieuse le produit de ce gène - la protéine FMRP. Les fonctions de la FMRP ont enfin été découvertes il y a quelques années et, aujourd'hui, l'absence de cette protéine est indiquée comme responsable du déclenchement neurobiologique du syndrome.

\subsection{Causes génétiques}

À partir de notre recherche bibliographique, nous allons décrire les causes génétiques abordées par la littérature depuis la première décennie du XXI ${ }^{\text {ème }}$ siècle, en visant à comprendre le mécanisme neurophysiologique entraîné par la mutation génétique du chromosome $\mathrm{X}$. Nous chercherons également à comprendre à quel moment exactement le processus biologique cause les symptômes que nous allons discuter plus bas.

Le syndrome de l'X fragile est une conséquence de la mutation du gène FMR1 (fragile mental retardation 1 gene) localisé dans le chromosome $\mathrm{X}$. Ce gène a pour fonction

\footnotetext{
${ }^{1}$ BERRY-KRAVIS Elizabeth et al (2012). Effects of STX209 (Arbaclofen) on Neurobehavioral function in children..., 01. Traduction libre de l'auteure.

${ }^{2}$ Voir MATOS Rhowena Jane (2007) Expressão dos receptores metabotrópicos de glutamato nos...

${ }^{3}$ Voir WIJETUNGE Lasani et al. (2013). Fragile X syndrome : From targets to treatments.

${ }^{4}$ BERRY-KRAVIS Elisabeth (2014). Mechanism based treatments in neurodevelopmental disorders: Fragile X Sydrome, 01. Traduction libre de l'auteure.
} 
de codifier la protéine FMRP (fragile mental retardation protein) et de transférer les répétitions du trinucléotide $\mathrm{CGG}$ - cytosine, guanine, guanine - dans cinq régions codifiées.

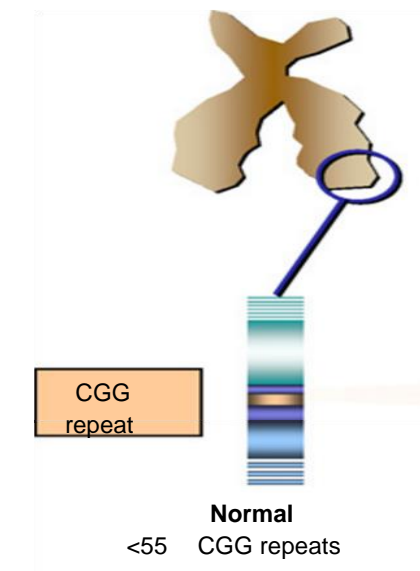

FMR1 mRNA
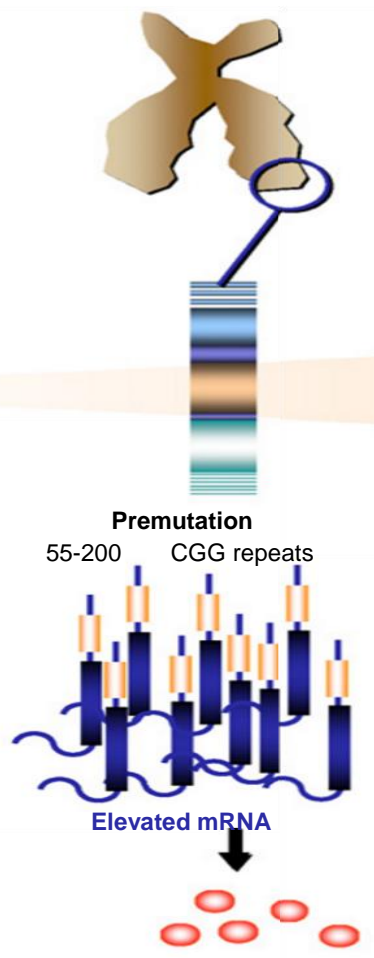

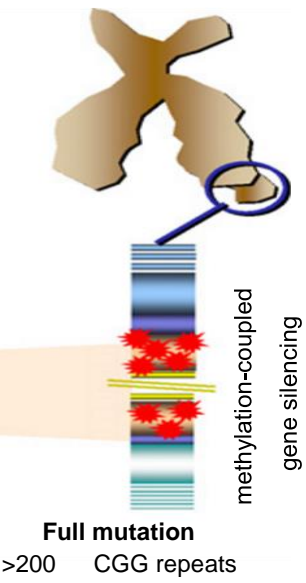

$>200$ CGG repeats

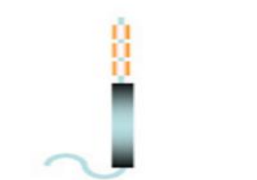

Little/no mRNA

Figure I : la fonction du gène FMR1 et le rapport entre les répétitions CGG, le niveau du mRNA et la production de la protéine FMRP ${ }^{1}$.

La région 5' est caractérisée par des variations du nombre de répétitions du trinucléotide. Normalement, les individus présentent de 5 à 54 répétitions du trinucléotide ${ }^{2}$. Les individus porteurs d'une premutation en présentent de 55 à 200 et la mutation génétique complète déclenche une expansion de plus de 200 répétitions du CGG. Cette expansion fait que le gène rend silencieuse la production de la protéine FMRP, c'est-à-dire qu'il n'en produit plus ou en produit très peu ${ }^{3}$. Cette mutation marquée par le nombre élevé de CGG répétés produit la méthylation de cytosines dans la région 5'. La méthylation est un processus d'ajout de méthyl $\left(\mathrm{CH}_{3}\right)$ dans l'ADN, qui régulerait les fonctions de la protéine. Il est réalisé par l'enzyme méthylasse. Autrement dit, la méthylation fait référence à un changement

\footnotetext{
${ }^{1}$ CHONCHAIYA Weerasak et al. (2009). Fragile $X$ : a Family of Disorders, 167. Traduction libre de l'auteure.

${ }^{2}$ Voir WIJETUNGE Lasani et al. (2013). Fragile X syndrome : From targets to treatments.

${ }^{3}$ Voir CORNISH Kimberly, LEVITAS Andrew et SUDHALTER Vioki (2007). Fragile X syndrome: the ...
} 
chimique de la structure de l'ADN et qui en modifie l'activité. Le processus cause une réduction de l'expression du gène FMR1 et, par conséquent, un manque de FMRP. La mutation met, ainsi, le gène en silence et il cesse de codifier la protéine FMRP. La figure 1 met en lumière la fonction du gène FMR1 en démontrant le rapport entre les répétitions de CGG, la quantité d'ARNm et la production de la FMRP chez les individus normaux, les porteurs de la prémutation et les porteurs de la mutation complète.

La prémutation est considérée par Cohen et ses collaborateurs comme l'élévation des répétitions du CGG entre 50 et 200. La mutation complète élèverait les répétitions du CGG au-delà de 200 et jusqu'à 1000 . Cohen et al. font remarquer que les chercheurs croyaient autrefois que les porteurs d'une prémutation n'étaient pas affectés, dans la mesure où ils ne présentaient aucun symptôme découlant de l'anomalie génétique. Or, les auteurs soutiennent que les femmes présentant un tableau clinique de prémutation pourraient souffrir de problèmes émotionnels, comme l'anxiété, la phobie sociale et la dépression ${ }^{1}$. L'étude menée par Cornish et al. relève même quelques troubles cognitifs et comportementaux qui ont récemment été identifiés suite à la prémutation du gène - c'està-dire à une mutation incomplète. Cette prémutation serait observée lors de l'expansion des répétitions du CGG de 55 à 200. À ces niveaux, la production de la FMRP étant relativement basse, les cas sont encore considérés comme normaux ou avec les symptômes réduits ${ }^{2}$. Les auteurs cités affirment que la symptomatologie de la prémutation peut être identique à celle de la mutation complète. Pour eux, les porteurs d'une prémutation peuvent donc présenter une pauvreté du contact visuel, des stéréotypies, une parole non articulée et de l'anxiété : des symptômes qui sont également indiqués dans les cas de mutation complète ${ }^{3}$.

Toujours selon Cornish et $a l$., une mutation complète est généralement associée à une hyperméthylation (méthylation complète) de la répétition du CGG, ce qui produit une diminution drastique voire une absence totale de la transcription ${ }^{4}$. Cette absence ou diminution de la production de la protéine entraîne une réaction moléculaire qui fragilise les connexions synaptiques. Les auteurs soutiennent que le manque ou la déficience de la FMRP est responsable du phénotype physique et du comportement qui sont caractéristiques du SXF. La littérature médicale a établi que le gène FMR1 se trouvait à l'origine de la cause principale du SXF. Ce gène serait la clé pour comprendre l'absence de l'ARN messager et

\footnotetext{
${ }^{1}$ Voir COHEN Michael, NERI Giovanni and WEKSBERG Rosanna (2002). Overgrowth syndromes.

${ }^{2}$ Ibidem

${ }^{3}$ Voir CORNISH Kimberly, LEVITAS Andrew et SUDHALTER Vioki (2007). Fragile X: the journey ...

${ }^{4}$ Ibidem.
} 
le manque de protéine FMRP. Les études indiquent que des recherches systématiques chez les souris et dans le cerveau autopsié d'humains, ont rendu possibles des découvertes par rapport à la fonction de la FMRP. Les chercheurs ont découvert que la FMRP affecte les échanges post-synaptiques dans la morphologie des épines dendritiques ${ }^{1}$. Nous remarquons également dans les études citées qu'à partir des années 2000, les chercheurs s'intéressent à l'expression du gène, cherchant à savoir s'il produit ou non la protéine et en quelle quantité. Jusque-là l'intérêt était centré, nous semble-t-il, sur le comportement du gène FMR1, c'està-dire sur le phénomène présenté par le gène et rendu visible par l'intervention scientifique.

En 2006, la psychiatre Marga Sabaratnam affirme que « le rôle précis de la FRMP est encore méconnu $»^{2}$. Le progrès scientifique concernant la découverte du mécanisme neurophysiologique du syndrome de l'X fragile est remarquable. Aujourd'hui, on sait que la FMRP est une protéine essentielle au bon fonctionnement du cerveau, notamment dans les synapses et dans les structures des cellules neuronales. Les scientifiques ont découvert que le manque de FMRP déclenche une forte production d'autres protéines qui entraînent à leur tour une insuffisance de la plasticité des synapses. Autrement dit, l'absence de FMRP dans le développement du cerveau provoquerait une anomalie dans la régulation des protéines neuronales, conduisant à l'émergence des anomalies cognitives et comportementales ${ }^{3}$.

Trois ans plus tard, il est découvert que la FMRP régule des protéines importantes pour la plasticité synaptique et qu'elle empêche également que d'autres protéines soient synthétisées en excès ${ }^{4}$. McLennan et $a l$. déclarent en 2011 que la FMRP transporte l'ARN dans les synapses et que son manque ou son inhibition se traduit par un dysfonctionnement de la plasticité synaptique qui entraînerait diverses gênes cognitives et troubles du comportement caractéristiques du $\mathrm{SXF}^{5}$. Les études de Jacquemont et al. indiquent que « la FMRP est une protéine de liaison de l'ARN cytoplasmique ${ }^{6}$, connu pour réprimer la traduction de l'ARN messager dans les synapses. Selon Kraan et al., la protéine joue un rôle

\footnotetext{
1 CORNISH Kimberly, LEVITAS Andrew, SUDHALTER Vioki (2007). Fragile X syndrome: the journey..., 80. Traduction libre de l'auteure.

${ }^{2}$ SABARATNAM Marga (2006). Fragile X Syndrome, 336. Traduction libre de l'auteure.

${ }^{3}$ Voir HALL Scott et al. (2010). Autism in Fragile X Syndrome : A Category Mistake?

${ }^{4}$ CHONCHAIYA Weerasak et al. (2009). Fragile X: A Family of Disorders, 169. Traduction libre de l'auteure.

${ }^{5}$ Voir MCLENNAN Yingratana, POLUSSA Jonathan, TASSONE Flora and HAGERMAN Randi (2011). Fragile X Syndrome.

${ }^{6}$ JACQUEMONT Sébastien et al. (2011). Epigenetic Modification of the FMR1 Gene in Fragile..., 01. Traduction libre de l'auteure.
} 
essentiel dans la régulation et dans la suppression de la transcription d'autres protéines. Berry-Kravis affirme que la protéine est impliquée dans le transport, dans la localisation et dans la régulation de la transcription d'un sous-ensemble des ARN messagers des dendritiques. L'auteur ajoute que la FMRP « est présente dans un complexe de protéine au sein du ribosome, où est régulée la transcription de la protéine dendritique en réponse à l'activation synaptique $»^{1}$. La protéine est également essentielle pour la maturation morphologique des épines dendritiques, comme pour la plasticité électrophysiologique et la force des synapses.

L'absence de la protéine FMRP déclenche un dérèglement des processus neuronaux dans le cerveau. Chonchaiya et al. soutiennent que l'absence de la FMRP déclenche une haute régulation d'autres protéines qui, à long terme, affaiblissent les connexions synaptiques. Selon Kraan et al., sans la FMRP, la régulation de la transcription des ARN messagers des épines dendritiques est rendue difficile au cours du développement, ce qui provoque une altération de la structure et du fonctionnement des réseaux neuronaux dans le cerveau $^{2}$. Dans cette même ligne, Berry-Kravis indique que le manque de la FMRP semble entraver la maturation morphologique des épines dendritiques et entraîner également une «plasticité synaptique anormale $»^{3}$.

Dans la bibliographie consultée sur le syndrome, l'affirmation prépondérante est que le mécanisme entraîné par le manque de protéine FMRP est le déclencheur des symptômes attribués à l'X fragile. Les chercheurs sont unanimes à soutenir que c'est le manque ou la déficience de la FMRP qui cause les caractéristiques physiques, cognitives et comportementales qui caractérisent le syndrome. Nous constatons donc, après cette révision bibliographique du processus biologique de l'X fragile, qu'il y a bien une anormalité dans les connexions synaptiques, provoquant à son tour une modification du fonctionnement du cerveau. Les processus cognitifs qui dépendent de cette sorte d'interaction neurochimique cérébrale sont nettement affectés. Nous verrons par la suite quels symptômes physiques et comportementaux sont attribués à l'X fragile, comme conséquences de ce fonctionnement cérébral déficient.

\footnotetext{
${ }^{1}$ BERRY-KRAVIS Elizabeth (2014). Mechanism Based Treatments in Neurodevelopmental Disorder..., 03. Traduction libre de l'auteure.

${ }^{2}$ Voir KRAAN Claudine et al. (2013). Neurobehavioural evidence for the involvement of the FMRl gene... ${ }^{3}$ BERRY-KRAVIS Elizabeth (2014). Mechanism Based Treatments in Neurodevelopmental Disorder..., 03. Traduction libre de l'auteure.
} 


\subsection{Symptomatologie}

La symptomatologie attribuée au SXF a d'emblée attiré notre attention. Le symptôme majeur du syndrome est la déficience intellectuelle, mais il existe une liste de psychopathologies, appelées symptômes du comportement par la génétique médicale, qui ont été admises comme conséquences du mécanisme neurophysiologique causé par la mutation génétique. Cependant, nous n'avons trouvé aucune explication justifiant que ce processus neurophysiologique du syndrome ait comme effet une psychopathologie ou trouble $d u$ comportement. Autrement dit, nous ne savons pas comment la mutation génétique produit, par exemple, un comportement obsessionnel-compulsif. Néanmoins, nous allons voir comment la pensée scientifique s'est construite au sujet de la symptomatologie du syndrome.

Le point de départ a été le retard mental lié au phénotype physique. Fryns s'appuie sur l'expérience vis-à-vis au syndrome pour montrer que l'X fragile est associé à une triade de symptômes cliniques : retard mental modéré, visage allongé avec de longues oreilles et macroorchidisme ${ }^{1}$. Toujours en 1989, Randi Hagerman, affirme que « le comportement des garçons atteints de l'X fragile est un élément qui indique comment leurs cerveaux sont organisés, y compris leurs capacités cognitives, du langage et de l'intégration sensorimotrice $»^{2}$. L'auteur ajoute que les problèmes présentés par les porteurs de l'X fragile vont du retard du langage à l'autisme, comprenant notamment «l'hyperactivité avec une attention courte, la parole persistante ou encombrée, et de fréquents maniérismes dans les mains, tels hand-flapping ou hand-biting $»^{3}$.

Tessa Webb indique une association entre l'X fragile et différentes manifestations cliniques tels le macroorchidisme ou le comportement autiste ${ }^{4}$. Selon Cohen et $a l$., les sujets peuvent présenter une proéminence des oreilles et de la mandibule, un visage allongé, une macrocéphalie relative, une articulation des doigts hyperextensive et, généralement pendant la puberté, un macroorchidisme (testicules plus grands que la normale). Chez les nouveaunés, on repère un poids élevé à la naissance et une macrocéphalie. Chez les adultes, les caractéristiques les plus incidentes sont la haute stature et le front proéminent ${ }^{5}$. Sabaratnam

\footnotetext{
${ }^{1}$ Voir FRYNS Jean-Pierre (1989). X-linked mental retardation and the fragile X syndrome: a clinical...

${ }^{2}$ HAGERMAN Randi (1989). Behavior and treatment of the fragile X syndrome, 56. Traduction libre de l'auteure.

${ }^{3}$ Ibidem, 59. Traduction libre de l'auteure.

${ }^{4}$ Voir WEBB Tessa (1989). The epidemiology of the Fragile X syndrome, 40.

${ }^{5}$ Voir COHEN Michael, NERI Giovanni and WEKSBERG Rosanna (2002). Overgrowth syndromes...
} 
affirme que chez les adultes le phénotype physique est plus formé et plus distingué que chez les enfants, tandis que le phénotype comportemental est plus évident chez les enfants ${ }^{1}$.

En ce qui concerne la symptomatologie du SXF, les études de Cohen et ses collaborateurs pointent une incidence de problèmes de langage, liés au faible Q.I., lui-même conséquence de la déficience ${ }^{2}$. Hagerman \& Hagerman, dans leur ouvrage également publié en 2002, affirment que les enfants porteurs du syndrome ont un « tempérament difficile » et que, dans la plupart des cas, il est possible d'observer une présence d'hyperactivité, d'irritabilité, de parole persistante et de traits autistiques - comme frapper, se mordre les mains et une pauvreté du contact oculaire. Toujours selon les auteurs, 1'hyperactivité serait observable à l'âge de deux ans environ et disparaîtrait à la puberté. Dans ce vaste ouvrage sur le SXF, nous pouvons percevoir la prévalence de la description phénoménologique du syndrome ${ }^{3}$.

Les auteurs suggèrent une checklist pour élaborer le diagnostic différentiel de l'X fragile, à partir des éléments suivants : retard mental, hyperactivité, courte durée d'attention, défense tactile, frapper les mains, mordre les mains, parole persistante, jonctions hyperextensibles, oreilles grandes ou proéminentes, testicules grands, ligne de Simian ou ligne de Sidney, passé familial de retard mental ${ }^{4}$. Plusieurs études et recherches ont été menées pour prouver l'existence des symptômes indiqués, notamment celui de l'hyperactivité, traité de manière exhaustive. L'ouvrage ne démontre à aucun moment la corrélation entre le mécanisme du SXF et l'ensemble de symptômes qu'il est censé entraîner. Ainsi, il existe un écart inexpliqué entre le mécanisme du SXF et cet ensemble de symptômes. Les auteurs ne s'interrogent pas sur la question suivante : pourquoi le manque de protéine FMRP a-t-il pour conséquence l'hyperactivité ? Une question qui pourrait d'ailleurs être étendue à l'autisme, au retard mental et à tous les autres symptômes indiqués.

Poursuivant notre ligne de pensée historique de construction du savoir sur la symptomatologie du syndrome, arrêtons-nous sur les recherches de Sabaratnam qui dessinent un tableau de «caractéristiques du comportement» et de «troubles psychiatriques $»^{5}$. Parmi ces derniers, il convient de mettre en relief le «trouble psychotique, avec un marmonnement persistant et des comportements stéréotypés qui

\footnotetext{
${ }^{1}$ Voir SABARATNAM Manga (2006). Fragile X syndrome.

${ }^{2}$ Voir COHEN Michael, NERI Giovanni and WEKSBERG Rosanna (2002). Overgrowth syndromes...

${ }^{3}$ Voir HAGERMAN Randi \& HAGERMAN Paul (2002). Fragile X syndrome : diagnoses....

${ }^{4}$ Ibidem, 77. Traduction libre de l'auteure.

${ }^{5}$ SABARATNAM Manga (2006). Fragile X syndrome, 327. Traduction libre de l'auteure.
} 
masquent une psychose $»^{1}$. L'auteur suggère également le retard du langage comme étant l'un des premiers symptômes : l'enfant commence à prononcer les mots vers deux ans et à dire des phrases courtes vers trois ans. Selon Hagerman et $a l$. le syndrome de l'X fragile est associé à « une gamme de handicapes intellectuels et émotionnels, allant du handicap mental aux problèmes d'apprentissage, à l'autisme et à l'anxiété »'

Garber et al., ajoute comme symptômes du syndrome les déficits sociaux, le comportement obsessionnel-compulsif, la dysfonction exécutive, les troubles de l'humeur, l'impulsivité et l'agressivité. . En outre, Borodyanskaya affirme qu'il existe de fortes associations positives entre le dysfonctionnement du gène FMR1 et les symptômes psychologiques, sans pour autant décrire quelles seraient ces associations. Sa recherche indique aussi que la mutation est davantage associée aux symptômes obsessionnelscompulsifs, à l'anxiété et à la sensibilité interpersonnelle ${ }^{4}$. Dans un article intitulé $A D H D$ and Genetics Syndromes, également de 2010, Lo-Castro et al. affirment que l'incidence du trouble d'hyperactivité dans les syndromes génétiques est prédominante dans le SXF. Les auteurs définissent l'hyperactivité comme un trouble neurobiologique, résultat d'une confluence entre divers risques génétiques et environnementaux - telle l'exposition au tabac, à l'alcool et à certains polluants 5 .

Dans une étude publiée un an plus tard, Jacquemont et al. ajoutent à la déficience intellectuelle «l'anxiété, l'agression, l'hyperactivité, l'impulsivité, la timidité, le trouble du déficit d'attention et l'autisme $»^{6}$. Toujours en 2011, McLennan et al. affirment que le SXF est considéré comme un trouble hétérogène lié à des facteurs génétiques multiples et, peutêtre, à des facteurs environnementaux. Selon ces chercheurs, les taux élevés d'autisme sont le résultat d'une dérégulation des connexions neuronales, due à une réduction de l'expression de la protéine?

Les recherches les plus actuelles indiquent que le syndrome de l'X fragile déclenche notamment des difficultés d'apprentissage, mais aussi des caractéristiques autistes comme

\footnotetext{
${ }^{1}$ SABARATNAM Manga (2006). Fragile X syndrome, 327. Traduction libre de l'auteure.

${ }^{2}$ HAGERMAN Randi et al. (2008). Advances in the treatement of fragile X syndrome, 378. Traduction libre de l'auteure.

${ }^{3}$ Voir GARBER Kathryn, VISOOTSAK Jeannie and WARREN Stephen (2008). Fragile X syndrome

${ }^{4}$ Voir BORODYANSKAYA Mariya (2010). Intergenerational effects of mutations...

${ }^{5}$ Voir LO-CASTRO Adriana, D'AGATI Elisa et CURATOLO Paolo (2008). ADHD and genetics syndromes.

${ }^{6}$ JACQUEMONT Sébastien et al. (2011). Epigenetic Modification of the FMRI Gene in Fragile X is Associated..., 01. Traduction libre de l'auteure.

${ }^{7}$ Voir MCLENNAN Yingratana, POLUSSA Jonathan, TASSONE Flora and HAGERMAN Randi (2011). Fragile X Syndrome...
} 
« un trouble de l'anxiété, un trouble de l'hyperactivité et un déficit d'attention, et une hypersensibilité aux stimuli sensoriels $»^{1}$. Nous remarquons à partir de la bibliographie consultée que toutes les psychopathologies citées sont vues exclusivement comme résultat du dysfonctionnement neurophysiologique entraîné par la mutation génétique. Nous ne trouvons pas d'explication de comment le manque d'une protéine causerait une phobie sociale ou un comportement obsessionnel-compulsif, par exemple. Ces catégories diagnostiques proviennent de manuels psychiatriques, et notamment du DSM-IV. Cependant, la plupart des chercheurs ne tissent que de frêles explications - quand ils en donnent - sur les attributions diagnostiques. Autrement dit, il est difficile de savoir ce qu'ils entendent par autisme, anxiété sociale, hyperactivité, ou par n'importe quelle catégorie nosographique d'origine $p s y$.

Nous observons ainsi un échec épistémologique lorsque cette médecine génétique s'approprie de concepts diagnostiques qui n'appartiennent pas à son champ de savoir, et sans indiquer sur quelle approche théorique elle base ses études. Il est, à notre avis, évident que cette approche médicale considère l'étiologie de ces psychopathologies comme étant uniquement de base organique. Cependant, même cette référence organiciste n'est que rarement mentionnée. Les rares références aux critères diagnostiques que nous avons trouvées proviennent du DSM et des échelles psychométriques basées sur ce même manuel psychiatrique. Parmi les recherches qui portent ces indications, nous pouvons citer les études de Hagerman (1989), Dykens et al. (1994), Cohen et al. (1996), Hagerman \& Hagerman (2002), Chonchaiya et al. (2009), Cordeiro et al. (2011) Abbeduto et al. (2014).

Néanmoins, il faut souligner que ces références sont minimales, comme par exemple dans l'ouvrage de Hagerman \& Hagerman publié en 2002. Les seules références faites par les auteurs au DSM III concernent d'autres recherches qui se sont elles-mêmes appuyées sur ce manuel psychiatrique afin de justifier les catégories diagnostiques. On peut également prendre l'exemple de recherches menés par Chonchaiya et al. et Cordeiro et al. qui ont utilisé des échelles psychométriques comme 1'ADOS (Autism Diagnostic Observation Schedule), l'ADIS (Anxiety Disorders Interview Schedule) ou l'ADAMS (Anxiety

\footnotetext{
${ }^{1}$ WIJETUNGE Lasani et al. (2013). Fragile X syndrome : From targets to treatments, 84 . Traduction libre de l'auteure.
} 
Depression and Mood Scale) pour servir de repères aux critères diagnostics d'autisme ou d'anxiété sociale chez les enfants atteints de l'X fragile'.

Cette appropriation des concepts psy faite par les scientifiques sans la moindre préoccupation épistémologique nous amène à nous poser certaines questions : le DSM et ses versions ont-ils légitimé un savoir pouvant faire face à toute contestation ? En outre, le DSM autorise-t-il les médecins à affirmer, par exemple, que le mécanisme biologique déclenché par le syndrome serait la base étiologique de diagnostics aussi disparates que la phobie et l'autisme ? Nous proposons ci-dessous un débat sur cette légitimation du savoir proposé par les manuels psychiatriques, ainsi que sur la manière dont les diagnostics sont imposés par le $D S M$.

\subsection{Diagnostic}

Avant d'amener la discussion sur les diagnostics psychopathologiques qui sont associés au syndrome, il convient d'indiquer les techniques utilisées lors du diagnostic de l'X fragile. Hagerman a remarqué que pour le diagnostic du syndrome de l'X fragile, le clinicien devrait être attentif aux signes du comportement, puis le diagnostic basé sur le seul phénotype physique n'est pas fiable ${ }^{2}$. Selon Maurel Ollivier, l'importance d'un diagnostic précoce repose sur deux motifs : la prévention du risque dans le cas d'une deuxième grossesse et la mise en place d'une thérapeutique adaptée ${ }^{3}$. Cohen et al. soulignent qu'il est particulièrement difficile de diagnostiquer le syndrome de l'X fragile à cause de l'ample expression du phénotype du syndrome qui rend difficile la détection de l'anomalie. Les auteurs soutiennent que le comportement contribue beaucoup plus au diagnostic que les phénotypes, mais que le SXF pourrait être indiqué par la technique de l'amniocentèse. Ils remarquent aussi que le diagnostic basé sur le test cytogénétique a été abandonné et que seule une analyse directe de l'ADN avec méthylation sensitive des enzymes pourrait indiquer le niveau de méthylation du FMR $1^{4}$.

Aussilloux rend compte, en 2003, de la particularité du diagnostic du SXF de l'époque quand il remarque que « le diagnostic du SXF n'est pas recherché en tant que tel,

\footnotetext{
${ }^{1}$ Voir CHONCHAIYA Weerasak et al. (2009). Fragile $X$ : a family of disorders ; CORDEIRO Lisa, BALLINGER Elizabeth, HAGERMAN Randi and HESSL David (2011). Clinical assessment of DSM-IV anxiety disorders in fragile $X$ syndrome...,

${ }^{2}$ Voir HAGERMAN Randi (1989). Behavior and treatment of the fragile $X$ syndrome.

${ }^{3}$ Voir OLLIVIER Maurel (2000). Médecin ou devin ? Diagnostic très précoce et anticipation.

${ }^{4}$ Voir COHEN Michael, NERI Giovanni et WEKSBERG Rosanna (2002). Overgrowth syndromes...
} 
on le trouve alors que l'on cherchait autre chose $»^{1}$. Selon lui, sans le diagnostic génétique, le médecin n'est pas en mesure d'affirmer qu'un bébé est porteur. Cornish et al. affirment qu'avant la découverte du SXF les enfants porteurs du syndrome étaient diagnostiqués comme autistes, arriérés, hyperactifs ou affectés de troubles de l'apprentissage. On considère qu'il existe un grand éventail d'expressions du syndrome, rendant impossible de ne fonder le diagnostic que sur caractéristiques comportementales et physiques. Les porteurs du syndrome présenteraient même parfois une apparence normale, ce qui rendrait difficile la reconnaissance de la mutation. Les auteurs concluent qu'un examen organique minutieux serait nécessaire pour détecter l'anomalie ${ }^{2}$.

Le diagnostic génétique donnerait avec précision le risque de retard mental, mais n'indiquerait pas la gravité de la déficience chez le futur adulte quant à son autonomie, sa qualité de vie et son image de soi. Toujours selon Cornish et al., les séquences de répétition du CGG pourraient être détectées et quantifiées par l'utilisation de la technologie du Southern Blot et par la restriction endonucléaire. Garber et ses collaborateurs suggèrent quant à eux une checklist de 28 questions type «oui ou non » pour élaborer le diagnostic : à partir de 17 réponses positives, un examen serait recommandé, et à partir de 26 , il serait nécessaire ${ }^{3}$.

Les recherches les plus actuelles recommandent un test génétique d'analyse de l'ADN, appelé test d'ADN de l'X fragile ou test d'ADN FMR1. Selon Chonchaiya et al., ce test est réalisable dans la plupart des laboratoires moléculaires des universités, et également proposé dans les laboratoires commerciaux pour « 200 à 500 dollars $»^{4}$. Nous pouvons finalement penser que la principale fonction du diagnostic pour le porteur du SXF serait de permettre une prise de soins spécifiques le plus tôt possible - soins basés uniquement sur l'environnement de l'enfant, étant donné que la génétique n'a pas de cure pour ce syndrome. Nous allons voir ci-dessous les possibilités de traitement suggérées par la littérature médicale.

\footnotetext{
${ }^{1}$ AUSSILLOUX Charles (2003). Suivi médical, psychologique..., 19.

${ }^{2}$ Voir CORNISH Kimberly, LEVITAS Andrew and SUDHALTER Vioki (2007). Fragile X syndrome...

${ }^{3}$ Voir GARBER Kathryn, VISOOTSAK Jeannie and WARREN Stephen (2008). Fragile X syndrome .

${ }^{4}$ CHONCHAIYA Weerasak et al. (2009). Fragile $X$ : a family of disorders, 166. Traduction libre de l'auteure.
} 


\subsection{Traitement}

Malgré les efforts et les avancés de la science médicale, les chercheurs n'ont pas encore trouvé de cure pour le syndrome de l'X fragile. Dans notre recherche bibliographique, nous avons relevé deux moments distincts quant aux traitements proposés par les scientifiques au cours des ans. Le premier est celui du traitement pharmacologique des comportements présentés par l'enfant atteint de l'X fragile, c'est-à-dire des phénomènes observés. Le deuxième moment, qui comprend les recherches les plus actuelles, défend un traitement moléculaire, c'est-à-dire l'introduction directe, dans la cellule, des éléments nécessaires pour pallier les préjudices du manque de la FMRP. C'est donc sur l'invisible du corps qu'intervient la médecine génétique. Nous allons décrire de manière plus détaillée ces deux moments de l'approche du traitement du syndrome de l'X fragile.

Dans les articles consultés jusqu'à 2011, nous observons que la question du traitement n'est que rarement abordée par les chercheurs. Ceux-ci se restreignent à des indications pharmacothérapeutiques pour remédier à des comportements supposés maladaptés et occasionnés par la mutation génétique. L'autre suggestion des chercheurs concerne la thérapie cognitive-comportementale, autrement dit, les techniques d'adaptation de comportement. La thérapie consisterait à remplacer un comportement non accepté socialement par un autre qui le soit. C'est par la récompense et la punition que l'on arrive à cet apprentissage.

Les recherches de Dykens et de ses collaborateurs ${ }^{1}$ démontrent que, pour déterminer la réussite d'une personne ayant un diagnostic de retard mental - c'est-à-dire pour que cette personne soit considérée comme socialement «compétente»-1'adaptation sociale, comprise comme l'adaptation aux diverses demandes sociales, est plus importante que le Q.I. Il conviendrait donc d'évaluer sa performance plutôt que sa capacité. Pour évaluer cette «compétence adaptative », les auteurs évoquent l'existence de divers outils qui ne sont pourtant pas explicités - mais nous pouvons supposer qu'il s'agit de tests psychologiques. Ainsi, le débat de l'époque tournait autour de l'importance de l'intelligence par opposition à l'adaptation du comportement.

Les chercheurs cités expliquent également que le comportement adapté varie selon le développement de la personne et qu'il s'agit donc d'un chemin amenant à l'indépendance personnelle et à la responsabilité sociale. Par exemple, un enfant apte à réaliser certains

\footnotetext{
${ }^{1}$ Voir DYKENS Elisabeth, HODAPP Robert and LECKMAN James (1994). Behavior and development...
} 
comportements, mais ne réussissant pas à les adopter, aurait, par définition, un fonctionnement adaptatif limité. À défaut d'une cure pour la mutation, les auteurs suggèrent des stratégies d'intervention qui optimisent le fonctionnement des individus affectés et de leurs familles. Comme support aux familles, ils suggèrent la programmation éducative spéciale et occupationnelle, la thérapie de langage et du comportement et, plus rarement, la psychothérapie et la psychopharmacologie ${ }^{1}$. Il y est aussi recommandé de dispenser aux parents un counseling psychologique pour mieux les préparer aux moments de confrontation où ils seraient susceptibles d'éprouver un sentiment de deuil et de tristesse face à l'insuffisance de leur enfant. Les chercheurs suggèrent aussi que les mères apprennent à interagir avec leur enfant : soit pour aplanir leurs difficultés à répondre aux nécessités spéciales de l'enfant (special needs), soit pour minimiser la possible perception de l'enfant comme un fardeau. L'une des interventions serait d'avoir recours à une thérapie familiale ou individuelle lorsque le stress atteint des moments de forte intensité.

Les auteurs commentent une situation dans laquelle, supposément, les parents n'accepteraient pas de s'inscrire volontairement dans un service proposé, relatant que ceci serait plus fréquent chez les femmes qui auraient la tendance à minimiser ou à nier leurs problèmes - les femmes dites timides et renfermées. Dykens et $a l$. les définissent comme réticentes à s'impliquer dans les services, imposant ainsi un défi aux professionnels. Ce défi, poursuivent les auteurs, serait plus redoutable dans le cas d'une famille où plusieurs enfants seraient affectés, ou encore dans le cas de mères arriérées ou ayant un faible niveau d'éducation qui ne seraient pas en mesure d'élever un enfant porteur de nécessités spéciales. Le risque d'angoisse croissante et de désordre émotionnel dans ces familles serait alors plus important et demanderait une intervention intensive, voire domiciliaire.

Toute cette étude se fonde explicitement sur les outils employés par la psychologie du comportement et suggère même comme traitement certaines techniques comportementales qui pourraient d'ailleurs être employées à domicile. Un exemple de ces techniques est l'enseignement de comportements souhaitables et acceptables socialement, et l'élimination de comportements mal adaptés. Une telle pratique s'appuie sur le renforcement positif et négatif des bons et des mauvais comportements. Un exemple de renforcement positif pour des comportements adaptés serait de dire «bon travail! », «gentil garçon! $»^{2}$, voire de donner des récompenses, comme de la nourriture ou des autocollants. Comme punition pour

\footnotetext{
${ }^{1}$ Voir DYKENS Elisabeth, HODAPP Robert and LECKMAN James (1994). Behavior and development...

${ }^{2}$ Ibidem, 94. Traduction libre de l'auteure.
} 
des comportements non souhaitables, les auteurs suggèrent une réprimande ou « une pause (time out) pour de légers chocs électriques $»^{1}$. Bien que l'étude soit ancienne par rapport aux avancées génétiques, il est intéressant d'observer la manière dont les auteurs, s'appuyant sur la base du behaviorisme, pensent l'humain. Les techniques utilisées sont les mêmes que pour des souris aux laboratoires.

Finalement, et revenant aux stratégies d'intervention, il faut souligner que la psychothérapie apparaît comme option de traitement. Cela dit, les auteurs remarquent que des objectifs et des stratégies sont nécessaires à la conduction des thérapies. Le psychothérapeute devra enseigner au patient des formes d'apprentissage adaptatif afin qu'il traite lui-même son sentiment de colère et de chagrin face à la stigmatisation sociale. Il devra orienter le patient de manière à lui faire percevoir sa limitation cognitive, élever son auto-estime et son indépendance, et travailler à l'émancipation de ses soins. Les femmes présentant une timidité et une anxiété sociale devront travailler et pratiquer de nouvelles compétences sociales.

Dans une recherche publiée en 2002, Epstein et $a l .^{2}$ invitent à réaliser un plan de traitement, qui devra être adapté à chaque patient. Cette stratégie est définie en onze étapes, parmi lesquelles :

1) «Identifier le comportement mal adapté spécifique comme cible à éliminer (comme taper ou crier)»; 2) «Analyser l'antécédent, le comportement et la conséquence (The ABC: Antecedent-Behavior-Consequence), considérant que la conséquence est la clé pour comprendre comment modifier le comportement, dans la mesure où c'est elle qui maintient le cycle du comportement »;3) «Esquisser les conséquences naturelles du comportement »;4) «Être consistant dans le changement du comportement ». En effet, selon les auteurs, la consistance et la prévisibilité dans la routine sont essentielles à la réussite du traitement. 5) «Offrir un comportement substitutif approprié »; 6) «Renforcer un comportement positif». À l'instar de Dykens, les auteurs proposent ici la technique des récompenses par de la nourriture, des autocollants et des mots d'encouragement.

La technique du time out (pause) est également maintenue, mais sans les chocs électriques. Elle est suggérée en présence de comportements agressifs et doit adresser à

\footnotetext{
${ }^{1}$ Voir DYKENS Elisabeth, HODAPP Robert and LECKMAN James (1994). Behavior and development..., 94. Traduction libre de l'auteure.

${ }^{2}$ In HAGERMAN Jensen \& HAGERMAN Paul (2002). Fragile X syndrome : diagnoses, treatment and research, 339. Traduction libre de l'auteure.
} 
l'enfant un message simple, facile à comprendre, vu que, selon les auteurs, les enfants présentant un retard mental ont des difficultés à comprendre les concepts abstraits. Nous voyons donc que le traitement ne passe pas par la dimension de traiter, ni par une cure en soi. De notre point de vue, il s'agit plutôt de faire apprendre à l'enfant des comportements acceptables. Cette pratique nous semble réduire le sujet à un ensemble de comportements qui sont, selon les normes sociales, acceptables ou non. Nous reviendrons plus tard sur cette thématique.

Dans leurs recommandations de traitement, Cohen et $a l$. soulignent que les problèmes de comportement causés par le SXF peuvent être résolus par la voie pharmacologique. Ils émettent plusieurs suggestions éducatives et médicamenteuses ciblant autant les enfants que les adultes: socialisation, sports, antipsychotiques, thérapie occupationnelle et orthophonie $^{1}$. Dans cette même lignée, Garber et ses collaborateurs recommandent la gestion des symptômes comportementaux, notamment par des interventions pharmacologiques. Les médicaments les plus souvent indiqués sont les stimulants et les antipsychotiques atypiques, prescrits pour les cas ayant reçu un diagnostic d'autisme ou manifestant des comportements agressifs ${ }^{2}$.

Chonchaiya et $a l$. indiquent les stimulants et l'antipsychotique aripiprazole, qui doit être administré à faibles doses pour diminuer l'agitation. Car étonnamment, cette médication induirait à hautes doses un comportement indésirable, c'est-à-dire l'augmentation de l'agressivité ${ }^{3}$. L'article de Hagerman et al. suggère quant à lui un médicament spécifique pour chaque trouble associé à l'X fragile : les stimulants pour le trouble déficitaire de l'attention avec hyperactivité (TDAH) ; les inhibiteurs de la sérotonine pour traiter l'anxiété aussi bien que de l'autisme ; et les antipsychotiques pour l'agression et l'instabilité de l'humeur' ${ }^{4}$.

Le deuxième moment de traitement proposé et qu'il convient de mettre en relief, traduit un changement de regard sur le syndrome. Il ne s'agit plus d'éliminer les comportements mal-adaptés, mais d'atteindre la molécule. Wijetunge et al. soulignent que le progrès de la connaissance des syndromes, comme celui de l'X fragile, a débouché sur

\footnotetext{
${ }^{1}$ Voir COHEN Michael, NERI Giovanni and WEKSBERG Rosanna (2002). Overgrowth syndromes...

${ }^{2}$ Voir GARBER Kathryn, VISOOTSAK Jeannie et WARREN Stephen 2008. Fragile X syndrome.

${ }^{3}$ Voir CHONCHAIYA Weerasak et al. (2009). Fragile $X$ : a family of disorders.

${ }^{4}$ Voir HAGERMAN Randi et al (2009). Advances in the Treatment of Fragile X Syndrome, 380.
} 
une nouvelle ère de traitement moléculaire des troubles du neurodéveloppement ${ }^{1}$. Castrén et ses collaborateurs accentuent que le SXF est un parfait exemple de la manière dont les essais sur les animaux (animal models) peuvent permettre d'élaborer de nouveaux traitements moléculaires ${ }^{2}$. Les nouvelles recherches se concentrent désormais sur le traitement ciblé moléculaire (targeted treatment).

En d'autres termes, les chercheurs essayent d'introduire dans la cellule des molécules aidant à réguler la production des protéines cérébrales, qui se sont trouvées modifiées en raison du manque de protéine $\mathrm{FMRP}^{3}$. Les études de Jacquemont et al. montrent que l'absence de la FMRP amène à une diminution de la répression du mGluR5 (metabotropic glutamate receptor 5) qui, à son tour, est fortement synthétisé. Pour ces auteurs, c'est cette haute production qui a pour conséquence les troubles cognitifs et comportementaux associés au syndrome ${ }^{4}$.

Castrén et $a l$. rapportent des recherches positives sur des modèles $\mathrm{X}$ fragile de souris et de mouches (Drosophila) avec le traitement ciblé. Les chercheurs ont introduit un antagoniste du mGluR5, c'est-à-dire une molécule régulant la haute production du métabotropique, avec des résultats satisfaisants. Ils ont remarqué une amélioration du phénotype du syndrome au niveau de la maturation des synapses, des déficits d'apprentissage et des problèmes d'anxiété et d'hyperactivité 5 . Dans cette même voie, Heulens et al., indiquent que l'un des parcours affectés par l'X fragile est celui des récepteurs $G A B A^{A}$ qui seraient impliqués dans «l'anxiété, la dépression, la mémoire et l'apprentissage, l'épilepsie et l'insomnie, tous présents dans le syndrome de l'X fragile $»^{6}$. Les scientifiques ont réalisé des essais sur des souris modèles $F M R l$, en introduisant des drogues anxiolytiques capables d'agir sur les récepteurs $G A B A$. Les résultats ont donné une même réaction sédative entre la souris contrôle et la souris $F M R l$, bien que l'hyperactivité n'ait pas été détecté chez les souris FMR $1^{7}$. Néanmoins, si les résultats sur les souris sont

\footnotetext{
${ }^{1}$ Voir WIJETUNGE Lasani et al. (2013). Fragile X syndrome : From targets to treatments...

${ }^{2}$ Voir CASTRÉN Eero et al (2012). Treatment of Neurodevelopmental Disorders in Adulthood, 14075.

3 Voir BERRY-KRAVIS Elizabeth (2014); GÜRKAN Kagan \& HAGERMAN Randi (2012); WIJETUNGE Lasani et al. (2013).

${ }^{4}$ Voir JACQUEMONT Sébastien et al. (2011). Epigenetic Modification of the FMR1 Gene in Fragile...

${ }^{5}$ Voir CASTRÉN Eero et al (2012). Treatment of Neurodevelopmental Disorders in Adulthood...

${ }^{6}$ HEULENS Inge et al. (2012). Pharmacological treatment of fragile X syndrome with..., 244. Traduction libre de l'auteure.

${ }^{7}$ Ibidem, 247. Traduction libre de l'auteure.
} 
satisfaisants, les recherches sont encore insuffisantes pour commencer le traitement chez les humains ${ }^{1}$.

Ces recherches pensent le traitement de l'X fragile et de l'autisme par l'usage de médicaments et par des thérapies cognitives-comportementales - aucune étude analysée n'indique la possibilité d'un traitement psychanalytique. Si nous situons notre recherche dans l'intersection entre les affections génétiques et les symptômes psychiques, il nous faut penser une certaine discontinuité qui est négligée par le collage établie dans les travaux qui font cette association. Cette discontinuité ne nous mène pas à proposer une séparation, mais une articulation singulière entre le syndrome et l'autisme, en occurrence, qui y introduit la dimension du langage. Cette discontinuité nous mène à questionner l'établissement d'une causalité sans faille, univoque, entre le mécanisme biologique et les symptômes psychiques (marqués par les diagnostics) qui sont supposément produits.

Autrement dit, les études sur l'X fragile y apportées suivent la logique étiologique du modèle de la médecine scientifique, c'est-à-dire, une logique qui essaye de penser et expliquer les phénomènes psychiques exclusivement par le biais chimique, physiologiste ou anatomique. Cette logique scientifique cherche une corrélation biunivoque qu'élide la dimension symbolique - et le rapport à l'Autre - qui opère chez l'enfant, tissant la constitution du sujet, dimension que la psychanalyse essaye d'introduire. La discontinuité suppose ainsi qu'au-delà du mécanisme biologique général du syndrome, il faut prendre en compte la dimension de l'immersion de l'enfant dans la culture et dans le langage, ce qui rend impossible de frayer un chemin linéaire qui ne prend en compte que des facteurs médicaux-génétiques.

C'est ainsi que nous soulignons ailleurs ${ }^{2}$ la notion de forclusion du sujet dans certaines recherches en génétique médicale. Nous comprenons ici le concept de forclusion de manière générale, en partant des considérations de Lacan dans son séminaire Les psychoses, où la forclusion du nom du père est considérée l'inclusion périmée « d'un corps signifiant $»^{3}$. Lacan présuppose que le nom du père est présent dans la structure, mais qu'il n'y trouve pas la même fonction articulatoire qu'il exercerait dans les névroses. En élargissant le concept de forclusion au-delà du concept de nom du père, nous pouvons penser

\footnotetext{
${ }^{1}$ Voir THURMAN Angela, McDUFFIE Andrea, HAGERMAN Randi and ABBEDUTO Leonard (2014). Psychiatric symptomes in boys...

${ }^{2}$ Voir MADEIRA Manoel \& VARELA Andrea (2016) L'émergence de la parole chez l'enfant à la...

${ }^{3}$ LACAN Jacques (1955-1956). Les psychoses, 171.
} 
simplement à une sorte d'inclusion vide où la notion de sujet n'a pas de poids épistémologique.

\subsection{Autisme versus $X$ fragile}

Ce qui a le plus attiré notre attention dans cette recherche bibliographique sur le $\mathrm{SXF}$, est l'affirmation presque unanime que ce syndrome est la cause génétique de l'autisme. Les chercheurs ont identifié des automatismes biologiques chez les porteurs de l'X fragile, comme se battre et se mordre les mains, ou comme la défense tactile, autant de signes indicatifs pointés dans le $D S M$ en tant qu'éléments de l'autisme. Ils furent apparemment suffisants pour ancrer ce constat scientifique de l'association entre le SXF et l'autisme. Un constat qui mérite pourtant amplement d'être discuté, notamment en ce qui concerne les nouvelles propositions de traitement moléculaire pour l'X fragile. Comme nous l'avons indiqué plus haut, les scientifiques considèrent l'X fragile et l'autisme comme le résultat d'un désarroi neurochimique au niveau des synapses. Ils proposent par conséquent un même médicament pour l'X fragile et pour les sujets diagnostiqués autistes, considérant, en d'autres termes, que ces deux maladies peuvent partager un même traitement ${ }^{1}$.

Un travail mené par Denise Cook démontre, dans ce sens, une intrication assez illustrative entre le Syndrome de l'X fragile et l'autisme: «Les troubles du neurodéveloppement, tels le Syndrome de l'X Fragile et le Trouble du Spectre Autistique, où il existe l'absence d'une seule protéine ou de maintes d'autres, amène à un défaut dans la capacité de régler les connexions du cerveau $»^{2}$. C'est-à-dire, l'autisme y apparaît aussi attaché au syndrome que son origine demeure purement organique, comme s'il s'agissait toutes les deux des affections, non pas seulement associées, mais de même nature. Une telle association entre l'autisme et le SXF existe depuis le début des années 1980, mais ne cesse d'être l'objet de controverses dans le milieu scientifique.

La première association entre l'autisme et l'X fragile date de 1982. Elle a été réalisée par Brown et $a l$., sur la base de critères diagnostiques du DSM-III ${ }^{3}$. En 1989, dans l'ouvrage The Fragile X Syndrome, Tessa Webb souligne que l'association n'était en réalité pas si

\footnotetext{
${ }^{1}$ Voir CASTREN Eero et al (2012) ; GURKAN Kagan and HAGERMAN Randi (2012); BERRYKRAVIS Elizabeth et $a l$. (2012).

${ }^{2}$ COOK Denise et al. (2014). Increasing our Understanding of Human Cognition..., 147. Traduction libre de l'auteure.

${ }^{3}$ In HAGERMAN Randi (1989). Behavior and treatment of the fragile X syndrome.
} 
évidente. L'auteure montre en effet que si l'on recherche le marqueur X chez les enfants diagnostiqués autistes, l'adéquation est très faible. À titre d'exemple, les recherches de Blomquist et $a l .{ }^{1}$ ont évalué un échantillon de 83 garçons diagnostiqués autistes et n'ont trouvé que 13 atteints de l'X fragile. Ils ont aussi évalué 19 filles, sans rapporter aucun cas de l'X fragile. Cette faible fréquence fut également le résultat des études de Watson et $a l^{2}$, qui ont identifié seulement $5 \%$ d'X fragile dans leur échantillon d'enfants autistes. Webb relève aussi un autre point important : si l'on inverse le sens de la recherche, c'est-à-dire si l'on cherche l'autisme chez les enfants atteints de l'X fragile, l'association devient alors significative. Dans un échantillon de dix enfants porteurs de l'X fragile, Levitas et $a l .{ }^{3}$ en ont identifié pas moins de six ayant l'autisme associé.

Dans ce même ouvrage, Randi Hagerman défend l'association entre l'autisme et l'X fragile, malgré son affirmation que «beaucoup des porteurs de l'X fragile ont un comportement amical et ils aiment la compagnie des autres $»^{4}$, caractéristiques absolument absentes chez les autistes. L'auteur soutient malgré tout cette comorbidité et émet l'hypothèse que la grande variabilité d'association entre l'X fragile et l'autisme rapportée par les recherches soit due aux différents critères de définition de l'autisme utilisés par les chercheurs ${ }^{5}$.

En 1991, Cohen et al. se sont aussi intéressés au débat des résultats conflictuels au sujet de la comorbidité de l'X fragile et l'autisme. À partir d'une méthodologie statistique, ils ont conclu que l'association était cohérente. Leur étude suggère en outre une association entre l'X fragile et l'évitement social, ajoutant que cet évitement pourrait être dû à l'existence de certains gènes dans le chromosome $X$, «la mutation pouvant altérer l'expression de ces gènes et avoir l'évitement social comme séquelle $»^{6}$. Nous pouvons remarquer donc, dans ce passage cité, la détermination génétique des symptômes liés au syndrome c'est-à-dire, l'autisme et l'évitement social indiqués par les chercheurs sont le résultat de l'altération de l'expression du gène.

Au fil des années, les recherches ont continué à appuyer cette association. Par exemple, en 2006, Sabaratnam met en relief les traits autistiques présents dans le syndrome :

\footnotetext{
${ }^{1}$ In WEBB Tessa (1989). The epidemiology of the Fragile X syndrome.

${ }^{2}$ Ibidem.

${ }^{3}$ WEBB Tessa (1989). The epidemiology of the Fragile X syndrome.

${ }^{4}$ HAGERMAN Randi (1989) Behavior and treatment of the fragile X..., 56. Traduction libre de

l'auteure.

5 Ibidem

${ }^{6}$ COHEN Michael et al. (1991) Overgrowth syndromes..., 200. Traduction libre de l'auteure.
} 
« aversion au regard, anxiété sociale, battement des mains (hand-flapping and hand-biting), défense sensorielle, adaptation pauvre face aux changements de la routine ${ }^{1}$. Chonchaiya, Schneider et Hagerman affirment, en 2009, que la cause de l'autisme chez un enfant est évidente lorsque le diagnostic de 1'ADN FMR1 est positif ${ }^{2}$. En 2011 McLennan et al. indiquent que le FMR1 est le gène le plus impliqué dans la cause de l'autisme et que les taux élevés d'autisme sont le résultat d'une dérégulation des connexions neuronales due à une réduction de l'expression de la protéine $\mathrm{FMRP}^{3}$.

Dans cette même voie, Berry-Kravis et al. pointent que «le SXF est la cause héréditaire connue la plus fréquente de l'autisme et de la déficience intellectuelle » ${ }^{4}$. Gürkan \& Hagerman soutiennent que l'autisme est un trouble du neurodéveloppement et qui comporte des similarités moléculaires avec l'X fragile. Ces similarités, selon les auteurs, peuvent justifier la recherche d'un seul traitement ciblé pour les deux pathologies 5 . L'affirmation la plus courante que nous observons dans les recherches les plus actuelles est que le SXF est « la cause la plus prévalente de l'autisme $»^{6}$.

Depuis la découverte du syndrome, la plupart des recherches consultées maintiennent le consensus que le syndrome de l'X fragile et l'autisme sont des pathologies associées, c'est-à-dire que l'X fragile est une cause génétique de l'autisme. Cependant, on trouve dans le milieu médical même des recherches importantes qui contredisent cette association. En 1994, Dykens et al. critiquent les études sur le SXF, argumentant que la fonction linguistique n'aurait pas reçu l'attention qu'elle méritait ; une attention que les chercheurs, soucieux d'associer l'autisme à l'X fragile, auraient accordé à d'autres facteurs du comportement ${ }^{7}$. Les auteurs mettent en relief le débat existant dans un milieu scientifique qui cherchait alors une cause génétique à l'autisme et misait sur le fait que le SXF pouvait être le grand responsable de cette pathologie. Ceci aurait détourné la recherche des autres aspects psychopathologiques beaucoup plus incidents que l'autisme, comme l'anxiété et

\footnotetext{
${ }^{1}$ SABARATNAM Marga (2006) Fragile-X syndrome, 327. Traduction libre de l'auteure.

${ }^{2}$ Voir CHONCHAIYA Weerasak, SCHNEIDER Andrea and HAGERMAN Randi (2009) Fragile $X: a$ family of disorders, 168.

${ }^{3}$ Voir MCLENNAN Yingratana, POLUSSA Jonathan, TASSONE Flora and HAGERMAN Randi 2011. Fragile $X$ Syndrome...

${ }^{4}$ BERRY-KRAVIS Elizabeth et al. (2012) Effects of STX209 (Arbaclofen) on Neurobehavioral..., 01. Traduction libre de l'auteure.

${ }^{5}$ Voir GÜRKAN Kagan \& Hagerman Randi (2012). Targeted treatments in autism and fragile X syndrome, 1316.

${ }^{6}$ Voir MCLENNAN Yingratana et al. (2011) HENDERSON Christina et al (2012) ; OSTERWEIL Emily et al. (2012) ; BERRY-KRAVIS Elizabeth et al. (2012) ; WIJETUNGE Lasani et al. (2013) ; BERRYKRAVIS Elizabeth (2014); OUYANG Lijing et al. (2014).

${ }^{7}$ Voir DYKENS Elisabeth, HODAPP Robert and LECKMAN James (1994). Behavior and development...
} 
l'hyperactivité. Quant aux recherches mettant en relation l'autisme et le SXF, il s'agit, selon Dykens et al., d'études simplifiées. Elles pourraient être remises en cause quant au critère de choix des sujets évalués : ceux-ci présentaient souvent un diagnostic préalable d'autisme susceptible d'induire les résultats. Les auteurs soutiennent que la marge d'erreur d'une telle démarche est très élevée. Un autre facteur à observer est l'absence de critères indiquant sur quelle base se fonde le diagnostic d'autisme ${ }^{1}$.

Selon Bernard Golse, les recherches indiquent que $7 \%$ seulement de la population autiste est atteinte du SXF. L'auteur interroge donc le fait qu'une aussi petite correspondance puisse être suffisante pour soutenir que le syndrome soit l'une des origines prédominantes de l'autisme. Au sujet de l'étiologie de l'autisme, Golse souligne que les facteurs génétiques sont considérés comme primaires, c'est-à-dire de prédisposition : ils ne provoquent pas la psychopathologie, mais en accroissent le risque ${ }^{2}$. Cette remarque faite par Golse établi la discontinuité qui nous avons cité auparavant. Il s'agit de mettre en tension la logique causale qui associe de manière immédiate l'X fragile à l'autisme, pour penser que les implications génétiques existent, mais qu'elles ne sont pour autant les seules déterminations du tableau clinique. Il s'agit ainsi de faire appel à une discontinuité qui introduit des interrogations où règne une sorte de certitude.

D'autres auteurs ont également remarqué la considérable différence qualitative dans le comportement et dans la structure du cerveau de ces pathologies ${ }^{3}$. Nous citerons ici la recherche menée par Hall et al. qui remet en question la liaison diagnostique entre le syndrome de l'X fragile et l'autisme. Selon les auteurs, il existe une similarité superficielle entre les phénomènes symptomatiques présentés par le SXF et par l'autisme ${ }^{4}$. Les sujets atteints par le SXF sont souvent diagnostiqués comme autistes alors qu'ils ne présentent pas cette psychopathologie. Leur travail montre une variation importante entre l'association du SXF à l'autisme en fonction de chaque outil d'évaluation - l'échelle the Social Communication Questionnaire (SCQ), l'échelle the Autism Diagnostic Observation Schedule (ADOS), l'échelle the Autism Diagnostic Interview-Revised (ADI-R) et le Diagnostic and Statistical Manual of Mental Disorders (DSM-IV). En d'autres termes, chacun de ces outils d'évaluation confère aux mêmes enfants syndromiques un diagnostic

\footnotetext{
${ }^{1}$ Voir DYKENS Elisabeth, HODAPP Robert and LECKMAN James (1994). Behavior and development...,

${ }^{2}$ Voir GOLSE Bernard, (2011). Le modèle psychanalytique dans le champ du handicap : ...

${ }^{3}$ Voir THURMAN Angela, MCDUFFIE Andrea, HAGERMAN Randi et ABBEDUTO Leonard (2014). Psychiatric symptoms in boys...

${ }^{4}$ Voir HALL Scott, LIGHTBODY Amy, HIRT Melissa, REZVANI Ava and REISS Allan, (2010). Autism in Fragile X Syndrome: A Category Mistake?
} 
fort différent. Cela signale un manque de fiabilité de ces échelles et, par conséquent, du diagnostic.

Nous indiquerons également les études de Gallagher et Hallahan ${ }^{1}$, qui ont affirmé l'existence de nouvelles recherches de l'imagerie cérébrale indiquant d'importantes différences au niveau de la structure et du fonctionnement du cerveau entre les individus porteurs de SXF et ceux porteurs d'autisme. Thurman et al., ont réalisé une recherche pour comparer le profil du SXF et le profil du trouble du spectre autiste non syndromique. Ils ont trouvé des différences qualitatives dans les symptômes psychiatriques des enfants atteints de l'X fragile et des enfants diagnostiqués comme autistes. Par exemple, la performance non verbale des enfants atteints de l'X fragile est plus faible que celle des enfants diagnostiqués comme autistes. En revanche, l'interaction sociale, la sociabilité sont plus fortes chez les individus atteints du $\mathrm{SXF}^{2}$.

Selon Abbeduto, McDuffie et Thurman, malgré les fortes associations entre l'autisme et le syndrome de l'X fragile, il reste encore trop d'incertitudes sur cette comorbidité. En outre, «il manque une réponse définitive à la question : 'le trouble du spectre autiste dans l'X fragile est-il le vrai trouble du spectre autiste ?' et l'évidence courante pointe la possibilité d'une réponse négative $»^{3}$. Il est loin d'être clair que l'autisme et l'X fragile présentent les mêmes déficiences psychologiques et neurobiologiques sousjacentes. Les auteurs ont mené une importante recherche à fin de mettre en lumière les différences entre le SXF et l'autisme. À partir d'une relecture remarquable de la littérature sur ce sujet, ils ont détecté cinq différences entre l'autisme et le syndrome de l'X fragile.

La première est que les difficultés sociales et de communication sont moins fortes chez les porteurs de le SXF. La deuxième se réfère au constat que les sujets atteints de l'X fragile portant le diagnostic d'autisme présentent également d'autres comorbidités, plus remarquables, qui les distinguent des sujets autistes non porteurs de le SXF. La troisième conclusion concerne la trajectoire du développement des symptômes autistes, différente chez les porteurs de l'X fragile et les sujets autistes. En particulier, les chercheurs ont remarqué que chez les porteurs du SXF, les améliorations au niveau de la communication allaient de pair avec celles de la cognition, ce qui n'est pas le cas chez les autistes. La

\footnotetext{
${ }^{1}$ Voir GALLAGHER A. \& HALLAHAN B. (2012). Fragile X-associated disorders: A clinical overview. 2 THURMAN Angela, MCDUFFIE Andrea, HAGERMAN Randi et ABBEDUTO Leonard (2014). Psychiatric symptoms in boys...

${ }^{3}$ ABBEDUTO Leonard, MCDUFFIE Andrea and THURMAN Angela (2014). The fragile X syndromeautism comorbidity : what do we really know ?, 01. Traduction libre de l'auteure.
} 
quatrième remarque montre que des comparaisons entre sujets atteints de l'X fragile autistes ou non - ont dévoilé des différences qui contredisent l'essence même de l'autisme. La dernière conclusion porte sur les recherches en neurobiologie. Les scientifiques soulignent des différences consistantes observées entre les individus atteints du SXF et les autistes, «quant à la structure et au fonctionnement du cerveau » ${ }^{1}$. L'ensemble des études citées ci-dessus nous conduisent à nous-mêmes à prendre position, et souligner que, $s$ 'il existe une cause génétique de l'autisme, il semblerait qu'il ne s'agisse pas du syndrome de l’X fragile.

\subsection{Autisme et DSM}

Ces questionnements soulevés par les experts de l'X fragile eux-mêmes amènent à une discussion préalable, que nous considérons essentielle: qu'est-ce que la science comprend par l'autisme? D'où vient ce mot si souvent prononcé à notre époque ? Cette entité psychopathologique a émergée dans un premier temps dans le champ de la médecine, de la psychiatrie et de la pédopsychiatrie ${ }^{2}$. Pour comprendre la construction du savoir scientifique impliquant les psychopathologies, et notamment en ce qui concerne à l'autisme, nous avons mené une recherche sur les différentes versions de l'outil diagnostic le plus utilisé dans le milieu médical : le DSM (Diagnostic and Statistical Manual of Mental Disorders).

Dans le texte d'introduction du récent $D S M V$, il est indiqué que cette nouvelle édition cible la pratique clinique, c'est-à-dire ceux qui vont identifier les troubles mentaux. Une remarque que l'on retrouve dans le passage suivant : «beaucoup de réflexions et de délibérations ont été impliquées dans l'évaluation du critère diagnostic, en considérant l'organisation de tous les aspects du manuel et en créant des nouvelles caractéristiques que nous croyions être beaucoup plus utiles pour les cliniciens $»^{3}$. Ce passage nous montre que la nouvelle édition du manuel persiste sur une idée d'encadrement des signes psychopathologiques, l'objectif du manuel étant d'offrir un outil scientifique pour

\footnotetext{
${ }^{1}$ ABBEDUTO Leonard, MCDUFFIE Andrea and THURMAN Angela (2014). The fragile X syndromeautism comorbidity : what do we really know ?,07. Traduction libre de l'auteure.

${ }^{2}$ Voir THOMAS Marie-Claude (2014). Genèses de l'autisme : Freud, Bleuler, Kanner., 09.

${ }^{3}$ AMERICAN PSYCHIATRIC ASSOCIATION (2013). Diagnostic and Statistical Manual of Mental Disorders, 5th edition, 05. Traduction libre de l'auteure.
} 
diagnostiquer de plus en plus. Ce n'est pas par hasard qu'en 2013, 1\% de la population mondiale a été diagnostiquée comme atteinte de l'autisme ${ }^{1}$.

En outre, les auteurs du DSM-IV affirment que l'APA (American Psychiatric Association) elle-même, ainsi que des spécialistes en santé mentale, ont reconnu qu'il avait une certaine immaturité dans la science du passé en ce qui concerne la fiabilité des diagnostics. Ce qui revient à dire qu'auparavant, la science n'était pas prête pour « assurer une validation des troubles des individus qui soit consistante, forte, et scientifiquement objective $»^{2}$. Des questions se posent inévitablement : dans une vingtaine d'années, le discours courant fera-il ces mêmes commentaires vis-à-vis la science du passé ? Avec l'émergence de nouveaux outils, le pourcentage de sujets atteints de maladies mentaux aurat-il doublé ? Autrement dit, il nous semble probable que, dans quelques années, la quête incessante de la vérité, caractéristique intrinsèque de la science, contestera de la même manière les affirmations scientifiques d'aujourd'hui.

Selon nous, il est important de consulter également, dans la science du passé, la façon dont a été abordé certain objet et le chemin qu'il a parcouru. Pour en revenir au sujet de l'autisme, la psychopathologie a suivi dans les manuels le parcours suivant: dans le DSM-III, l'autisme était inclus parmi les Troubles habituellement diagnostiqués pendant la première enfance, la deuxième enfance ou l'adolescence, et plus spécifiquement dans la catégorie Troubles globaux du développement. Son diagnostic s'accompagnait de six critères - le début avant l'âge de trente mois; pas de réaction vis-à-vis des autres personnes; déficit massif du développement du langage, avec écholalie, inversion de pronoms, langage métaphorique; réponses bizarres à des aspects variés de l'environnement; et absence d'idées délirantes, d'hallucinations, de relâchement des associations ou d'incohérence comme observé dans la schizophrénie $e^{3}$ Le DSM-III-R révisé - replace l'autisme dans la catégorie des Troubles Envahissants du Développement et lui confère les caractéristiques suivantes : altération qualitative des interactions sociales ; altération de la communication verbale et non verbale et de l'activité d'imagination; restriction marquée du champ des activités et d'intérêts; début durant la première ou la

\footnotetext{
${ }^{1}$ Voir AMERICAN PSYCHIATRIC ASSOCIATION (2013). Diagnostic and Statistical Manual of Mental Disorders, 5th edition.

${ }^{2}$ Ibidem, 55. Traduction libre de l'auteure.

${ }^{3}$ Voir AMERICAN PSYCHIATRIC ASSOCIATION (1984) Mini DSM-III : Critères diagnostiques.
} 
deuxième enfance ${ }^{1}$. Il est indiqué dans cette version du DSM que le syndrome de l'X fragile, lui « responsable d'un dysfonctionnement cérébral », pourrait être un facteur prédisposant de l'autisme ${ }^{2}$.

Au DSM-IV, l'autisme demeure parmi les Troubles habituellement diagnostiqués pendant la première enfance, la deuxième enfance ou l'adolescence. Mais il est désormais appelé Trouble autistique. Dans cette version du DSM, il est défini comme un «développement nettement anormal ou déficient de l'interaction sociale et de la communication, avec un répertoire considérablement restreint d'activités et d'intérêts $»^{3}$. En ce qui concerne les critères diagnostiques, sont indiqués l'altération des interactions sociales réciproques, c'est-à-dire l'incapacité à établir des relations avec les pairs; l'altération de la communication, des performances verbales et non verbales; et le répertoire restreint d'activités et d'intérêts. Dans la $5^{\text {ème }}$ et dernière version du DSM, l'autisme est inclus dans la catégorie Troubles du neurodéveloppement. On y trouve les mêmes critères diagnostiques que dans DSM-IV, c'est-à-dire que le trouble s'observe par le déficit persistant au niveau de la communication et de l'interaction sociale, même si on note également un certain type de comportement restreint et répétitif. Cependant l'autisme est considéré comme un trouble du neurodéveloppement, c'est-à-dire une pathologie liée au dysfonctionnement cérébral.

Pour nous aider à découvrir d'où vient le pouvoir attribué aux manuels psychiatriques américains, regardons les contributions du spécialiste d'histoire intellectuelle, Christopher Lane, dans son remarquable ouvrage Comment la psychiatrie et l'industrie pharmaceutique ont médicalisé nos émotions, traduit en français en 2010. Au cours de sa recherche, l'auteur a eu accès à des lettres inédites de correspondance entre psychiatres membres de l'APA, aussi bien qu'à des documents échangés par des dirigeants d'entreprises pharmaceutiques. Lane a également réalisé des entretiens avec les plus importants psychiatres impliqués dans l'élaboration du DSM. L'auteur cherchait notamment à savoir comment la timidité, une affection bénigne de l'humain, était devenue une maladie mentale, appelée depuis le DSM la phobie sociale.

\footnotetext{
${ }^{1}$ AMERICAN PSYCHIATRIC ASSOCIATION (1989) DSM-III-R : Manuel diagnostique et statistique des troubles mentaux, 40.

${ }^{2}$ Ibidem, 39.

3 AMERICAN PSYCHIATRIC ASSOCIATION (1995 [1996]). DSM-V: Manuel diagnostique et statistique de troubles mentaux, 79.
} 
Selon Christopher Lane, l'Association Américaine de Psychiatrie (APA) a transformé dans les années quatre-vingt des émotions du quotidien en maladies mentales. Ce petit groupe de psychiatres américains autoséléctionnés aurait promu, par exemple, un individu auparavant diagnostiqué comme introverti en psychotique léger ${ }^{1}$. Toujours selon Lane,

«il n’a fallu que quelques années aux psychiatres en question pour mettre à jour le manuel et transformer des émotions ordinaires en maladies relevant d'un traitement médical, mais leurs discussions se sont rarement attardées sur les conséquences à long terme de leurs décisions $»^{2}$.

Selon le neurobiologiste François Gonon, la tendance de la psychiatrie contemporaine est de comprendre l'étiologie des troubles mentaux ayant comme base une conception exclusivement neurobiologique. En voulant introduire la psychiatrie dans le champ de la médecine scientifique, l'APA réalise une rupture avec les précédentes classifications de maladies mentales, dans la mesure où « elle se voulait a-théorique afin d'améliorer la fiabilité et la validité des diagnostics $»^{3}$.

Le problème, selon Lane, est que les consignes du manuel ne sont pas seulement suivies par le milieu psychiatrique, mais également par les agences de santé publique, par les tribunaux et par les universités. Le DSM est devenu une autorité mondiale, couramment appelée la bible de la santé mentale. Dans un article publié en 2010 dans le journal The New York Times, le journaliste Ethan Watters fait une remarque qui corrobore avec la pensée de Lane. Il écrit que la psychiatrie américaine tend à imposer au reste du monde sa conception étroitement neurobiologique des maladies mentales. Un tel succès de diffusion ne reflète pourtant en rien les résultats de la psychiatrie américaine, puisque, selon le journaliste, le nombre de patients n'a pas diminué aux États-Unis, bien au contraire ${ }^{4}$.

Si nous nous intéressons principalement aux enjeux du diagnostic de l'autisme par rapport à son association au syndrome de l'X fragile, l'ouvrage de Lane nous aide néanmoins à visualiser la logique de fonctionnement du DSM. Parce que les spécialistes de l'X fragile se sont largement appuyés sur ce manuel, il nous semble important de savoir

\footnotetext{
${ }^{1}$ LANE Christopher (2010). Comment la Psychiatrie et l'industrie pharmaceutique ..., 09.

${ }^{2}$ Ibidem, 10.

${ }^{3}$ GONON François (2011). La psychiatrie biologique : une bulle spéculative ?, 55.

${ }^{4}$ WATTERS Ethan (2010). The americanization of Mental Illness. In GONON François (2011), 55.
} 
dans quel contexte il est apparu, quelles sont ses références épistémologiques, c'est-à-dire quelles sont les bases théoriques de construction des catégories diagnostiques et comment elles sont utilisées. Le manuel a élaboré, nous semble-t-il, une sémiologie fixe pour rendre les psychopathologies plus objectives, mesurables, identifiées et, par conséquent, médicalisées ${ }^{1}$.

Le passage suivant, que nous avons trouvé dans l'avant-propos de l'ouvrage DSMIV : Diagnostics Différentiels, est particulièrement intéressant dans la mesure où il ne nous semble pas être suivi par les adeptes du manuel : «[...] un individu ne peut se résumer à l'information contenue dans des arbres de décision, des tableaux ou des listes de symptômes. Ainsi, on doit bien se garder d'utiliser le DSM-IV ou ce manuel sans réflexion ou comme un livre de recettes $»^{2}$. Mais, contrairement à cette indication, le DSM n'est-il pas devenu précisément un livre de recettes sur le plan des maladies mentales ?

Lane nous offre une piste de décryptage de la manière d'opérer du manuel, basée sur le phénomène observé, c'est-à-dire sur l'ensemble des signes indicatifs qui caractérisent la psychopathologie. Des signes qui légitiment le diagnostic, comme l'affirme Lane : « une fois le terme diagnostic fixé avec ses critères associés dans le DSM, les utilisateurs du manuel n'auraient idéalement qu'à en interpréter les signes, exactement de la même façon, en prenant principalement en compte le nombre de critères présentés par un patient $»^{3}$. Et il poursuit : «en pratique, pourtant, preuve supplémentaire d'un raisonnement vicié, le psychiatre examinateur ne cherchera bien souvent qu'à corroborer les signes des syndromes et de traits préalablement décrits $»^{4}$. Autrement dit, la pratique du spécialiste se réduit à l'observation des signes indicatifs de la psychopathologie prédéterminés dans le manuel. En outre, cet ensemble de signes est suffisant pour indiquer le diagnostic et la conduite thérapeutique - les pharmacotropiques. Le manuel, nous semble-t-il, est utilisé exactement comme ses auteurs ont recommandé de se bien garder : un livre de recettes ${ }^{5}$.

Selon le psychanalyste Alfredo Jerusalinsky, quand la médecine se confronte à une pathologie qui échapperait à son champ de savoir, elle établit une sémiologie rigide pour expliquer ce qui est de l'ordre du psychique. Les signes de la pathologie seraient alors

\footnotetext{
${ }^{1}$ Voir FENDRIK Silvia (2011). O DSM-IV : uma metafisica comportamentalista?

${ }^{2}$ FIRST Michael, FRANCES Allen and PINCUS Harold (1995 [1999]). DSM-IV: Diagnostics différentiels, VI.

${ }^{3}$ LANE Christopher (2010). Comment la Psychiatrie et l'industrie pharmaceutique..., 97.

${ }^{4}$ Ibidem.

${ }^{5}$ Voir FIRST Michael, FRANCES Allen and PINCUS Harold (1995 [1999]) DSM-IV: Diagnostics différentiels.
} 
précédemment déterminés comme caractéristiques prévalentes. Le signe serait pris comme l'indicateur d'un signifié psychopathologique déterminé, situé de façon immuable dans une classification nosographique descriptive et fixe. « Les signes ne sont pas interprétables, mais seulement indicatifs $»^{1}$, affirme l'auteur. Le risque de prendre les signes comme indicatifs est que l'opération classificatoire de la pathologie se retrouve suffisante en elle-même pour supposer une étiologie et, par ailleurs, suffisante pour déterminer une conduite thérapeutique. La quête de l'étiologie de la maladie, fondamentale dans le processus de traitement de l'affection psychique, est abandonnée ou supposée de base exclusivement organique $^{2}$. L'autisme, comme nous avons pu le remarquer, n'échappe pas à cette conception de cause neurobiologique. Il nous semble sur cela que Maud Mannoni nous mis en garde de façon remarquable dans son ouvrage L'enfant arriéré et sa mère, en affirmant que

«théoriquement, une meilleure connaissance des facteurs organiques devrait simplifier et renforcer nos moyens d'action ; mais trop souvent, en fait, la croyance initiale au caractère déterminant de facteurs organiques sert fâcheusement d'excuse à notre impuissance $»^{3}$.

Faut-il exclure tous les traits de subjectivité - comme semble le faire la science - en raison d'une impuissance face aux manifestations de l'inconscient? Ne pouvons-nous pas affirmer que lorsque les spécialistes de l'X fragile indiquent que la mutation génétique du chromosome X entraîne des symptômes du comportement, tels l'hyperactivité ou la phobie sociale, par exemple, sans aucune référence à la dimension psychique de l'enfant atteint, ils ne font que reproduire cette pratique mise en question par Mannoni ?

\subsection{Conclusion}

Dans ce chapitre, nous avons présenté le syndrome du chromosome $\mathrm{X}$ fragile, depuis sa découverte. La relecture de la littérature médicale nous a montré qu'il s'agit d'une mutation génétique impliquant de sérieuses conséquences visibles - et invisibles - chez les sujets porteurs. Ce qui a particulièrement attiré notre attention sont les psychopathologies

\footnotetext{
${ }^{1}$ JERUSALINSKY Alfredo (2011). Uma discussão com a Neurociência., 75. Traduction libre de l'auteure.

2 Ibidem

${ }^{3}$ MANNONI Maud (1964). L'enfant arriéré et sa mère, 18.
} 
liées au syndrome: des symptômes psy supposément déclenchés par le désarroi neurophysiologique entrainé par le SXF. Les signes indicatifs de chaque symptôme, qui permettent les diagnostics respectifs, se trouvent décrits dans les différentes versions du DSM. Ce syndrome impose des limites aux manifestations des enfants atteints, notamment au niveau cognitif. Néanmoins, il nous semble problématique le saut opéré entre le processus neurophysiologique et le symptôme psychique, qui ne laissent pas de place pour penser également le rôle des facteurs sociaux, culturaux et psychiques qui constituent l'enfant et ses symptômes.

Nous comprenons que les études sur l'X fragile s'appuient sur les critères du DSM, soit pour indiquer un diagnostic, soit une causalité uniquement organique des maladies mentales. Cependant, comme nous avons mis en relief dans ce deuxième chapitre, en ce qui concerne au traitement des enfants atteints de l'X fragile, les outils thérapeutiques sont limités et peu nombreuses. Nous voudrions, donc proposer la psychothérapie psychanalytique aux soins accordés à ces enfants. Il nous faut, cependant, trouver une voie possible que nous permette une façon de nous rapprocher du savoir de la génétique médicale. Nous développerons au prochain chapitre un ensemble de recherches sur l'épigénétique qui nous semblent ouvrir le chemin pour l'articulation entre génétique médicale et psychanalyse. 


\section{Chapitre III}

\section{L'épigénétique : l'indétermination génétique}

\subsection{Ouverture}

Au deuxième chapitre, nous avons travaillé sur la conceptualisation médicale du syndrome de l'X fragile, ainsi que la symptomatologie comportementale qui lui est associée. Des symptômes - autisme, hyperactivité, phobie, entre autres déjà cités - sont abordés de manière exclusivement organique, ce qui a pu créer des fragilités argumentatives soulevant quelques questions. Car il s'agit d'une médecine qui utilise des diagnostics sans références ni articulations avec le champ psy, dont sont pourtant issus les concepts en question. Dans les recherches citées au sujet du syndrome de l'X fragile, la dimension de la subjectivité et du sujet ${ }^{1}$ lui-même restent marginales, dans la mesure où la science a tendance d'exclure de son champ d'étude l'importance et l'influence des relations sociales - relations du sujet avec ses semblables, ses parents, sa famille - dans le développement et le traitement des affections organiques.

De fait, la médecine adopte un autre cadre de référence épistémologique que la psychanalyse, cadre non partagé et difficilement conciliable. Dejours note que les deux disciplines adoptent des champs d'investigation différents sur un même phénomène et qu'il est peu aisé d'établir une véritable articulation entre elles ${ }^{3}$. Selon notre entendement, le savoir-faire est, avec la condition humaine, le point de tension entre les deux champs. Le regard exclusivement médical sur une maladie peut amener à négliger l'incidence des représentations psychiques qui se tissent à la formation des symptômes, étant fondamentales à prendre en compte dans le traitement.

Théorisant sur la pratique médicale en milieu hospitalier, Schwering montre l'existence d'une position transgressive de l'acte médical face au corps malade, quand ce dernier se trouve « fondamentalement astreint à considérer le patient comme un corps sur

\footnotetext{
${ }^{1}$ Nous utilisons ici le concept de sujet tel qu'il est défini par Jacques Lacan et qui sera développé au prochain chapitre.

${ }^{2}$ Voir MAGISTRETTI Pierre \& ANSERMET François (2010). Neurosciences et psychanalyse: une ...

${ }^{3}$ Voir DEJOURS Christophe (2001). Le corps, d'abord.
} 
lequel agir selon les principes de son savoir scientifique $»^{1}$. La transgression, selon Schwering, serait à mettre en lien avec un moment où «l'autre est réduit à un objet sur lequel l'acteur [le médecin] a toute maîtrise $»^{2}$. Cette omnipotence du discours médical s'observe également au sein des écrits théoriques sur le syndrome de l'X fragile. Aucune place n'est faite aux articulations avec les autres champs de savoir qui peuvent pourtant contribuer à une construction de connaissances sur le syndrome, ni d'ailleurs à la prise en compte de la subjectivité du patient en question.

Quand la génétique médicale plaque un mécanisme organique sur l'autisme, par exemple, elle réalise un passage qui marginalise la dimension du sujet ${ }^{3}$. En outre, à propos des symptômes associés au SXF, nous avons indiqué dans un précédent travail que,

« considérer ces symptômes sans articulation avec ceux qui entourent l'individu reviendrait à nier que la timidité, par exemple, n'existe qu'en relation à quelqu'un ou à quelque chose. On pourrait en dire autant de la phobie. Cela revient à nier que le langage se transmet ; et que les troubles ainsi nommés se réfèrent également à ceux qui sont en relation avec l'enfant - et il en est de même pour le traitement de ces troubles $»^{4}$.

Cela dit, il ne faudrait pas pour autant négliger les possibles effets organiques causés par la mutation génétique du chromosome X. La déficience intellectuelle, par exemple, est une caractéristique importante chez les porteurs du syndrome ; elle impose ses limites aux patients les plus jeunes, notamment dans le milieu scolaire, où prévalent les processus cognitifs.

Sachant que l'ambition principale de cette thèse est de tisser un dialogue entre la génétique médicale et la psychanalyse à partir du syndrome de l'X fragile, par où pourraiton articuler des pratiques aussi distinctes ? Ce sont les nouvelles recherches en épigénétique qui tracent la voie choisie pour mettre en pratique notre entreprise. Il convient de signaler qu'il existe au sein même du syndrome de l'X fragile des mécanismes épigénétiques qui contribuent à son déclenchement ${ }^{5}$. «L'épigénétique ouvre le chemin d'une compréhension

\footnotetext{
${ }^{1}$ SCHWERING Karl-Leo (2007). Techniques chirurgicales et techniques magiques, 4.

${ }^{2}$ Ibidem.

${ }^{3}$ Voir VARELA Andrea, MADEIRA Manoel et MORETTO Lívia (2015). Síndrome do cromossomo X frágil: uma possível articulação entre psicanálise e genética médica?

${ }^{4}$ Ibidem, 54. Traduction libre de l'auteure.

${ }^{5}$ Nous reviendrons sur cette discussion par la suite.
} 
de l'être humain dans son ensemble et considérant l'interaction dynamique entre 'Nature' et 'Nurture' (environnement) » ${ }^{1}$ tel que l'affirme Salmo Raskin, représentant brésilien du Projet Génome, indiquant que l'on peut penser l'humain sous une perspective amplifiée et moins déterministe. $\mathrm{Si}$, dans le domaine des sciences médicales, les pratiques se fondent sur l'empirisme ${ }^{2}$, autrement dit, sur ce qui peut être prouvé ou réfuté, l'épigénétique démontre en s'appuyant sur des données réelles qu'il existe des effets corporels provoqués par l'environnement et que, plus surprenant, ces effets peuvent être transmis aux prochaines générations.

Dans ce chapitre, nous aborderons le concept d'épigénétique, ainsi que les nouvelles recherches qui semblent s'ouvrir au champ psy. Nous nous interrogerons également sur le concept d'environnement pour la génétique médicale et verrons de quelle manière elle peut s'articuler avec l'environnement de la psychanalyse. Les recherches sur l'autisme et l'épigénétique seront également abordées, rappelant que le choix de cette psychopathologie se justifie par sa prédominance dans les recherches sur le syndrome de l'X fragile. Les pratiques psychothérapiques, en phase de devenir un objet d'étude de l'épigénétique, seront également abordées dans ce chapitre, étant donné qu'elles représentent un outil fondamental pour tisser des liens entre la psychanalyse et la génétique médicale.

\subsection{Le concept d'épigénétique $e^{3}$}

Le terme épigénétique fut employé pour la première fois en 1942 par Conrad Waddington $^{4}$ qui le concevait alors comme «une branche de la biologie étudiant les interactions occasionnelles entre les gènes et ses produits, donnant naissance au phénotype $»^{5}$. Selon Edith Heard ${ }^{6}$, Waddington a été le premier à relever la pertinence du lien occasionnel entre phénotype et génotype pour la compréhension des processus de

\footnotetext{
${ }^{1}$ RASKIN Salmo (2015). Genética e psicanálise : um encontro possível ?, 163. Traduction libre de l'auteure.

2 Voir ALBERTI Sonia. \& FULCO Ana Paula (2005). Um estudo, uma denúncia e uma proposta: a psicanálise...

${ }^{3}$ Nous avons consulté les ouvrages sur l'épigénétique disponibles à la Bibliothèque Nationale de France et les articles ont été réunis lors de l'écriture de cette thèse via la base de données PubMed, Nature, Elsevier avec les mots clés : epigenetics ; behavior ; psychotherapy.

${ }^{4}$ Voir ARMSTRONG Lyle (2014). Epigenetics.

5 Texte original : «a branch of biology which studies the causal interactions between genes and their products which bring the phenotype into being », 1 .

${ }^{6}$ Voir HEARD Edith (2013). Epigénétique et mémoire cellulaire.
} 
développement. «Waddington propose donc de fusionner les termes épigénèse et génétique pour designer de ce nouveau l'étude des mécanismes par lesquels les gènes déterminent les caractères ${ }^{1}$, affirme Heard. À partir des années 80 , le terme acquiert un nouveau sens et commence à être compris non plus comme une mutation de la séquence de l'ADN, mais comme un ensemble de modifications transmises et qui expliqueraient certaines particularités dans l'activité génétique. C'est le généticien Robert Holliday qui, en 1994, redéfinit le terme épigénétique comme une étude des modifications d'expression des gènes transmissibles au cours des divisions cellulaires, sans qu'il n'y ait de modification dans la chaîne de l'ADN².

Actuellement, l'épigénétique est définie comme un ensemble de «modifications de l'ADN et de la chromatine, qui exercent un rôle critique quant à la régulation de diverses fonctions génomiques $»^{3}$ ou encore comme «l'étude des modifications de la fonction du gène par mitose et/ou par méiose, n'impliquant aucune modification de la séquence $\mathrm{ADN} »^{4}$. Selon François Gonon, l'épigénétique étudie les mécanismes moléculaires qui expliquent comment un facteur environnemental est susceptible de provoquer d'importantes modifications au niveau de l'activité des gènes, lesquelles peuvent même être transmises à la prochaine génération ${ }^{5}$. L'environnement opère ainsi des altérations génétiques significatives qui n'atteignent pas le matériel génétique de base (ADN). Si le gène en vient à s'exprimer différemment suite à l'influence des facteurs environnementaux, l'ADN n'en sera pas altéré.

L'épigénétique, selon Heard, « fait naître l'espoir que nous sommes bien plus que la séquence de nos gènes ${ }^{6}$. L'héritage de la génétique mendelienne indique que l'individu est le résultat exclusif de l'interaction entre les gènes des parents. Suivant la pensée darwinienne, il y aurait ainsi une détermination génétique accompagnant l'évolution des espèces. Le Projet Génome, immense initiative de la science contemporaine réunissant des chercheurs de divers pays, est considéré aujourd'hui comme «l'un des plus grands pas

\footnotetext{
${ }^{1}$ HEARD Edith (2013). Epigénétique et mémoire cellulaire., 23.

${ }^{2}$ Ibidem, 30.

3 WONG Albert et al. (2013). The epigenetic perspective, 09. Texte original : « refers to DNA and chromatin modifications that play a critical role in regulation of various genomic functions ».

${ }^{4}$ ARMSTRONG Lyle (2014). Epigenetics, 2. Texte original : « the study of changes in gene function that are mitotically and/or meiotically heritable and that do not entail a change in the sequence of DNA ».

${ }^{5}$ Voir GONON François (2011). La psychiatrie biologique : Une bulle spéculative?

${ }^{6}$ HEARD Edith (2013). Epigénétique et mémoire cellulaire, 55.
} 
jamais réalisés par la science ${ }^{1}$. Misant sur une cartographie intégrale du génome humain, les scientifiques croyaient pouvoir déchiffrer son code génétique, apportant ainsi «l'espoir d'un meilleur contrôle des maladies et d'une meilleure estimation des risques génétiques individuels de développer un cancer, des problèmes cardiaques, du diabète ou la maladie d'Alzheimer $»^{2}$, explique Perbal. Selon les mots enthousiastes de Bill Clinton, Président des États-Unis à l'époque de la divulgation des premiers résultats du projet, le séquençage représentait alors «le langage avec lequel Dieu a créé la vie $»^{3}$. Autrement dit, on croyait fortement que l'identification des gènes permettrait l'élaboration d'un traitement de la prédisposition génétique à une maladie, donnant une nette prédominance à la pratique médicale sur la détermination génétique. La maladie aurait ainsi pu être traitée avant même sa possible apparition.

L'épigénétique met en question ce déterminisme en relevant que l'environnement peut provoquer des modifications au niveau de l'expression du gène. Un même gène peut ainsi s'exprimer sous une certaine forme au sein d'une cellule et ne pas s'exprimer dans un autre. Comme l'indique Wong, «bien que le génotype soit identique pour la plupart des cellules d'un organisme déterminé, les phénotypes et les fonctions cellulaires montrent des différences radicales, ce qui pourrait bien être contrôlé par différentes régulations épigénétiques $»^{4}$. Eva Jablonka rappelle un exemple classique qui a beaucoup contribué à la recherche sur l'héritage épigénétique : l'inactivation aléatoire du chromosome $X$ chez des femelles mammifères. « Au tout début du développement, l'un des deux chromosomes X de chaque cellule devient condensé et inactif. [...] Bien que les femelles possèdent deux chromosomes $\mathrm{X}$, elles ont fonctionnellement le même dosage de gènes liés au chromosome $\mathrm{X}$ que la paire masculine $\mathrm{XY}$, étant donné que seul un chromosome $\mathrm{X}$ est actif $»^{5}$, explique Jablonka.

\footnotetext{
${ }^{1}$ RASKIN Salmo (2015). Genética e psicanálise : um encontro possível ?, 150. Traduction libre de l'auteure.

2 PERBAL Laurence (2014) Une brève histoire de la génétique humaine, 158.

${ }^{3}$ Ibidem, 160.

${ }^{4}$ WONG Albert et al. (2013). The epigenetic perspective, 09. Texte original : « Although the genotype of most cells of a given organism is the same, cellular phenotypes and functions differ radically, and this can be controlled by differential epigenetic regulation $»$.

5 JABLONKA Eva et MARION Lamb (1995) Epigenetic inheritance and evolution: the Lamarckian dimension, 91-92. Texte original : «Early in development, one of the two X chromosomes in each cell becomes condensed and inactive [...] Functionally, although females have two X chromosomes, they have the same dose of $\mathrm{X}$ linked genes as $\mathrm{XY}$ males because only one $\mathrm{X}$ chromosome is active ».
} 


\section{Les mécanismes épigénétiques}

Les modifications épigénétiques connues, en ce qui concerne la chromatine complexe de l'ADN, protéines et autres composants qui constituent le chromosome - sont : la méthylation de l'ADN, les modifications post-traductionnelles des histones comme la méthylation ou l'acétylation, et l'expression d'ARN non codants ${ }^{1}$. Une méthylation importante de l'ADN peut rendre le gène inactif en empêchant son contact avec les facteurs de transcription par condensation de la chromatine. Monhonval et Lotstra ont ainsi mis en évidence que «la machinerie transcriptionnelle n'est plus en mesure, par manque de place, d'approcher le promoteur du gène afin d'initier la transcription de ce gène, ce qui permettrait son expression $»^{2}$. Il a été prouvé que certains facteurs environnementaux, comme «le benzène, la pollution aérienne, l'arsenic, la cigarette, l'alcool, les perturbateurs endocriniens, l'activité physique et le régime diététique $»^{3}$ peuvent modifier la méthylation de l'ADN.

En ce qui concerne les modifications post-traductionnelles des histones, elles sont capables, de la même manière que la méthylation de l'ADN, d'empêcher l'accès de ce dernier « à la machinerie transcriptionnelle ${ }^{4}$ en modifiant la structure de la chromatine qui l'entoure. Avec pour conséquence, une possible non-expression du gène. Enfin, les ARN non codants qui résultent de la transcription de l'ADN, régulent eux aussi les procédés de transcription ou de traduction ; ils deviennent par conséquent impliqués dans la régulation de l'expression génique ${ }^{5}$. Comme nous l'avons signalé précédemment, le syndrome de l'X fragile est un exemple de l'actuation des mécanismes épigénétiques. L'expansion du trinucléotide CGG - cause physiologique du syndrome, détaillée au deuxième chapitre s'accompagne d'une méthylation de l'ADN et de «modifications des histones, typiques d'un statut hétérochromatique incompatible avec la transcription $»^{6}$, ce qui implique la nontraduction de la protéine FMRP. Autrement dit, la méthylation de l'ADN et les modifications des histones empêche le gène FMR1 de produire sa protéine et le rend ainsi inexpressif.

\footnotetext{
${ }^{1}$ Voir MONGET Philippe \& VEITIA Reiner (2014). Introduction à la génétique moderne.

${ }^{2}$ MONHONVAL Pauline \& LOTSTRA Françoise (2014). Transmission transgénérationnelle des ..., 31.

${ }^{3}$ RIVOLLIER F. et al. (2014). Hypothèse épigénétique de la schizophrénie : revue de la littérature, 383.

${ }^{4}$ Ibidem.

${ }^{5}$ Ibidem, 382.

${ }^{6}$ Voir TABOLACCI Elisabetta et al. (2016). Transcriptional Reactivation of the FMR1 Gene. A Possible...
} 
Ce sont là les marques épigénétiques que l'on connaît aujourd'hui et qui sont en partie responsables de la passerelle qui existe entre l'ADN et l'environnement extérieur' ${ }^{1}$. Ces interactions ont une base physiologique, elles sont réversibles et transgénérationnelles. Néanmoins, selon Rivoller et al. « les processus par lesquels les facteurs environnementaux agissent au niveau moléculaire pour induire des modifications épigénétiques restent mal connus $»^{2}$.

\subsection{L'environnement et son influence}

L'épigénétique montre donc qu'une interférence est possible entre l'environnement et les fonctions organiques de l'individu, considérées autrefois comme prédéterminées par sa charge génétique. De telles découvertes soulèvent néanmoins quelques questions : à quel environnement se réfère précisément la génétique ? D'après Wong, il existe une liste croissante d'événements environnementaux susceptibles de causer des modifications épigénétiques, qu'il s'agisse de l'environnement purement biologique ou de celui lié au comportement $^{3}$. De multiples facteurs environnementaux sont aussi considérés comme d'importants modulateurs de la santé mentale : « un bouleversement social, des conditions de travail stressantes, la discrimination liée au sexe, l'exclusion sociale, un mode de vie déséquilibré, les risques de violences, les maladies physiques et les violations des Droits de l'Homme $»^{4}$.

Grâce aux études épigénétiques, ces altérations provoquées par l'environnement extérieur ont commencé à être prouvées scientifiquement. Nous allons maintenant nous pencher sur des études qui nous semblent particulièrement pertinentes pour illustrer le chemin parcouru par la recherche épigénétique, et qui considèrent des éléments subjectifs comme composants de l'environnement et les mettent en relation avec la condition humaine.

Dans une étude réalisée sur enfants de femmes ayant vécu le Hunger Winter de la Deuxième Guerre Mondiale - hiver au cours duquel l'accès à la nourriture a été bloqué par les nazis -, Armstrong constate une augmentation de la propension aux maladies comme le diabète, les maladies cardiaques et l'obésité $e^{5}$. Les données apportées par cette recherche

\footnotetext{
${ }^{1}$ Voir RASKIN Salmo (2015). Genética e psicanálise : um encontro possível?

${ }^{2}$ RIVOLLIER F. et al. (2014). Hypothèse épigénétique de la schizophrénie : revue de la littérature, 383.

${ }^{3}$ Voir WONG Albert et al. (2013). The epigenetic perspective.

${ }^{4}$ ARMSTRONG Lyle (2014). Epigenetics, 245. Texte original : « rapid social change, stressful work conditions, gender discrimination, social exclusion, unhealthy lifestyle, risks of violence, physical illhealth, and violations of human rights ».

${ }^{5}$ ARMSTRONG Lyle (2014). Epigenetics, 03.
} 
indiquent que l'adversité du régime maternel a provoqué des conséquences épigénétiques transmises aux prochaines générations. C'est là un exemple où la nutrition provoque, en tant qu'environnement, des altérations dans les fonctions corporelles de l'individu. Behl et al. signent une autre étude montrant l'influence de l'environnement sur les fonctions organiques. Les chercheurs y soulignent l'augmentation du risque d'obésité infantile ainsi que des troubles métaboliques, chez des enfants exposés au tabac par leurs mères durant la grossesse ${ }^{1}$. L'utérus maternel toxique est ainsi considéré comme un environnement susceptible d'altérer les fonctions métaboliques de l'individu.

Nous avons également trouvé dans la littérature médicale des études comme celle de Kahn \& Ahmed qui montrent l'influence de composants chimiques, comme le Bisphénol A (BPA), dans le développement de pathologies graves chez l'être humain ${ }^{2}$. Le BPA est présent dans la fabrication du plastique et il peut contaminer l'organisme en cas d'ingestion. Selon Kahn \& Ahmed, la substance peut affecter le système endocrinien, altérant la production, la synthèse et le transport des hormones. Les chercheurs prouvent que le BPA agit comme une interférence épigénétique dans les cellules du système immunologique, contribuant au déclenchement de processus inflammatoires et de maladies auto-immunes.

Outre ces changements organiques, l'environnement peut aussi altérer les comportements ; et plus encore, le comportement peut agir comme environnement capable d'altérer les fonctions organiques. Le terme comportement est utilisé de manière récurrente dans la littérature médicale lorsqu'elle aborde la dimension de l'expression humaine, et c'est pour cette raison que nous avons choisi de l'utiliser ici $^{3}$. Au sein de la littérature médicale sur l'épigénétique, nous avons trouvé diverses études utilisant le modèle animal pour comprendre le comportement humain. Avant d'aborder de telles études, il convient de souligner ici que le Projet Génome Humain cité plus haut est parvenu à identifier et cartographier environ 25000 gènes chez l'espèce humaine, alors qu'on en pronostiquait l'existence de $100000^{4}$. Le résultat a été donc décevant, à en croire le généticien Raskin, dans la mesure où nous nous retrouvons génétiquement très proches de certaines autres espèces défavorisées dans l'échelle de l'évolution. Le verre de terre, par exemple, possède

\footnotetext{
${ }^{1}$ Voir BEHL Mamta et al. (2013). Evaluation of the Association between Maternal smoking, childhood ...

${ }^{2}$ Voir KAHN Deena \& AHMED Ansar (2015). Epigenetic regulation of non-lymphoid cells by bisphenol...

${ }^{3}$ On entend ici par « comportement » l'action humaine réalisée sur l'environnement par un individu et liée à la manière dont celui-ci perçoit un phénomène donné. Le comportement est, ainsi, déterminé par la réponse qu'il cause. Voir SAMPAIO Ângelo (2005). Skinner: sobre ciência e comportamento humano.

${ }^{4}$ Voir PERBAL Laurence (2014). Une brève histoire de la génétique humaine.
} 
19000 gènes et certaines mouches en ont 15 000. Toujours selon Raskin, le plus surprenant a été de constater la présence chez l'être humain de près de $90 \%$ des gènes des rats ${ }^{1}$. De tels résultats nous amènent à penser que la différence entre les humains et les autres espèces dépasse largement les séquences de l'ADN.

\subsection{Le modèle animal}

La découverte que la quasi-totalité des gènes du rat sont présents chez les humains a contribué au renforcement de l'utilisation du modèle animal dans la recherche sur l'espèce humaine. On peut citer ici les études menées par Lutz \& Turecki à partir d'expérience sur des rats, faisant observer que le soin maternel porté par les mères-rats sur leurs petits, influence les réponses endocriniennes et comportementales de ces derniers ${ }^{2}$. Ceux qui, au commencement de leurs vies, ont reçu de tels soins (licking and grooming) montrent à l'âge adulte, et par rapport à ceux qui ont reçu des soins maternels insuffisants, une diminution des comportements anxieux ainsi qu'une faible réaction de l'axe $\mathrm{HPS}^{3}$ dans les situations de stress.

Selon Juruena et al., l'axe HPS est l'un des axes endocriniens les plus étudiés qui soit, pour être le déterminant de la réponse de l'organisme aux stimuli externes et internes, parmi lesquels les facteurs de stress psychologiques ${ }^{4}$. «L'activité de l'axe HPS est gouverné par la sécrétion de CRH (corticotrophine) et vasopressine (AVP) par l'hypothalamus, lesquelles activent à leur tour la sécrétion de l'hormone adrénocorticotrophique (ACTH) par la glande pituitaire qui stimule finalement la sécrétion de glucocorticoïdes par le cortex surrénal $»^{5}$. Les glucocorticoïdes ont pour fonction physiologique de provoquer une « redistribution énergétique et d'augmenter la disponibilité de combustible pour différents tissus, aidant à la capacité de survie devant la perception d'une menace (de stress) » ${ }^{6}$. L'étude menée par Lutz \& Turecki relate également que les soins maternels influencent la plasticité synaptique de l'hippocampe : «comparé aux descendants ayant reçu un niveau élevé de soins maternels, ceux qui ont reçu un faible niveau de soins présentent une tendance à

\footnotetext{
${ }^{1}$ Voir RASKIN Salmo (2015). Genética e psicanálise : um encontro possível?.

${ }^{2}$ Voir LUTZ P.-E. \& TURECKI G. (2014). Dna methylation and childhood maltreatment: from DNA...

${ }^{3}$ En anglais, HPA: hypothalamic pituitary adrenal axis. En français, HPS: axe hypothalamo-hypophysosurrénalien.

${ }^{4}$ Voir JURUENA Mario et al (2004) O eixo hipotálamo-pituitária-adrenal, a função dos receptores...

${ }^{5}$ Ibidem, 190. Traduction libre de l'auteure.

${ }^{6}$ FRIES Gabriel (2014). O papel da resiliência celular, estresse e epigenética na patofisiologia..., 11. Traduction libre de l'auteure.
} 
l'augmentation de la potentialisation à long terme de l'hippocampe et à la dépression $»^{1}$, soulignent les chercheurs.

Le maternage $e^{2}$ des rats, c'est-à-dire les soins donnés aux petits après leur naissance, est l'objet d'importantes études dans le champ de l'épigénétique. «Le stress précoce est bien connu pour être la cause, à court et à long terme, de divers troubles cognitifs, émotionnels et autres performances comportementales $»^{3}$, soulignent les chercheurs chinois. La carence maternelle et la séparation maternelle sont d'autres objets d'étude aux résultats surprenants. Il semble de commun accord entre les chercheurs que les expériences vécues au début de la vie peuvent provoquer des altérations neurophysiologiques, des modifications de comportement et même des marques épigénétiques transmises plus tard aux prochaines générations. Corroborant cette idée, Armstrong affirme que «les bas niveaux de soins maternels durant la petite enfance mènent à une augmentation de la méthylation de l'ADN et à une diminution de l'acétylation des histones dans une même région promotrice qui, à son tour, augmente la réponse de l'axe HPS dans des situations ultérieures de stress ${ }^{4}$.

On peut citer comme exemple de l'influence du stress précoce les études de Qin et al., qui ont évalué les effets de la carence maternelle (MD - maternal deprivation) dans le développement neurocomportemental précoce des rats ${ }^{5}$. Les chercheurs ont retiré des petits de leurs mères deux jours après leur naissance, et évalué leur comportement réflexe pendant trois semaines. Ils ont noté alors que les rats $M D$ présentaient un faible poids corporel et un retard significatif des griffes des membres avant et des réflexes auditifs, ainsi qu'un léger retard dans la marche et le comportement-réponse en situation d'urgence. "Ces résultats suggèrent que la $M D$ (carence maternelle) a des effets nocifs au début du développement neurocomportemental des bébés-rats $»^{6}$, affirment-ils.

\footnotetext{
${ }^{1}$ LUTZ P.-E. \& TURECKI G. (2014). Dna methylation and childhood maltreatment:from DNA..., 145. Traduction libre de l'auteure.

${ }^{2}$ La manipulation des nouveau-nés : le léchage et le toilettage.

${ }^{3}$ QIN Lina, TU Wenqiang, SUN Xiumin et al. (2011). Retardation of neurobehavioral development and..., 142. Texte original : «Early-life stress is well-known to cause various short and long term disturbances in cognitive, emotional and other behavioral performances. »

${ }^{4}$ ARMSTRONG Lyle (2014). Epigenetics, 242. Texte original : « low levels of maternal care during early life led to an increase in DNA methylation and a decrease in histone acetylation in the same promoter region, which in turn increased the HPA responses to stress later in life ».

${ }^{5}$ Voir QIN Lina, TU Wenqiang, SUN Xiumin et al. (2010). Retardation of neurobehavioral development and reelin down-regulation...

${ }^{6}$ QIN Lina, TU Wenqiang, SUN Xiumin et al. (2010). Retardation of neurobehavioral development and reelin down-regulation..., 145. Texte original : "These results suggest that MD has harmful effects on the early neurobehavioral development of rat pups ».
} 
Des chercheurs grecs ont également étudié les effets de la séparation maternelle dans une recherche utilisant le modèle animal ${ }^{1}$. En accord avec Tata et ses collaborateurs, «la séparation maternelle en particulier augmente l'anxiété et les comportements dépressifs, et prédispose aux dysfonctions cognitives $»^{2}$. Dans cette étude, les nouveau-nés ont été séparés durant les six jours qui suivirent leurs naissances, et divisés en trois groupes : le premier, caractérisé par une séparation courte, de 15 minutes ; le second par une séparation longue, de 180 minutes ; et le troisième non-exposé à une séparation. Les chercheurs formèrent enfin un autre sous-groupe, à partir d'un échantillon de chacun des groupes précédents, dont les animaux ont été exposés à un épisode hypoxique-ischémique ${ }^{3}$.

Le principal objectif de cette recherche était de savoir si les expériences négatives des premiers jours de vie, et antérieures à l'épisode hypoxique-ischémique, aggraverait les dommages cérébraux fonctionnels provoqués par cet épisode. Les résultats ont signalé une déficience des mémoires de référence et d'apprentissage, ainsi que de la mémoire spatiale de l'animal. Les rats exposés à la plus longue séparation ont démontré une déficience cognitive plus importante que les autres : une plus longue période de latence dans la localisation de la plateforme et une déficience de la mémoire spatiale de référence ${ }^{4}$. Aux yeux des chercheurs, «le stress précoce des rats, vu comme résultat de la séparation d'avec leurs mères durant leurs premières semaines de vie, provoque des modifications neuroendocriniennes et comportementales qui persistent au cours de la vie adulte $»^{5}$.

\subsection{Les marques épigénétiques chez les humains}

Les recherches utilisant le modèle animal, rapportées ci-dessus, nous montrent que les expériences vécues par les rats au cours des premiers jours de leurs vies sont considérées comme un environnement susceptible d'altérer les fonctions organiques et les réponses programmées pour certains stimuli donnés. Ce qui attire notre attention est que l'environnement stressant soit mis en relation avec la présence ou l'absence de soins de la mère aux nouveau-nés. Autrement dit, ces soins maternels jouent le rôle d'un potentiel

\footnotetext{
${ }^{1}$ Voir TATA Despina et al. (2015). Effects of maternal separation on behavior and brain damage...

${ }^{2}$ Ibidem, 52. Texte original : «Specifically, maternal separation enhances anxiety and depression-like behaviors and predisposes to cognitive dysfunction. »

${ }^{3}$ Ibidem.

${ }^{4}$ Ibidem, 57. Texte original : «Moreover, animals that experienced longer maternal separation were impaired in spatial reference memory ».

${ }^{5}$ Ibidem, 52. Texte original : " early stress in rats as a result of separation from their dam during the first weeks of life causes neuroendocrine and behavioral changes that persist into adulthood. »
} 
régulateur du développement maturationnel des animaux étudiés. De tels résultats ont ouvert de nouvelles voies à l'étude des êtres humains et les chercheurs ont également entrepris de décrire les marques épigénétiques de l'homme. Selon Gonon, citant un article publié par de grands noms de la psychiatrie américaine, « les études épigénétiques commencent à révéler les bases biologiques de ce qui était connu depuis bien longtemps par les cliniciens : les expériences précoces conditionnent la santé mentale des adultes » ${ }^{1}$.

Cela dit, Gonon met en garde, lui aussi, que la correspondance des résultats observés chez des rats en situation expérimentale contrôlée ne sera pas si facile à retrouver chez des humains en conditions naturelles. Il convient de garder en mémoire que, malgré les efforts et les tentatives des chercheurs, les recherches sur les animaux ne seront jamais équivalentes à celles réalisées sur les hommes, précisément parce qu'il existe - et c'est une des thèses que nous défendons ici - toute une dimension symbolique qui nous différencie des autres espèces. Malgré tout, nous tenons à valoriser ces études qui démontrent l'interaction natureenvironnement, et plus particulièrement celles qui considèrent que les expériences vécues dans la petite enfance peuvent influencer le développement global du jeune individu.

Avant d'approfondir notre étude des recherches faites sur les humains, il est intéressant de se pencher sur un autre mouvement nature-psyché, indiquant cette fois qu'une maladie grave, en tant que représentante du corps organique, peut altérer les représentations psychiques de celui qui en souffre ${ }^{2}$. Schwering défend que le contexte d'internement hospitalier imposé par la maladie grave peut renvoyer et réactualiser le patient à des stages primitifs de sa condition psychique, comme celui de sa situation originelle de dépendance de soins maternels ${ }^{3}$. La maladie expose certaines parties du corps, et notamment des organes internes, qui n'ont pas été investis libidinalement durant la petite enfance. Le travail psychique qui se présente alors au patient consiste à réaliser une subversion libidinale ${ }^{4}$ des organes en question, ce qui, toujours en accord avec Schwering, « équivaut à un travail de symbolisation primaire $»^{5}$. Ainsi, le corps malade impose au patient la nécessité d'une

\footnotetext{
${ }^{1}$ GONON François (2011) La psychiatrie biologique : une bulle spéculative?, 60. C'est nous qui soulignons.

${ }^{2}$ Voir SCHWERING Karl-Leo (2015) Corps d'outrance : souffrance de la maladie grave à l'Hôpital.

${ }^{3}$ Voir SCHWERING Karl-Leo (2014). Symbolisation primaire et subversion libidinale dans la maladie grave.

${ }^{4}$ Concept introduit par Christophe Dejours pour aborder une activité pulsionnelle au cours de la petite enfance. Il se réfère en particulier au « processus grâce auquel le corps érotique se décolle progressivement du corps biologique ». DEJOURS Christophe (2011). Le corps, d'abord, 11.

${ }^{5}$ SCHWERING Karl-Leo (2014). Symbolisation primaire et subversion libidinale dans la maladie..., 171.
} 
réorganisation psychique, c'est-à-dire la recherche de nouvelles représentations qui réactualisent les premiers moments de la constitution psychique ${ }^{1}$; c'est là un exemple évident de l'interaction du biologique avec ce que nous appelons la psyché humaine.

Pour en revenir aux recherches en épigénétique, il convient d'indiquer qu'en ce qui concerne les études génétiques réalisées sur des êtres humains, les chercheurs se sont beaucoup intéressés à l'influence des mauvais traitements subis au cours de la petite enfance, vus comme des facteurs susceptibles de générer des altérations au sein des fonctions neurophysiologiques et endocriniennes, persistantes durant la vie d'adulte et pouvant être transmise à la prochaine génération. Soulignons également que les recherches citées ci-dessus et qui reposent sur un modèle animal ont précisément pour objet la relation des nouveau-nés avec les adultes porteurs de soins - ce qui constitue l'un des points centraux de notre intervention. Dans ces nouvelles études, sont considérés maltraitances infantiles la négligence parentale, la violence physique, sexuelle et psychologique, et l'abandon ${ }^{2}$. Lutz \& Turecki avancent que les mauvais traitements sont de puissants facteurs prédictifs du développement de futures psychopathologies. «Durant la vie adulte, [la maltraitance] est fortement associée à l'obésité, aux troubles de la personnalité, à la dépression, aux troubles mentaux liés à l'usage de substances, à l'agressivité et aux comportement violents, ainsi qu'aux comportements suicidaires $»^{3}$, soulignent les auteurs.

Parmi les recherches qui corroborent l'idée de Lutz \& Turecki on retiendra en particulier les études de Martin-Blanco et al., publiées dans la revue Journal of Psychiatric Research. Les auteurs y relatent que le stress ressenti durant la petite enfance modifie le fonctionnement de l'axe hypothalamo-pituitaire-surrénal (axe HPS). Selon l'article, « chez les humains, la méthylation de la région promotrice du gène GR (connu sous le nom de NR3C1) se montre élevée chez les enfants exposés au stress maternel durant la grossesse et chez les victimes de traumatismes durant l'enfance $»^{4}$. Le gène GR fonctionne comme un facteur de transcription régulant l'activité de l'expression génique, mais ne s'activant que dans les moments de stress, lors desquels les niveaux de glucocorticoïdes se trouvent

\footnotetext{
${ }^{1}$ Nous reviendrons sur ce sujet au prochain chapitre, en s'intéressant au concept de sujet chez Freud.

${ }^{2}$ Voir LUTZ P.-E. \& TURECKI G. (2014). Dna methylation and childhood maltreatment: from...

${ }^{3}$ Ibidem, 142. Texte original : «It is strongly associated during adulthood with obesity, personality disorders, depression, substance use disorders, aggressive and violent behaviors, as well as suicidal behaviors. »

${ }^{4}$ MARTIN-BLANCO Ana et al. (2014). Association between methylation of the glucocorticoid..., 35. Traduction libre de l'auteure.
} 
particulièrement élevés ${ }^{1}$. En outre, il est mis en évidence que cette méthylation peut désorganiser le fonctionnement même de l'axe HPS.

Sur cette même ligne, Schechter et ses collaborateurs indiquent que les femmes souffrant de troubles de stress post-traumatique liés à la violence interpersonnelle ( $I V$ PTSD: interpersonal violence - posttraumatic stress disorder), font preuve d'une grande difficulté à exercer leurs fonctions parentales avec leurs enfants en bas âge ${ }^{2}$. En outre, ces femmes présentent également une dérégulation de l'axe HPS, conséquence de la violence reçue dans leur petite enfance.

Les chercheurs ont appliqué un protocole comportemental à 45 femmes et à leurs enfants âgés de 12 à 42 mois. En plus des entretiens et de l'utilisation d'un questionnaire, l'interaction mère-enfant, avec des moments de jeu et de séparation imposée, a été observée et filmée. Les mères ont été également évaluées pendant qu'elles assistaient aux scènes de séparation de leur propre fils et d'autres enfants. Dans une analyse sanguine ultérieure, les chercheurs ont découvert d'importantes associations entre le pourcentage moyen de méthylation du gène récepteur de glucocorticoïde $\mathrm{NR} 3 \mathrm{Cl}$ et des facteurs environnementaux comme le IV-PTSD maternel ; du stress au moment de l'exercice des fonctions parentales (parenting stress) et d'activité neuronale dans les régions corticales impliquées dans la régulation émotionnelle ${ }^{3}$. Ils ont constaté également que des « mères souffrant d'IPV-PTSD avec faible méthylation du gène $N R 3 C l$ avaient une plus forte tendance à relater davantage de stress parental subjectif $»^{4}$. Selon les auteurs, il s'agirait d'une recherche pionnière quant à la mise en évidence de deux marqueurs biologiques - la méthylation du gène récepteur de glucocorticoïde $\mathrm{NR} 3 \mathrm{Cl}$ et la diminution de l'activité neuronale des régions liées à l'émotion - associés à des facteurs de difficultés, pour des mères dont on a diagnostiqué un IPV-PTSD, à exercer leurs fonctions maternelles.

Cette recherche nous semble à même de soulever un débat qui dépasse les déterminismes purement organiques, autrement dit, qui considère les marqueurs biologiques comme cause des difficultés maternelles. Il est intéressant d'élargir notre champ de vision et de prendre en compte que les relations humaines sont en constante interaction avec le corps et qu'il existe un facteur - symbolique - agissant également sur cette modulation. La

\footnotetext{
${ }^{1}$ Voir FRIES Gabriel (2014). O papel da resiliência celular, estresse e epigenética na patofisiologia... ${ }^{2}$ Voir SCHECHTER Daniel et al. (2015) Methylation of NR3C1 is related to maternal PTSD, parenting stress...

${ }^{3}$ Ibidem.

${ }^{4}$ Ibidem, 08. Texte original : «IPV-PTSD mothers with lower NR3C1 methylation had a greater tendency to report more subjective parenting stress ».
} 
violence reçue pendant l'enfance par ces mères montre, d'une certaine manière, comment les relations parentales se sont constituées pour chacune d'elles de forme singulière, révélant une certaine souffrance psychique. On suppose qu'il puisse également exister, au moment où ces femmes deviennent mères, une actualisation, un retour de la représentation psychique de ce qui a été vécu pendant l'enfance, conduisant aux difficultés relatées dans la relation avec leurs enfants. Une hypothèse plausible serait que, pour ces femmes, la violence subite n'ait pas seulement causé une dérégulation de l'axe HPS, mais aussi une construction du savoir inconscient de ce qu'est être mère, influençant ainsi la relation avec leurs propres enfants. C'est pourquoi nous proposons que ce facteur subjectif soit pris en compte dans les débats touchant à la génétique médicale. De même, il nous semble nécessaire que la psychanalyse acquière un minimum de connaissances sur le fonctionnement neurophysiologique du corps humain. Il convient de laisser de côté nos $a$ priori et de regarder ensemble corps et psyché, l'un répondant à l'autre, modifiant et se trouvant modifié, en modulation constante.

\section{L'autisme et l'épigénétique}

Nous avons choisi l'autisme comme point de rencontre de nos différents débats, premièrement parce qu'il intègre le cadre symptomatique du syndrome de l'X fragile et deuxièmement parce qu'il sert de modèle pour penser les concepts de sujet et de transfert en clinique psychanalytique. Suite à une augmentation significative des cas diagnostiqués ${ }^{1}$, l'autisme est actuellement une psychopathologie de première ligne, qui se trouve également au cœur des recherches en épigénétique. Il s'agit d'une pathologie qui suscite l'intérêt de divers champs de connaissances, lesquels concentrent leurs efforts sur des productions scientifiques et sur des recherches touchant à son étiologie et à son traitement.

Il nous semble important de l'aborder ici, sachant que l'autisme apparaît comme une grande énigme pouvant être le résultat de multiples facteurs, aussi bien organiques que psychiques, ou même un produit de l'interaction de ces deux derniers. Certaines recherches de la génétique médicale, par exemple, veulent localiser, dans le génome, l'étiologie de l'autisme. Comme nous l'avons indiqué au premier chapitre, le gène FMR1 altéré dans le syndrome de l'X fragile est un fort candidat au rôle de déclencheur de la psychopathologie. Néanmoins, malgré l'avancement important des techniques de recherche, on ne sait toujours

\footnotetext{
${ }^{1}$ Nous y reviendrons au prochain chapitre.
} 
pas «quelle est la taille de son composant génétique, ni quels et ni combien de gènes font partie de ce composant $»^{1}$.

La Simons Foundation Autism Research Initiative (SFARI) a créé une banque de données en ligne avec pour objectif de concentrer les recherches récentes sur des gènes déjà associés à l'autisme. En avril 2017, la banque de données comptait 859 gènes impliqués dans la pathologie ${ }^{2}$. Ces recherches mettent en évidence des altérations génétiques qui composent le trouble du spectre autiste, pouvant aussi bien être héritées que se produire comme de nouvelles mutations. Néanmoins, d'après le généticien Raskin, «les bases moléculaires, dans la plupart des cas, restent inexpliquées. Seuls environ 5\% des patients souffrant de TSA (trouble du spectre autistique) ont une anormalité chromosomique visible au caryotype $»^{3}$. Ce débat méritera d'être approfondi au prochain chapitre, dans la mesure où le thème semble d'une importance primordiale aux yeux de notre proposition d'articulation entre psychanalyse et génétique médicale.

En ce qui concerne l'épigénétique, Loke et al. ont passé en revue la littérature sur les mécanismes épigénétiques associés à l'autisme. Selon les chercheurs, les principaux marqueurs épigénétiques rencontrés sont : 1) une méthylation au sein du gène récepteur de l'ocytocine $(O X T R)$, hormone impliqué dans la régulation de l'anxiété, dans la mémoire sociale et cognitive, dans le comportement agressif et sexuel et dans le lien mère-enfant ;2) une modification au sein du gène GADI, responsable de la codification de l'enzyme qui catalyse le $G A B A$ (acide gamma-aminobutyrique) - principal neurotransmetteur inhibiteur du système nerveux central ; 3) une altération au sein de la protéine En2, impliquée dans le contrôle du modèle de formation - développement embryonnaire - durant le neurodéveloppement ; 4) une dérégulation de la protéine Reelin (RELN), glucoprotéine impliquée dans la régulation du positionnement des neurones du système nerveux et du renforcement des connexions synaptiques du cerveau adulte. Ce facteur épigénétique est vu comme un fort candidat dans l'échelle d'évaluation du SFARI database ; 5) une mutation du gène $M E C P 2$, responsable du Syndrome de Rett et considéré comme gène responsable de l'autisme syndromique. Des niveaux anormaux de transcription du gène dans le cortex frontal de patients souffrant d'ASD (Autism Spectrum Disorder) ont été découverts ${ }^{4}$.

\footnotetext{
1 RASKIN Salmo (2015). Genética e psicanálise : um encontro possível?, 154. Traduction libre de l'auteure.

${ }^{2}$ Disponible sur http://sfari.org

${ }^{3}$ RASKIN Salmo (2015). Genética e psicanálise : um encontro possível?, 155. Traduction libre de l'auteure.

${ }^{4}$ Voir LOKE Yuk et al. (2015). The role of epigenetic change in autism spectrum disorders.
} 
La littérature passée en revue par Loke et ses collaborateurs expose les possibles altérations neurophysiologiques provoquées par l'environnement et rencontrées chez les patients autistes. Toutefois, l'étude ne nous dit pas quel environnement a pu jouer ce rôle de modulateur de telles altérations. Kubota \& Mochizuki montrent l'influence de facteurs hormonaux et nutritionnels dans l'incidence de l'autisme. En outre, «les expériences inadéquates imposées aux enfants, comme l'abus et la malnutrition, par des parents souffrant de problèmes psychiatriques, peuvent être associées aux ASD » ${ }^{1}$. Les auteurs associent également le stress mental précoce à des altérations dans l'expression du gène, mais en faisant alors référence à des recherches effectuées sur des rats.

Selon LaSalle, le déclenchement de l'autisme implique également des facteurs de risque maternel. La chercheuse estime que «l'âge avancé de la mère, l'obésité maternelle, les dernières positions dans l'ordre de naissance et le court intervalle de temps entre deux grossesses $»^{2}$, ajoutés aux facteurs génétiques, sont impliqués dans l'origine de l'autisme. Dans cette même direction, Schaevitz \& Swenney soutiennent que les facteurs nutritionnels sont un fort candidat environnemental au déclenchement du syndrome. Selon les auteurs, « de nombreuses vitamines et acides aminés essentiels sont altérés chez les mères comme chez les enfants affectés par l'autisme $»^{3}$. De plus, ils suggèrent que l'une des formes de prévention de l'autisme puisse passer par une supplémentation de vitamines chez la mère avant la conception ${ }^{4}$.

Dans cette même direction, Varadinova \& Boyadjeva ont réexaminé la littérature dans l'intention d'associer l'autisme et le FASD (Fetal Alcohol Spectrum Disorder). Selon les chercheurs, « les $A S D$, comme les $F A D$, présentent des traits communs en ce qui concerne les difficultés comportementales d'interaction sociale et les faiblesses de communication $»^{5}$. Les auteurs ont soulevé l'hypothèse que l'exposition de l'enfant à l'alcool dans

\footnotetext{
1 KUBOTA Takeo \& MOCHIZUKI Kazuki (2016) Epigenetic Effect of Environmental Factors on Autism Spectrum Disorders. Texte original : « inappropriate child rearing, such as child abuse and malnutrition by parents with psychiatric problems, can be associated with ASDs ».

${ }^{2}$ LaSALLE Janine (2013). Epigenomic strategies at the interface of genetic and environmental risk factors for autism, 397. Texte original : « advanced maternal age, maternal obesity, later birth order and shorter pregnancy spacing interval. »

${ }^{3}$ SCHAEVITZ Laura \& SWEENEY Joanne (2012). Gene-Environment Interactions and Epigenetic Pathways in Autism: The importance of ... 324. Texte original : «Several of the essential vitamins and amino acids, which play critical roles in $\mathrm{C} 1$ metabolism, are altered both in the mothers and the children affected by ASDs ». ${ }^{4}$ Ibidem.

5 VARADINOVA Miroslava \& BOYADJIEVA Nadka (2015). Epigenetic mechanisms: A possible link between autism spectrum disorders and fetal alcohol spectrum, 77. Texte original : «ASDs as well as FASDs are characterized by common traits in regard to social inter-action difficulties and behavioral and communication weaknesses. »
} 
l'environnement intra-utérin puisse provoquer des modifications épigénétiques, comme celles qui seraient impliquées dans le diagnostic de l'autisme : «il se peut que l'exposition prénatale à l'alcool augmente le risque d'ASD, en cela qu'elle cause des modifications épigénétiques pendant le neurodéveloppement $»^{1}$, indiquent-ils.

Il est important de noter que cette psychopathologie est vue exclusivement ici comme un trouble du neurodéveloppement, causé par un mauvais fonctionnement cérébral. En particulier, le fait que l'environnement humain ne soit pas pris en considération dans ces études sur l'autisme attire notre attention. Les recherches consultées ne s'intéressent qu'à l'environnement physique - qu'il s'agisse de malnutrition, d'alcool ou de facteurs hormonaux - pour avancer que l'autisme est le résultat de l'interaction entre gènes et environnement. Pour quelles raisons des recherches établissant un si fort argument se refusent-elles à considérer la relation de l'enfant avec ses semblables et avec ses parents, comme un élément tout aussi capable de produire des altérations épigénétiques? C'est le débat que nous désirons fomenter ici ; et l'articulation que nous proposons a pour objectif d'élargir, au-delà du diagnostic, le regard porté sur l'enfant.

\subsection{L'environnement et la psychanalyse}

Il nous semble pertinent d'amplifier le concept d'environnement, apporté par la psychanalyse, afin d'établir un dialogue avec la génétique médicale. Nous avons choisi deux célèbres théoriciens qui ont beaucoup contribué à la connaissance de l'environnement de l'enfant par la psychanalyse, l'un dans le champ clinique et l'autre dans le champ pédopsychiatrique. Il faut souligner que nous n'y avons pas l'intention de les comparer ou de les mettre sur un même plan équivalent : il s'agit d'une brève référence afin d'indiquer la place primordiale de ce qui nous pouvons appeler environnement pour les tous petits.

On peut se référer à ce sujet aux contributions de Winnicott, qui a remarqué l'importance d'un tel concept pour le développement de l'enfant. Pour Winnicott, la notion d'environnement peut se traduire par la fonction maternelle. L'auteur considère qu'une mère est suffisamment bonne quand elle parvient à répondre aux besoins de son bébé « et de le faire d'une façon si adaptée que celui-ci est en mesure de ressentir une brève

\footnotetext{
${ }^{1}$ VARADINOVA Miroslava \& BOYADJIEVA Nadka (2015). Epigenetic mechanisms: A possible link between autism spectrum disorders and fetal alcohol spectrum, 77. Texte original : « It is possible that prenatal alcohol exposure increases the risk of ASDs by causing epigenetic modifications during neurodevelopment ».
} 
expérience d'omnipotence au moment où il surgit de la matrice que constitue la relation mère-nourrisson ${ }^{1}$. Il ne s'agit donc pas seulement d'offrir des soins basiques mais bien d'être capable de «se mettre à la place de l'enfant et de savoir ce dont il a besoin quant à son corps en général et donc quant à sa personne $»^{2}$; en particulier, il s'agit de lui donner un environnement capable de lui garantir le holding, le handling et l'object-presenting ${ }^{3}$.

C'est la mère en tant qu'environnement qui rendra possible, selon Winnicott, le développement émotionnel du bébé, en le protégeant des angoisses inimaginables ${ }^{4}$ auxquelles il se trouve confronté à tout moment. Le mouvement réalisé par la mère suffisamment bonne, accueillant et répondant au bébé dans les moments d'angoisse mais étant également capable de prendre ses distances, permet au bébé d'expérimenter ce que Winnicott appelle une continuité de l'existence. Si le bébé ne reçoit pas ces soins maternels ou si ces derniers sont insuffisants, son développement affectif, ainsi que la maturation $d u$ moi, en deviennent compromis, au risque de générer de graves conséquences: «schizophrénie infantile ou autisme; schizophrénie latente; défense du faux self; personnalité schizoïde $»^{5}$. «Si personne ne se trouve là pour faire fonction de mère, le développement de l'enfant s'en trouve infiniment compliqué $»^{6}$, renforce Winnicott au sujet du rôle fondateur et essentiel de l'environnement dans la relation à l'enfant.

Au champ pédopsychiatrique, nous citons les contributions de René Spitz, qui a alerté très tôt sur les effets de la privation maternelle chez les bébés, relatés dans son ouvrage La première année de la vie ${ }^{7}$. Spitz a réalisé une recherche sur des bébés au sein de deux institutions différentes, selon une méthode longitudinale, avec observations exhaustives des enfants. Au sein de la première institution, 123 bébés ont été observés, privés de leurs mères durant une période ininterrompue de trois mois, composant ainsi ce que Spitz conçoit comme une privation affective partielle. Cependant les observations se sont étendues sur une période de douze à dix-huit mois. On a constaté qu'un total de dix-neuf enfants ont développé clairement un syndrome appelé dépression anaclitique et qui se définit par le comportement introspectif du bébé : celui-ci, en plus de souffrir d'une perte de poids, de

\footnotetext{
${ }^{1}$ WINNICOTT Donald (1965). Processus de maturation chez l'enfant : Développement..., 10.

2 Ibidem, 11.

${ }^{3}$ Ibidem, 14. Holding : la manière dont l'enfant est porté ; Handling : la manière dont il est traité, manipulé ; Object-presenting : le mode de présentation de l'objet.

${ }^{4}$ Winnicott dénote quatre sortes d'angoisse : 1) Se morceler ; 2) Ne pas cesser de tomber ; 3) Ne pas avoir de relation avec son corps ; et 4) Ne pas avoir d'orientation.

${ }^{5}$ Ibidem, 12-13.

${ }^{6}$ WINNICOTT Donald (1971). Jeu et réalité, 204.

${ }^{7}$ Voir SPITZ René (1965). De la naissance à la parole : La première année de vie.
} 
rhumes successifs et d'insomnie, refuse l'approximation d'un adulte et ne démontre aucun intérêt envers ce qui l'entoure. Cela dit, l'auteur souligne qu'aussitôt retrouvés les soins de la mère ou d'une remplaçante, les symptômes s'atténuent peu à peu et l'enfant reprend le cours de son développement.

Dans la seconde institution, les 91 enfants observés ont été allaités par leurs mères jusqu'à leur troisième mois, mais ont fait l'expérience, après cette période, de ce que Spitz appelle privation affective totale. L'auteur a observé qu'auprès de leurs mères, le développement des bébés suivait son cours normalement. Au moment de la séparation, ils se trouvaient alors pris en charge par une infirmière pouvant avoir jusqu'à douze enfants sous sa responsabilité. Les soins basiques comme l'alimentation, l'hygiène et l'attention médicale, restaient donc garantis.

Or, il a été constaté que les bébés développaient rapidement des symptômes de dépression anaclitique et qu'avec le temps, les enfants devenaient passifs et inertes dans leurs lits ; sans même parvenir à se mettre sur le ventre, ils devenaient totalement passifs. À l'âge de quatre ans, ces enfants ne s'asseyaient pas, ne parlaient pas, ne marchaient pas. Le quotient de développement avait décliné progressivement, atteignant finalement un niveau considéré $d^{\prime}$ ' «idiotie » et il se vérifiait également un indice de mortalité significatif. Ces résultats nous permettent de soulever la question suivante : si des examens de caractère organique étaient réalisés sur ces bébés, rencontrerait-on des altérations neurophysiologiques, voire des marques épigénétiques, témoignant des marques corporelles provoquées par l'absence ou privation de la fonction maternelle ?

Nous nous intéressons également au constat fait par l'auteur au sujet du retour de la présence de la mère ou d'un remplacement de cette fonction - au-delà des soins basiques qui s'avère provocateur d'une atténuation des symptômes présentés par l'enfant. Un tel constat démontre l'effet modulateur que la présence de l'autre - qu'il s'agisse des parents ou de qui incarne la fonction maternelle - dans la relation avec le bébé, exerce sur ce dernier et sur son corps. Au prochain chapitre, nous aborderons la définition de cette fonction, développant le concept de l'Autre tel qu'il est défini par Lacan et son implication dans la constitution du sujet.

Nous croyons à l'idée que les pratiques psychothérapiques peuvent également incarner une fonction de modulation, rendant possible l'atténuation des symptômes présentés par l'enfant en clinique. La psychothérapie serait ainsi vue comme un environnement configuré par la relation analyste-patient, qui repose sur le transfert. De 
manière surprenante, les chercheurs du domaine médical commencent à relever de possibles marques épigénétiques fournies par l'environnement psychothérapique.

\subsection{La psychothérapie comme environnement}

Penser la psychothérapie comme environnement capable de modifier les symptômes présentés par le sujet est l'un des principaux piliers de la psychanalyse depuis ses débuts. L'environnement psychothérapique de la psychanalyse se constitue à partir du moment où le patient adresse la parole à l'analyste, une parole soutenue par le transfert. Nous reviendrons au prochain chapitre sur ces concepts que nous avons choisi comme fondamentaux pour penser une articulation possible avec la génétique médicale. Il est intéressant de remarquer ici que la psychanalyse défend que la relation établie au sein de l'environnement psychanalytique est capable de modifier, transformer un symptôme qui causerait une souffrance chez le patient. Parmi ces symptômes, on inclut également des affections organiques pouvant surgir en réponse à une représentation psychique qui ne peut pas être adressée par le biais de la parole, mais qui n'en est pas moins porteuse d'un sens et d'un dire.

Selon Ziegler et al., seules quatre études, jusqu'à aujourd'hui, ont enquêté sur la dynamique des mécanismes épigénétiques liés aux pratiques psychothérapeutiques ${ }^{1}$. Ces recherches représentent pour nous un champ fertile à travers lequel nous tâcherons d'approcher la psychanalyse de la génétique médicale. Bien que les psychothérapies auxquelles ces études se réfèrent adoptent un abordage cognitivo-comportemental, nous reconnaissons qu'elles ouvrent un espace de débat sur les effets de divers autres abordages théoriques, parmi lesquels la psychothérapie psychanalytique. De fait, en ce qui concerne la psychanalyse, les thérapies cognitivo-comportementales présentent des affinités onto et épistémologiques privilégiées avec certains discours médicaux. Notre intérêt dépasse le simple fait de mettre la psychanalyse à l'épreuve de la science : il se révèle dans la tentative d'ancrer l'espace de la psychanalyse aux côtés d'autres disciplines qui traitent de l'enfance, que ce soit au niveau du diagnostic, de la recherche ou du traitement.

\footnotetext{
${ }^{1}$ Voir ZIEGLER Christiane et al. (2016). MAOA gene hypomethylation in panic disorder - reversibility of an epigenetic risk pattern by psychotherapy.
} 
La première étude que l'on trouve dans la littérature abordant l'épigénétique et la psychothérapie a été menée par Perroud et ses collaborateurs. Les chercheurs ont effectué un test sur 115 patients diagnostiqués d'un Trouble de la Personnalité Borderline (TPB) et sur un groupe témoin de 52 individus. L'objectif était de comparer la méthylation de l'ADN de la protéine BNDF (Brain-Derived Neurotrophic Factor) - protéine impliquée dans le neurodéveloppement - chez les sujet TPB et témoins. S'appuyant sur de récentes études qui ont démontré l'implication de cette protéine dans le trouble borderline, les auteurs ont supposé que l'altération du niveau de la BNDF pourrait être la conséquence de mécanismes épigénétiques provoqués par des mauvais traitements au cours de l'enfance ${ }^{1}$. Les deux autres objectifs de la recherche étaient, d'une part, d'observer si une haute méthylation BNDF chez les patients TPB était liée aux mauvais traitements infantiles et, d'autre part, d'évaluer si les processus épigénétiques pourraient être modifiés par le biais d'une psychothérapie spécifique (I-DBT : Intensive Dialectical Behavior Therapy ${ }^{2}$ ) chez les patients TPB.

Un premier échantillon de l'ADN des participants a été collecté une semaine avant le début de la psychothérapie et un second lors de la dernière séance. Les résultats montrent une élévation significative de la méthylation de la protéine BNDF des patients TPB par rapport au groupe témoin. Après les quatre semaines de psychothérapie, les individus évalués ont présenté un changement au niveau de la méthylation dans les sites CpG de l'ADN, sachant que ceux qui ont répondu le mieux au traitement ont retrouvé les niveaux de méthylation du groupe témoin. Selon la conclusion des chercheurs, « les résultats mettent en évidence que les changements de méthylation dans les sites $\mathrm{CpG}$ correspondent aux réponses au traitement, et ce, indépendamment de la méthode utilisée pour traiter les patients $»^{3}$. Ils remarquent toutefois que la durée du traitement a été relativement courte et qu'un traitement plus long rendrait possible l'obtention de résultats plus concrets.

Dans cette même direction, Yehuda et al. ont réalisé une étude pilote sur d'anciens combattants de guerre diagnostiqués de trouble de stress post-traumatique (en anglais : PostTraumatic Stress Disorder, PTSD). Leur objectif était alors d'examiner la méthylation des gènes $G R$ (NR3C1) et FKPB5 et de mesures neuroendocriniennes associées, cortisol et

\footnotetext{
${ }^{1}$ Voir PERROUD Nader et al. (2013). Response to psychotherapy in borderline personality disorder ... ${ }^{2}$ I-DBT consiste en des thérapies quotidiennes individuelles et de groupe, dont l'objectif est de diminuer des comportements cibles préalablement sélectionnés.

${ }^{3}$ PERROUD Nader et al. (2013). Response to psychotherapy in borderline personality disorder ..., 04. Texte original : "Our results underscore the fact that methylation changes in CpGs are associated with treatment response independently of the method used to treat patients »C'est nous qui soulignons.
} 
NPY, avant et après une exposition prolongée à la psychothérapie. Les auteurs remarquent que certains cas ont montré de hauts niveaux de méthylation du gène GR, une faible expression de celui-ci dans l'hippocampe, une augmentation de l'activité de l'axe HPS en réponse au stress et une méthylation du gène $F K B P 5:$ des modifications associées aux adversités vécues au cours de l'enfance.

Comme nous l'avons vu précédemment, le gène $G R$ ne se montre actif que dans des situations vécues comme stressantes par l'individu et lors desquelles l'axe HPS libère les glucocorticoïdes en grandes quantités. De son côté, le gène FKPB5 agirait sur le $G R$, atténuant l'activité de ce dernier. Mises côte-à-côte, « ces découvertes suggèrent que les adversités vécues pendant l'enfance influencent l'état épigénétique et l'activité de transcription des gènes qui régulent la réponse au stress de l'axe HPS $»^{1}$. Pour les chercheurs, la réactivité au stress est impliquée dans le risque de divers troubles affectifs ainsi nommés et classifiés dans le DSM IV et $V$ - comme le PTSD. De faibles niveaux de glucocorticoïdes et un certain renforcement de la sensibilité du gène $G R$ ont été associés à cette psychopathologie, renforçant la thèse de la présence de mécanismes épigénétiques dans les dits troubles affectifs.

Seize anciens combattants de guerre - quatorze hommes et deux femmes - ont donc été évalués et, après douze semaines de psychothérapie (exposition prolongée) et trois mois d'accompagnement postérieur, on a constaté, en plus d'une diminution des symptômes de stress post-traumatique, une variation de l'expression du gène FKBP5. Selon les auteurs, les sujets qui se sont adaptés au traitement $(n=8)$ ont présenté, en plus des améliorations symptomatiques, une diminution de la méthylation du gène. En revanche, ceux qui n'ont pas obtenu les mêmes résultats par rapport au traitement $(n=8)$ ont présenté, au cours de la même période, une augmentation de la méthylation. Aucune variation significative n’a été rencontrée dans la méthylation du gène $G R$.

L'abordage psychothérapique auquel les participants ont été soumis dans le cadre de la recherche n'est pas détaillé dans l'étude, mais les chercheurs relatent la réalisation d'une « évaluation psychologique globale » menée par un psychologue clinicien et l'utilisation, pour le diagnostic et l'évaluation psychologique, des outils suivants : SCID - Structured Clinical Interview for DSM-IV; CAPS - Clinician Administered PTSD Scale; PSS-SR -

\footnotetext{
1 YEHUDA Rachel et al. (2013). Epigenetic biomarkers as predictors and correlates of symptom improvement..., 02. Texte original : «Taken together, these findings suggest that childhood adversity influences the epigenetic state and transcriptional activity of genes that regulate HPA-axis responses to stress. »
} 
PTSD Symptom Scale - Self-Report Version; CTQ - Childhood Trauma Questionnaire et, enfin, le DRRI - Deployment Risk and Resiliency Inventory.

Selon les auteurs, l'étude suggère que «la psychothérapie menant à des changements symptomatiques substantiels constitue une forme de 'régulation environnementale' qui peut altérer l'état épigénétique $»^{1}$. Venue de chercheurs s'appuyant largement sur l'aspect techniciste exigé par la science, cette affirmation a pour nous une grande valeur, dans la mesure où elle corrobore notre proposition d'inclusion de la pratique psychanalytique dans les discours sur les soins aux enfants atteints de problèmes organiques, et en particulier de syndromes génétiques.

Les troubles de l'anxiété ont été également l'objet de recherches associant des mécanismes épigénétiques avec la psychothérapie. L'étude menée par Roberts et ses collaborateurs $^{2}$ a évalué des mécanismes épigénétiques du gène SERT (serotonin transporter), qui est communément associé à diverses sortes d'expériences négatives de la vie. Ce gène est chargé de transporter le neurotransmetteur sérotonine jusqu'à l'activité synaptique. La sérotonine, quant à elle, est une importante monoamine aux multiples fonctions dans l'organisme, comme celle de la régulation de l'appétit ou du sommeil, et elle est impliquée dans les réactions d'anxiété, de peur et de perception de la douleur.

Cette recherche s'est effectuée sur un échantillon de 116 enfants diagnostiqués de trouble d'anxiété - selon l'échelle ADIS-IV-C-P : Anxiety Disorders Interview Schedule for DSM-IV, Child and Parents Versions - qui ont été évalués avant et après la soumission à deux semaines de psychothérapie cognitivo-comportementale ${ }^{3}$ et accompagnés pendant six mois après la fin du traitement. On a noté une altération au niveau de la méthylation de l'ADN du gène SERT correspondant à la réponse des participants au traitement. Ce critère de réponse au traitement a été défini au moment de l'accompagnement ultérieur (follow-up), une fois que l'enfant eut cessé de présenter le comportement original d'anxiété. Les résultats obtenus ont indiqué une augmentation du pourcentage de méthylation de l'ADN chez les répondants au traitement, tandis que les non-répondants ont présenté une diminution de ce

\footnotetext{
1 YEHUDA Rachel et al. (2013). Epigenetic biomarkers as predictors and correlates of symptom improvement..., 12. Texte original : «the data suggest that psychotherapy resulting in substantial symptom change constitutes a form of 'environmental regulation' that may alter epigenetic state »C'est nous qui soulignons.

${ }^{2}$ Voir ROBERTS S. et al. (2014). Serotonin transporter methylation and response to cognitive ...

${ }^{3}$ Application d'un manuel basé sur la Thérapie Cognitivo-Comportementale pour le diagnostic primaire de trouble de l'anxiété.
} 
pourcentage. «Ces découvertes suggèrent que l'association entre la modification de méthylation de l'ADN et la réponse au traitement est plus forte chez ceux qui répondent de manière générale que chez ceux qui répondent en relation à un trouble en particulier ${ }^{1}$, en concluent les auteurs.

La plus récente recherche à avoir associé traitement psychiatrique, épigénétique et psychothérapie a été celle de Ziegler et al. Les chercheurs, dans une première étude, ont découvert des altérations au niveau de la méthylation du gène MAOA (monoamine oxydase) chez des patients diagnostiqués de trouble panique. Selon les auteurs, la MAOA est une enzyme clé de la dégradation des amines biogéniques comme la sérotonine et la dopamine, et elle est considérée comme l'un des principaux candidats aux facteurs de risques du trouble panique $^{2}$. Dans une étude ultérieure, Ziegler et ses collaborateurs ont enquêté sur les mécanismes épigénétiques du gène MAOA, lors d'une exposition des patients à une psychothérapie cognitivo-comportementale (CBT: Cognitive Behavioral Therapy). On a évalué 56 femmes, réparties en deux groupes: un premier comptant 28 femmes diagnostiquées de trouble panique et un second, témoin, composé de 28 femmes saines. Le critère d'inclusion de patientes de sexe féminin uniquement n'a été défini qu'en raison de la localisation du gène $M A O A$ dans le chromosome $\mathrm{X}^{3}$.

Les patientes du premier groupe ont été soumises à six semaines de psychothérapie standard pour un trouble panique ${ }^{4}$, soit six séances pour chaque patiente, d'une durée de 90 minutes pour les trois premières, et de 100 à 240 minutes pour les trois dernières. Le traitement incluait également des « devoirs à la maison intensive, adaptée aux peurs particulières de l'individu face à certaines situations $»^{5}$. Les chercheurs ont évalué avant et après la psychothérapie la quantité d'attaques paniques par semaine, autant pour renseigner le degré de sévérité de la maladie que pour observer la réponse au traitement. Une diminution des épisodes d'attaques paniques a été observée chez 11 patientes, considérées répondantes, tandis que les 17 autres ont persisté avec les mêmes quantités d'épisodes et

\footnotetext{
${ }^{1}$ ROBERTS S. et al. (2014). Serotonin transporter methylation and response to ..., 04. Texte original : «These findings suggest that the association between DNA methylation change and treatment response is strongest for those who are more general responders, rather than those whose response is disorder specific. » ${ }^{2}$ Voir ZIEGLER Christiane et al. (2016). MAOA gene hypomethylation in panic disorder - reversibility of an epigenetic risk pattern by psychotherapy.

${ }^{3}$ Ibidem, 06.

${ }^{4}$ Selon la méthode définie par l' Exposure-based CBT manual - MAC: mechanisms of action for CBT within the BMBF network 'Improving the Treatment of Panic Disorder'.

${ }^{5}$ ZIEGLER Christiane et al. (2016). MAOA gene hypomethylation in panic disorder - reversibility of an epigenetic risk pattern by psychotherapy, 2. Texte original : «intensive homework adapted to the individual's particular fears of situations ».
} 
ont été considérées non-répondantes. L'étude a été répétée sur un échantillon indépendant de 20 femmes soumises au même protocole de traitement. La proportion des répondantes au traitement a été alors de $50 \%$.

On a analysé des échantillons ADN des trois groupes, avant et immédiatement après l'intervention thérapeutique, et les résultats « ont montré une dynamique différenciée de la méthylation du gène $M A O A$ pendant le traitement ${ }^{1}$. En comparaison au groupe témoin, les répondantes ont présenté une augmentation significative de la méthylation du gène en question, tandis que les non-répondantes ont présenté une réduction encore plus grande de la méthylation du $M A O A^{2}$. Il est important de rappeler que plus grande est la méthylation du gène, plus faible sera son expression et vice-versa. De tels résultats ont amené les chercheurs à conclure qu'en plus de l'altération de la méthylation du gène $M A O A$ chez les patients diagnostiqués de trouble panique, il apparaît que le mécanisme épigénétique peut être inversé par la psychothérapie, ce qui laisse envisager l'hypothèse « que le succès de la psychothérapie (CBT) rétablit les niveaux fonctionnels des monoamines par le biais d'une augmentation de la méthylation du MAOA et donc d'une diminution conséquente de l'expression du $M A O A »^{3}$. Autrement dit, les résultats suggèrent que la psychothérapie, en tant qu'environnement, a été capable d'inverser des mécanismes épigénétiques également provoqués par une influence environnementale.

L'un des avantages de l'utilisation de la méthode psychothérapeutique, selon Yehuda et al., est la possibilité de provoquer des changements symptomatiques sans avoir recours à des médicaments qui pourraient, de leur côté, interférer sur la structure biologique étudiée. Nous ne nous attarderons pas sur le débat autour d'une conduite thérapeutique suivant l'application d'un manuel standard pour la psychopathologie en question. Mais l'idée que les scientifiques commencent à accorder un espace à la recherche sur les effets d'une pratique psychothérapique mérite notre attention. Si de telles études sont encore rares, elles donnent déjà d'importants résultats. Cette thèse pourrait bien être le premier pas d'une recherche future et conjointe de la psychanalyse et de la génétique médicale, avec l'ambition de mettre également en évidence les effets corporels provoqués par la psychothérapie psychanalytique.

\footnotetext{
${ }^{1}$ ZIEGLER Christiane et al. (2016). MAOA gene hypomethylation in panic disorder - reversibility of an epigenetic risk pattern by psychotherapy, 06.

${ }^{2}$ Ibidem.

3 Ibidem, 06. Texte original : «it could be hypothesized that successful CBT reinstates functional monoamine levels by increasing $M A O A$ methylation with subsequently decreased MAOA expression. »
} 


\subsection{Conclusion}

Dans ce chapitre, nous avons abordé le thème de l'épigénétique et rapporté les recherches au travers desquelles nous pensons pouvoir articuler la psychanalyse et la génétique. Pour réaliser une telle articulation, l'acquisition de certaines connaissances, même généralisées, sur les études et concepts d'un domaine qui n'est pas le nôtre, nous semble de première importance. Faire preuve d'un intérêt à connaître le champ de l'autre autre savoir - est en effet un point essentiel, que ce soit pour critiquer ou pour, comme dans notre cas, faire l'essai d'un rapprochement. De même, et sans la moindre prétention de notre part à ce sujet, on ne pourrait nier l'idéal qui serait atteint si la médecine génétique s'intéressait également aux contributions psychanalytiques. Mais nous nous contenterons pour l'instant de montrer au travers des seules recherches en épigénétique que la psychothérapie - et pourquoi pas la psychanalyse - produit des effets objectifs ${ }^{1}$ commençant à être prouvés de manière empirique.

C'est bien ce que suggère la recherche de Yehuda et $a l$. citée plus haut, en concluant que : «la psychothérapie menant à des changements symptomatiques substantiels constitue une forme de 'régulation environnementale' pouvant altérer l'état épigénétique $»^{2}$. Suivant le chemin tracé par ces chercheurs, nous pensons comme Ansermet et Giacobino que «le passage du génomique à l'épigénétique ne permettrait-il pas de redonner une place aux prises en charge cliniques, psychothérapiques et psychanalytiques $»^{3}$ quant à la recherche et au traitement des patients porteurs de syndromes. Penser le sujet comme non déterminé, ni génétiquement ni par l'environnement, mais comme singulier et unique, nous semble être une brèche élective à travers laquelle nous aimerons élargir notre thèse. C'est sur ce sujet même et sur sa constitution, un sujet sur lequel s'applique la pratique psychanalytique, que nous développerons notre prochain chapitre, en cherchant à établir une articulation avec la génétique médicale autour du traitement aux enfants syndromiques. C'est dans ce sens que nous avons choisi de développer les concepts de sujet et de transfert qui nous semblent centraux pour tisser la clinique de la psychanalyse aux études en génétique. Plus tard, dans notre cinquième chapitre, nous allons aborder trois cas cliniques illustrant notre approche

\footnotetext{
${ }^{1}$ Voir VARELA Andrea, MADEIRA Manoel et MORETTO Lívia. (2015). Síndrome do cromossomo X frágil: uma possível articulação entre psicanalise e genética médica?

2 YEHUDA Rachel et al. (2013). Epigenetic biomarkers as predictors and correlates of symptom improvement..., 12. Texte original : « the data suggest that psychotherapy resulting in substantial symptom change constitutes a form of 'environmental regulation' that may alter epigenetic state »C'est nous qui soulignons.

${ }^{3}$ ANSERMET François \& GIACOBINO Ariane (2012). Autisme : À chacun son génome, 64.
} 
de la clinique d'enfants porteurs - ou supposés porteurs - de syndromes génétiques. Ces études de cas nous aideront à penser les spécificités d'une telle clinique, mais aussi les discours et leurs effets sur le symptôme et, en particulier, sur la place occupée par l'enfant au sein du fantasme parental. 


\section{Chapitre IV}

\section{Le dispositif clinique de la psychanalyse : quelques considérations sur les concepts de sujet et de transfert}

\subsection{Ouverture}

Nous avons montré, dans le deuxième chapitre, qu'un diagnostic couramment associé au syndrome de l'X fragile est celui de l'autisme, et que notre approche se spécifie pour remettre en question cette correspondance. Maintes recherches sur l'X fragile attribuent une origine uniquement biologique au dit trouble du spectre autistique. Ces recherches suivent la logique organiciste du DSM-IV et $V^{1}$, indiquant que les troubles mentaux ont toujours une origine organique. Malgré cette correspondance d'exclusivité biologique, la clinique de l'autisme, à notre avis, peut bien illustrer une sorte de porte d'entrée pour l'articulation des études de la génétique médicale avec celles de la psychanalyse. C'est dans ce sens que nous y interrogerons l'approche psychanalytique en ce qui concerne l'autisme. La discussion autour de l'autisme étant au cœur des recherches sur le syndrome de l'X fragile, nous allons d'abord réfléchir sur la clinique psychanalytique auprès des enfants autistes, pour ensuite étudier deux concepts qui nous supposons essentiels l'articulation y prétendue, à savoir les notions de sujet et de transfert.

Nous partons ainsi de l'autisme, en établissant un bref commentaire, pour penser la clinique psychanalytique auprès des enfants, au sens large, ayant comme horizon les articulations possibles entre ces deux champs de savoir : celui de la psychanalyse et celui de la génétique médicale. Si l'on fait souvent correspondre le syndrome de l'X fragile à l'autisme, nous avons montré comment des recherches médicales attribuent au syndrome des psychopathologies multiples. Nous assistons actuellement à un débat très intense autour de l'autisme, tant par rapport à l'étiologie qu'en ce qui concerne son traitement. L'étiologie de l'autisme est l'objet de conflits entre différents domaines, notamment ceux qui sont relevés dans notre recherche. Selon Bernard Golse ${ }^{2}$, en France, un enfant sur cent est

\footnotetext{
${ }^{1}$ Voir AMERICAN PSYCHIATRIC ASSOCIATION (1995 [1996]). DSM-V :Manuel diagnostique...

${ }^{2}$ Voir GOLSE Bernard (2013) Mon combat pour l'autisme.
} 
diagnostiqué autiste. À partir de ces données, la psychanalyste Catherine Vanier remarque ce qui pouvait suggérer l'existence d'une épidémie autiste ${ }^{1}$.

Néanmoins, ce phénomène peut être expliqué, toujours selon Catherine Vanier, par l'imposition de ce diagnostic qui serait devenu une sorte d'étiquette que l'on attribue à des troubles divers qui auparavant n'avaient pas cette appellation, autrement dit « cette étiquette est désormais accolée à des troubles allant de l'autisme de Kanner, forme la plus grave de la maladie, à des troubles qui ne relevaient pas jusque-là de cette appellation $»^{2}$. Il n'existe pas donc une épidémie autiste, autrement dit, il n'y a pas un accroissement du nombre d'enfants affectés par cette pathologie, mais une augmentation des diagnostics attribués, en raison de l'élargissement des critères établis par rapport à l'origine de cette spécificité clinique.

Il y a donc une extension des phénomènes qui justifient le diagnostic d'autisme, bien au-delà du seuil symptomatique d'origine. Cela peut être expliqué par l'amplification du spectre autistique dû à l'évolution des manuels psychiatriques - notamment le DSM-IV et $V$. Les catégories de psychose de l'enfant, par exemple, ont disparu de ces manuels, ce qui nous amène à supposer que les enfants affectés par symptômes psychotiques ont reçu également un diagnostic d'autisme ${ }^{3}$, ce qui contribue davantage encore à l'augmentation des statistiques de cette psychopathologie.

Le diagnostic différentiel est important pour la psychanalyse, particulièrement en ce qui concerne la direction du traitement ${ }^{4}$. C'est-à-dire que les catégories nosographiques ne guident pas la pratique psychanalytique, mais il est fondamental différencier, par exemple, la structure psychotique de la structure autistique dans la direction de la cure. Le rapport du sujet à l'Autre est foncièrement différent dans les deux psychopathologies, notamment dans l'autisme où le tissage de ce rapport rencontre de solides obstacles à son établissement. Cette conception clinique a des implications tangibles en ce qui concerne la place de l'analyste dans le traitement et la condition du transfert. Nous reviendrons sur ces concepts psychanalytiques qui nous allons développer afin de mettre en place notre proposition autour du traitement des enfants syndromiques.

La clinique psychanalytique de l'autisme peut, à notre avis, apporter un regard cliniquement plus spécifique sur la symptomatologie des enfants autistes. Elle permettrait

\footnotetext{
${ }^{1}$ Voir VANIER Catherine (2014). Autisme : comment rendre les parents fous !,

${ }^{2}$ Ibidem, 23.

${ }^{3}$ Voir JERUSALINSKY, Alfredo (2011). Gotinhas e comprimidos para crianças sem história...

${ }^{4}$ Voir QUINET, Antonio (1991). As 4+1 condições da análise.
} 
d'aborder la souffrance psychique, au sens large, notamment celle des enfants, situant avant tout diagnostic la présupposition d'un sujet. Nous considérons que le traitement fondé sur la suppression ou le changement d'un comportement non accepté socialement efface les possibilités de l'émergence du sujet. Ce n'est que sur le pari de l'émergence du sujet que la clinique psychanalytique opère.

La psychanalyse a établi une coupure épistémologique avec les pratiques médicales à l'époque de son surgissement, lorsqu'elle a décalé la pratique du regard sur les hystériques vers la pratique de leur écoute ${ }^{1}$. La pratique médicale, à son tour, peut avoir tendance à privilégier une approche uniquement organique des psychopathologies de l'enfant, pouvant parfois exclure la dimension de la subjectivité psychique de celui-ci. La clinique psychanalytique accorde une place centrale à la parole du sujet, la parole traversée par les signifiants qui composent le tissu du langage à partir duquel le sujet émerge. Ainsi, les concepts de sujet et de transfert nous semblent orienter la clinique que nous voudrions mettre en relief, et c'est à travers ces deux dimensions fondamentales de la psychanalyse que nous proposons un dialogue avec la génétique médicale.

\subsection{L'autisme comme point historique de tension entre génétique médicale et psychanalyse}

\section{Autisme - un bref historique}

L'autisme a été désigné pour la première fois par le psychiatre Eugen Bleuler, dans ses échanges de travail avec Freud, en 1911. Bleuler considérait l'autisme comme une forme particulière de la schizophrénie de l'adulte $^{2}$. Pour lui «nous appelons autisme ce détachement de la réalité combiné à la prédominance relative ou absolue de la vie intérieure $»^{3}$. Selon la psychanalyste Marie-Claude Thomas, Bleuler enlève l'éros de l'autoérotisme freudien et crée le nouveau mot autisme ${ }^{4}$. Plus tard, le psychiatre autrichien Léo Kanner, dans son article Autistic Disturbances of Affective Contact, publié en 1943 aux États-Unis, popularise la psychopathologie et la décrit comme «un trouble inné de la communication et du contact affectif $»^{5}$ chez l'enfant.

\footnotetext{
${ }^{1}$ Voir MOSCHEN RICKES Simone et GLEICH Paulo (2009). Letras em oficina: a afirmação retumbante do "não".

${ }^{2}$ Voir BENTATA Hervé (2013). L'autisme aujourd'hui : Quelques vérités issues de ...

${ }^{3}$ BLEULER Eugen (1911) in : THOMAS Marie-Claude (2014) : Genèses de l'autisme : Freud, ..., 106.

${ }^{4}$ Ibidem, 77.

5 JANIN-DUC Dominique (2013). La clinique des autismes et leurs contextes..., 131.
} 
Également en 1943, Hans Asperger, qui reconnaissait Bleuler comme fondateur de «ce terme qui constitue un concept et une des créations linguistiques les plus impressionnantes dans le domaine de la nomenclature médicale » ${ }^{1}$, écrivait, en allemand, le texte Les psychopathes autistiques pendant leur enfance. Asperger définit une autre forme d'autisme de celle de son compatriote Léo Kanner, car il distinguait des enfants présentant d'importantes difficultés de communication, mais également des capacités intellectuelles de haut niveau. À propos de l'autisme, le psychiatre indique que «l'anomalie principale du psychopathe autistique est une perturbation des relations vivantes avec l'environnement, perturbation qui explique toutes les anomalies $»^{2}$. Pour lui, la personnalité de l'enfant est organisée à partir de cette limitation des relations avec l'environnement. La notion d'autisme est donc née au sein de la psychiatrie.

Marie-Claude Thomas nous fait observer que, dans l'autisme chez Bleuler, il prédomine un excès d'affectivité, alors que l'autisme de Kanner - et nous rajoutons l'autisme d'Asperger - est décrit en tant qu'un manque d'affectivité chez l'enfant ${ }^{3}$. Toujours selon Thomas, «Leo Kanner n'a pas découvert l'autisme qui aurait existé de tout temps et en tous lieux dont il suffirait de faire une description ; il a fait un geste de partage, il a construit, et non pas décrit, un 'tableau clinique', il l'a fabriqué en une entité psychopathologique $»^{4}$. L'auteur ne mentionne pas Asperger, étant donné que lui aussi aurait fabriqué une nouvelle psychopathie de l'enfance - bien que, en comparaison avec Kanner, Asperger portait plus d'attention à la création des tableaux cliniques. Le fait que Kanner ait développé et publié ses travaux aux États-Unis, où il pouvait jouir des conditions de publication plus favorables, a peut-être contribué à ce qu'il soit toujours la référence de l'origine de l'autisme. Quant à Asperger, il lui était plus difficile de faire circuler ses travaux et d'être reconnu, lui aussi, comme étant à l'origine de la notion d'autisme, vu le contexte autrichien pendant la guerre.

Malgré leur pertinence, nous ne reprendrons pas les critiques épistémologiques faites dans son ouvrage par Marie-Claude Thomas, en ce qui concerne l'entité psychopathologique qui a été créée depuis Bleuler et qui, dans un sens opposé, a été reprise par Kanner et Asperger. Ce qui nous intéresse, c'est de comprendre d'où et dans quel contexte a surgi la psychopathologie autistique et comment elle est abordée par la

\footnotetext{
${ }^{1}$ ASPERGER Hans [1944]. Les psychopathies autistiques pendant l'enfance, 51.

${ }^{2}$ Ibidem, 115 .

${ }^{3}$ THOMAS Marie-Claude (2014). Genèses de l'autisme : Freud, Bleuler, Kanner, 113.

${ }^{4}$ THOMAS Marie-Claude (2011). L'autisme et les langues, 12. C'est nous qui soulignons.
} 
psychanalyse. L'autisme n'est ici qu'un point de jonction entre les études sur l'X fragile et la clinique psychanalytique, à partir duquel nous travaillerons ensuite sur les notions qu'incident dans la clinique, à savoir le sujet et le transfert.

\section{Autisme - l'énigme de l'étiologie génétique}

Selon Catherine Vanier, jusqu'aujourd'hui, la cure de l'autisme n'est assurée par aucune spécialité ${ }^{1}$. Comme nous l'avons déjà indiqué au premier chapitre, en 2013, 1 \% de la population mondiale a été diagnostiqué comme atteint par l'autisme ${ }^{2}$, ce qui élèverait ce chiffre à une dimension épidémique. Vanier indique également qu'il n'existe pas non plus de cause de l'autisme véritablement confirmée : «nous ignorons aujourd'hui les causes de l'autisme, ignorance qui participe à rendre les parents fous. Certains y voient un désordre physiologique, une cause biologique, génétique, neurologique, une cause chimique, microbienne, sans que rien n'ait pu être prouvé $»^{3}$.

En effet, le généticien Salmo Raskin souligne que «malgré tous les arguments en faveur d'une importante contribution génétique dans l'étiologie du trouble du spectre autistique, les bases moléculaires, dans la plupart des cas, demeurent inexpliquées $»^{4}$, constat corroboré par Ansermet et Giacobino ${ }^{5}$. Parmi les recherches qui travaillent sur l'étiologie génétique de l'autisme, celle de Sebat et $a l .{ }^{6}$, publié dans la revue Science, a particulièrement attiré notre attention. Les auteurs ont étudié l'ADN de 195 patients non syndromiques, 118 sans historique familial d'autisme et 47 ayant un membre de la famille porteur. Dans le premier groupe, les chercheurs ont trouvé des modifications génétiques chez $10 \%$ des patients, et seulement chez $3 \%$ des patients du deuxième groupe. Cela indique, selon les auteurs, que les mutations génétiques non héritées (appelées « de novo »), sont plus fréquentes que celle transmises génétiquement. Ce résultat peut corroborer nos propositions sur l'importance de l'épigénétique, que nous avons travaillé dans le chapitre trois.

\footnotetext{
${ }^{1}$ Voir VANIER Catherine (2014) Autour de l'Autisme: comment rendre les parents fous!...

2 AMERICAN PSYCHIATRIC ASSOCIATION (2013). Diagnostic and Statistical Manual of Mental Disorders, 5th edition, 05. Traduction libre de l'auteure

${ }^{3}$ VANIER Catherine (2014) Autour de l'Autisme : comment rendre les parents fous! Entretien avec..., 24 (c'est nous qui mettons en relief)

${ }^{4}$ RASKIN Salmo (2015) Genética e psicanálise : um encontro possível ? 55. Traduction libre de l'auteure.

${ }^{5}$ Voir ANSERMET François \& GIACOBINO Ariane (2012) Autisme : à chacun son génome.

${ }^{6}$ Voir SEBAT Jonathan et al. (2007) Strong association of de novo copy number mutations...
} 
Citons également un article de Christian et al. qui a étudié 397 patients, soit 35 individus sans historique familial d'autisme et 362 ayant au moins un membre de la famille porteur. Les chercheurs ont trouvé 51 altérations génétiques chez 46 individus porteurs d'autisme dans lesquels sept de novo (20\%), c'est-à-dire non héritées, et 44 (12\%) chez les individus des familles affectées. Malgré l'échelle peu significative des individus sans historique familial d'autisme, l'étude de Christian et al. indique également un taux plus important d'altérations génétiques non héritées (20\%) par rapport aux possiblement héritées (12\%) dans l'étiologie de l'autisme ${ }^{1}$. Il faut encore souligner que ces altérations génétiques dans les familles marquées par un diagnostic d'autisme sont simplement indicatives, c'est-à-dire que ces altérations ne peuvent pas être rattachées fermement au diagnostic.

François Ansermet et Ariane Giacobino, l'un psychanalyste et l'autre généticienne, ont affirmé que, jusqu'à présent, il n'existe pas un gène responsable par l'autisme, c'est-àdire que les recherches rattachent la causalité de cette psychopathologie à des prédispositions génétiques complexes et multifactorielles ${ }^{2}$. Ainsi, le gène qui impliquerait la psychopathologie à lui tout seul n'a pas encore été pointé. Les auteurs indiquent que d'autres causalités organiques sont étudiées, telles l'exposition au mercure, au cadmium, au nickel, aux pesticides, les infections, le stress immunitaire ${ }^{3}$ - et dans chaque domaine de recherche, nous trouvons une étiologie différente. Comme nous avons observé au troisième chapitre, il existe à l'heure actuelle 859 gènes associés à l'autisme.

Si la médecine, fondée sur le DSM, considère l'autisme en tant que trouble du neurodéveloppement, les chercheurs se penchent sur le génome pour y trouver une cause génétique de ce disfonctionnement du cerveau. Néanmoins, toujours selon Ansermet \& Giacobino «la génétique met surtout en évidence des variations individuelles, non applicables à tous les autistes. Elle démontre qu'il existe, certes, des déterminations génétiques, mais que celles-ci sont toujours différentes, propres à chaque cas $»^{4}$. Autrement dit, il ne s'agit pas de nier toute incidence génétique dans l'autisme, mais d'indiquer que les résultats scientifiques pointent une pluralité de variations génétiques. «Plutôt que de

\footnotetext{
${ }^{1}$ Voir CHRISTIAN Susan et al. (2008) Novel submicroscopic chromosomal abnormalities detected in Autism Spectrum Disorder.

${ }^{2}$ ANSERMET François \& GIACOBINO Ariane (2012) Autisme, à chacun son génome, 70.

${ }^{3}$ Ibidem, 27.

${ }^{4}$ Ibidem, 70 .
} 
présider à la répétition du même, le déterminisme génétique rencontre la question de la production de la différence $»^{1}$, affirment les auteurs.

Finalement, au-delà de l'indétermination de la cause, nous trouvons curieusement la question de la singularité, toujours mise en avant par la psychanalyse. La médecine génétique serait peut-être elle aussi amenée à penser au cas par cas, comme la psychanalyse est habituée à étayer sa clinique.

\section{Psychanalyse et autisme - repères généraux}

Dans la psychanalyse, il existe une pléthore de principes cliniques pour traiter l'autisme, principes qui se confondent avec son histoire, et également avec les tensions historiques entre les écoles anglaise et française. Prenant la suite de Mélanie Klein, Frances Tustin, dans son célèbre ouvrage Le trou noir de la psyché, considère que le fameux cas Dick, situe une première expérience de la clinique psychanalytique de l'autisme. Elle y soutient que Klein n'a pas pris connaissance de l'article de Kanner, dont le tableau clinique établi coïncidait avec celui de Dick. Nous pouvons ainsi poser la question sur les conséquences que la connaissance de cet article aurait eu pour Klein. Quoi qu'il en soit, Mélanie Klein a bien distingué le cas Dick des névrosés, par « sa profonde indifférence, son apathie, son absence. [...] Ce jeune sujet est tout entier dans l'indifférencié »², a affirmé Lacan.

Tustin affirme que les enfants autistes «ont développé, au tout début de leur existence, une formation massive de réactions d'évitement afin de répondre à une prise de conscience traumatisante de la séparation corporelle entre eux et leur mère $»^{3}$. En ce qui concerne l'étiologie de l'autisme, elle nous indique déjà les hypothèses sur des causes organiques et psychiques de la psychopathologie de l'époque. Par rapport à l'association entre l'autisme et le syndrome de l'X fragile, Tustin remarque que «l'hypothèse organiciste selon laquelle il s'agirait d'une déficience génétique à penser en termes de 'chromosome fragile' n'a pas été confirmée par les tentatives d'application du traitement qu'elle suggère $»^{4}$. C'est-à-dire que cette association entre $l^{\prime} \mathrm{X}$ fragile et l'autisme était déjà mise

\footnotetext{
${ }^{1}$ ANSERMET François \& GIACOBINO Ariane (2012) Autisme, à chacun son génome, 10.

${ }^{2}$ LACAN Jacques (1954) Les écrits techniques de Freud, 81.

${ }^{3}$ TUSTIN Francis (1986) Le trou noir de la psyché, 23.

${ }^{4}$ Ibidem.
} 
en tension par Tustin à partir de son expérience clinique avec les enfants, et elle exerçait déjà une résistance à cette liaison.

Esther Bick et Donald Meltzer, deux célèbres psychanalystes d'orientation kleinienne, ont établi, eux aussi, des théories originales autour de l'autisme. Bick a proposé le terme identification adhésive pour penser une identification narcissique distinguée repérable dans l'autisme. Cette notion se fonde sur l'observation réitérée du nouveau-né qui s'agrippe pour éviter la menace de séparation. L'adhésivité permet de ne pas différencier soi et l'objet, supprimant tout écart. Selon Bick, si l'objet n'existe pas, il n'y a pas d'objet contenant, il n'y a pas de représentation ni de pensée ${ }^{1}$. Meltzer, à son tour, a suggéré le terme démantèlement pour penser l'autisme, à partir d'un processus de morcellement du self, spécialement au niveau de la capacité de l'enfant à établir une expérience perceptuelle. Il s'agit d'une dispersion des sens vers l'objet le plus attractif de l'instant. Ce processus éparpille les objets en une multitude de petits morceaux, chacun porteur d'une qualité sensorielle particulière ${ }^{2}$.

Curieusement, Jacques Lacan, l'auteur sur qui, après Freud, nous nous basons pour discuter les concepts de transfert et de sujet, a très peu abordé la question de l'autisme. Situant le moi comme «siège des illusions ${ }^{3}$, caractérisé essentiellement par la méconnaissance, Lacan opère la coupure entre le moi et le sujet, ce dernier étant celui qui énonce, qui émerge à partir de l'inconscient, de l'Autre comme lieu du langage. Le moi existe donc à partir de l'Autre, il est «constitué par rapport à l'Autre »" étant au départ un objet du discours de cet Autre. Au début de son enseignement, Lacan articule intrinsèquement l'imaginaire au symbolique, mettant en relief le caractère constitutif de ce dernier registre : «le moment où l'homme devient humain, c'est le moment où il entre dans la relation symbolique $»^{5}$, affirme-t-il. Pour Lacan, c'est l'Autre qui convoque le petit être humain à entrer dans le monde symbolique, à partir d'un processus qu'il a nommé l'aliénation primordiale.

C'est cet assujettissement primordial qui lui permettra de situer l'Autre comme « le lieu de la parole, garant de la vérité ${ }^{6}$. C'est la relation de l'enfant à l'Autre qui lui permettra de se constituer en tant que sujet du langage. «Cet Autre est d'ores et déjà en nous sous la

\footnotetext{
${ }^{1}$ BICK Esther (1967) L'expérience de la peau dans les relations d'objet précoces, 143.

${ }^{2}$ MELTZER Donald (1975) La psychologie des états autistiques et de l'état mental post-autistique, 45.

${ }^{3}$ LACAN Jacques (1953-1954) Les écrits techniques de Freud, 76.

${ }^{4}$ Ibidem, 61.

${ }^{5}$ LACAN Jacques (1953-1954) Les écrits techniques de Freud, 178.

${ }^{6}$ LACAN Jacques (1955-1956). Les psychoses, 12.
} 
forme de l'inconscient, mais rien dans notre développement ne peut se réaliser, si ce n'est à travers une constellation qui implique l'Autre absolu comme siège de la parole $»^{1}$, affirmet-il. Le sujet sera donc, «né dans, constitué par, et ordonné à un champ qui lui est extérieur $\gg^{2}$.

C'est dans ce sens que Françoise Dolto, à partir de la compréhension de l'importance fondatrice du langage dans la constitution du sujet, affirme que «l'autisme n'existe qu'en raison de l'importance de la fonction symbolique chez l'être humain ${ }^{3}$. L'enfant, toujours selon Dolto, ne naît pas autiste, car ce dernier est «fabriqué ${ }^{4}$, dit-elle. Elle soutient que l'autisme est un processus réactionnel d'adaptation de l'enfant, où le bébé perd sa relation affective et symbolique à la mère.

À son tour, Maud Mannoni défend que l'organisation autistique s'établit comme une manière, pour l'enfant, de vivre sans affect par le développement des «mécanismes de défense $»^{5}$. Toujours selon Maud Mannoni, chez l'enfant autiste, il n'existe pas d'espace interne ni de représentation de l'objet originel. En outre, il manquerait à l'autiste tout vestige de symbolisme, le corps de l'enfant n'étant pas «érogéinesé » ${ }^{6}$. Pour Mannoni, la pulsion y serait sans destin - l'auto sans l'éros. Remarquons que ces deux psychanalystes ont participé au début de la théorisation autour de l'autisme en France, rehaussant la noninscription symbolique au cœur de la problématique.

Nous pouvons trouver actuellement une psychanalyse à la fois ancrée sur la théorie lacanienne et plus ouverte aux dialogues avec d'autres champs de savoirs, y compris la médecine. Dans ce sens, Marie-Christine Laznik souligne que, au début de ses recherches, elle soutenait que l'autisme prenait origine dans un défaut de la relation mère-bébé. C'està-dire qu'elle concevait une difficulté des parents - assez souvent, un défaut d'investissement libidinal - qui mettrait la relation de l'enfant à l'Autre en risque ${ }^{7}$. Par ses études actuelles, néanmoins, elle indique que c'est le bébé qui peut devenir autiste qui trouble ses parents dès la naissance, puisqu'il ne s'adresse pas aux autres. Selon Laznik,

\footnotetext{
${ }^{1}$ LACAN Jacques (1956-1957). La relation d'objet, 372.

${ }^{2}$ LACAN Jacques (1964). Les quatre concepts fondamentaux..., 240. (Commentaire de Jacques-Alain Miller).

${ }^{3}$ DOLTO Françoise (1985). La cause des enfants, 391.

${ }^{4}$ Ibidem, 386.

${ }^{5}$ MANNONI Maud (1973). Éducation impossible.

${ }^{6}$ Voir ALLOUCH Eliane (2015) Corps et psyché en psychanalyse : L'apport de l'autisme et des psychoses infantiles.

${ }^{7}$ Voir LAZNIK Marie-Christine (2014). Une psychanalyste avec les parents : et trois enfants autistes se mettent à parler.
} 
normalement, il existe un rôle actif du bébé dans l'aliénation primordiale : celui-ci se laisse aliéner, se laisse regarder et toucher, et, dans le même temps, il prend la position active en lançant des regards aux parents, en offrant son corps à l'autre. Autrement dit, «l'enfant joue également dans cette partie un rôle essentiel. Il regarde, il se meut vers l'adulte. [...] L'investissement libidinal sur l'enfant s'inscrit dans ses mouvements, dans sa motricité et certainement pas sur une image immobile $»^{1}$. En outre, ajoute-elle,

« il ne suffit pas que les parents souhaitent investir libidinalement leur bébé, encore faut-il que soient présentes les conditions symboliques pour que les parents puissent réaliser cet investissement et que leurs fantasmes lui soient largement favorables. Le bébé doit aussi regarder [...] être capable de mettre en œuvre un signe, un regard porté vers les parents de sorte qu'ils puissent s'éprouver justement dans leurs existences en tant que parents $»^{2}$.

À l'heure actuelle, Marie-Christine Laznik indique que le syndrome autistique se traduit cliniquement par un non établissement de certaines structures psychiques, voire un défaut du réseau de représentations inconscientes. «Pour se défendre de l'envahissement des perceptions affectives provenant des adultes, le bébé se ferme et perd la possibilité d'acquérir des représentations de mots qui lieraient ces mêmes expériences affectives $»^{3}$, soutient-elle.

Bien que faisant remonter la cause de l'autisme à la naissance, Laznik se garde d'affirmer quelle en est l'étiologie : organique ou psychique. L'auteure nous semble apporter des contributions cliniques fécondes pour la direction du traitement notamment dans son ouvrage Une psychanalyste avec les parents : et trois enfants autistes se mettent à parler, où elle relate la cure de trois enfants autistes. C'est à partir d'un travail autour de la parole, du langage, du symbolique qu'elle mène la direction du traitement de ces enfants, opérant, en transfert, la fonction d'une sorte d'Autre primordial de l'enfant. Selon Laznik, «l'analyste fait le pari qu'en reconnaissant à toute production de l'enfant, gestuelle ou langagière, une valeur signifiante et en se constituant lui-même comme lieu d'adresse de ce

\footnotetext{
${ }^{1}$ LAZNIK Marie-Christine (2013). Lacan et l'autisme, 86.

${ }^{2}$ Ibidem, 87.

${ }^{3}$ LAZNIK Marie-Christine (2014). Une psychanalyste avec les parents: et trois enfants autistes se mettent à parler, 33 .
} 
qu'il considère dès lors comme message, l'enfant va pouvoir se reconnaître après coup comme source de ce message $» 1$.

Le psychanalyste argentin Alfredo Jerusalinsky, à son tour, pense l'articulation des possibles déterminations génétiques à la psychogénèse de l'autisme, celle-ci étant même une source d'espoir pour le traitement de l'enfant et pour ses parents ${ }^{2}$. Jerusalinsky soutient que la prédétermination neurobiologique de l'autisme n'est pas toujours certaine. Ainsi, on ne sait pas si une problématique organique vient faire résistance à l'ordre symbolique, à l'immersion dans le langage, ou si ces difficultés d'insertion sont la «conséquence de la fixation d'une matrice énonciative et symboliquement inadéquate, automatisée $»^{3}$. Nous pouvons faire correspondre cette matrice symbolique à la dimension du grand Autre chez Lacan. Ainsi, ces auteurs nous indiquent que l'autisme ne s'établit pas par une causalité linéaire, qu'elle soit exclusivement psychique ou organique, selon ce que lui attribuent les chercheurs du syndrome de l'X fragile.

Toujours selon Jerusalinsky, dans l'articulation des possibles causalités psychiques et organiques, il faut considérer deux autres possibilités. La première hypothèse soutient que «l'origine organique s'établit à partir de la neuroplasticité, par une modalisation inadéquate $\mathrm{du}$ fonctionnement $\mathrm{du}$ cerveau que provoque la matrice énonciative prévalente ${ }^{4}$. C'est-à-dire, dans ce cas, qu'il s'agirait d'une difficulté de relation à l'Autre qui impliquerait une conséquence organique. La deuxième hypothèse conçoit des « tableaux génétiques ou neurologiques qui, par leurs traits innés, éloignent les enfants de l'idéal des parents. Ils font également obstacle à l'investissement des parents, ce qui peut déclencher, dans un nombre considérable de cas, le surgissement de traits autistiques secondaires $»^{5}$. Jerusalinsky pense ainsi au chemin ontologique inverse, où une limitation organique produit une barrière au niveau relationnel. Comme nous l'indique l'auteur, l'enfant autiste peut se trouver fixé dans ce qu'il appelle des « automatismes neurobiologiques »-des réponses motrices propres de l'espèce humaine, qui sont normalement surmontées par l'immersion de l'enfant dans la maille symbolique de l'Autre. Ainsi, dans ces cas, le processus qui inscrit l'enfant dans le système symbolique ne devient pas effectif, et le sujet psychique, le sujet du langage ne se structure pas.

\footnotetext{
${ }^{1}$ LAZNIK Marie-Christine (2014). Une psychanalyste avec les parents: et trois enfants autistes se mettent à parler, 22.

${ }^{2}$ Voir JERUSALINSKY Alfredo (2011). Uma discussão com as neurociências.

${ }^{3}$ Ibidem, 77. Traduction libre de l'auteure.

${ }^{4}$ Ibidem, 79. Traduction libre de l'auteure.

${ }^{5}$ Ibidem.
} 
Néanmoins, ce qui fait que l'enfant ne soit pas capté par l'Autre, ou ce qui fait qu'il refuse ce rapport est encore obscur. Dans la littérature psychanalytique, certains auteurs indiquent que la difficulté a lieu dans l'établissement du lien parents-enfants ${ }^{1}$. D'autres signalent qu'il y a quelque chose du côté du bébé, dès la naissance, qui refuse le rapport à l'Autre ${ }^{2}$. Il faut mettre en relief l'importance de l'analyse au cas par cas, du singulier. Nous croyons qu'il peut exister des tableaux organiques qui accroissent le risque pour l'enfant de devenir autiste. D'abord, par une question biologique, autrement dit lorsque l'organisme de l'enfant empêche les échanges avec l'environnement, puis par une question psychique. C'est-à-dire qu'en général, il peut y avoir chez les parents des enfants nés avec une pathologie quelconque, un désinvestissement libidinal de leur enfant, dans le sens où l'enfant qui a été imaginé, investi, nommé - voire désiré - ne correspond pas à l'enfant de la réalité. Cela peut poser des difficultés importantes à l'établissement du lien parents-bébé et l'enfant demeure pris par des automatismes biologiques, sans la voie de la symbolisation qui le convoque au langage, à l'être parlant.

Nous insistons : il faut considérer le cas par cas. La théorie psychanalytique a été construite par Freud à partir de sa finesse clinique d'analyser la singularité de chaque patient. Chaque cas était unique et ce qui était important pour Freud, dans la dialectique de la théorie avec la pratique, c'était de conduire le patient à la cure. «Loin de réduire le comportement du sujet à un dysfonctionnement inadapté à normaliser, la psychanalyse est un pari épistémologique et éthique sur la clinique $»^{3}$, nous indique de façon remarquable François Ansermet. Avant toute catégorisation, la pratique psychanalytique s'intéresse aux possibilités de structuration et d'émergence du sujet, qui s'ourdit par le langage, par les échanges. C'est ainsi que la parole engagée en transfert et le jeu, pour les enfants, sont le protagoniste de la scène analytique.

L'objectif de notre thèse n'est pas de faire une clinique de l'autisme, mais de partir de l'autisme pour mettre en tension et joindre la psychanalyse et la génétique médicale. Estce que, dans la différence de savoir-faire de chacune, nous pouvons trouver un point de rencontre pour faire dialoguer les deux pratiques ? Certes, la pratique médicale apporte un regard assez différent du regard psychanalytique, selon ses bases et références épistémologiques. Nous savons qu'il est ardu de concilier les deux pratiques et nous ne

\footnotetext{
${ }^{1}$ Voir DOLTO Françoise (1985). La cause des enfants.

${ }^{2}$ Voir LAZNIK Marie-Christine (2014) Une psychanalyste avec les parents : et trois enfants autistes se mettent à parler.

${ }^{3}$ ANSERMET François \& GIACOBINO Ariane (2012) Autisme : à chacun son génome, 75.
} 
prétendons pas soumettre l'une à l'autre. Chacune porte sa propre histoire et ses outils de quête sur l'inconnu, outils de construction et de production de savoir. Toutefois, - comme nous nous sommes penchés au tout début de cette thèse - en suspendant leurs possibles divergences, mais en considérant leurs différences, ce travail vise à tisser ces deux champs de savoir comme deux approches possibles d'un même traitement.

Il nous semble important de connaître les fondements de la pratique de chaque domaine que nous voulons mettre en tension. Nous développerons ci-dessous les concepts de sujet et de transfert, éléments de l'expérience analytique, qui relèvent d'une dimension subjective qui n'est le plus souvent pas prise en compte par les recherches et par les thérapeutiques de la génétique médicale.

\subsection{Le concept de sujet}

C'est toute la structure du langage que l'expérience psychanalytique découvre dans l'inconscient ${ }^{1}$.

Jacques Lacan

Pour travailler sur la conception de sujet en psychanalyse, nous nous appuierons sur l'acception que lui attribue Jacques Lacan, auteur qui fonde cette notion dans ce domaine. Il faut remarquer que le sujet lacanien et ce qu'on peut pointer rétroactivement comme le sujet freudien n'apportent pas les mêmes dimensions. Toutefois, c'est à partir de Freud que Lacan bâtit sa proposition conceptuelle, il nous semble donc indispensable de faire ce retour à Freud. «La psychanalyse ne peut situer l'essence du psychisme dans la conscience, mais doit forcément regarder la conscience comme une qualité du psychique $»^{2}$, écrit Freud, ce qui démontre la rupture qu'il opère par rapport à la centralité de la conscience caractéristique de la science moderne.

Nous revenons au tout début de la pensée de Freud, dans son texte prépsychanalytique de 1895, L'esquisse d'une psychologie scientifique. Bien que Freud ait méprisé ce texte, nous pouvons en tirer des idées assez importantes en ce qui concerne sa conception sur l'origine du psychisme. Freud y théorise sur le fonctionnement de l'appareil

\footnotetext{
${ }^{1}$ LACAN Jacques (1957) L'instance de la lettre dans l'inconscient..., 492.

${ }^{2}$ FREUD Sigmund (1914). Le moi et le ça, 258.
} 
psychique et sur l'origine du moi, qui serait liée à la capacité de l'organisme à réaliser des échanges avec la réalité par le biais des perceptions et des affects. C'est par une action spécifique que l'appareil psychique tend à repousser la tension accumulée pour éviter le déplaisir. «Une levée de stimulation n’y est possible que par une intervention [...] qui exige un changement dans le monde extérieur [...] qui ne peut se produire, en tant qu'action spécifique, que par des chemins déterminés ${ }^{1}$. Autrement dit, l'excitation ne peut se trouver apaisée que par une intervention capable de suspendre momentanément la libération des quantités à l'intérieur du corps.

Selon Freud, le bébé humain est incapable de mettre fin à la tension provoquée par les excitations intérieures. La seule action que le petit humain peut faire est de crier et de gigoter, ce qui est insuffisant pour mettre fin à sa détresse. Nous voudrions mettre en relief la remarque de Freud qui nous semble essentielle pour comprendre le processus de constitution psychique de l'enfant: c'est par l'aide étrangère, c'est-à-dire par un autre expérimenté que les besoins du bébé seront satisfaits. Et Freud poursuit : «[l'action] se produit par aide étrangère, quand, par la décharge par voie de changement interne, l'attention d'un individu expérimenté est attirée sur l'état de l'enfant. Cette voie de décharge prend ainsi la fonction secondaire très importante de l'entente et la détresse initiale de l'être humain est la source originaire de tous les motifs moraux $»^{2}$. L'appareil psychique sera donc construit par les échanges du bébé avec le monde extérieur. À partir de cette aide étrangère, la tension baisse, et le bébé vit ce que Freud appelle l' «événement de satisfaction » ${ }^{3}$. C'est bien ici qui s'établit le circuit pulsionnel, où, dans un premier moment, le bébé cherche l'objet oral, celui-ci qui a été responsable par sa satisfaction. L'image de l'objet apaisant sera associée à cette expérience et elle sera investie de nouveau, en produisant une éconduite de la tension par l'hallucination de l'objet: «Le tout représente alors un événement de satisfaction qui a les conséquences les plus marquantes pour le développement fonctionnel de l'individu $»^{4}$.

Freud reprendra cette théorisation dans le chapitre VII de L'interprétation du rêve, où il indique qu'

\footnotetext{
${ }^{1}$ FREUD Sigmund (1895). Esquisse d'une psychologie scientifique, 57.

${ }^{2}$ Ibidem, 59.

${ }^{3}$ Ibidem.

${ }^{4}$ Ibidem.
} 
«il apparaît une perception de cette expérience dont l'image mnésique reste désormais associée à la trace mémorielle de l'excitation de besoin. Dès que ce besoin survient une nouvelle fois, il se produira une motion psychique qui veut investir de nouveau l'image mnésique de cette perception et provoquer de nouveau la perception elle-même ${ }^{1}$.

Cette première activité psychique, qui est rendue possible par l'intervention de l'extérieur - c'est-à-dire d'un autre - laissera des traces permanentes dans le psychisme. Nous indiquons que ces traces sont ce que Freud appelle les traces mnésiques, soit « une trace de la perception qui reste dans l'appareil psychique $»^{2}$, traces qui sont réactivées lorsque la tension émerge. Freud ajoute « cette première activité psychique a donc pour but une identité de perception, à savoir la répétition de cette perception qui est connectée à la satisfaction du besoin $»^{3}$. Ces traces seront ultérieurement identifiées par Jacques Lacan comme les signifiants, indiqué dans son Séminaire XI : "nous pouvons tout de suite leur donner, à ces Wahrnehmungszeichen, leur vrai nom de signifiants $»^{4}$. Nous y voyons les premières esquisses du psychisme de l'individu qui est mis en mouvement à partir de la tentative de satisfaction des besoins, autrement dit de l'accomplissement du souhait. C'est la pulsion, caractérisée par Freud en tant que force interne constante, irréductible dans sa quette de satisfaction, qui met en fonctionnement l'appareil psychique ${ }^{5}$. Nous insistons, toujours avec Freud : «rien d'autre qu'un souhait n'est en mesure de donner à notre appareil animique l'impulsion au travail $»^{6}$. Cela nous amène à déduire que les souhaits (articulés eux-mêmes à la satisfaction de la pulsion), au-delà de mettre l'appareil psychique en mouvement, selon Freud, sont éminemment présents dans la constitution du psychisme.

L'inconscient sera donc nourri de ces premières perceptions de l'objet et de l'affect qui deviendront les représentants de la pulsion. Néanmoins, c'est à partir du moment où ces représentants sont empêchés d'accéder au système conscient, autrement dit à partir de la scission opérée par le refoulement originaire, que les systèmes inconscient et préconscient/conscient sont constitués, opérant chacun avec ses lois et règles singulières. Le refoulement originaire, d'après Freud, est « une première phase du refoulement qui

\footnotetext{
${ }^{1}$ FREUD Sigmund (1900) L'interprétation du rêve, 620.

${ }^{2}$ Ibidem, 612 .

${ }^{3}$ Ibidem, 640

${ }^{4}$ LACAN Jacques (1964). Les quatre concepts fondamentaux de la psychanalyse, 46.

${ }^{5}$ FREUD Sigmund (1915). Metapsychologie, 14.

${ }^{6}$ FREUD Sigmund (1900). L'interprétation du rêve, 621. (C'est nous qui soulignons.)
} 
consiste en ceci que le représentant psychique (représentant-représentation) de la pulsion se voit refuser la prise en charge dans le conscient. Avec lui se produit une fixation; le représentant correspondant subsiste, à partir de là, de façon inaltérable et la pulsion demeure liée à lui » ${ }^{1}$. Si la présupposition fondamentale de la psychanalyse, selon Freud, est que le psychique est différencié en conscient et inconscient ${ }^{2}$, cela n'est possible qu'à partir du moment où une séparation ${ }^{3}$ marquée entre les activités psychiques consciente et inconsciente se produit. C'est ainsi lorsqu'une représentation est maintenue à l'écart de la conscience par la voie du refoulement originaire que se sont fondées les deux systèmes du psychisme.

Si auparavant le critère utilisé par Freud dans les investigations des activités psychiques était d'indiquer le caractère conscient ou inconscient ${ }^{4}$ de celles-ci, à partir de son ouvrage Le moi et le ça, il établit de manière définitive son deuxième topique. Il affirme : « Je propose pour en tenir compte d'appeler l'être qui part du système $P c$, et qui est d'abord $p c s$, le moi [das Ich] et pour ce qui est du psychique autre que lui, dans lequel il se continue et qui se comporte comme ics, de l'appeler comme le fait Groddeck, le ça [das Es] $»^{5}$. «Un individu, souligne Freud, est donc pour nous un ça psychique, non connu et inconscient, sur lui se trouve posé en surface le moi, développé à partir du système- $P c$ comme noyau ${ }^{6}$. Cela nous indique déjà que le sujet pour Freud, c'est le sujet de l'inconscient.

L'inconscient qui opère par ses lois particulières, déterminant les mouvements psychiques de chacun. C'est Lacan qui défendra que les manifestations de l'inconscient les rêves, les lapsus, les actes manqués, les mots d'esprit et les symptômes -, à l'instar des mécanismes basiques du langage, fonctionnent de manière élective par la condensation et le déplacement conçus par Freud. C'est le linguiste Roman Jakobson, lors de ses études sur le problème des aphasies, qui a fait correspondre les pôles métaphorique et métonymique aux mécanismes freudiens de la condensation et du déplacement ${ }^{7}$. Pour Jakobson, les aphasies sont le résultat de l'altération «plus ou moins grave, soit de la faculté de sélection et de substitution, soit de celle de combinaison et de contexture $»^{8}$. Dans le trouble de la similarité, notamment, c'est la métaphore qui devient impossible, tandis que dans celui de

\footnotetext{
${ }^{1}$ FREUD Sigmund (1915). Métapsychologie, 48. (C'est nous qui soulignons.)

${ }^{2}$ Voir FREUD Sigmund (1923). Le moi et le ça.

${ }^{3}$ Voir FREUD Sigmund (1915). Métapsychologie.

${ }^{4}$ Voir FREUD Sigmund (1923). Le moi et le ça.

${ }^{5}$ Ibidem, 268.

${ }^{6}$ Ibidem. (C'est nous qui soulignons.)

${ }^{7}$ Voir JAKOBSON Roman (1963). Essais de linguistique générale.

${ }^{8}$ Ibidem, 61.
} 
la contiguïté, c'est la métonymie qui échoue. Jakobson poursuit : «c'est ainsi que dans une étude sur la structure des rêves, la question décisive est de savoir si les symboles et les séquences temporelles utilisés sont fondés sur la contiguïté ('déplacement' métonymique et 'condensation' synecdochique freudiens) ou sur la similarité ('identification' et 'symbolisme' freudiens) »1.

L'aphorisme de Jacques Lacan l'inconscient est structuré comme un langage naît ainsi de la proposition du fonctionnement de l'inconscient freudien, à partir de L'interprétation $d u$ rêve, et de la correspondance que Jakobson établit ensuite. L'inconscient lui-même opère à partir des lois linguistiques - la condensation et le déplacement - que Lacan, à l'instar de Jakobson, interprète comme métaphore et métonymie $^{2}$. Dans l'analyse du rêve, dit Lacan, la «Verdichtung, condensation, c'est la structure de surimposition des signifiants où prend son champ la métaphore [...] la Verschiebung ou déplacement, c'est plus près du terme allemand ce virement de la signification que la métonymie démontre $»^{3}$ ou en outre, affirme-t-il « les mécanismes dits du condensé (Verdichtung) et du virement (Verschiebung) recouvrent exactement les structures par où s'exercent dans le langage les effets de métaphore et de métonymie ${ }^{4}$. Lacan opère alors une rupture avec la psychologie de l'ego, et insiste sur le fait que les concepts psychanalytiques, dans leur sens plein, demeurent dans le champ de langage, et s'ordonnent à la fonction de la parole ${ }^{5}$. Le symptôme, ajoute Lacan, « se résout tout entier dans une analyse de langage, parce qu'il est lui-même structuré comme un langage, qu'il est langage dont la parole doit être délivrée $»^{6}$.

C'est à partir de cette conception de structuration de l'inconscient que Lacan étoffe son concept de sujet. Remarquons que le petit humain est immergé dans le langage avant même de naître. L'Autre parle de lui, lui attribue un nom propre - marque singulière de l'entrée dans le monde symbolique, puisque «quand un nom désigne une personne déterminée, c'est exactement en cela que consiste le passage à l'état humain » ${ }^{7}$ affirme Lacan. Le bébé est plongé dans les eaux du signifiant d'où il sera convoqué à parler lorsque l'Autre parle de lui et pour lui, supposant en lui un sujet naissant. Dans ce que concerne les

\footnotetext{
${ }^{1}$ JAKOBSON Roman (1963). Essais de linguistique générale, 65-66.

${ }^{2}$ LACAN Jacques (1957). L'instance de la lettre dans l'inconscient.

${ }^{3}$ Ibidem, 511.

${ }^{4}$ LACAN Jacques (1958). La psychanalyse vraie, et la fausse, 166.

${ }^{5}$ LACAN Jacques (1966). Fonction et champ de la parole et du langage, 246.

${ }^{6}$ Ibidem, 269.

${ }^{7}$ LACAN Jacques (1953) Les écrits techniques de Freud, 178.
} 
formes primaires de symbolisation, Schwering nous indique que le maternage «s'exprime grâce au bain de langage dont elle enveloppe son enfant. Les onomatopées, les vocalises, les petits mots et autres formes primaires du langage vont ainsi fournir les protoreprésentations dont se servira le petit d'homme pour construire un premier espace de pensée $» 1$.

Le bébé, dit Lacan, « est un être humain, qui est né dans un état d'impuissance, et que, très précocement, les mots, le langage, lui ont servi d'appel, et d'appel des plus misérables, quand c'était de ses cris que dépendait sa nourriture $»^{2}$. Le sujet est donc « effet du langage $»^{3}$, auquel il doit sa condition d'être humain. C'est par le langage que le sujet est constitué et mis en relation avec la culture : «Les paroles fondatrices qui enveloppent le sujet sont tout ce qui l'a constitué, ses parents, ses voisins, toute la structure de la communauté, et non pas seulement constitué comme symbole, mais constitué dans son être $»^{4}$.

C'est dans cette chaîne symbolique que le sujet émerge. Ce lieu symbolique est indiqué par Lacan comme le grand Autre ${ }^{5}$, «lieu où se situe la chaîne du signifiant qui commande tout ce qui va pouvoir se présentifier du sujet, c'est le champ de ce vivant où le sujet $a$ à apparaître $»^{6}$. Cependant, pour que le petit humain y arrive à être parlant, il faut qu'il ait une place réservée dans le champ de l'Autre, une place attribuée par ceux qui s'occupent de lui. Le sujet naît dans le champ de l'Autre, où se passera la première opération de constitution psychique, à savoir l'aliénation ${ }^{7}$.

Nous avons vu avec Freud que dans l'expérience de satisfaction, le bébé aura ses premières activités psychiques par le biais de l'aide étrangère, c'est-à-dire, par l'intervention de l'autre qui satisfait ses besoins. C'est cet autre qui amènera l'objet, voire deviendra l'objet même capable de baisser la détresse du bébé. C'est dans cet échange que le petit humain est aliéné dans le champ de l'Autre primordial, représenté par n'importe quelle personne qui incarne cette fonction d'aide étrangère. Cet échange avec l'Autre laissera des traces - traces de langage, selon Lacan, des signifiants qui s'inscrivent dans le

\footnotetext{
${ }^{1}$ SCHWERING Karl-Leo (2014). Symbolisation primaire et subversion libidinale dans la maladie... 170.

${ }^{2}$ LACAN Jacques (1953). Les écrits techniques de Freud, 178.

${ }^{3}$ LACAN Jacques (1960). Position de l'inconscient, 315.

${ }^{4}$ LACAN Jacques (1954-1955). Le moi dans la théorie de Freud et dans la technique de la..., 30.

5 «Il y a deux autres à distinguer, au moins deux - un autre avec un $A$ majuscule, et un autre avec un petit $a$, qui est le moi. L'Autre, c'est de lui qu'il s'agit dans la fonction de la parole » LACAN Jacques (19541955). Le moi dans la théorie de Freud et dans la technique de la ...276.

${ }^{6}$ LACAN Jacques (1964). Les quatre concepts fondamentaux de la psychanalyse, 185.

${ }^{7}$ « La première opération essentielle où se fonde le sujet c'est l'aliénation »Ibidem, 191.
} 
corps du sujet et qui donnent le contour de son histoire. L'opération de l'aliénation, selon Lacan, consiste à l'origine en ce qu' « avant le langage, le désir n'existe que sur le seul plan de la relation imaginaire du stade spéculaire, projeté, aliéné dans l'autre ${ }^{1}$. Autrement dit, le sujet est attrapé par l'Autre, restant aliéné dans son désir. Il ne se constituera que dans la relation à l'Autre, d'où il extrait et subjective son désir.

C'est également par la médiation de l'image de l'autre que le petit humain appréhende sa propre image corporelle dans ce que Lacan a nommé le stade du miroir ${ }^{2}$. «C'est dans un mouvement de bascule, d'échange avec l'autre que l'homme s'apprend comme corps, comme forme vide du corps $»^{3}$. Le stade du miroir représente le moment où le sujet assume son image spéculaire, dans un mouvement d'assomption jubilatoire, lorsqu'il n'a pas toujours la mâtrise de la marche et qu'il est encore dans l'impuissance motrice et qu'il dépend toujours de l'autre pour être nourri ${ }^{4}$. Le stade du miroir, ajoute plus tard Lacan, «c'est l'aventure originelle par où l'homme fait pour la première fois l'expérience qu'il se voit, se réfléchit et se conçoit autre qu'il n'est - dimension essentielle de l'humain, qui structure toute sa vie fantasmatique $»^{5}$. C'est dans un mouvement de précipitation que le petit humain vit l'expérience d'unité corporelle, d'où auparavant il n'avait que la sensation de corps morcelé - « le stade du miroir est un drame dont la poussée interne se précipite de l'insuffisance à l'anticipation - et qui pour le sujet, pris au leurre de l'identification spatiale, machine les fantasmes qui se succèdent d'une image morcelée du corps à une forme que nous appellerons orthopédique de sa totalité »6 .

Influencé par l'article du stade du miroir de Jacques Lacan, Winnicott met en relief le rôle du visage de la mère dans la relation spéculaire - «le précurseur du miroir, c'est le visage de la mère $»^{7}$, affirme-t-il. Winnicott souligne, et celle-ci est une remarque essentielle, que le visage de la mère envoie à son enfant son propre image, c'est-à-dire «ce qu'il voit, c'est lui-même $»^{8}$. C'est l'image que la mère porte de son enfant qui est reflétée et perçue par le bébé. Ce stade est situé comme fondateur de la constitution du sujet, où s'établissent ses premières expériences dans le rencontre avec l'Autre. Selon nous avons observé brièvement au troisième chapitre, la mère est considérée en tant qu'environnement

\footnotetext{
${ }^{1}$ LACAN Jacques (1953-1954). Les écrits techniques de Freud, 193.

${ }^{2}$ Ibidem, 192.

${ }^{3}$ Ibidem, 193.

${ }^{4}$ LACAN Jacques (1949). Le stade du miroir comme formateur de la fonction du Je..., 93.

${ }^{5}$ LACAN Jacques (1953-1954). Les écrits techniques de Freud, 94.

${ }^{6}$ Ibidem, 96.

${ }^{7}$ WINNICOTT Donald (1971). Le rôle de miroir de la mère et de la famille dans le ..., 203.

${ }^{8}$ Ibidem.
} 
pour l'enfant. Cependant, Winnicott nous avertit indiquant que ce mouvement spéculaire ne va pas de soi, pouvant ne pas s'établir avec consistance.

Dans ce sens, Madeira, Robert et Kupermann ${ }^{1}$ indiquent que Winnicott situe le plus souvent les psychoses à partir des difficultés maternelles à créer l'illusion, c'est-à-dire, d'union et d'indifférenciation avec son enfant, plutôt que d'y introduire la désillusion - bien qu'il y puisse concevoir manifestement cette origine ${ }^{2}$. Prenons comme exemple un texte de 1962, Intégration du moi au cours du développement de l'enfant, où Winnicott définit la «mère suffisamment bonne » comme étant «capable de satisfaire les besoins de son nourrisson, au début, et de le faire de façon si adaptée que celui-ci est en mesure de ressentir une brève expérience d'omnipotence au moment où il surgit de la matrice qui constitue la relation mère-nourrisson $»^{3}-$ aucune référence à la désillusion n'étant faite au long du texte. Les fonctions de la mère étant distinguées par les « soins », la «protection », le « soutien du moi $»^{4}$. Ainsi, pour Winnicott, comme nous avons observé dans le chapitre précédant, «les trois phénomènes de l'évolution du moi et les trois aspects des soins accordés au nourrisson et à l'enfant » seraient le holding, le handling et la présentation d'objets. Ceux-ci seraient des constituants fondamentaux de l'unité du moi, souvent repris par Winnicott ${ }^{5}$, et qui permettraient à l'enfant de réussir « une catégorie unaire », l'assomption d'un je énonciatif 6 . À défaut de ces fonctions, l'enfant serait exposé à des « angoisses inimaginables », comme celles du morcellement, de la chute, «de ne pas avoir de relation avec son corps » ou de désorientation ${ }^{7}$. Et Winnicott poursuit : «on reconnaîtra que ces variantes constituent spécifiquement l'essence des angoisses psychotiques et qu'elles appartiennent à la schizophrénie ou à l'apparition d'un élément schizoïde caché dans une personnalité par ailleurs non psychotique $»^{8}$.

\footnotetext{
${ }^{1}$ MADEIRA Manoel, ROBERT Priscilla e KUPERMANN Daniel (2015). Subjetivação do corpo: entre devoração e abandono.

${ }^{2}$ Voir WINNICOTT Donald (1971). Jeu et réalité, 204.

${ }^{3}$ WINNICOTT Donald (1969). Intégration du moi au cours du développement de l'enfant, 10.

${ }^{4}$ Ibidem, 13-15.

${ }^{5}$ Voir WINNICOTT Donald (1971). Jeu et réalité, 204 ; WINNICOTT Donald [non daté]. La crainte de l'effondrement, 207.

${ }^{6}$ Voir WINNICOTT Donald (1967). A delinquência como sinal de esperança, 85. Traduction libre de l'auteure.

${ }^{7}$ WINNICOTT Donald (1969). Intégration du moi au cours du développement de l'enfant, 11.

${ }^{8}$ Ibidem.
} 
Le bébé, donc est toujours dépendant de et aliéné à l'Autre - son unité corporelle n'étant qu'une illusion. La perception est structurée par le symbolique, c'est-à-dire par le pouvoir de la nomination :

«C'est là qu'intervient la relation symbolique. Le pouvoir de nommer les objets structure la perception elle-même. Le percepi de l'homme ne peut se soutenir qu'à l'intérieur d'une zone de nomination. C'est par la nomination que l'homme fait subsister les objets dans une certaine consistance. S'ils n'étaient que dans un rapport narcissique avec le sujet, les objets ne seraient jamais perçus que de façon instantanée $»^{1}$, écrit Lacan.

Le stade du miroir, c'est ainsi la période où, par le biais de la parole de l'Autre, le sujet humain se différencie tout en s'identifiant : étant nommé, il devient également capable de nomination, constituant son lien à la culture. Il faut mettre en relief la fonction de la parole, du discours de l'Autre dans ce processus vécu par l'infans, où il se reconnait à partir de la reconnaissance de l'Autre qui lui dit «ça, c'est toi ». C'est donc dans le discours de l'Autre que le sujet se situe, que le sujet ex-iste, comme insiste Lacan. L'Autre porte la fonction d'anticipation de l'image corporelle du bébé, et suppose chez lui un sujet naissant ${ }^{2}$. Le sujet est ainsi éminemment structuré dans le rapport à l'Autre primordial, fonction souvent incarnée par les parents.

C'est dans cette dialectique que se passera la deuxième opération de constitution psychique, c'est-à-dire ce que Lacan a nommé la séparation ${ }^{3}$, opération qui « achève la circularité de la relation du sujet à l'Autre ${ }^{4}$. Il ajoute ensuite «par la séparation, le sujet trouve, si l'on peut dire, le point faible du couple primitif de l'articulation signifiante $»^{5}$. Ce point faible évoque l'intervalle qui coupe les signifiants dans le discours de l'Autre, c'està-dire comme ce qui fait partie de la structure même du signifiant. La séparation, par les différentes formes de perte de l'objet, subjective à l'enfant que le désir de l'Autre est irrémédiablement désir d'autre chose - elle instaure une interrogation sur les vicissitudes de l'Autre. C'est à partir du moment où le sujet rencontre le manque marqué par le discours

\footnotetext{
${ }^{1}$ LACAN Jacques (1954-1955). Le moi dans la théorie de Freud...202.

${ }^{2}$ LACAN Jacques (1958-1959). Le désir et son interprétation, 257.

${ }^{3}$ LACAN Jacques (1964). Les quatre concepts fondamentaux de la psychanalyse, 194.

${ }^{4}$ Ibidem, 193.

${ }^{5}$ Ibidem, 199.
} 
de l'Autre qu'il se voit face à l'énigme du désir, énigme à partir de laquelle il appréhendera la sienne ${ }^{1}$. Selon Winnicott, c'est dans la mesure où la mère $s$ 'éloigne de son bébé, c'est-àdire, que son absence est imposée à l'enfant que celui-ci commence à subjectiver le moi et le non-moi ${ }^{2}$. Autrement dit, la séparation progressive de la mère permet la constitution de l'unité corporelle de l'enfant, dans un jeu de présence et absence de l'objet.

Nous avons étudié le concept de sujet - son émergence à partir du champ de l'Autre, sa constitution par le langage. Le sujet, lorsqu'il émerge «dans les guillemets du discours $»^{3}$ s'adressant à l'écoute du psychanalyste, instaure le transfert, le seul champ à partir duquel l'aventure psychanalytique peut avoir lieu.

\subsection{Le concept de transfert}

Chaque fois qu'un homme parle à un autre d'une façon authentique et pleine, il y a, au sens propre, transfert, transfert symbolique ${ }^{4}$.

Jacques Lacan

Le concept de sujet en psychanalyse, en tant qu'il est constitué par le langage, se confond avec la structure même de l'inconscient. Si Lacan soutenait que le symptôme, comme nous l'avons repéré, « se résout tout entier dans une analyse de langage, parce qu'il est lui-même structuré comme un langage, qu'il est langage dont la parole doit être délivrée $»^{5}$, la psychanalyse pensera que c'est par la voie du transfert que des changements symptomatiques peuvent advenir.

Nous avons vu au deuxième chapitre, la vaste symptomatologie supposée engendrée par le syndrome de l'X fragile. Parmi ces symptômes, la plupart peut être comprise comme étant subjective, se rapportant au psychique. Le pari de notre travail repose sur ce fait : le sujet, dans son rapport à l'Autre, est entièrement impliqué dans la production de son symptôme, sans nier, néanmoins, la possible incidence des facteurs organiques. Ainsi, nous proposons que le traitement psychanalytique peut également apporter ses contributions dans

\footnotetext{
${ }^{1}$ LACAN Jacques (1964). Les quatre concepts fondamentaux de la psychanalyse.

${ }^{2}$ Voir WINNICOTT Donald (1971). Jeu et réalité.

${ }^{3}$ LACAN Jacques (1956). Séminaire sur la lettre volée, 56.

${ }^{4}$ LACAN Jacques (1953-1954). Les écrits techniques de Freud, 127.

${ }^{5}$ Ibidem, 269.
} 
les soins accordés aux enfants atteints de syndromes génétiques. De plus, malgré les contraintes organiques, nous considérons que ces enfants ont une histoire, un désir, un dire qui les constituent. Il faut que les symptômes soient pris globalement, c'est-à-dire sans exclure les conditions organiques, psychiques et sociales qui entourent l'enfant.

En psychanalyse, les changements symptomatiques présentés par les enfants ne sont possibles qu'à partir du transfert. Le transfert n'est pas seulement l'ancrage de la clinique psychanalytique, mais la condition par laquelle s'établit la voie de la traversée de la cure analytique. Selon Freud, « une analyse sans transfert est une impossibilité » ${ }^{1}$. Nous allons donc suivre ses pistes pour la construction de ce concept, pistes élargies par Lacan dans son enseignement, en lui conférant ses propres contours.

$\mathrm{Au}$ début de la découverte du transfert, dans l'analyse des hystériques, Freud affirmait que ce phénomène était «le plus grave obstacle auquel on puisse se heurter $»^{2}$, c'est-à-dire « quand la malade s'effraie de transférer des représentations pénibles émergeant du contenu de l'analyse sur la personne du médecin ${ }^{3}$. Le transfert était donc considéré en tant qu'obstacle qui devrait être éclairci ${ }^{4}$, étant en même temps «l'arme la plus puissante de la résistance $»^{5}$. Dans une définition classique qu'il apporte dans Le cas Dora, le transfert y est épinglé comme « des rééditions, des reproductions des motions et fantaisies appelées à être éveillées et rendues conscientes tandis que l'analyse avance, s'accompagnant d'un remplacement - caractéristique de toute cette catégorie - d'une personne antérieure par la personne du médecin $»^{6}$. Néanmoins, bien que la résistance s'articule au transfert, son émergence ne s'introduit pas forcément comme obstacle indésirable, puisque « la raison de cet obstacle tient à la nature même du traitement $»^{7}$. Comme le souligne Alain Vanier, « la résistance est un effet fondamental, et non pas un parasite de la cure $»^{8}$.

Bien qu'articulé à la résistance, Freud comprend le phénomène du transfert comme un facteur essentiel à la cure analytique : il «devient son plus puissant auxiliaire si l'on réussit à le deviner chaque fois et à le traduire au malade $»^{9}$. En tant qu' « arme la plus puissante de la résistance », formule que Freud lui-même réitère, le transfert, selon lui,

\footnotetext{
${ }^{1}$ FREUD Sigmund (1925). Autoprésentation, 89.

${ }^{2}$ FREUD Sigmund (1895). Études sur l'hystérie, 329.

${ }^{3}$ Ibidem, 330.

${ }^{4}$ Ibidem, 331.

${ }^{5}$ FREUD Sigmund (1912). Sur la dynamique du transfert, 112.

${ }^{6}$ FREUD Sigmund (1905). Dora : fragment d'une analyse d'hystérie, 113

${ }^{7}$ FREUD Sigmund (1895). Études sur l'hystérie, 245.

${ }^{8}$ VANIER Alain (2011). Pour introduire "la direction de la cure », 16.

${ }^{9}$ FREUD Sigmund (1905). Dora : fragment d'une analyse d'hystérie, 115.
} 
«était, le meilleur instrument de la cure analytique ${ }^{1}$. Il s'agit donc d'une traduction des résistances par l'analyste, conduisant le patient à la cure. Freud découvre au fur et à mesure les ruses de l'inconscient dans le setting analytique, ruses qui ne peuvent être mises en jeu que dans le transfert. La résistance surgit ainsi comme un mécanisme puissant de l'inconscient dont la négligence pouvait mettre à terre les efforts du traitement analytique.

Dans son texte Sur la dynamique du transfert, Freud différencie le «transfert positif » et «transfert négatif $»^{2}$, distinguant « le transfert de sentiments tendres de celui de sentiments hostiles $»^{3}$. La résistance se sert des deux variantes transférentielles s'appuyant sur des motions érotiques refoulées ${ }^{4}$ dans le processus de la cure analytique. Autrement dit, caractérisé comme étant «positif» ou «négatif», le transfert sera toujours un élément essentiel dans le chemin de la cure. Freud rehausse, dans ce sens, la dimension de la technique analytique, mettant en lumière la façon dont l'analyste manie les éléments du transfert.

L'analyste serait ainsi attentif aux répétitions - celles du discours, certes, mais également celles qui impliquent la répétition en transfert des rapports les plus précoces du patient. Selon Freud, celui-ci «revit des relations de sentiment qui sont issues de ses investissements d'objet les plus précoces, de la période refoulée de son enfance $»^{5}$. Cette traduction indique au patient que l'investissement libidinal sur la personne du médecin est, dans la réalité, l'investissement issu des relations vécues par le sujet. L'analyste doit également savoir que tout l'amour ou toute la haine adressée par le patient, porte une autre cible que celle de la personne de l'analyste.

Dans l'analyse du cas Dora, Lacan tisse l'une de ses premières réflexions les plus consistantes sur le concept de transfert. Si, chez Freud, le transfert établit « des rééditions, des reproductions des motions et fantaisies appelées à être éveillées $»^{6}$, mais qui ne font pas partie de la réalité, Lacan soulignera que «le transfert est la mise en acte de la réalité de l'inconscient $»^{7}$, l'analyste étant le représentant de cette réalité. Comme le soulignera Freud, la question de la répétition est fort présente dans le transfert, et Lacan nous prévient que ce

\footnotetext{
${ }^{1}$ FREUD Sigmund (1925). Autoprésentation, 89.

${ }^{2}$ Ibidem, 113.

${ }^{3}$ Ibidem.

${ }^{4}$ Ibidem, 114.

${ }^{5}$ Ibidem.

${ }^{6}$ FREUD Sigmund (1905). Dora : fragment d'une analyse d'hystérie, 113.

${ }^{7}$ LACAN Jacques (1964). Les quatre concepts fondamentaux de la psychanalyse, 133.
} 
phénomène permet que quelque chose d'original soit fabriqué par le sujet, dans un processus « créateur $»^{1}$. Il s'agit de l'histoire du sujet racontée dans le présent, c'est-à-dire « l'histoire est le passé pour autant qu'il est historicisé dans le présent - historicisé dans le présent parce qu'il a été vécu dans le passé »², dit Lacan. C'est autour d'une réécriture de l'histoire du sujet, portée par la parole adressée à l'analyste n'étant pas qu'un simple souvenir, que le processus analytique est mis en action. Cette réécriture n'est rien d'autre que le discours inconscient, mis en scène en analyse où la parole pleine est convoquée à émerger.

À l'instar de Freud, Lacan pense le transfert comme l'équivalent de l'amour, remarqué dans le début de son enseignement, à savoir «le transfert, c'est l'amour $»^{3}$. L'amour est un effet de transfert et aimer, selon lui, est essentiellement vouloir être aimé ${ }^{4}$. Néanmoins, il ne s'agit pas de l'amour en tant qu'Éros, mais de «l'amour-passion $»^{5}$, l'amour qui se passe au niveau de l'imaginaire. Bien que ce phénomène comporte des incidences, des projections imaginaires, il se situe entièrement au plan symbolique. Toujours selon Lacan, sur le plan imaginaire il se produit « cette oscillation du miroir qui permet à des choses imaginaires et réelles qui n'ont pas l'habitude de coexister pour le sujet, de se rencontrer dans une certaine simultanéité, ou en certains contrastes ${ }^{6}{ }^{6}$ souligne-t-il. Ainsi, l'analyste sera souvent appelé à soutenir l'identification du sujet à l'idéal du moi ${ }^{7}$.

Il faut remarquer que, selon Lacan, le transfert - en tant que phénomène où deux sujets se rencontrent - est fonction de l'analysant et non pas de l'analyste, celui-ci s'attribuant la tâche de le manier. Ce rapport analysant-analyste constitue une relation d'inconscient à inconscient ${ }^{8}$, et non pas d'un rapport de dualité d'ego à ego. L'expérience analytique se soutient dans un rapport à trois : analysant-analyste-parole pleine ${ }^{9}$.

Le principe de cette conception repose sur l'idée que l'analyse est le rapport où quelqu'un parle à un autre - « ce fait est constitutif $»^{10}$, dit Lacan. L'entrée dans une analyse requiert que le patient suppose que l'analyste porte une vérité sur son symptôme, et qu'il sache comment le guérir. C'est la condition même du transfert, ce qui a été appelé par Lacan

\footnotetext{
${ }^{1}$ LACAN Jacques (1960-1961). Le transfert, 207.

${ }^{2}$ LACAN Jacques (1954). Les écrits techniques de Freud, 20.

${ }^{3}$ Ibidem, 106.

${ }^{4}$ LACAN Jacques (1964). Les quatre concepts fondamentaux de la psychanalyse, 228.

${ }^{5}$ Ibidem, 130.

${ }^{6}$ LACAN Jacques (1954). Les écrits techniques de Freud, 197.

${ }^{7}$ LACAN Jacques (1960-1961). Le transfert, 409.

${ }^{8}$ Ibidem, 221.

${ }^{9}$ LACAN Jacques (1954). Les écrits techniques de Freud, 18.

${ }^{10}$ LACAN Jacques (1960-1961). Le transfert, 208.
} 
le sujet supposé savoir: «Dès qu'il y a quelque part le sujet supposé savoir, il y a transfert $»^{1}$. Le patient répond à l'analyste, à ce sujet supposé savoir, avec l'amour. Cette demande d'amour est une des modalités de la résistance, au moment où le sujet se confronte au dévoilement de son désir. Le patient peut mettre son symptôme en mouvement lorsque cette demande est transformée, dans le transfert, par l'intermédiation du sujet supposé savoir, devenant une question, une énigme de savoir². «L'interprétation, pour déchiffrer la diachronie des répétitions inconscientes doit introduire dans la synchronie des signifiants qui s'y composent, quelque chose qui soudain rende la traduction possible $»^{3}$, ajoute Lacan.

Le transfert s'établit différemment dans la clinique avec des enfants, bien que l'analyste ait toujours affaire au sujet de l'inconscient. C'est un adulte qui conduit l'enfant en consultation et qui, souvent, porte une demande qui sera adressée à l'analyste - que ce soient les parents, un médecin, un enseignant. Il y a ainsi un transfert qui se tissera entre l'analyste et les parents, transfert également nourri par l'imaginaire, lorsque l'analyste est situé en condition de sujet supposé savoir, ce qui est une possibilité, non pas une règle. Nous pouvons considérer, comme Angela Vorcaro, que le discours des parents peut être compris, lui aussi, comme des manifestations de l'enfant ${ }^{4}$. Nous allons discuter de façon plus précise dans le prochain chapitre, les effets de ce discours - y compris le discours médical - sur le symptôme de l'enfant. Toujours selon Vorcaro, le symptôme de l'enfant peut venir signifier son interprétation du lien parental, apportant une certaine vérité sur la dynamique familiale. L'enfant répond ainsi à partir de la place qui lui est destinée dans le fantasme des parents. Vorcaro souligne l'importance de l'analyste dans la distinction de l'enfant-symptôme du symptôme de l'enfant, essentielle pour bien saisir la demande. Selon Vorcaro encore, « la différence du transfert de l'enfant, c'est qu'il ne substitue pas une névrose ordinaire. Les états névrotiques des enfants sont déjà des névroses de transfert $»^{5}$. Sur ce sujet, Erick Porge affirme également que la névrose infantile «est déjà constituée en tant que névrose de transfert avant de rencontrer l'analyste $»^{6}$. C'est cela que l'auteur nomme de « transfert pour les coulisses », parler à la cantonnade, c'est-à-dire, «parler à un personnage qui n'est pas dans la scène $»^{7}$. Le symptôme de l'enfant indiquerait une rupture dans le supposé savoir

\footnotetext{
${ }^{1}$ LACAN Jacques (1964) Les quatre concepts fondamentaux de la psychanalyse, 210.

${ }^{2}$ Voir QUINET Antonio (1991) As 4+1 condições da análise.

${ }^{3}$ LACAN Jacques (1958) La direction de la cure et les principes de son pouvoir, 70

${ }^{4}$ Voir VORCARO Ângela (1999) Transferência e interpretação na clínica com crianças....

${ }^{5}$ Ibidem, 57. Traduction libre de l'auteure.

${ }^{6}$ PORGE Erik (1998). A transferência para os bastidores, 16. Traduction libre de l'auteure.

${ }^{7}$ Ibidem, 13.
} 
des parents, qui adressent à leur tour le message de l'enfant à un autre - l'analyste. Selon Jerusalinsky, le transfert dans la clinique avec des enfants permet à ces dernier 'l'expansion fictionnelle dans l'Autre incarnée par les parents ou par qui se soit, expansion qui n'a pas été permise. L'analyste est fiable parce que il permet cette expansion fictionnelle que les autres n'ont pas permis $»^{1}$.

Dans l'autisme, le travail analytique et l'établissement du transfert gardent également leurs spécificités : «le travail avec un enfant autiste s'effectue à l'envers de la cure analytique classique : le but de l'analyste n'est pas d'interpréter les fantasmes d'un sujet de l'inconscient déjà constitué, mais de permettre à un tel sujet d'advenir »², soutient Laznik. Dans ce sens, l'analyste fait une inversion de la demande négative que l'autiste luimême ne peut pas faire, l'analyste étant « chargé de ce qui est en jeu dans le transfert, par le biais d'un acte analytique : produire l'inversion qu'il [l'enfant] n'a pas pu produire $»^{3}$. Sur cette spécificité de transfert, Jerusalinsky rajoute que dans le premier transfert dans lequel un autiste engage l'analyste en tant qu'objet, il le fait par le « réel de son corps $»^{4}$. C'est-à-dire, c'est à partir du corps de l'enfant, des mouvements caractéristiques de l'autisme que l'analyste peut essayer d'établir un rapport de cure. Autrement dit, c'est à partir d'une discontinuité d'un geste quelconque, d'une rupture de la continuité, qu'un espace vide peut avoir lieu et le signifiant peut être introduit.

\subsection{Conclusion}

Nous reprenons donc la proposition de cette thèse, celle de réaliser une articulation entre la psychanalyse et la génétique médicale à partir du traitement des enfants atteints de syndromes génétiques, notamment le syndrome de l'X fragile. Dans le traitement psychanalytique, nous considérons ce qui est décisif dans la constitution du sujet, c'est-àdire son rapport à l'Autre, ce dernier étant le lieu du langage, lieu de l'émergence du désir. Nous considérons également que des implications organiques peuvent entraver les échanges de l'enfant avec ceux qui l'entourent, ce qui, à son tour, peut agir sur ses acquisitions instrumentales 5 .

\footnotetext{
${ }^{1}$ JERUSALINSKY Alfredo (2011). Para compreender a criança..., 28. Traduction libre de l'auteure.

${ }^{2}$ LAZNIK Marie-Christine (2014). Une psychanalyste avec les parents : et trois enfants se ..., 23.

${ }^{3}$ VORCARO Ângela (1999) Transferência e interpretação na clínica ..., 70. Traduction libre de l'auteure.

${ }^{4}$ JERUSALINSKY Alfredo (2011). Para compreender a criança..., 127. Traduction libre de l'auteure.

5 Voir CORIAT Lydia \& JERUSALINSKY Alfredo (1982). Aspectos estruturais e instrumentais do desenvolvimento.
} 
Nous avons discuté, au début de ce chapitre, sur des enjeux autour du diagnostic d'autisme, puisque cette psychopathologie est fortement présente dans le discours médical sur l'X fragile. Ce syndrome est considéré comme cause génétique de l'autisme, à partir des critères diagnostiques qui, à leur tour, ne sont pas fiables, pointés dans les recherches exposées au premier chapitre. Autrement dit, selon l'outil d'évaluation, il est possible qu'un enfant soit diagnostiqué autiste ou pas. Ce que nous voudrions contester dans ces recherches, c'est le caractère exclusivement organique de l'étiologie de l'autisme.

Nous avons discuté également deux concepts cruciaux de la psychanalyse, dans l'intention de nous rapprocher du dialogue avec l'épigénétique. Si cette discipline nous indique que l'environnement peut opérer des changements dans l'activité du gène, est-ce que les rapports sociaux, le rapport à l'Autre, le traitement psychanalytique - appuyé sur le transfert - ne peuvent pas également modifier le fonctionnement organique ? La découverte de la plasticité synaptique, par exemple, est une piste prometteuse pour concevoir que les expériences vécues, les stimulus qui l'enfant reçoit, produisent des traces dans le cerveau et le modifient.

Pour la psychanalyse, l'Autre non seulement opère des changements, mais au-delà, il est condition de l'émergence du sujet. C'est le symbolique, l'immersion du sujet dans le langage qui permet son assomption dans la culture, en tant que sujet du désir, capable de produire ses propres narratives, en tant que protagoniste de sa propre histoire. Jerusalinsky ainsi indique que

« ce qui permet que le désir se constitue est le fait que l'Autre mette en jeu une trace (le nom) qui aliène le sujet de son objet, opérant une séparation : cette trace, c'est donc de l'ordre du langage. Langage non pas comme fonction psychologique, mais comme structure qui capture le sujet et le situe dans son rapport à la culture $» 1$.

Dans ce sens-là, nous croyons que les marques symboliques déterminent le développement maturationnel de l'enfant et sont également impliquées dans la production de ses symptômes psychiques. Nous pouvons y apporter les contributions de Winnicott lorsqu'il souligne que le développement de l'enfant ne va pas de soi : «ce n'est pas

\footnotetext{
${ }^{1}$ JERUSALINSKY Alfredo (2010). Psicanálise e desenvolvimento infantil, 19. Traduction libre de l'auteure.
} 
simplement une question de neurophysiologie $»^{1}$, c'est-à-dire, il faut un environnement sécurisant, la mère suffisamment bonne.

Le corps de l'enfant, ainsi, n'opère pas seul ou de manière automatisée. Les déterminations symboliques capturent le corps de l'enfant, en le mettant au service de l'expression symptomatique psychique, au même temps que s'ignore ou se oppose la fonction physiologique des organes $»^{2}$, affirme Jerusalinsky. Ces déterminations se situent dans le rapport primitif, archaïque de l'infans avec ses objets. C'est cela qui Freud indique comme étant l'identification primaire dans le development de l'enfant - identification qui se confondrait avec l'investissement libidinal. Ainsi, l'identification serait « la forme la plus précoce et la plus originelle de liaison de sentiment $»^{3}$ entre l'enfant et ses objets.

Le premier objet élu par l'enfant sont ses soignants primordiaux, choisis à partir des expériences de satisfaction. L'identification « la plus significative [...] directe, immédiate et plus précoce que tout investissement d'objet $»^{4}$ est celle avec le père de la préhistoire. Cette identification implique, d'abord une reconnaissance du bébé en tant qu'humain, puis, que l'enfant soit inscrit dans une filiation. Si on utilise le langage génétique, l'Autre est facteur constitutif de l'environnement qui fait marque dans l'organisme de l'enfant. C'est donc l'Autre qui interfère dans le système pulsionnel, qui découpe le réel du corps dans des parties hétérogènes et qui délimite les zones érogènes par où l'investissement libidinal sera dirigé.

Notre pratique clinique démontre des possibles effets d'une cristallisation $\mathrm{du}$ symptôme chez l'enfant; effets parfois des signes univoques portées par la parole des parents qui, à leur tour, portent à eux les signes du discours médical. L'action de ces discours sur l'enfant sont tangibles lorsqu'on entreprend son écoute. Dans le chapitre suivant, nous établiront la présentation de trois cas cliniques pour mieux soutenir notre proposition. L'écoute non seulement de l'enfant, mais de ce qui est dit de l'enfant permet, à notre avis, d'identifier à quels signes le symptôme est attaché. Lorsque les signes sont interrogés, lorsque le sujet - et ses parents - se posent la question sur le symptôme et les singularités familiales, le caractère univoque du signe s'affaiblit pour donner place à une sorte de polysémie. C'est sur ce pari que notre pratique clinique est ancrée.

\footnotetext{
${ }^{1}$ WINNICOTT Donald (1958). La première année de la vie : conceptions modernes du développement...,

2 JERUSALINSKY Alfredo (2010). Psicanálise e desenvolvimento infantil, 24. Traduction libre de l'auteure.

${ }^{3}$ FREUD Sigmund (1921). Psychologie des masses et l'analyse du moi, 44

${ }^{4}$ FREUD Sigmund (1923). Le moi et le ça, 275.
} 


\title{
Chapitre V
}

\section{La clinique psychanalytique en acte : présentation des cas cliniques}

\subsection{Ouverture}

\begin{abstract}
Je m'efforce tout simplement d'aller au-delà d'une étiquette qui fut le point de départ de la cristallisation d'une angoisse familiale ${ }^{1}$.
\end{abstract}

Maud Manonni

$\mathrm{Au}$ chapitre précédent, nous avons présenté des concepts de la clinique psychanalytique qui nous semblent cruciaux dans son articulation avec la génétique médicale. Nous partons de l'importance de l'immersion de l'enfant dans le champ de l'Autre, c'est-à-dire le champ de la culture et du langage qui nous proposons d'introduire dans la notion d'environnement. Ce préalable implique la notion d'une constitution psychique qui nous semble prendre forme dans le concept du sujet. C'est, donc, un petit sujet qui, dans la clinique de l'enfant, établira avec le psychanalyste son transfert, concept-clé par lequel nous pouvons soutenir notre pratique en lien avec la génétique médicale.

Pour être l'un des principaux symptômes psychiques attribués au syndrome de l'X fragile, nous avons choisi l'autisme pour indiquer la manière dont la psychanalyse soutient sa pratique et intervient sur le jeune patient. Nous avons vu comment la psychanalyse pense l'enfant qui s'engage dans un suivi, qu'il soit, ou non, porteur d'un syndrome génétique ou diagnostiqué autiste. Il s'agit d'un sujet en constitution - constitution qui se fait à partir de et par la rencontre avec l'Autre, lieu du langage.

Si notre thèse prétend s'ouvrir à d'autres champs de savoir, nous présenterons dans ce chapitre trois cas cliniques issus de notre pratique, dans l'intention de mettre en évidence les moyens possibles de construire et penser les traitements en psychanalyse - des moyens qui, comme le projette ce travail, s'offrent à la lecture de professionnels issus d'autres champs de savoir, sans avoir forcément des liens avec la psychanalyse. Les cas cliniques peuvent en quelque sorte montrer les possibles effets d'un traitement psychanalytique. Nous désirons de fait, à partir d'eux, révéler les agencements possibles de la pratique

\footnotetext{
${ }^{1}$ MANONNI Maud (1964). L'enfant arriéré et sa mère, 40.
} 
psychanalytique, en particulier sur des enfants, en se concentrant sur les différentes formes d'émergence des notions de sujet et de transfert dans les tissages cliniques.

Avant d'entrer dans la présentation des cas cliniques, signalons la spécificité de la méthode psychanalytique. L'écriture des cas est un outil essentiel de la méthodologie de recherche psychanalytique, par laquelle Freud a pu construire et donner consistance à sa théorie. La prise en note de l'expérience d'écoute, initialement des hystériques, a permis à Freud de développer des concepts cruciaux de la psychanalyse, parmi lesquels l'inconscient, le transfert et la névrose. En accord avec Luiz Carlos Nogueira, «l'exposition de ces cas cliniques est en réalité la transmission de la recherche psychanalytique ${ }^{1}$. Autrement dit, les cas cliniques représentent la transmission de ce qu'est la psychanalyse elle-même. Selon Christian Dunker, «le cas clinique est l'élément central de l'argumentation psychanalytique pour défendre son efficacité, de l'explication de l'action de sa méthode et de son dialogue avec la psychopathologie $»^{2}$.

Le rapport que nous faisons ici de trois cas cliniques d'enfants à l'histoire marquée par le diagnostic de l'X fragile nous aidera à illustrer les éléments qui composent la clinique d'enfants porteurs de maladies organiques. Ils indiqueront en outre, et d'une manière générale, l'importance du dialogue entre la pratique médicale et la psychanalyse lors du traitement d'un enfant porteur d'un syndrome génétique. Il s'agit, d'une certaine manière, de cas ordinaires de la clinique psychanalytique qui ressortent dans leur ensemble et non en raison d'une spécificité surprenante. Autrement dit, on retiendra précisément ici un processus passible de répétition dans la clinique psychanalytique, processus qui concerne les enfants syndromiques, et qui consiste, d'une manière générale, en la complexification symbolique opéré chez ces jeunes patients. C'est donc à partir de ces trois cas cliniques que nous conclurons ce chapitre en énonçant notre proposition d'intervention qui se fonde sur la recherche théorico-clinique, avec comme arrière-pensée l'application de la clinique psychanalytique dans les services de génétique médicale destinés aux enfants.

Notons que les noms de toutes les personnes impliquées dans le rapport de cas ont été modifiés afin de préserver les identités de celles-ci. Tout au long du suivi, et pour chacun

\footnotetext{
${ }^{1}$ NOGUEIRA Luiz Carlos (1999). A pesquisa em Psicanálise, 84. Traduction libre de l'auteure.

${ }^{2}$ DUNKER Christian (2011). Estrutura e constituição da clínica psicanalítica, 537. Traduction libre de l'auteure.
} 
des trois patients, la prise de note a été effectuée immédiatement après chaque séance, constituant ainsi le journal clinique qui donne corps à notre débat.

5.2. Maria : le pari sur le sujet

Histoire du transfert

5.3. Flora : le mutisme comme signe du syndrome

Flora : histoire du transfert

\subsection{Le cas de Benjamin}

\subsection{Note sur une proposition de recherche théorico-clinique}

Finalement, quelle contribution la psychanalyse pourrait-elle apporter à la génétique médicale par rapport au traitement d'enfants porteurs du syndrome de l'X fragile ? En ce qui concerne ce syndrome, nous n'avons trouvé dans la littérature aucune étude psychanalytique qui aborde la thématique. Quant aux études qui abordent les aspects psychiques de l'X fragile, la plupart des recherches consultées se limitent à la quantification des symptômes comportementaux, mesurés par l'utilisation d'échelles psychométriques et/ou d'autres outils standards. Autrement dit, l'intérêt de ces études est de mesurer l'incidence d'un comportement quelconque, que ce soit pour affirmer sa présence ou son absence.

Face à la rareté des travaux qui se penchent sur les représentations psychiques qui traversent le syndrome de l'X fragile, nous avons proposé au Centre de Référence "Déficiences intellectuelles des causes rares » du Département de Génétique et Cytogénétique du Groupe Hospitalier la Pitié-Salpêtrière un projet de recherche qualitative, autour des familles d'enfants atteints de l'X fragile. L'objectif était, par le biais de la conduite d'entretiens semi-structurés avec les parents de chaque enfant, de produire un matériel abordant les représentations psychiques autour du syndrome. En d'autres termes, nous cherchions à cerner les possibles conséquences psychiques qui caractérisent l'expérience des parents d'avoir un enfant atteint de l'X fragile. Pour ce faire, nous avons distingué quatre 
temps généraux que nous considérons décisifs dans la relation parents-enfant et dans le développement de l'enfant, et où peuvent être relevés les aspects subjectifs en question :

1) Avant la naissance : l'enfant qui a été imaginé, et peut-être idéalisé par ses parents ;

2) L'enfance avant le diagnostic : le contexte familial et le comportement de l'enfant avant la confirmation d'une maladie génétique ;

3) L'annonce du diagnostic et ses effets à court terme : de possibles effets sur la dynamique familiale et sur le comportement de l'enfant ;

4) L'enfance après le diagnostic : la configuration de la dynamique familiale, le rapport des parents avec l'enfant atteint de l'X fragile.

Bien qu'approuvé par le chef de service du laboratoire, ce projet n'a pu être exécuté, en raison d'une impasse opérationnelle ${ }^{1}$.

À l'orée de notre retour au Brésil où allait se réaliser la seconde partie de notre recherche doctorale, nous avons proposé un autre projet au Service de Génétique Médicale de l'Hospital de Clínicas de Porto Alegre. Dans ce projet, plus ambitieux d'un certain point de vue, l'idée était de proposer un accompagnement psychanalytique à des enfants diagnostiqués porteurs de l’X fragile et traités au sein du service de Génétique Médicale. Nous y proposions un travail d'enquête sur les effets cliniques que la psychothérapie régulière pourrait apporter au niveau des symptômes des enfants porteurs de l'X fragile. L'objectif était d'évaluer, à la fin de la recherche, les éventuelles améliorations dans le cadre symptomatique de l'enfant présenté au début du traitement. La méthodologie utilisée pour servir de base aux consultations s'est construit autour de quatre moments :

1) Entretiens initiaux semi-structurés pour l'élaboration du premier rapport, constitué par le discours des parents / responsables et par l'observation du thérapeute ;

2) Le thérapeute, sur la base des opérateurs psychanalytiques du transfert et de l'attention flottante, identifie les contenus psychiques relatés dans les comptes-rendus écrits des séances ;

3) Le matériel clinique est évalué au travers d'une analyse de contenu, faisant appel aux concepts psychanalytiques ;

\footnotetext{
${ }^{1}$ Cette thèse, réalisée en cotutelle, se divise en deux moments : deux ans à l'Université Paris Diderot et deux ans à l'Université de Sao Paulo. Le projet en question a été approuvé peu de temps avant notre retour au Brésil où s'est initié la seconde partie du travail. Nous ne disposions alors plus du temps nécessaire pour l'exécuter.
} 
4) Un second rapport est élaboré à la fin du suivi, également constitué des témoignages des parents et des observations du thérapeute, afin d'être comparé, en fin de recherche, au rapport initial.

Ce projet a également été approuvé par le Comité d'Éthique et Recherche de l'Hospital de Clínicas et se trouve aujourd'hui au début de son exécution. Il sera donc impossible d'en aborder ici les données, dans la mesure où son approbation a demandé un temps d'attente relativement long et que le délai défini pour la remise de cette thèse s'est avéré insuffisant pour permettre leur collecte et leur analyse. Toutefois, vu son importance, nous avons annexé à cette thèse le projet de recherche approuvé par le Service de Génétique Médicale de l'Hospital de Clínicas de Porto Alegre, donnant ainsi à ce travail une ligne d'horizon.

Derrière les deux projets de recherche que nous avons élaborés, se trouve le véritable moteur de notre travail : proposer une approximation de la psychanalyse avec la génétique médicale, à travers l'inclusion de la psychanalyse dans le traitement proposé aux enfants porteurs de syndromes génétiques. Bien qu'il n'ait pas été possible de rapporter les résultats de cette approximation, tout le processus d'élaboration et d'adéquation des projets, le contact avec les médecins, la sollicitation d'autorisation à l'Hôpital pour son exécution, nous semblent valides et laissent entrevoir un chemin sinueux mais empruntable pour la rencontre entre les deux champs de savoir. Si nous avons choisi le syndrome de l'X fragile pour proposer un dialogue avec la génétique médicale, ce sentier ouvert pourra aussi bien être utilisé par tous les psychanalystes, médecins et autres professionnels intéressés par cette intersection de savoirs en ce qui concerne le traitement d'enfant porteurs de syndromes génétiques.

\subsection{Conclusion}

Ce dernier chapitre mise sur les concepts de sujet et transfert comme éléments théoriques clés de l'articulation entre médecine génétique et psychanalyse. À partir de ces concepts et du rapport du Cas Maria, nous avons introduit également la notion de fantasme, comme pilier de la clinique psychanalytique, particulièrement flagrant dans le travail avec des enfants, dans la mesure où ceux-ci convoquent viscéralement le thérapeute dans les trames fantasmatiques de leurs jeux. En conséquence, le fantasme apparaît ici comme une 
dimension systématiquement travaillée à partir de chaque rapport clinique. La discussion du Cas Maria soulève cependant des doutes sur l'inclusion du concept lacanien de lettre pour penser un possible dédoublement que la jeune fille opère par rapport au $X$ de sa maladie de l'X fragile au X de Xuxa.

Les topiques suivants, abordant les cas de Flora et Benjamin, présentent globalement des mouvements cliniques semblables à celui du cas de Maria, c'est-à-dire une certaine prise de consistance du tissu symbolique, marquée dans les trois cas par un dédoublement dans l'acquisition du langage (dans la possibilité d'adresse de la parole à l'Autre) et par un enrichissement des trames fantasmatiques. Nous insistons sur le fait qu'au travers de ces cas cliniques, relativement ordinaire pour le travail de la psychanalyse, nous cherchons à marquer une répétition générale des effets palpables que cette dernière est susceptible d'apporter, et des possibilités de production de ces effets chez des enfants syndromiques ou sujets à des limitations organiques. Finalement, l'expérience et le champ clinique se présentent à nous comme un support possible à l'articulation que nous proposons avec insistance : c'est dans l'émergence du sujet en transfert que s'inscrit une rencontre possible. 


\section{Considérations finales}

L'écriture de cette thèse touche à sa fin. Toutefois, la conclusion que nous en tirons pour autant qu'il soit possible d'arriver à une conclusion quant à notre parcours -, c'est qu'il s'agit en fait d'un commencement. La fin de ce travail ouvre sur de nouveaux horizons de recherche impliquant une intersection entre psychanalyse et génétique médicale. Nous croyons en effet qu'au-delà du syndrome de l'X fragile, et même au-delà de la génétique, le dialogue que nous proposons dans notre thèse peut s'étendre à d'autres domaines concernés par l'investigation de nouveaux modes d'action face aux questions humaines.

Nous pensons avoir trouvé dans les recherches en épigénétique des brèches possibles pour la construction d'un travail en articulation. Si la science se trouve confrontée - et elle l'a démontré - à des marques épigénétiques causées par l'action de l'environnement, la psychanalyse, comme nous l'avons indiqué dans le chapitre quatre, considère que les marques dues à la rencontre de l'enfant avec l'Autre du langage sont ce qui constitue le sujet. Ce sont ces marques, symboliques, qui permettent et conditionnent le développement de l'enfant et de ses acquisitions instrumentales d'échange avec le milieu.

Tout d'abord, nous avons abordé, dans le premier chapitre, les rencontres - réussies et manquées - de la psychanalyse avec différentes branches de la médecine. Lors d'un bref retour à Freud, nous avons signalé le rapport intrinsèque de l'apparition de la psychanalyse liée à la clinique médicale. Nous avons indiqué que la coupure épistémologique effectuée par Freud était plutôt due à son choix d'objet de recherche - les «facteurs psychologiques » - qu'à un refus explicite de considérer les possibles facteurs organiques qui seraient aussi imbriqués dans le fonctionnement de l'appareil psychique.

Toujours dans le premier chapitre, nous avons signalé certains travaux qui nous servent de références et qui indiquent, d'une certaine manière, différentes possibilités de l'action de la psychanalyse auprès du milieu médical. Nous avons ainsi cité des auteurs ayant témoigné de leurs pratiques à l'hôpital, en tant que membres de l'équipe de soins. Nous avons pu noter que les différentes populations prises en charge par les psychanalystes présentaient un point commun dans leurs pratiques : il s'agissait d'offrir, par l'écoute clinique, un lieu pour les représentations psychiques qui traversent le corps malade en demande de soins, et qui jouent aussi un rôle décisif dans la composition du tableau clinique. Nous avons également cité des travaux qui sont pour nous fondamentaux pour la construction du dialogue entre le savoir 
psychanalytique et le savoir médical, notamment celui des neurosciences. La notion de plasticité cérébrale indique que l'expérience laisse une trace - les connexions neuronales sont organisées, réorganisées ou supprimées à partir de la convocation de l'activité cérébrale faite par l'expérience. Avec la découverte de la plasticité cérébrale, nous avons pu observer que « le cerveau n'est pas une instance fixe et rigide, programmée une fois pour toutes, mais que sa forme, qui dépend de la taille et du volume des connexions entre neurones, est soumise à variation et à modification au cours de la vie $»^{1}$. Le dialogue avec les neurosciences est également un champ fertile pour la production de nouvelles recherches portant sur la constitution et sur l'organisation du psychisme. La rencontre de la psychanalyse et de la génétique médicale se montre encore, d'une certaine manière, timide. Toutefois, les travaux que nous avons mis en relief annoncent que la psychanalyse a aussi quelque chose à dire et à apporter en ce qui concerne les affections d'ordre génétique. Et c'est dans le but d'élargir ce débat et de proposer une pratique que nous avons développé notre thèse.

La prise en compte de la dimension psychique dans le milieu médical, où dominent des questions d'ordre objectif - y compris où le risque de mort est imminent - se révèle un enjeu qui exige une position éthiquement et épistémologiquement fondée. Pour nous, les pratiques cliniques des travaux exposés dans ce premier chapitre indiquent, au-delà de la prise en compte de la dimension psychique dans le contexte de la maladie, la réintroduction du sujet dans le discours médical. C'est également à partir de cette prémisse que nous proposons notre pratique en articulation avec le savoir de la génétique médicale, particulièrement en ce qui concerne le traitement offert aux enfants porteurs de syndromes génétiques.

Nous avons choisi le syndrome de l'X fragile pour servir de pont au rapprochement de la psychanalyse et de la génétique médicale. Notre rencontre avec ce syndrome a eu lieu durant notre pratique clinique, lorsque nous avons pris la petite Maria en psychothérapie. Comme nous avons ressenti le besoin d'approfondir nos connaissances sur cette maladie, nous avons mené une recherche bibliographique, qui a fait l'objet de notre second chapitre. Nous avons exposé les facettes du discours sur ce syndrome au fil des années, depuis sa découverte. Causé par la mutation du gène FMR1, le syndrome de l'X fragile est considéré comme la principale cause de déficience intellectuelle héritée, transmis aussi bien par le père que par la mère à leurs descendants.

\footnotetext{
${ }^{1}$ MALABOU Catherine (2011). Souffrance cérébrale, souffrance psychique et plasticité, 489.
} 
La symptomatologie comportementale ${ }^{1}$ exposée dans la littérature - qui indique une dimension psychique - a provoqué en nous une certaine étrangeté et nous ne nous sommes pas gardé de remettre en question le rapport biunivoque entre mécanisme organique et symptôme comportemental. Pour nous, il demeure discutable d'affirmer que l'absence de production de la protéine FMRP serait à la fois responsable du déclenchement de diagnostics aussi différents que la névrose obsessionnelle et l'autisme, par exemple. Nous comprenons l'importance de cette protéine comme régulatrice des processus synaptiques. Cependant, ce passage direct du processus neurophysiologique au symptôme psychique, sans que soient prises en compte d'autres causalités, mérite d'être remis en question - cette remise en cause étant la source de nouvelles études. Dans ce contexte, l'association de l'X fragile à l'autisme a également été l'objet de questionnement dans ce chapitre. Historiquement, le syndrome a été considéré comme cause génétique prévalente de l'autisme, notion qui, effectivement, est fortement soutenue par des recherches contemporaines en génétique médicale ${ }^{2}$. Toutefois, dans ce chapitre, nous avons présenté des études soutenant que cette association est inappropriée, fruit de failles dans l'utilisation des critères diagnostiques différentiels.

L'évolution de la dimension du traitement de ce syndrome a également retenu notre attention. Comme nous l'avons observé dans le chapitre deux, les propositions thérapeutiques sont peu nombreuses et les rares existant se limitent à la perspective de gestion des symptômes par des médicaments ou des pratiques éducatives. Les psychothérapies sont rarement indiquées et, lorsqu'elles sont suggérées, elles adoptent toutes un abordage cognitivo-comportemental. Il n'y a pas encore de prévision de cure pour la mutation génétique - les études contemporaines se penchent sur le targeted-treatment : il s'agit, en utilisant le modèle animal, d'introduire directement dans la cellule des molécules qui aideraient à pallier les effets de l'absence de la protéine FMRP. Si les résultats des recherches sur le rat ont été considérés comme satisfaisants, cela n'a toutefois pas été le cas dans les recherches sur l'homme ${ }^{3}$.

C'est par le biais du traitement que nous avons résolu de promouvoir le dialogue entre la psychanalyse et la génétique. Nous proposons que la psychanalyse puisse aussi être incluse dans les soins offerts aux enfants syndromiques. Pour ce faire, nous avons cherché

\footnotetext{
${ }^{1}$ Voir le chapitre deux. Parmi les symptômes, citons notamment l'hyperactivité, l'autisme, la phobie sociale, la névrose obsessive, les troubles du langage.

${ }^{2}$ Voir BERRY-KRAVIS Elisabeth (2014). Mechanism based treatments in neurodevelopmental...

${ }^{3}$ Voir THURMAN Angela, McDUFFIE Andrea, HAGERMAN Randi and ABBEDUTO Leonard (2014).

Psychiatric symptoms in boys...
} 
une voie permettant de rapprocher la psychanalyse de ce champ. Nous avons tenté de promouvoir cette rencontre par les nouvelles études fournies par l'épigénétique, dont la prémisse fondamentale est d'indiquer que l'activité génique est modifiée par l'environnement, et que ces modifications peuvent être transmises à la génération suivante.

Nous avons donc mené, dans notre chapitre trois, une recherche bibliographique sur l'épigénétique, pour chercher tout autant à en comprendre l'objet et les propositions dans le domaine de la génétique, qu'à nous demander quelles recherches menées dans ce domaine pourraient s'ouvrir au savoir psychanalytique. Nous avons pris soin d'indiquer ce que la génétique considère comme environnement et de quelles modifications dans l'activité du gène il s'agissait. Nous avons trouvé diverses recherches utilisant le modèle animal, qui observent que les soins maternels précoces (des mères rates) étaient de potentiels modulateurs de l'expression génétique des bébés rats. La conclusion des chercheurs selon laquelle les expériences vécues au début de la vie peuvent provoquer des modifications neurophysiologiques, des modifications du comportement, voire des marques épigénétiques pouvant être transmises aux générations suivantes ${ }^{1}$, nous semble une porte ouverte pour introduire dans la génétique la conception même d'environnement pour la psychanalyse. C'est la rencontre avec l'Autre primordial, incarné par ceux qui s'occupent de l'enfant, qui conditionne et qui permet son développement et, partant, l'émergence du sujet. Il s'agit là d'une notion cruciale par laquelle la psychanalyse, telle que nous la concevons ici, pourrait proposer à la génétique médicale comme formule d'articulation théorico-cliniques - les échanges avec l'Autre étant un facteur également constitutif de ce que la génétique comprend comme environnement (nous y reviendrons).

Nous avons également trouvé des recherches-pilotes qui considéraient la psychothérapie comme un environnement capable de provoquer, voire d'effacer des marques épigénétiques chez les populations étudiées ${ }^{2}$. Il convient de souligner que l'abordage utilisé était la théorie cognitivo-comportementale (TCC), et que, de notre point de vue, cela se justifie par les affinités ontologiques et épistémologiques de cette théorie avec le discours médical. Nous ne considérons toutefois pas ce rapprochement de l'abordage comportemental et de la génétique médicale comme exclusif et définitif. Nous pensons que la non-inclusion de la psychanalyse dans ces recherches est due, en premier lieu, au nondialogue entre ces deux domaines - dialogue que cette thèse vise à soutenir de bout en bout.

\footnotetext{
${ }^{1}$ Voir TATA Despina et al. (2015). Effects of maternal separation on behavior and brain damage...

${ }^{2}$ Voir PERROUD Nader et al. (2013). Response to psychotherapy in borderline personality disorder...
} 
Relevons, au-delà ou en deçà des divergences entre les domaines en question, une méconnaissance mutuelle flagrante. En second lieu, elle est également due à l'existence de possibles résistances du fait que les effets de la psychanalyse ne soient pas quantifiables, vu qu'elle n'a pas recours à des instruments standardisés capables de les mesurer. Les cas cliniques exposés dans le dernier chapitre nous permettent de remarquer qu'il existe des effets pouvant être observés tant dans le discours que dans la propre reconfiguration du symptôme présenté par l'enfant. Ce sont justement les effets auxquels s'intéresse le savoir médical. Il nous semble tout à fait possible que la psychothérapie psychanalytique soit adoptée comme outil de soins pour les enfants porteurs de syndromes génétiques.

Relevons donc les brèches dans le discours sur lesquelles nous parions comme voies permettant à la psychanalyse d'entrer en tant que traitement possible. C'est ainsi, à partir d'ouvertures qui fragilisent les résistances et qui réinventent les constructions du savoir, que deviendra possible une articulation entre génétique médicale et psychanalyse. Articulation dont le principe repose sur le pari que cette réinvention du savoir rendra plus consistants aussi bien la recherche que le traitement. Reprenons le passage suivant d'Ansermet et Giacobino : «Loin de réduire le comportement du sujet à un dysfonctionnement inadapté à normaliser, la psychanalyse est un pari épistémologique et éthique sur la clinique ${ }^{1}$. C'est sur ce pari de l'émergence d'un sujet, avant tout diagnostic qui le représente, que la clinique psychanalytique mobilise sa pratique. Et nous insistons : si un diagnostic est nécessaire en ce qui concerne la conduite du traitement, son effet peut avoir de sérieuses conséquences sur le développement de l'enfant. Comme nous l'avons vu dans les cas cliniques exposés, il se peut également que le diagnostic - ou le simple soupçon de diagnostic - contribue à la production de symptômes psychiques ou d'entraves au développement de la constitution même du sujet.

Revenons maintenant au débat entre psychanalyse et génétique médicale à partir de la notion d'environnement, dans lequel nous pouvons penser que la psychanalyse met en relief, de façon prépondérante, la dimension de l'Autre. Dans son séminaire Les quatre concepts fondamentaux de la psychanalyse, Lacan reprend quelques-unes de ses conceptions de base, en proposant notamment que l'inconscient n'est pas ontique, dans le sens où il ne se réduit pas à un individu, où l'inconscient est tissé par rapport à une structure sociale et langagière qui est préexistante au petit humain et où c'est dans cette structure que le sujet peut s'ourdir.

\footnotetext{
${ }^{1}$ ANSERMET François \& GIACOBINO Ariane (2012). Autisme : à chacun son génome, 75.
} 
Ce qui serait ontique dans la «fonction de l'inconscient $»^{1}$, affirme Lacan, c'est la béance aux inscriptions des traits qui entrent en jeu dans le rapport du sujet à l'Autre.

Comme c'est justement par cette voie que nous pensons l'articulation entre psychanalyse et génétique, notamment l'épigénétique, nous avons présenté et développé dans le chapitre quatre les notions de sujet et de transfert, car nous jugeons que ce sont des concepts-clés pour la proposition de la clinique psychanalytique comme possibilité thérapeutique pour les enfants porteurs de syndromes. Ce que vient indiquer le concept de sujet, apporté par la psychanalyse, c'est que cette expérience qui s'inscrit en forme de trace, est rendue possible justement par l'action de l'Autre du langage. Nous insistons : la condition d'être humain dépend de l'insertion du bébé dans le champ du langage, dans le champ de l'Autre.

Quant au transfert, ce serait le pari sur un traitement qui agisse justement par rapport - le rapport transférentiel. Pour que le transfert s'établisse, il faut que la parole soit adressée à quelqu'un qui l'écoute ${ }^{2}$. C'est par la voie du transfert qu'un déplacement symptomatique (que ce soit son atténuation ou même son extinction) peut être visé. Nous insistons toujours avec Freud qu' « une analyse sans transfert est une impossibilité » ${ }^{3}$. Ainsi, si nous proposons une articulation par le biais du traitement psychanalytique, il est impossible de ne pas considérer, parmi les effets prétendus, la condition et la manifestation mêmes du transfert pour que se produise quelque chose visant à la cure.

Nous reconnaissons la nécessité de l'existence d'un appareil physiologique à partir d'où la dimension psychique, les marques symboliques, puissent organiser les fonctions corporelles. Il faut un corps apte, un système nerveux central qui permette aux inscriptions, aux traces de l'expérience d'être enregistrées. C'est dans ce contexte que nous soulignons que l'organique est traversé par l'action du langage - du rapport avec l'Autre -, tout autant que son fonctionnement est la condition pour que s'opère le tissage du sujet. La prévalence de chacun ne pourra être observée qu'à partir du cas par cas, ce qui vaut autant pour le savoir médical que pour le savoir psychanalytique.

Dans notre cinquième et dernier chapitre, nous avons présenté trois cas cliniques d'après lesquels nous avons pu observer de quelle façon les conceptions de sujet et de transfert se reflètent sur la pratique clinique. Le récit des cas de trois enfants dont les

\footnotetext{
${ }^{1}$ Voir LACAN Jacques (1964). Les quatre concepts fondamentaux de la psychanalyse, 39.

${ }^{2}$ Voir LACAN Jacques (1960-1961). Le transfert.

${ }^{3}$ FREUD Sigmund (1925). Autoprésentation, 89.
} 
histoires ont été traversées par le diagnostic du syndrome de l'X fragile indique à quel point est singulière l'expérience d'être porteur - ou de supposer être porteur - d'une maladie génétique, et, notamment, à quel point est singulière également l'expérience analytique. Certes, les effets de cette rencontre ne peuvent pas être mesurés, mais ils sont tangibles et significatifs au long du parcours clinique.

C'est le pari sur le devenir du sujet et de son désir qui ancre notre pratique et notre éthique. En pensant à la possibilité d'étendre la portée de cette pratique, nous nous sommes rendue à la rencontre de deux services de génétique, dans deux hôpitaux différents, situés dans différents pays, dans la même intention: l'inclusion de la psychanalyse comme traitement possible des enfants porteurs de l'X fragile. L'acceptation de notre présence et de notre projet d'intervention dans ces deux services est un premier pas vers l'intersection des savoirs que nous visons. Nous nous hasardons à supposer qu'à l'avenir, fondés sur les études épigénétiques, les effets d'un traitement psychanalytique puissent être pris comme objet d'investigation également empirique. Ainsi, finalement, psychanalyse et génétique médicale se retrouveront autour des incontournables facettes qui constituent ce qui demeure humain trop humain. 


\section{Références Bibliographiques}

ABBEDUTO Leonard, MCDUFFIE Andrea and THURMAN Angela (2014). The fragile X syndrome-autism comorbidity: what do we really know ? Frontiers in genetics. 5:355: $1-10$.

ALBERINI Cristina (2010). La dynamique des représentations mentales. Neurosciences et psychanalyse: une rencontre autour de la singularité. Sous la direction de MAGISTRETTI P. \& ANSERMET F. Paris : Odile Jacob.

ALBERTI, Sonia. \& FULCO, Ana Paula (2005). Um estudo, uma denúncia e uma proposta: a psicanálise na interlocução com outros saberes em saúde mental, como avanço do conhecimento sobre o sofrimento psíquico. Revista Latinoamericana de Psicopatologia Fundamental, VIII Diciembre-Sin mes, 721-737.

ALLOUCH Éliane (2015). Corps et psyché en psychanalyse : l'apport de l'autisme et des psychoses infantiles. Paris, Campagne Première.

AMERICAN PSYCHIATRIC ASSOCIATION (1980). Mini DSM-III : Critères diagnostiques. Traduction française par J.-D. Guelfi. Paris : Masson, 1984.

AMERICAN PSYCHIATRIC ASSOCIATION (1987) DSM-III-R : Manuel diagnostique et statistique des troubles mentaux. Texte révisé. Traduction française par J.-D. Guelfi. Masson, Paris, 1989.

AMERICAN PSYCHIATRIC ASSOCIATION - DSM-IV (1995) Manuel diagnostique et statistique des Troubles mentaux, $4^{\circ}$ édition. Traduction française par J.-D. Guelfi et al. Masson, Paris, 1996.

AMERICAN PSYCHIATRIC ASSOCIATION (2013). Diagnostic and Statistical Manual of Mental Disorders, 5th ed. American Psychiatric Association, Arlington, VA.

ANSERMET François (2009). Le vertige de savoir : Psychanalyse et Médecine prédictive. Mental Revue Internationale de Psychanalyse, Paris, 144-151.

ANSERMET François \& MAGISTRETTI Pierre (2004). À chacun son cerveau : plasticité neuronale et inconscient. Paris : Odile Jacob.

ANSERMET François \& GIACOBINO Ariane (2012). Autisme : À chacun son génome. Paris, Navarin - Champ Freudien.

ARMSTRONG Lyle (2014). Epigenetics. New York and London: Garland Science. 
ASPERGER Hans (1944). Les psychopathes autistiques pendant l'enfance. Traduction française par E. Wagner, N. Rivollier et D. l'Hôpital. Paris : Institut Synthélabo, 1998. AUBERT GODARD Anne (2002). L'aventure de la grossesse, aujourd'hui. Laennec, Vol. 2, Tome 50, 38-63.

AUBERT GODARD Anne (2005). Filiation en question : maladies génétiques, identités incertaines, filiations perturbées. Dialogue, $\mathrm{n}^{\circ} 168,25-44$.

AULAGNIER Piera (1975). La violence de l'interprétation. Paris: PUF, 2003.

AUSSILOUX Charles (2003). Le syndrome de l'X fragile : suivi médical, psychologique et éducatif: actes du colloque du 25 janvier 2003. Paris : Mosaïques, 2004.

BALZAGETTE Gérard (2015). La discontinuité neuropsychique. Figures de la psychanalyse, $\mathrm{n}^{\circ} 28,41-50$.

BARROS Manoel de (2010) Poesia completa. Rio de Janeiro: Leya.

BENTATA Hervé (2013). L'autisme aujourd'hui: Quelques vérités issues de l'histoire et de l'expérience. La Revue Lacanienne, 14: 63-66.

BEHL Mamta, RAO Deepa, AAGAARD Kjersti et al. (2013). Evaluation of the Association between Maternal smoking, childhood obesity and Metabolic Disorders : A National Toxicology Program Workshop Review. Environ. Health Perspect. 121:170-180.

BERNARDINO Leda (2004). As psicoses não-decididas da infância: um estudo psicanalítico. São Paulo: Casa do Psicólogo.

BERRY-KRAVIS Elizabeth et al., (2012). Effects of STX209 (Arbaclofen) on Neurobehavioral Function in Children and Adults with Fragile X Syndrome: A Randomized, Controlled, Phase 2 Trial. Sci Transl Med 4, 152ra 127.

BERRY-KRAVIS Elizabeth, (2014). Mechanism Based Treatments in Neurodevelopmental Disorders: Fragile X Syndrome. Pediatric Neurology xx : 1-6.

BICK Esther (1967). L'expérience de la peau dans les relations d'objet précoces. Les écrits de Martha Harris et d'Esther Bick. Traduction française par Jacques Pourrinet et Jeanne Pourrinet. Larmor-Plage: Hublot, 1998.

BORODYANSKAYA, M., COFFEY S., ONO M. and HAGERMAN R. (2010) Intergenerational effects of mutations in the fragile $\mathrm{X}$ mental retardation 1 gene. In M.A. Barnes (org) Genes, brain and development: The neurocognition of genetic disorders. New York: Cambridge University Press.

BRUN Danièle (2010). «La place de la psychanalyse dans la médecine », selon Jacques Lacan. Cliniques méditerranéennes, n82, 63-71. 
BRUN Danièle (2015). L'expérience de la Société Médecine et Psychanalyse : Hasard, Besoin, Désir ? Le Coq-héron, $\mathrm{n}^{\circ} 222,77-79$.

CALLIGARIS Contardo (1983). Hypothèse sur le fantasme. Paris: Seuil.

CHRISTIAN Susan (2008) Novel Submicroscopic chromosomal abnormalities detected in Autism Spectrum Disorder. In: Biol Psychiatry June 15; 63(12): 1111-1117.

CHONCHAIYA Weerasak, SCHNEIDER Andrea et HAGERMAN Randi (2009). Fragile $\mathrm{X}$ : A Family of Disorders. Advances in Pediatrics, $\mathrm{n}^{\circ}$ 56, 165-186.

CLAVREUL Jean (1978). L'ordre medical. Paris: Seuil.

COHEN, M., NERI G. and WEKSBERG R. (2002). Overgrowth syndromes. Oxford et Paris: Oxford University Press.

COOK Denise, NURO Erin and MURAI Keith K. (2014). Increasing our Understanding of Human Cognition Through the Study of Fragile X Syndrome. Inc. Develop. Neurobiol. 74:147-177.

CORDEIRO Lisa, BALLINGER Elizabeth, HAGERMAN Randi, HESSL David, (2011). Clinical assessment of DSM-IV anxiety disorders in fragile X syndrome: prevalence and characterization. Journal of Neurodevelopment Disorders, 3:57-67.

CORIAT Lydia \& JERUSALINSKY Alfredo [1982]. Aspectos estruturais e instrumentais do desenvolvimento. In: Escritos da Criança. Porto Alegre: Centro Lydia Coriat, 1996.

CORIAT Elsa (1997). Psicanálise e clínica de bebês. Porto Alegre: Artes e Ofícios.

CORNISH Kimberly, LEVITAS Andrew and SUDHALTER Vioki, (2007). Fragile X syndrome: the journey from genes to behavior. In: Neurogenetic developmental disorders: variation of manifestation in childwood. Edited by Mazzocco and Ross. Cambridge: MIT Press.

CRESPIN Graciela (2007). L'épopée symbolique du nouveau-né: de la rencontre primordiale aux signes de souffrance précoce. Ramonville Saint-Agne : Erès.

DAVIES Kay (1989). The Fragile X Syndrome. Oxford: Oxford University Press.

DEFOE Daniel (1719). Robinson Crusoé. Paris: Gallimard, 2001.

DEJOURS Christophe (2001). Le corps, d'abord. Paris : Payot.

DOLTO Françoise (1985). La cause des enfants. Paris : Robert Laffont.

DOLTO Françoise (1986). Tout est langage. Paris : Gallimard, 1994.

DUNKER Christian (2011). Estrutura e constituição da clínica psicanalítica. São Paulo: Annablume. 
DYKENS Elisabeth, HODAPP Robert. and LECKMAN James. (1994). Behavior and development in fragile X syndrome. London: Sage Publications.

ECO Umberto (1979). Lector in Fabula. São Paulo, Nova Perspectiva, 2004.

FENDRICK Silvia (2011). O DSM-IV: uma metafisica comportamentalista? O livro negro da psicopatologia contemporânea. Jerusalinsky e Fendrik (orgs.). São Paulo: Via Lettera.

FIRST Michael, FRANCES Allen and PINCUS Harold Alan. (1995). DSM-IV: Diagnostics différentiels. Paris : Masson, 1999.

FORBES Jorge (2007). Uma hipótese de trabalho: A influência da Psicanálise sobre a expressão dos Genes. Asephallus. Revista eletrônica do núcleo Sephora, vol. 3, nº 5 , 28-32.

FORBES Jorge (2011). Desautorizando o sofrimento socialmente padronizado em pacientes afetados por doenças neuromusculares (Tese de doutorado). Programa de Neurologia da Faculdade de Medicina da Universidade de São Paulo, São Paulo.

FOUCAULT Michel (1963). Naissance de la clinique. Paris : PUF, 2009.

FREUD Sigmund (1888-1893). Quelques considérations pour une étude comparative des paralysies motrices organiques et hystériques. Archives de Neurologie, 26 (77), 2943.

FREUD Sigmund (1895) Esquisse d'une psychologie. Toulouse : Érès, 2011.

FREUD Sigmund (1895). Études sur l'hystérie et textes annexes. CEuvres complètes, v. II, Paris : PUF, 2005.

FREUD Sigmund (1887-1902). La naissance de la psychanalyse. Paris : PUF, 2009.

FREUD Sigmund (1900). L'interprétation du rêve. Euvres complètes, v. IV, Paris : PUF, 2003.

FREUD Sigmund (1901). La psychopathologie de la vie quotidienne. Cuvres complètes, v. V, Paris : PUF, 2012.

FREUD Sigmund (1905). Dora : Fragment d'une analyse d'hystérie. Paris : Quadrige/PUF, 2010 .

FREUD Sigmund (1908). Le poète et l'activité de la fantaisie. Euvres complètes, v. VIII. Paris : PUF, 2007.

FREUD Sigmund (1912). Sur la dynamique du transfert. Cuvres complètes, v. XI, Paris : PUF, 2009. 
FREUD Sigmund (1914). Pour introduire le narcissisme. Euvres complètes, v. XII, Paris : PUF, 2005.

FREUD Sigmund (1915). Métapsychologie. Paris : Gallimard, 2009.

FREUD Sigmund (1916-1917). Leçons d'introduction à la psychanalyse. Euvres complètes, Paris : Quadrige /PUF, 2010.

FREUD Sigmund (1918). L'Homme aux loups. Cinq psychanalyses. Paris : Quadrige/PUF, 2014.

FREUD Sigmund (1923). Le moi et le ça. CEuvres complètes, v. XVI, Paris : PUF, 2010.

FREUD Sigmund (1925). Autoprésentation. CEuvres complètes, v. XVII, Paris : PUF, 2006.

FREUD Sigmund (1937). L'analyse finie et l'analyse infinie. Euvres complètes, v. XX, Paris : PUF, 2010.

FRIES Gabriel (2014). O papel da resiliência celular, estresse e epigenética na patofisiologia, progressão e resposta ao tratamento dos transtornos de humor. Tese de doutorado apresentada ao Programa de Pós-Graduação em Ciências BiológicasBioquímicas da Universidade Federal do Rio Grande do Sul, Porto Alegre.

FRYNS Jean-Pierre (1989). X-linked mental retardation and the fragile X syndrome: a clinical approach. The Fragile X syndrome. Edited by Kay Davies. Oxford, Oxford University Press.

GALLAGHER, A., \& HALLAHAN, B. (2012). Fragile X-associated disorders: A clinical overview. Journal of Neurology, 259, 401-413.

GAO Fen-Biao (2002). Understanding Fragile X syndrome: Insights from Retarded Flies. Revue Neuron, San Francisco, 859-862.

GARBER K., VISOOTSAK J. and WARREN S. (2008). Fragile X syndrome. European Journal of Human Genetics: Jun; 16(6) 666-72.

GARGIULO Marcela (2009). Vivre avec une maladie génétique. Paris : Albin Michel.

GARGIULO Marcela et DURR Alexandra (2014). Anticiper le handicap. Les risques psychologiques des tests génétiques. Esprit, nº 406, 52-65.

GEORGIEFF Nicolas (2010). Psychanalyse, neurosciences et subjectivités. Neuropsychiatrie de l'enfance et de l'adolescence, $\mathrm{n}^{\circ} 58,343-350$.

GOLSE Bernard (2011). Le modèle psychanalytique dans le champ du handicap : approche causale ou approche narrative ? Contraste, $\mathrm{n}^{\circ} 34-35,157-178$.

GOLSE Bernard (2012). Entre neurosciences et psychanalyse : un dialogue enfin possible et qui pourtant dérange. Adolescence, $\mathrm{n}^{\circ} 80,269-285$. 
GOLSE Bernard (2012). Quelle prise en charge pour les enfants autistes aujourd'hui ? Autisme et secteur de psychiatrie infanto-juvénile. Sous la direction de Jacques SAFARTY. Paris : PUF.

GOLSE Bernard (2013). Mon combat pour les enfants autistes. Paris : Odile Jacob.

GONON François (2011). La psychiatrie biologique : une bulle spéculative ? In : Esprit. Novembre 2011, 54-73.

GORI Roland \& DEL VOLGO Marie-José. (2005). La santé totalitaire : Essai sur la médicalisation de l'existence. Paris: Flammarion.

GÜRKAN Kagan and HAGERMAN Randi (2012). Targeted treatments in autism and fragile X syndrome. Research in Autism Spectrum Disorders, 6:1311-1320.

HALL Scott, LIGHTBODY Amy, HIRT Melissa, REZVANI Ava and REISS Allan, (2010). Autism in Fragile X Syndrome: A Category Mistake? J. Am. Acad. Child Adolesc. Psychiatry, 49 (9):921-933.

HAGERMAN Randi (1989). Behaviour and treatment of the fragile $\mathrm{X}$ syndrome. The Fragile X syndrome. Edited by Kay Davies. Oxford, Oxford University Press.

HAGERMAN J. \& HAGERMAN P. (2002). Fragile X syndrome: diagnosis, treatment and research. Third edition. New York: The Johns Hopkins University Press.

HAGERMAN Randi et al. (2009) Advances in the Treatment of Fragile X Syndrome. Pediatrics, 123;378 (DOI: 10/1542/peds.2008-0317).

HEARD Edith., Épigénétique et mémoire cellulaire. Leçons inaugurales du Collège de France (2013), Fayard.

HENDERSON Christina et al. (2012). Reversal of Disease-Related Pathologies in the Fragile X Mouse Model by Selective Activation of GABAв Receptors with Arbaclofen. Science Translation Medicine, 4, 152ra 128.

HOGENBOOM Marga. (2001). Living with genetic syndromes associated with intellectual disability. London, Philadelphia: Jessica Kingsley Pub.

IRWIN Scott, WEILER Ivan Jeanne, BECKEL-MITCHENER Andrea and GREENOUGH William (2002). Brain Structure and the Functions of FMRI Protein. In : Fragile X syndrome: diagnosis, treatment and research. Third edition, ed. by Hagerman and Hagerman. New York: The Johns Hopkins University Press.

JABLONKA Eva \& LAMB Marion (1995) Epigenetic inheritance and evolution: the Lamarckian dimension. Oxford, Oxford University Press. 
JACQUEMONT et al. (2011). Epigenetic Modification of the FMRl Gene in Fragile X Syndrome Is Associated with Differential Response to the mGluR5 Antagonist AFQ056. Science Translation Medicine. 3:64: 64ra1.

JAKOBSON Roman (1956). Essais de linguistique générale : les fondations du langage. Paris : Les éditions de minuit, 2003.

JANIN-DUC Dominique (2013). La clinique des autismes et leurs contextes thérapeutiques. La Revue Lacanienne, 14: 131-146.

JERUSALINSKY Alfredo (2008). Saber Falar: Como se adquire a língua? 2. ed. Rio de Janeiro: Vozes.

JERUSALINSKY Alfredo (2010). Psicanálise e desenvolvimento infantil. Porto Alegre: Artes e Ofícios.

JERUSALINSKY Alfredo (2011). Para compreender a criança: chaves psicanalíticas. São Paulo: Instituto Langage.

JERUSALINSKY Alfredo. \& LAZNIK Marie Christine (2011). Uma discussão com a neurociência. In: O livro negro da psicopatologia contemporânea. Orgs: Jerusalinsky, A. \& Fendrik, S. São Paulo: Via Lettera.

JURUENA Mario, CLEARE Anthony et PARIANTE Carmine (2004). O eixo hipotálamopituitária-adrenal, a função dos receptores de glicocorticoides e sua importância na depressão. Rev. Bras. Psiquiatr. 26(3):189-201.

KAHN Deena \& Ansar AHMED (2015). Epigenetic regulation of non-lymphoid cells by bisphenol A, a model endocrine disrupter: potential implications for immunoregulation. Front. Endocrinol. 6:91. Doi: 10.3389/fendo.2015.00091

KANNER Leo (1943). Autistic Disturbance of affective contact. The Nervous Child, 2, 217 250.

KANNER Leo (1973). Childhood psychosis: initial studies and new insights. Washington: V. H. Winston \& Sons.

KRAAN Claudine et al. (2013). Neurobehavioural evidence for the involvement of the FMRl gene in female carriers of fragile $\mathrm{X}$ syndrome. Neuroscience and Biobehavioral Reviews. 37: 522-547.

KRAEMER Sebastian (2008). Fragile male, not fragile-X. Advances in Psychiatric Treatment, London, 398-400. 
KUBOTA Takeo \& MOCHIZUKI Kazuki (2016). Epigenetic Effect of Environmental Factors on Autism Spectrum Disorders. Int. J. Environ. Res. Public Health, 13, 504 : $1-12$

LACAN Jacques (1949). Le stade du miroir comme formateur de la fonction du Je - telle qu'elle nous est révélée dans l'expérience psychanalytique. In : Écrits I. Paris : Seuil, 1999.

LACAN Jacques (1953-1954). Le séminaire, livre I : Les écrits techniques de Freud. Paris : Seuil, 1975.

LACAN Jacques (1958). Introduction au commentaire de Jean Hyppolite. In : Écrits I. Paris : Seuil, 1999.

LACAN Jacques (1954-1955). Le séminaire, livre II : Le moi dans la théorie de Freud et dans la technique de la psychanalyse. Paris : Seuil, 1978.

LACAN Jacques (1955). Séminaire sur la lettre volée. In : Écrits I. Paris : Seuil, 1999.

LACAN Jacques (1955-1956). Le séminaire, livre III : Les psychoses. Paris : Seuil, 1978.

LACAN Jacques (1957). L'instance de la lettre dans l'inconscient ou la raison depuis Freud. In : Écrits I. Paris : Seuil, 1999.

LACAN Jacques (1957-1958). Le séminaire, livre V: Les formations de l'inconscient. Paris : Seuil, 1998.

LACAN Jacques (1958). La direction de la cure et les principes de son pouvoir. In : Écrits II. Paris : Seuil, 1999.

LACAN Jacques (1958). La psychanalyse vraie, et la fausse. In : Autres écrits. Paris : Seuil, 2001

LACAN Jacques (1958-1959). Le séminaire, livre VI : Le désir et son interprétation. Paris : Seuil, 1998.

LACAN Jacques (1960-1961). Le séminaire, livre VII : Le transfert. Paris : Seuil, 1998.

LACAN Jacques (1964). Position de l'inconscient. In : Écrits II. Paris : Seuil, 1999.

LACAN Jacques (1964). Le séminaire, livre XI : Les quatre concepts fondamentaux de la psychanalyse. Paris : Seuil, 1973.

LACAN Jacques (1966). Fonction et champ de la parole et du langage en psychanalyse. In : Écrits I. Paris : Seuil, 1999.

LACAN Jacques (1966). La place de la psychanalyse dans la médecine. Conférence. Le Bloc-Notes de la psychanalyse, $\mathrm{n}^{\circ}$ 7, 9-40. Georg éditeur. 
LACAN Jacques (1968-1969). Le Séminaire, livre XVI : D'un Autre à l'autre. Paris: Seuil, 2006.

LACAN Jacques (1969). Note sur l'enfant. In : Autres écrits. Paris : Seuil, 2001.

LACAN Jacques (1970-1971). Le Séminaire, livre XVIII : D’un discours qui ne serait pas du semblant. Paris: Seuil, 2007.

LACAN Jacques (1971-1972). Le Séminaire, livre XIX : ... Ou pire. Paris : Seuil, 2011.

LACAN Jacques (1977-1978). Le séminaire, livre XXV : Le moment de conclure. Paris : Association Lacanienne Internationale, 2004.

LANE Christopher (2007). Comment la psychiatrie et l'industrie pharmaceutique ont médicalisé nos émotions. Paris, Flammarion, 2009.

LaSALLE Janine (2013). Epigenomic strategies at the interface of genetic and environmental risk factors for autism. Journal of Human Genetics, 58, 396-401. doi: 10.1038/jhg.2013.49.

LAZNIK Marie Christine (2014). Une psychanalyste avec les parents: et trois enfants autistes se mettent à parler. Toulouse : Éres.

LAZNIK Marie Christine (2014) Empathie émotionnelle et autisme. Autismes et psychanalyses : évolution de pratiques, recherches et articulations. Sous la direction de Marie Dominique AMY. Toulouse : Éres.

LEFORT Rosine \& Robert (2003). La distinction de l'autisme. Paris : Seuil.

LEJEUNE Severine (2008). Déficience mentale liée à l'X: les enjeux d'un diagnostic génétique chez les filles mineures asymptomatiques. Revue Neuropsychiatrie de l'enfance et de l'adolescence, 286-289.

LOKE Yuk, HANNAN Anthony and CRAIG Jeffrey (2015). The role of epigenetic change in autism spectrum disorders. Front in Neurol, 6:107. doi: 10.3389/fneur.2015.00107

LUTZ, P.-E \& TURECKI, G. (2014). Dna methylation and childhood maltreatment: from animal models to human studies. Neuroscience, $\mathrm{N}^{\circ} 264$, p. 142-156.

MADEIRA Manoel, ROBERT Priscilla e KUPERMANN Daniel (2015). Subjetivação do corpo: entre devoração e abandono

MADEIRA Manoel \& VARELA Andrea (2016). L'émergence de la parole chez l'enfant à la croisée de la médecine génétique et de la psychanalyse. Topique (Paris),135, p. 135148.

MAGISTRETTI Pierre \& ANSERMET François (2010). Neurosciences et psychanalyse : une rencontre autour de la singularité. Paris : Odile Jacob. 
MALABOU Catherine (2011). Souffrance cérébrale, souffrance psychique et plasticité. Études, $\mathrm{n}^{\circ} 414,487-498$.

MALABOU Catherine (2015). Une seule vie : résistance biologique, résistance politique. Esprit, $\mathrm{n}^{\circ} 1,30-40$.

MANNONI Maud (1964). L'enfant arriéré et sa mère. Paris : Seuil, 1981.

MANNONI Maud (1973). Éducation impossible. Paris : Seuil.

MANNONI Maud (1970). Le psychiatre, son «fou » et la psychanalyse. Paris : Seuil.

MANNONI Maud (1967). L'enfant, sa «maladie » et les autres. Paris : Seuil, 1974.

MANNONI Maud (1982). D'un impossible à l'Autre. Paris, Seuil.

MARTIN-BLANCO Ana, FERRER Marc, SOLER Joaquim et al. (2014). Association between methylation of the glucocorticoid receptor gene, childhood maltreatment, and clinical severity in borderline personality disorder. Journal of psychiatric research, $\mathrm{n}^{\circ}$ 57, 34-40.

MCLENNAN Y., POLUSSA J., TASSONE F. and HAGERMAN R. (2011). Fragile X Syndrome. Current Genomics, Sacramento, 216-224.

MELTZER Donald (1975 [2002]). La psychologie des états autistiques et de l'état mental post-autistique. Explorations dans le monde de l'autisme. Traduction française par G. Haag, M. Haag, L. Iselin, A. du Châtelier et G. Nagler. Paris : Payot.

MILLER Jacques-Alain (1999). Elementos de biologia lacaniana. Trad : Yolanda Vilela. Belo Horizonte : Escola Brasileira de Psicanálise-MG, 2001.

MONGET Philippe \& VEITIA Reiner (2014). Introduction à la génétique moderne. Palaiseau, Éditions de l'École polytechnique.

MONHONVAL Pauline \& LOTSTRA Françoise (2014) Transmission transgénérationnelle des traits acquis par l'épigénétique. Cahiers de psychologie clinique. Vol 2, n 43, 2942. Doi : $10.3917 /$ cpc.043.0029.

MORETTO, Maria Lívia (2001). O que pode um analista no hospital ? São Paulo: Casa do Psicólogo.

MORETTO, Maria Lívia (2016). Dispositivos clínicos de atenção, acolhimento e atendimento psicológico nas instituições de saúde. In: Desafios atuais das práticas em hospitais e nas instituições de saúde. Orgs: Kamers M, Marcon H.H. e Moretto M.L. São Paulo: Escuta. 
MOYLAN Carrie et al (2010). The effects of child abuse and exposure to domestic violence on adolescent internalizing and externalizing behavior problems. Journal of family violence. $\mathrm{N}^{\circ} 25(1), 53-63$.

NOGUEIRA Luiz Carlos (1999). A pesquisa em Psicanálise. Psicologia USP, 2004, 15(1/2), 83-106.

OLLIVIER Maurel (2000) Médecin ou devin? Diagnostic très Précoce et anticipation.

Exemple du syndrome de Williams. Archive Pédiatrie, Paris, 1221-1227.

OOSTRA Ben and HOOGEVEEN Andrea (2002). FMRl Protein Studies and Animal Model for Fragile X Syndrome. Fragile X syndrome: diagnosis, treatment and research. Third edition, ed. by Hagerman and Hagerman. New York: The Johns Hopkins University Press.

OPPENHEIM Daniel et HARTMANN Olivier (2005). Les limites de l'expérience du vivant: l'enfant, son cancer, ses parents, ses soignants. Les Temps Modernes, $\mathrm{n}^{\circ} 630$ 631, 164-174.

OPPENHEIM Daniel (2015). Face à la mort d'enfants, voir, penser, dire, être. Empan, nº 97, 63-68.

OUYANG Lijing et al. (2014). A comparison of family financial and employment impacts of fragile X syndrome, autism spectrum disorders and intellectual disability. Research in Developmental Disabilities. 35: 1518-1527.

PERROUD N, SALZMANN A, PRADA P et al. (2013). Response to psychotherapy in borderline personality disorder and methylation status of the BDNF gene. Transl Psychiatric, 3, e207. Doi: 10.1038/tb.2012.140.

POMMIER Gérard (2004). Comment les neurosciences démontrent la psychanalyse. Paris : Flammarion

PORGE Erik (1998). Transferência para os bastidores. Littoral : a criança e o psicanalista. Rio de Janeiro : Companhia de Freud.

POTIER Rémy, PUTOIS Olivier, LYONNET Stanislas, WEITZMAN Jonathan, VILLA François (2016). Regards croisés sur une pathologie développementale d'origine génétique: Réflexions épistémologiques et cliniques sur l'impact psychique du syndrome de microdélétion 22q11.2. Topique, n $135,103-117$.

QUEIROZ Telma \& CORRÊA José Roberto (2002). Algumas considerações sobre a falha epistemo-somática e suas manifestações na criança. Revista Latinoamericana de Psicopatologia Fundamental, vol. V, nº 4, 74-84. 
QIN Lina, TU Wenqiang, SUN Xiumin, ZHANG Jianlong, CHEN Yuchuan et ZHAO Hu (2011). Retardation of neurobehavioral development and reelin down-regulation regulated by further DNA methylation in the hippocampus of the rat pups are associated with maternal deprivation. Behavioural Brain Research. 217:142-147.

QUINET Antonio (1991) As 4+1 condições da análise. Rio de Janeiro, Jorge Zahar Editor. RASKIN Salmo (2015). Genética e psicanálise: um encontro possível? Por uma (nova) psicopatologia da infância e da adolescência. Orgs: M. Kamers, R. Mariotto e R. Voltolini. São Paulo, Escuta.

RICKES Simone \& GLEICH Paulo (2009). Letras em oficina: a afirmação retumbante do “não”. Psicologia \& Sociedade, v. 21, ed. Especial, 112-122.

RIOLFI Claudia Rosa (2011). Corpo e responsabilidade: efeitos da psicanálise sobre portadores de doenças degenerativas. Mal-estar e Subjetividade, vol. XI, nº 1, 241265.

RIVOLLIER F., LOTERSZTAJN L., CHAUMETTE B., KREBS M. -O. et KEBIR O. (2014). Hypothèse épigénétique de la schizophrénie : revue de la littérature. L'Encéphale, 40, 380-386.

ROBERTS Jane, TONNSEN Bridgette, ROBINSON Marissa, McQUILLIN Samuel, HATTON Deborah (2014). Temperament factor structure in fragile X syndrome: The children's behavior questionnaire. Research in Developmental Disabilities, 35:563571 .

ROBERTS S, LESTER KJ, HUDSON et al. (2014). Serotonin transporter methylation and response to cognitive behaviour therapy in children with anxiety disorders. Transl Psychiatry, 4, e444. Doi: 10.1038/tp.2014.83.

ROSA João Guimarães (1967). Grande sertão Veredas. Rio de Janeiro: Nova Fronteira, 2006.

SABARATNAM Manga (2006). Fragile X syndrome. Psychiatric 5:9: 325-330.

SAMPAIO Ângelo Augusto (2005). Skinner: sobre ciência e comportamento humano. Psicologia Ciência e Profissão. Vol. 25, 3, 373-380. Disponible en http://pepsic.bvsalud.org/scielo.php?script=sci_arttext\&pid=S1414-98932005000300004\& $\underline{\operatorname{lng}=p t \& n r m=i s s o}$

SAUSSURE Ferdinand de (1916). Cours de linguistique générale. Paris : Payot, 1996. 
SCHAEVITZ Laura \& SWEENEY Jeanne (2012). Gene-Environment Interactions and Epigenetic Pathways in Autism: The Importance of One-Carbon Metabolism. ILRA Journal, 53:3/4: 322-340.

SCHECHTER Daniel, MOSER Dominik, GIACOBINO Ariane et al. (2015) Methylation of $\mathrm{NR} 3 \mathrm{C} 1$ is related to maternal PTSD, parenting stress and maternal medial prefrontal cortical activity in response to child separation among mothers with histories of violence exposure. Front. Psychol. 6:690. doi: 10.3389/fpsyg.2015.00690

SCHWERING Karl-Leo (2001). Le traitement psychique de l'organe transplanté : ingestion, incorporation, sexualisation. Psychiatrie de l'enfant, XLIV, 1, p. 127-167.

SCHWERING Karl-Leo (2007). Techniques chirurgicales et techniques magiques. Cliniques méditerranéennes, $\mathrm{n}^{\mathrm{o}}$ 76, 91-105.

SCHWERING Karl-Leo (2014). Symbolisation primaire et subversion libidinale dans la maladie grave. Formes primaires de symbolisation. Orgs : A. Brun \& R. Roussillon. Paris : Dunod.

SCHWERING Karl-Leo (2015). Corps d'outrance : Souffrance de la maladie grave à l'hôpital. Paris: PUF.

SEBAT Jonathan (2007). Strong Association of De Novo Copy Number Mutations with Autism. In: Science. April 20; 316(5823): 445-449.

SONUGA-BARKE E., "It's the Environment Stupid !” (2010) Journal of Child Psychology and Psychiatry, vol. 51, $\mathrm{n}^{\circ} 2,113-115$.

SPITZ René (1965 [1968]). De la naissance à la parole : La première année de vie. Paris : PUF.

SQUIRES Claire, JOUANNET Pierre, WOLF Jean-Philippe, CABROL Dominique et KUNTSMANN Jean-Marie (2008). Psychopathologie et procréation médicalement assistée : comment les couples infertiles élaborent-ils la demande d'enfant? Devenir, vol 20, 135-149.

SQUIRES Claire (2011). Essai sur le don de gamètes. Topique, ${ }^{\circ}$ 116, 73-88.

SQUIRES Claire (2012). Tabous, fantasmes et pensée magique autour de la naissance. Cliniques Méditerranéennes, $\mathrm{n}^{\circ}$ 85, 23-39.

SQUIRES Claire (2016). Le mérycisme: un lien à éclipses. Revue française de psychanalyse, vol. 80, 832-840. 
TABOLACCI Elisabetta, PALUMBO Federica, NOBILE Veronica et NERI Giovanni (2016). Transcriptional Reactivation of the FMR1 Gene. A Possible Approach to the Treatment of the Fragile X Syndrome. Genes, 7:49, 1-16.

TATA Despina et al. (2015). Effects of maternal separation on behavior and brain damage in adult rats exposed to neonatal hypoxia-ischemia. Behavioural Brain Research. 280: 51-61.

TORDJMAN Sylvie (2010). Regards croisés entre la psychanalyse et les neurosciences. In: Revue Neuropsychiatrie de l'enfance et de l'adolescence, Rennes 351-358.

THOMAS Marie-Claude (2011). L'autisme et les langues. Paris: L'Harmattan.

THOMAS Marie-Claude (2014). Genèses de l'autisme: Freud, Bleuler, Kanner. Paris: Epel.

THURMAN Angela, MCDUFFIE Andrea, HAGERMAN Randi and ABBEDUTO Leonard (2014). Psychiatric symptoms in boys with fragile X syndrome: a comparison with nonsyndromic autism spectrum disorder. Research in Developmental Disabilities 35:1072-1086.

TONNSEN Bridgette, CORNISH Kim, WHEELER Anne and ROBERTS Jane (2014). Maternal Predictors of Anxiety Risk in young Males with fragile X. Am J Med Genet Part B $9999: 1-11$.

TUSTIN Frances (1986[1989]). Le trou noir de la psyché. Paris : Editions du Seuil.

VANIER Alain (2011). Pour introduire «la direction de la cure». Figures de la psychanalyse, $\mathrm{n}^{\circ} 21,13-20$.

VANIER Catherine (2006). Le bébé et la pulsion. «Le sourire de la Joconde quelques années plus tard ». Recherches en psychanalyse, $n^{\circ} 6,71-79$.

VANIER Catherine (en collaboration avec COSTA-PRADES Bernadette), (2014). Autisme : comment rendre les parents fous ! Paris, Albin Michel.

VANIER Catherine (2014). Autour de l'Autisme : comment rendre les parents fous! Entretien de Catherine Vanier réalisée par Olivier Douville. Figures de la psychanalyse, $\mathrm{n}^{\circ} 28,21-31$.

VANIER Catherine et al. (2015). Interview de Catherine Vanier réalisée par Françoise de Barbot et Martine Frischmann. Contraste, n 41, 47-63.

VARADINOVA Miroslava \& BOYADJIEVA Nadka (2015). Epigenetic mechanisms: A possible link between autism spectrum disorders and fetal alcohol spectrum disorders. Pharmacological Research. 102: 71-80. 
VARELA Andréa, MADEIRA Manoel et MORETTO Maria Lívia (2015). Síndrome do cromossomo X frágil: uma possível articulação entre psicanálise e genética médica? Rev. SBPH vol. $18, \mathrm{n}^{\circ} 2,45-60$.

VILLA François (2007). Le refoulement organique et les progrès techniques de la médecine. Cliniques méditerranéennes, nº76, 45-60.

VILLA François (2014). Perspectives théoriques : La participation du refoulement organique à la formation du caractère. Revue française de psychanalyse, vol. 78, 978989.

VORCARO Ângela (1999) Transferência e interpretação na clínica com crianças autistas e psicóticas. Estilos da Clínica vol. 4, n 7, 52-72.

VORCARO Ângela e LUCERO Ariana (2011). A criança e a debilidade mental: uma abordagem lacaniana. Psicologia USP, vol. 22, n 4, 813-832.

WINNICOTT Donald (1952). Psychose et soins maternels. De la pédiatrie à la psychanalyse. Paris, Payot, 1992, p. 187-197.

WINNICOTT Donald (1958) La première année de la vie: Conceptions modernes du développement affectif au cours de la première année de la vie. De la pédiatrie à la psychanalyse. Paris : Payot, 1989.

WINNICOTT Donald (1965). Processus de maturation chez l'enfant : Développement affectif et environnement. Paris: Payot, 1970.

WINNICOTT Donald (1966) Thinking about children. Edited by Shepherd, Johns and Robinson. U.K., A Merloyd Lawrence book, 1999.

WINNICOTT Donald (1967). A delinquência como sinal de esperança. Tudo começa em casa. São Paulo, Martins Fontes, p.81-91.

WINNICOTT Donald (1969). Intégration du moi au cours du développement de l'enfant. Processus de maturation chez l'enfant. Paris, Payot, 2010, p.9-19.

WINNICOTT Donald (1971). Le rôle de miroir de la mère et de la famille dans le développement de l'enfant. Jeu et réalité. Paris: Gallimard, 1975.

WIJETUNG Lasani, SUMANTRA Chattarji, WYLLIE David and KIND Peter (2013). "Fragile X syndrome: From targets to treatments", in: Neuropharmacology, n68, p.83-96.

WONG Albert, GOTTESMAN Irving and PETRONIS Arturas (2013). The epigenetic perspective. In: Epigenetics, Environment and Genes. Edited by KANG Sun Woo. Toronto, Apple Academic Press Inc. 
YEHUDA Rachel, DASKALAKIS Nikolaos, DESARNAUD Frank et al. (2013). Epigenetic biomarkers as predictors and correlates of symptom improvement following psychotherapy in combat veterans with PTSD. Frontiers in Psychiatric, vol. 4, nº 118, 01-14. Doi: 10.3389/fpsyt.2013.00118.

ZIEGLER C, RICHTER J et al. (2016). MAOA gene hypomethylation in panic disorder reversibility of an epigenetic risk pattern by psychotherapy. Transl. Psychiatric, 6, e773. Doi: 10.1038/tp.2016.41. 


\title{
Annexe \\ PROJET DE RECHERCHE
}

\author{
Contributions psychanalytiques dans les soins accordés aux enfants atteints \\ du syndromes de l’X fragile.
}

Présenté au Service de Génétique Médicale de l'Hospital das Clínicas de Porto Alegre, par Andréa Sousa Varela, doctorante à l’Université Paris Diderot - Sorbonne Paris Cité en cotutelle avec l'Universidade de São Paulo

\section{Présentation et justificative du projet de recherche}

Dans une recherche commencée en mémoire de Master, nous avons constaté que le syndrome de l'X fragile (SXF) apparaissait comme la plus fréquente de cause héréditaire de handicap intellectuel. Et au-delà de cette pathologie, nous avons trouvé dans la littérature médicale d'autres symptômes comportementaux associés à l'X fragile, parmi lesquels l'hyperactivité, la phobie, les difficultés d'attention et de concentration, l'anxiété sociale, l'autisme, les troubles de langages et même la névrose obsessive (voir HAGERMAN \& HAGERMAN 2002 ; GÜRKAN \& HAGERMAN 2012). En outre, les individus porteurs de l'X fragile peuvent également présenter des symptômes physiques, comme les oreilles et mâchoires proéminentes, un allongement facial, une hyper-extension de l'articulation des doigts et, pendant la puberté, un macroorchidisme (COHEN et al. 2002).

Le syndrome de l'X fragile se caractérise par la mutation du gène FMR1, gène dont la fonction est de codifier la protéine FMRP (Fragile X Mental Retardation Protein) et qui contient des répétitions du trinucléotide CGG. Chez les humains normaux, on compte 7 à 55 répétions. Le gène muté en possèderait plus de 200, ce qui inhiberait la synthèse de la protéine FMRP et produirait des réactions moléculaires fragilisant les connexions synaptiques. Cohen, Neri et Weksberg (2002) soulignent que dans plus de 95\% des cas, le syndrome est causé par un seul type de mutation, expliqué par l'expansion et l'hyperméthylation du potentiel instable de la répétition du trinucléotide CGG, inhibant ainsi 
la synthèse de la protéine FMRP. Or, cette protéine joue un rôle central dans le fonctionnement cérébral, particulièrement en ce qui concerne les synapses et la structure des cellules neuronales. D'après la littérature consultée, c'est l'absence de la FMRP qui causerait les symptômes physiques et comportementaux associés au SXF.

Il n'existe aucun moyen de guérison pour ce syndrome. Le traitement proposé par la médecine utilise des recours pharmacologiques pour traiter les troubles du comportement (GARBER et al. 2008). Toutefois, nous remarquons que les recherches sur le traitement moléculaire ont considérablement avancé au cours des dernières années. Elles misent sur l'introduction directe de protéines dans la cellule, afin de pallier les dommages générés par l'absence de FMRP. Selon Thurman et al. (2014), si les expériences sur des rats ont donné des résultats satisfaisants, la recherche n'est pas encore suffisamment avancée pour pouvoir commencer un traitement sur les humains. Or, si le traitement prédominant est encore celui de la gestion des symptômes comportementaux, impliquant une dimension subjective, pourquoi ne pas inclure la psychanalyse, en tant que pratique psychothérapique, dans les soins proposés aux enfants porteurs de syndromes génétiques?

Notre projet mise donc sur l'hypothèse que la clinique psychanalytique peut elle aussi, à partir d'une interlocution avec la génétique médicale, contribuer au traitement proposé aux patients porteurs de l'X fragile. Si le syndrome de l'X fragile peut avoir pour conséquence une symptomatologie psychique aussi diversifiée, comment la psychanalyse pourrait-elle, avec des outils théorico-cliniques, intervenir sur la singularité de chaque sujet ?

Pensant et voulant mettre en évidence la singularité des patients, nous nous proposons ici à articuler les savoirs de la psychanalyse et de la génétique médicale, dans le but de générer un dialogue qui puisse contribuer au traitement des patients. Dans le champ de la psychanalyse, malheureusement, rares sont les travaux qui tentent de mettre en œuvre cette articulation. Le psychiatre et psychanalyste Jorge Forbes (2011) affirme dans sa thèse de doctorat défendue à la Faculté de Médecine de l'Université de São Paulo, que la psychothérapie psychanalytique est un dispositif de traitement efficace pour les personnes affectées par des maladies dégénératives. Dans le cadre de sa recherche, il proposa un accompagnement psychanalytique de quinze semaines à un groupe de 42 patients porteurs de maladies neuromusculaires d'origine génétique; après application d'une échelle d'évaluation, il remarqua des améliorations considérables de certains aspects sociaux et subjectifs. Nous tenons à souligner que cette tentative d'approximation de deux champs de savoir distincts constitue un défi de taille, dans la mesure où la génétique et la psychanalyse, 
ne partageant pas les mêmes objets d'étude, utilisent chacune un langage et des références propres. Mais nous avons bien trouvé des chercheurs déterminés à explorer les incertitudes et l'inattendu propres à la condition humaine.

\section{L'épigénétique, la génétique et la psychanalyse}

Dans le champ de la génétique, il existe des recherches qui s'ouvrent au savoir $p s y$, en démontrant, à partir de l'épigénétique, l'influence de l'environnement sur les fonctions neurophysiologiques (voir MONGET \& VEITIA 2014 ; SCHECHTER ET AL. 2015 ; MONHONVAL \& LOTSTRA 2014) et soulignant que cette influence peut aussi être transmise aux prochaines générations. Nous retiendrons notamment les études de MartinBlanco et al. (2014, p. 35), publiées dans la revue Journal of Psychiatric Research: les auteurs y relatent que le stress vécu au cours de la petite enfance modifie le fonctionnement de l'axe hypothalamo-pituitaire-surrénal (axe HPS). Selon l'article, « chez les humains, la méthylation de la région promotrice du gène GR (connu sous le nom de NR3C1) se montre élevée chez les enfants exposés au stress maternel durant la grossesse et chez les victimes de traumatismes durant l'enfance». En outre, il est souligné que cette méthylation peut désorganiser le fonctionnement même de l'axe HPA.

Dans cette même direction, citons l'étude de Lutz \& Turecki (2014) publiée dans la revue Neuroscience, et qui passe en revue les études ayant utilisé un modèle animal pour encourager la recherche sur l'impact de l'environnement sur le comportement humain. Une expérience menée sur des rats, permit d'observer l'influence des soins maternels sur les réponses endocrines et comportementales de ces derniers. Ceux qui, au commencement de leurs vies, reçurent de tels soins (licking and grooming), présentèrent à l'âge adulte une diminution des comportements anxieux ainsi qu'une faible réaction de l'axe HPA dans des situations de stress, en comparaison à ceux qui reçurent des soins maternels insuffisants. En

outre, il apparaît que les soins maternels influencent aussi la plasticité synaptique de l'hippocampe : «comparé aux descendants ayant reçu un niveau élevé de soins maternels, ceux qui ont reçu un faible niveau de soins présentent une tendance à l'augmentation de la potentialisation à long terme de l'hippocampe et à la dépression » (LUTZ \& TURECKI, 2014, p.145).

Il convient de relater ici les principales recherches qui nous semblent corroborer cette proposition d'articulation entre la psychanalyse et la génétique médicale, en cela qu'elles 
adoptent une démarche qui prend pour objet d'étude les pratiques psychothérapiques en tant qu'environnement capable de produire ou inverser des mécanismes épigénétiques.

Selon Ziegler et al. (2016) on ne compte aujourd'hui que quatre études ayant enquêté sur la dynamique des mécanismes épigénétiques liés aux pratiques psychothérapeutiques. Ces recherches représentent pour nous un champ fertile à travers lequel nous tâcherons de rapprocher la psychanalyse de la génétique médicale. Bien que de telles études se réfèrent à des psychothérapies dont l'abordage est cognitivo-comportemental, nous considérons néanmoins qu'elles ouvrent un espace de débat sur les effets de certains autres abordages théoriques, parmi lesquels celui de la psychothérapie psychanalytique.

La première étude que l'on trouve dans la littérature abordant l'épigénétique et la psychothérapie fut menée par Perroud et ses collaborateurs (2013). Les chercheurs ont effectué un test sur 115 patients diagnostiqués d'un Trouble de la Personnalité Borderline (TPB) et sur un groupe témoin de 52 individus. L'objectif était de comparer la méthylation de l'ADN de la protéine BNDF (Brain-Derived Neurotrophic Factor) - protéine impliquée dans le neurodéveloppement - chez les sujets TPB et témoins. S'appuyant sur de récentes études qui démontrèrent l'implication de cette protéine dans le trouble borderline, les auteurs ont supposé que l'altération du niveau de la BNDF pourrait être la conséquence de mécanismes épigénétiques provoqués par des mauvais traitements au cours de l'enfance Les deux autres objectifs de la recherche étaient, d'une part, d'observer si une haute méthylation BNDF chez les patients TPB était liée aux mauvais traitements infantiles et, d'autre part, d'évaluer si les processus épigénétiques pourrait être modifiés par le biais d'une psychothérapie spécifique (I-DBT : Intensive Dialectical Behavior Therapy ${ }^{1}$ ) chez les patients TPB.

Un premier échantillon de l'ADN des participants fut collecté une semaine avant le début de la psychothérapie et un second lors de la dernière séance. Les résultats montrent une élévation significative de la méthylation de la protéine BNDF des patients TPB par rapport au groupe témoin. Après les quatre semaines de psychothérapie, les individus évalués présentèrent un changement au niveau de la méthylation dans les sites CpG de l'ADN, sachant que ceux qui répondirent le mieux au traitement atteignent les niveaux de méthylation du groupe témoin. Selon la conclusion des chercheurs, « les résultats mettent en évidence que les changements de méthylation dans les sites $\mathrm{CpG}$ correspondent aux réponses

\footnotetext{
${ }^{1}$ L'I-DBT consiste en des thérapies quotidiennes individuelles et de groupe, dont l'objectif est de diminuer des comportements cibles préalablement sélectionnés
} 
au traitement, et ce, indépendamment de la méthode utilisée pour traiter les patients» (PERROUD et al., 2013, p.04). Ils remarquent toutefois que la durée du traitement fut relativement courte et qu'un traitement plus long rendrait possible l'obtention de résultats plus concrets.

Dans une même direction, Yehuda et al. ont réalisé une étude pilote sur d'anciens combattants de guerre diagnostiqués de trouble de stress post-traumatique (en anglais : PostTraumatic Stress Disorder, PTSD). Leur objectif était alors d'examiner la méthylation des gènes $G R$ (NR3C1) et FKPB5 et de mesures neuroendocriniennes associées, cortisol et NPY, avant et après une exposition prolongée à la psychothérapie. Les auteurs remarquent que certains cas ont montré de hauts niveaux de méthylation du gène GR, une faible expression de celui-ci dans l'hippocampe, une augmentation de l'activité de l'axe HPS en réponse au stress et une méthylation du gène FKBP5 : des modifications associées aux adversités vécues au cours de l'enfance. Comme nous l'avons vu précédemment, le gène $G R$ ne se montre actif que dans des situations vécues comme stressantes par l'individu et lors desquelles l'axe HPS libère les glucocorticoïdes en grandes quantités. De son côté, le gène $F K P B 5$ agirait sur le $G R$, atténuant l'activité de ce dernier. Mises côte-à-côte, « ces découvertes suggèrent que les adversités vécues pendant l'enfance influencent l'état épigénétique et l'activité de transcription des gènes qui régulent la réponse au stress de l'axe HPS » (YEHUDA et al., 2013, p.02). Pour les chercheurs, la réactivité au stress est impliquée dans le risque de divers troubles affectifs - ainsi nommés et classifiés dans le DSM IV et $V$-comme le PTSD. De faibles niveaux de glucocorticoïdes et un certain renforcement de la sensibilité du gène $G R$ ont été associés à cette psychopathologie, renforçant la thèse de la présence de mécanismes épigénétiques dans les dits troubles affectifs.

Seize anciens combattants de guerre - quatorze hommes et deux femmes - ont donc été évalués et, après douze semaines de psychothérapie (exposition prolongée) et trois mois d'accompagnement postérieur, on constata, en plus d'une diminution des symptômes de stress post-traumatique, une variation de l'expression du gène FKBP5. Selon les auteurs, les sujets qui se sont adaptés au traitement $(\mathrm{n}=8)$ présentèrent, en plus des améliorations symptomatiques, une diminution de la méthylation du gène. En revanche, ceux qui n'obtinrent pas les mêmes résultats par rapport au traitement $(\mathrm{n}=8)$ présentèrent, au cours de la même période, une augmentation de la méthylation. Aucune variation significative ne fut rencontrée dans la méthylation du gène $G R$. 
L'abordage psychothérapique auquel les participants furent soumis dans le cadre de la recherche n'est pas détaillé dans l'étude, mais les chercheurs relatent la réalisation d'une «évaluation psychologique globale » menée par un psychologue clinicien et l'utilisation, pour le diagnostic et l'évaluation psychologique, des outils suivants : SCID - Structured Clinical Interview for DSM-IV; CAPS - Clinician Administered PTSD Scale; PSS-SR PTSD Symptom Scale - Self-Report Version; CTQ - Childhood Trauma Questionnaire et, enfin, le DRRI - Deployment Risk and Resiliency Inventory.

Selon les auteurs, l'étude suggère que « la psychothérapie menant à des changements symptomatiques substantiels constitue une forme de 'régulation environnementale' qui peut altérer l'état épigénétique » (YEHUDA et al., 2013, p. 12). Une telle affirmation a pour nous une grande valeur, dans la mesure où elle corrobore notre proposition d'inclusion de la pratique psychanalytique dans les discours sur les soins aux enfants atteints de problèmes organiques, et en particulier de syndromes génétiques.

Les troubles de l'anxiété furent également l'objet de recherches associant des mécanismes épigénétiques avec la psychothérapie. L'étude menée par Roberts et ses collaborateurs (2014) évalua des mécanismes épigénétiques du gène SERT (serotonin transporter), qui est communément associé à diverses sortes d'expériences négatives de la vie. Ce gène est chargé de transporter le neurotransmetteur sérotonine jusqu'à l'activité synaptique. La sérotonine, quant à elle, est une importante monoamine dont les fonctions dans l'organisme sont multiples et qui est impliquée dans les réactions d'anxiété, de peur et de perception de la douleur.

Cette recherche s'effectua sur un échantillon de 116 enfants diagnostiqués de trouble d'anxiété - selon l'échelle ADIS-IV-C-P : Anxiety Disorders Interview Schedule for DSM$I V$, Child and Parents Versions - qui furent évalués avant et après la soumission à deux semaines de psychothérapie cognitivo-comportementale ${ }^{1}$ et accompagnés pendant six mois après la fin du traitement. On nota une altération au niveau de la méthylation de l'ADN du gène SERT correspondant à la réponse des participants au traitement. Ce critère de réponse au traitement fut défini au moment de l'accompagnement ultérieur (follow-up), une fois que l'enfant eut cessé de présenter le comportement original d'anxiété. Les résultats obtenus indiquèrent une augmentation du pourcentage de méthylation de l'ADN chez les répondants

\footnotetext{
${ }^{1}$ Application d'un manuel basé sur la Thérapie Cognitivo-Comportementale pour le diagnostic primaire de trouble de l'anxiété.
} 
au traitement, tandis que les non-répondants présentèrent une diminution de ce pourcentage. «Ces découvertes suggèrent que l'association entre la modification de méthylation de l'ADN et la réponse au traitement est plus forte chez ceux qui répondent de manière générale que chez ceux qui répondent en relation à un trouble en particulier » (ROBERT et al., 2014, p.04), concluent les auteurs.

La plus récente recherche à avoir associé traitement psychiatrique, épigénétique et psychothérapie fut celle de Ziegler et al. (2016). Les chercheurs, dans une première étude, découvrirent des altérations au niveau de la méthylation du gène MAOA (monoamine oxydase) chez des patients diagnostiqués de trouble panique. Selon les auteurs, la MAOA est une enzyme clé de la dégradation des amines biogéniques comme la sérotonine et la dopamine, et elle est considérée comme l'un des principaux candidats aux facteurs de risques du trouble panique (ZIEGLER et al., 2016). Dans une étude ultérieure, Ziegler et ses collaborateurs enquêtèrent sur les mécanismes épigénétiques du gène $M A O A$, lors d'une exposition des patients à une psychothérapie cognitivo-comportementale (CBT : Cognitive Behavioral Therapy). On évalua 56 femmes, réparties en deux groupes : un premier comptant 28 femmes diagnostiquées de trouble panique et un second, témoin, composé de 28 femmes saines. Le critère d'inclusion de patientes de sexe féminin uniquement ne fut défini qu'en raison de la localisation du gène MAOA dans le chromosome X (ZIEGLER et al., 2016, p.06).

Les patientes du premier groupe furent soumises à six semaines de psychothérapie standard pour un trouble panique, soit six séances pour chaque patiente, d'une durée de 90 minutes pour les trois premières, et de 100 à 240 minutes pour les trois dernières. Le traitement incluait également une «tâche ménagère intensive, adaptée aux peurs particulières de l'individu face à certaines situations » (ZIEGLER et al., 2016, p.02). Les chercheurs évaluèrent avant et après la psychothérapie la quantité d'attaques paniques par semaine, autant pour renseigner le degré de sévérité de la maladie que pour observer la réponse au traitement. Une diminution des épisodes d'attaques paniques fut observée chez 11 patientes, considérées répondantes, tandis que les 17 autres persistèrent avec la mêmes quantité d'épisodes et furent considérées non-répondantes. L'étude fut répétée sur un échantillon indépendant de 20 femmes soumises au même protocole de traitement. La proportion des répondantes au traitement fut alors de $50 \%$.

On analysa des échantillons ADN des trois groupes, avant et immédiatement après l'intervention thérapeutique, et les résultats «montrèrent une dynamique différenciée de la 
méthylation du gène MAOA pendant le traitement » (ZIEGLER et al., 2016, p.05). En comparaison au groupe témoin, les répondantes présentèrent une augmentation significative de la méthylation du gène en question, tandis que les non-répondantes présentèrent une réduction encore plus grande de la méthylation du MAOA. Il est important de rappeler que plus grande est la méthylation du gène, plus faible sera son expression et vice-versa. De tels résultats amenèrent les chercheurs à conclure qu'en plus de l'altération de la méthylation du gène $M A O A$ chez les patients diagnostiqués de trouble panique, il apparaît que le mécanisme épigénétique peut être inversé par la psychothérapie, ce qui laisse envisager l'hypothèse « que le succès de la psychothérapie (CBT) rétablit les niveaux fonctionnels des monoamines par le biais d'une augmentation de la méthylation du MAOA et donc d'une diminution conséquente de l'expression du MAOA » (ZIEGLER et al., 2016, p.06). Autrement dit, les résultats suggèrent que la psychothérapie, en tant qu'environnement, a été capable d'inverser des mécanismes épigénétiques également provoqués par une influence environnementale.

Suivant le chemin tracé par les recherches citée ci-dessus, ne pourrait-on pas penser, comme nous l'invitent Ansermet et Giacobino, que «le passage du génomique à l'épigénétique nous permet de donner une place aux soins cliniques, psychothérapiques et psychanalytiques » (2012, p.64) dans la recherche et le traitement des patients porteurs d'un syndrome? De telles recherches nous engagent en direction de l'articulation de la psychanalyse avec la génétique médicale. Nous sommes convaincus qu'un premier pas vers un travail commun apporterait d'importants progrès pour les recherches et le traitement de personnes porteuses de syndromes génétiques. C'est pourquoi nous proposons ce projet de recherche à réaliser au sein de l'Hospital de Clínicas de Porto Alegre, et qui consiste à proposer un accompagnement psychologique d'orientation psychanalytique aux enfants porteurs de syndromes génétiques et en particulier du syndrome de l'X fragile.

Nous chercherons ainsi à découvrir quels effets cliniques liés aux symptômes de l'enfant porteur de l'X fragile, la psychothérapie régulière pourrait apporter. Un dialogue permanent avec l'équipe technique sera indispensable au développement de notre projet. En plus d'un rapprochement des domaines de connaissance, nous considérons en effet que les échanges de points de vue au sein d'une équipe augmentent l'amplitude de l'abordage clinique en ce qui concerne les difficultés du patient et la singularité de son contexte familial.

Notre hypothèse est que la psychothérapie psychanalytique, en tant que partie intégrante du traitement proposé aux enfants, puisse être un instrument fondamental d'atténuation des symptômes psychiques possiblement déclenchés par une maladie 
génétique. Nous avons la conviction que l'enfant est un être en construction et que son développement est attelé à un échange avec l'environnement - ses parents, ses semblables, la société en général. La psychanalyse pense l'enfant à partir de ses échanges avec l'Autre un Autre avec une majuscule, qui ne fait pas référence à une personne spécifique mais à un entourage. La relation avec l'Autre, qui marque l'immersion du bébé dans le langage, conditionne la structuration psychique de l'enfant. Et c'est donc dans les échanges réalisés avec l'Autre que l'enfant s'approprie les instruments nécessaires pour se mettre en relation avec son milieu : l'apprentissage, la marche, la communication, la socialisation (CORIAT \& JERUSALINSKY, 1982).

Comme nous l'avons signalé plus haut, les recherches en épigénétique nous sont apparues comme un champ fertile de rapprochement entre la psychanalyse et la génétique médicale. L'idée que l'environnement opère activement des changements dans l'expression des gènes, même quand il n'y a pas d'altération du matériel génétique - $\mathrm{ADN}$ - « fait naître l'espoir que nous sommes bien plus que la séquence de nos gènes », signale la généticienne Edith Heard (2013, p.55). Certains chercheurs ont démontré l'influence de l'environnement sur le développement de certaines pathologies, y-compris sur la transmission de ces marques épigénétiques aux autres générations (voir ARMSTRONG 2014 ; AVITAL \& JABLONKA 2000 ; HUI et al. 2011).

Le généticien Salmo Raskin - un des représentants brésiliens du Projet Génôme corrobore notre proposition majeure : miser sur la singularité du sujet, qui n'est déterminé ni génétiquement ni par l'environnement. Raskin (2015), dans son texte Génétique et psychanalyse: une rencontre possible?, réunit des résultats de diverses recherches scientifiques qui pointent vers une non causalité génétique de certaines psychopathologies, comme l'autisme, la schizophrénie, le trouble bipolaire et le trouble de déficit d'attention avec hyperactivité. Selon Raskin, «l'épigénétique ouvre un sentier de compréhension de l'être humain dans la somme et l'interaction dynamique entre 'Nature' et 'Nurture' » (2015, p.163). La dualité psychique vs biologique ne nous semble pas permettre l'avancement des recherches ni l'amélioration du traitement proposé aux patients. Il est fondamental de mettre un terme aux déterminismes, aussi bien environnementaux que génétiques, et de prendre en compte la singularité de chaque sujet.

Une telle idée est également défendue et diffusée par le psychanalyste François Ansermet et par la généticienne Ariane Giacobino dans un ouvrage commun : Autisme, à chacun son génome. Ils avertissent notamment qu'il faut être vigilant quant au risque du tout 
épigénétique, selon lequel le déterminisme environnemental suivrait la même logique causale que le déterminisme génétique : «l'épigénétique est, par conséquent, objet d'une distorsion qui tend à faire d'elle une nouveau déterminant [...]. Le recours à l'environnement modifie la liaison causale en jeu mais la fixe de la même manière » (ANSERMET \& GIACOBINO, 2012, p.64). Selon ces mêmes auteurs, l'environnement est également sensible à des propriétés de labilité et réversibilité, c'est-à-dire que les marques épigénétiques sont elles aussi variables en fonction du temps, de l'environnement chimique, physique, toxique ou social.

En ce qui concerne les recherches génétiques sur l'origine de l'autisme, les auteurs citent des découvertes récentes qui indiquent « des variations individuelles, non applicables à tous les autistes. Elle [la génétique] démontre qu'il existe sans aucun doute des déterminations génétiques mais que celles-ci sont toujours différentes, propres à chacun des cas » (ANSERMET \& GIACOBINO, 2012, p.70). Chaque autiste aurait donc sa base génétique particulière, unique. Une telle découverte nous amène à la rencontre de l'un des piliers de la psychanalyse, postulat de Freud au commencement de la construction de la théorie psychanalytique : la singularité du sujet. Nous voyons donc ici un point commun facilitant l'approximation des deux champs de savoir. C'est la différence qui marque notre identité, comme le dit de manière explicite l'ouvrage des auteurs cités plus haut : Autisme, à chacun son génome.

Le rapprochement possible entre psychanalyse et génétique médicale se ferait, de notre point de vue, par le biais de la prise en compte de la dimension de l'Autre comme facteur constitutif de l'environnement. Si les échanges avec l'Autre, responsables, selon la théorie psychanalytique, de la structuration du sujet, pouvaient être admis par la génétique médicale comme élément constitutif de l'environnement, une condition fondamentale aux possibles articulations serait alors établie.

Nous jugeons nécessaire de considérer, en ce qui concerne les soins proposés, les aspects psychiques qui sont partie intégrante de l'histoire de la subjectivité de la famille dont est issu le jeune patient. Nous considérons que ces éléments subjectifs sont directement impliqués dans la relation de l'enfant avec son entourage, et donc dans son propre développement.

Si les possibles résistances à la psychanalyse peuvent s'alimenter du fait que ses effets ne sont pas mesurables, de tels effets peuvent néanmoins être clairement perçus, en 
particulier dans la clinique d'enfants. Dans un article publié dans la revue française Topique, nous avons examiné les altérations symptomatiques générées par le travail psychanalytique chez deux enfants aux histoires marquées par le syndrome de l'X fragile. Parmi elles, on peut citer l'acquisition du langage, l'apaisement de l'angoisse, l'amélioration des résultats scolaires et l'autonomie de l'enfant (MADEIRA et VARELA, 2016).

Les recherches en psychologie qui abordent les aspects psychiques de la maladie peuvent donc bien être utiles au milieu médical, dans la mesure où elles multiplient les possibilités d'interventions et proposent de nouvelles modalités de traitement, en accord avec les nécessités de chaque patient.

\section{Objectifs de la recherche}

\section{Objectifs généraux :}

A) Évaluer les possibles effets cliniques de la psychothérapie psychanalytique sur les symptômes des enfants porteur du syndrome de l'X fragile ;

B) Évaluer, avant et après le traitement, les difficultés linguistiques, comportementales et/ou relationnelles relatées par les parents/responsables de l'enfant ainsi que par l'équipe qui accompagne le patient, afin de confirmer ou non un changement de la symptomatologie présentée ;

\section{Objectifs spécifiques}

A) Réaliser une psychothérapie psychanalytique sur des enfants du Service de Génétique Médicale du HCPA ;

B) Réaliser une pré-évaluation pour identifier les difficultés de l'enfant en termes de langage et de comportement ;

C) Réaliser une évaluation en fin d'accompagnement pour constater ou non des changements dans le cadre symptomatique de l'enfant ;

D) Proposer un dialogue entre la génétique et la psychanalyse, en réalisant un échange de savoir entre les deux champs.

\section{Population}

La recherche portera sur des enfants âgés de trois à douze ans, présentant un syndrome de l'X fragile, avec mutation complète ou pré-mutation, hospitalisés au sein du Service de Génétique Médicale de l'HCPA. On utilisera un échantillon d'une dizaine 
d'enfants choisis sur des critères pratiques. Parmi eux, nous prendrons soin d'en sélectionner cinq sous traitement médicamenteux (psychotropes) et cinq qui ne prennent aucun médicament. Le responsable de l'enfant sera invité à signer un terme de consentement de participation à la recherche sur la durée proposée. Aucun bénéfice financier n'est prévu pour les participants. Signalons que l'engagement intellectuel des enfants ne sera pas critère d'inclusion ou d'exclusion de celles-ci pour la recherche.

\subsection{Critères d'inclusion}

Enfants (de 3 à 12 ans) diagnostiqués porteurs de l'X fragile, avec mutation complète ou pré-mutation ;

Le responsable légal devra signer un terme de consentement ;

Enfants résidant à Porto Alegre ou en région métropolitaine.

\subsection{Critères de non-inclusion}

Enfants résidant hors de la région métropolitaine de Porto Alegre ;

Enfants porteurs d'autres syndromes génétiques associés.

\section{Méthodologie}

La méthodologie utilisée se fonde sur les recherches qualitatives qui veulent comprendre les éléments subjectifs de la réalité, particulièrement difficiles à mesurer ou à quantifier. L'instrument utilisé sera celui du suivi psychologique d'orientation psychanalytique sur les enfants $\mathrm{X}$ fragile préalablement sélectionnées. Les consultations auront lieu une fois par semaine pendant huit mois, à raison de 45 minutes par séance, au Centre de Recherche Clinique de l'HCPA, sous la responsabilité de la chercheuse associée, Mme Andréa Varela. Signalons toutefois qu'il est possible que les patients ne viennent pas à tous les rendez-vous.

La recherche prévoit une rencontre initiale pour donner des éclaircissements sur le projet au patient et à ses responsables ainsi qu'une rencontre finale pour présenter les résultats obtenus. Elle compte également sur une participation régulière aux réunions de l'équipe médicale, permettant un échange de points de vue sur les cas cliniques, et en particulier sur l'évolution symptomatique des patients. On pourra de cette manière établir un dialogue interdisciplinaire sur les cas cliniques, ouvrant la porte à un échange de connaissances et à une tentative d'amélioration des stratégies de traitement. 
Nous prétendons réaliser une pré-évaluation afin d'identifier les difficultés de l'enfant dans les dimensions intrinsèquement liées du langage et du comportement. De telles informations seront recueillies à partir du discours des parents/responsables et de l'équipe accompagnant le patient. C'est ainsi que, lors des premières séances, seront évalués les points suivants. Il ne s'agit pas ici de questions objectives posées aux parents ou aux enfants, mais de critères de référence du psychanalyste par rapport au cadre clinique de ces derniers :

1) L'enfant a-t-il une relation avec les autres ? En d'autres termes, adresse-t-il son regard, montre-t-il des objets, comprend-il les gestes et les intentions des autres ?

2) L'enfant fait-il usage de la parole ? Si oui, cette parole est-elle adressée aux autres ? Utilise-t-il la parole pour attirer l'attention ou le regard des gens ? Ou bien s'agit-il de mots isolés, répétés, sans véritable sens ni relation avec les autres ?

3) Son vocabulaire est-il riche ? L'enfant parvient-il à organiser ses mots pour former des phrases ? Parvient-il à transmettre des idées subjectives ? Est-il capable, par exemple, de parler de ses sentiments, de tristesse ou de contrariété, ou au contraire extériorise-t-il ces sentiments par des agressions?

4) L'enfant, dans ses relations ou en jouant, démontre-t-il une capacité à subjectiver les sentiments des autres ? Peut-il raconter une histoire? Peut-il relater des événements survenus ? Peut-il replacer ces événements dans une relation de cause à effet? Lorsqu'il joue, est-ce qu'il invente un scénario ? Est-ce qu'il élabore une histoire avec des personnages? Quel est le niveau de symbolisation de ces personnages ? Est-ce qu'ils se réfèrent directement à l'enfant ou maintiennent-ils la distance d'un faire-semblant ? Et dans d'autres types de jeux, jusqu'où l'enfant parvient-il à soutenir ce faire-semblant? Par exemple, lorsqu'il s'agit de se bagarrer pour jouer et pas pour de vrai, manger pour jouer et pas de vrai, mordre pour jouer et pas pour de vrai. Enfin, l'enfant a-t-il des moments d'angoisse pendant ces jeux ou bien le faire-semblant se déroule-t-il en toute tranquillité ?

5) L'enfant parvient-il à faire un usage figuré du langage ? Autrement dit, comprendil que les mots et expressions peuvent avoir plusieurs sens? Dans quelle mesure parvient-il, à partir de ces jeux de langages, à faire de l'humour, des blagues ?

6) L'enfant présente-t-il des difficultés d'apprentissage ? A-t-il de bonnes notes à l'école ? Parvient-il à acquérir les connaissances prévues pour son âge ? 
7) L'enfant présente-t-il des difficultés relationnelles à l'école avec ses camarades ou avec les professeurs ? Se montre-t-il agressif ou agité ? Parvient-il à se concentrer sur les activités scolaires ? Se montre-t-il isolé des autres enfants ? Accepte-t-il les règles imposées par l'école?

8) L'enfant présente-t-il des difficultés relationnelles à la maison, avec ses parents ou avec ses frères et sœurs ? Accepte-t-il les limites définies par ses parents ? A-t-il l'air triste ? Arrive-t-il à jouer? Comment joue-t-il : toujours tout seul ou nécessairement accompagné ? Se concentre-t-il exclusivement sur les jouets électroniques, comme les ordinateurs ou jeux-vidéos ? L'enfant a-t-il du mal à dormir? Présente-t-il des symptômes d'énurésie nocturne ?

9) L'enfant présente-t-il des symptômes liés à ses nécessités biologiques : contrôle sphinctérien, impossibilité d'aller aux toilettes, constipation, encoprésie ? L'enfant présente-t-il des symptômes liés à l'alimentation : ne mange pas certains aliments, sans justification organique?

10) D'une manière générale, l'enfant semble-t-il angoissé ? Présente-t-il des phobies, c'est-à-dire, des peurs disproportionnées aux dangers auxquels il est exposé ?

La méthodologie utilisée par la psychanalyse repose sur un accompagnement régulier d'un cas clinique individuel. Le matériel clinique prévoit deux moments de prise de notes : un premier pendant la séance, et un second, plus détaillé, après la séance. La collecte de données est ainsi faite par le chercheur-thérapeute lui-même, dans la mesure où c'est le matériel clinique qui constitue les données de la recherche. Les données ne seront pas collectées sous forme de question-réponse, mais au travers de l'expérience et d'écriture du cas clinique. Autrement dit, le matériel clinique est constitué dans son ensemble pendant les séances: il inclut le discours familial, le cadre clinique de l'enfant, l'évolution symptomatologique et les échanges entre la thérapeute, l'enfant et sa famille. Le matériel clinique est évalué au travers de l'analyse de contenu. Cette articulation entre collecte de données et relation thérapeutique est largement travaillée par la littérature psychanalytique. Citons en référence de cette tradition deux textes de Maud Mannoni au sujet de divers cas cliniques d'enfants dans des institutions (voir MANNONI 1964/1977 et 1967/1999).

La pratique clinique suit comme principe de base l'écoute psychanalytique, à travers de laquelle elle cherche à mettre en évidence les contenus inconscients présents dans le langage et dans les jeux des enfants, mais aussi dans le discours de ceux qui s'en occupent. 
Nous partons ainsi de certains concepts psychanalytiques, comme ceux de l'attention flottante et du transfert (FREUD, 1912), pour donner une direction opérationnelle à la recherche dans ce domaine.

La notion d'attention flottante signifie que le thérapeute est attentif à ce qui traverse les contenus manifestes du discours des patients ; en d'autres termes, à ce qui est latent et inconscient dans ce discours. Chez les enfants, c'est dans le jeu que l'imaginaire inconscient se met en scène. Le transfert est la relation que le thérapeute établit avec ses patients. Selon Luciano Elia (1999), elle est condition structurelle de la recherche en psychanalyse. C'est à partir du transfert qu'émergent les productions inconscientes singulières, constituant la spécificité de l'objet d'investigation psychanalytique (LO BIANCO, 2003).

Pour Freud (1912, p.152), la psychanalyse se caractérise par la «coïncidence entre clinique et recherche », apportant ainsi la notion d'une méthode pensée au cours de sa mise en œuvre. Comme chaque cas implique une condition transférentielle particulière, nous proposons une méthode de recherche basée l'étude détaillée de cas cliniques et sur son articulation constante avec l'étude de la théorie psychanalytique et avec les recherches en génétique médicale.

À la fin de la période de suivi proposée - et préalablement informée aux familles une synthèse de l'évolution de chacun des cas sera faite à l'équipe médicale. Si nécessaire, les familles seront acheminées vers d'autres institutions afin de donner suite à l'accompagnement psychothérapique. En raison de l'immense demande qui lui est imposée, le Service de Psychologie de l'HCPA n'est pas en condition d'accueillir ni de donner suite au travail avec les patients accompagnés par le projet au sein de l'Hôpital.

Une analyse de données sera réalisée de manière concomitante aux consultations, avec notamment comme objectif de mettre en évidence les effets cliniques produits par l'accompagnement psychologique. S'agissant d'une recherche qualitative, les données produites par notre étude seront difficilement mesurables avec pertinence par des outils quantitatifs. Mais l'analyse qualitative que nous proposons repose sur les observations cliniques exposées plus haut - observations qui apportent des éléments substantiels du développement de l'enfant. Nous chercherons donc à analyser, par le biais de la méthodologie d'analyse de contenu, si les symptômes présentés initialement par les enfants ont montré des modifications pouvant être associées au traitement psychanalytique. L'analyse qualitative visera à penser l'évolution clinique des enfants par rapport à ces symptômes. 
Pour ce faire, prenant en référence les critères listés ci-dessus, nous établirons deux moments d'analyse du cadre clinique des enfants : un premier au début et un second à la fin $\mathrm{du}$ traitement. Pour chacune de ces analyses, nous émettrons un rapport clinique caractérisant de manière détaillée les symptômes présentés par l'enfant. Les rapports seront élaborés sur la base de deux sources principales : 1) l'observation clinique de la thérapeute, 2) le discours des parents/responsables relatant les difficultés passées par l'enfant.

L'élaboration du premier rapport sera le fruit de trois sessions maximum - période au cours de laquelle la thérapeute tâchera de composer l'ensemble du cadre clinique. En psychanalyse, ces premières rencontres sont appelées entretiens préliminaires (MANNONI, 1979) et ont précisément comme objectif de produire une première appréhension du cas d'étude. Les entretiens initiaux sont à demi structurés, dans la mesure où la thérapeute connaît les références préalables de l'analyse (questionnaire détaillé plus haut) et les soulève au cours des séances. Les parents / responsables se voient ainsi interrogés sur l'histoire de la famille ainsi que sur le comportement de l'enfant et ses symptômes.

Le second rapport clinique se réfèrera aux mêmes critères : la recherche prétend effectuer une comparaison du cadre final avec le cadre initial et analyser ainsi les altérations produites au cours de la période de traitement. En plus de la source de données du matériel clinique, le second rapport comptera également sur des entretiens semi-structurés avec les parents, ainsi que sur les observations de la thérapeute. L'analyse finale des résultats de la recherche, qui consiste à se penser les effets du traitement, se fera donc à partir de la confrontation entre le premier et le second rapport.

Notre recherche publiée récemment dans la revue Topique, et qui présente brièvement deux cas cliniques d'enfants diagnostiqués porteurs du syndrome de l'X fragile, laisse entrevoir le type d'évolutions symptomatiques qui peuvent être repérées. Citons ici le cas de Flora, cinq ans, qui présentait au début du traitement ce que son pédiatre appela «mutisme sélectif » (symptôme que le médecin n'attribuait pas au syndrome). De fait, Flora ne parlait qu'au sein du noyau familial, refusant d'adresser la parole à d'autres personnes qu'à ses parents et à son frère. Flora fut suivie pendant dix mois. Au cours de son traitement, l'enfant commença peu à peu à s'adresser à d'autres personnes : à sa thérapeute, à son institutrice, à ses camarades, à des inconnus. Ainsi, le traitement psychanalytique semble avoir produit un décollement entre le symptôme (mutisme) et le syndrome génétique décollement qui, bien que présent dans le discours médical, n'était pas effectif cliniquement parlant. Autrement dit, psychologiquement, Flora signifiait son syndrome par le symptôme 
du mutisme. En somme, les résultats de ce traitement sont ponctués par la tension entre les cadres cliniques du début et de la fin du traitement, cadres où apparaissent des symptômes cruciaux comme le mutisme sélectif dans le cas de Flora.

En outre, le cas de Flora nous aura servi de paradigme en ce qui concerne la durée de recherche proposée, en l'occurrence huit mois. La littérature psychanalytique présente une large variation de temps de traitement. On sait que les expériences cliniques en consultation particulières peuvent se dérouler sur une période de plusieurs années. Mais à l'opposé, on sait que dans certaines institutions où la psychanalyse est insérée, et en particulier dans les dispositifs qu'Ana Cristina Figueiredo appelle «ambulatoires publics» (1997), les traitements ont une durée très réduite et adaptée à l'institution dans laquelle ils sont réalisés. Enfin, les prises en charge psychanalytiques démontrent des caractéristiques très variables, passant d'un traitement psychiatrique de patients en crise (voir MADEIRA, 2015) à un traitement court en milieu hospitalier (voir MORETTO, 2001). Notons que nous n'avons trouvé dans la littérature psychanalytique aucune étude équivalente à celle que nous proposons ici, articulant syndrome génétique et clinique infantile.

La recherche qui se rapproche le plus de la nôtre fut menée par le psychanalyste Jorge Forbes et son équipe (FORBES, 2011). L'étude propose un accompagnement psychanalytique à un groupe de 42 patients souffrant de maladies neuromusculaires diverses et d'origines génétiques. La recherche fut réalisée à la Clinique de Psychanalyse du Centre du Génome Humain de l'Université de São Paulo (USP), dans l'objectif d'étudier les effets de la psychothérapie psychanalytique chez ces patients. La recherche a évalué les résultats de manière globale après les quatre premiers mois du travail, indiquant des améliorations symptomatiques considérables.

Mais il est fondamental de noter que les patients pris en charge dans cette Clinique continuèrent leurs traitements après l'évaluation. Autrement dit, l'évaluation avait pour objectif de défendre la validité du dispositif psychanalytique, et dans la mesure où ils n'impliquèrent pas l'interruption des accompagnements, ces derniers eurent finalement une durée indéterminée. En ce sens, il est important de noter qu'une amélioration symptomatique peut connaître des régressions si le traitement n'est pas maintenu sur une durée substantielle. C'est en sachant l'impossibilité de l'Hospital de Clínicas de Porto Alegre à donner une continuité au travail réalisé avec les patients dans le cadre de ce projet, que nous proposons un accompagnement de huit mois, temps stipulé pour l'obtention d'améliorations symptomatiques possiblement plus consistantes. 
En somme, la méthodologie utilisée peut être résumée ainsi : 1) entretiens initiaux semi-structurés pour l'élaboration du premier rapport, constitué du discours des parents / responsables et par l'observation du thérapeute ; 2) le thérapeute, sur la base des opérateurs psychanalytiques du transfert et de l'attention flottante, identifiera les contenus psychiques relatés dans les comptes-rendus écrits des consultations ; 3) ce matériel clinique sera évalué au travers d'une analyse de contenu, faisant appel aux concepts psychanalytiques ; 4) un second rapport sera élaboré à la fin du suivi, également constitué des témoignages des parents et des observations du thérapeute. Ce second rapport sera comparé au rapport initial. Les résultats de la recherche surgiront à partir de cette confrontation entre les cadres cliniques initiaux et finaux des enfants.

\subsection{Recrutement}

Le contact avec les éventuels patients se fera par le médecin responsable du service qui remettra aux participants les documents d'information et de consentement à inclusion dans la recherche.

\subsection{Conduite de la recherche auprès de chaque patient}

Nous proposons pour chaque patient un suivi hebdomadaire avec des séances de 45 minutes sur huit mois, totalisant a priori trente-deux séances (mais considérant, par rapport à cette prévision, d'éventuelles absences de la part des participants).

\subsection{Fin de la recherche}

Il sera proposé à tous les participants de la recherche un entretien avec la chercheuse à propos des résultats. Suite à cette rencontre, les parents/responsables recevront une synthèse écrite de la recherche.

\subsection{Durée prévue pour chaque participant}

La durée prévue pour chaque participant est de huit mois.

\subsection{Matériel nécessaire}

Une salle de consultation. Matériel graphique et ludique pour la réalisation des séances. 


\subsection{Budget de la recherche}

Utilisation d'une salle pour 10 patients - en consultation hebdomadaire pendant huit mois :

Coût de l'utilisation d'une salle au Centre de Recherche Clinique : 7,55 Reais Brésiliens. Coût total : 2,416 Reais.

Matériel ludique (jouets et matériel graphique) : 300 Reais.

Coût total de la recherche : 2716 Reais Brésiliens.

\section{Chronogramme}

Après approbation du projet par le Comité Ethique de l'HCPA, la prévision est de réaliser la recherche sur douze mois, soit huit consacrés au travail clinique (sélection, suivi et orientation) et trois à l'élaboration des résultats. Prévoyant de commencer les activités en juin de l'année en cours, nous proposons le chronogramme suivant :

\begin{tabular}{|c|c|c|c|}
\hline Activités & Mai 2017 & $\begin{array}{c}\text { Juin 2017- Mars } \\
2018\end{array}$ & $\begin{array}{c}\text { Mars 2018 - Juin } \\
2018\end{array}$ \\
\hline Sélection & $\mathbf{X}$ & & \\
\hline Consultations & & $\mathbf{X}$ & $\mathbf{X}$ \\
\hline Orientations & & $\mathbf{X}$ & $\mathbf{X}$ \\
\hline Analyse de données & & & \\
\hline $\begin{array}{c}\text { Élaboration des } \\
\text { résultats }\end{array}$ & & & \\
\hline
\end{tabular}

\section{Présentation des résultats}

La particularité de la méthodologie proposée ici est que l'analyse de donnée se fait tout au long de la recherche, pendant les consultations avec l'enfant et sa famille, et dans un dialogue permanent avec l'équipe médicale. Après la finalisation du projet, on prévoit une rencontre avec l'enfant et ses parents/responsables pour évaluer le chemin parcouru et les résultats obtenus. En ce qui concerne l'équipe médicale, les résultats lui seront présentés formellement non seulement en réunion mais également au travers des productions écrites 
découlant par la recherche - à commencer par la thèse de doctorat et les articles scientifiques. Notons que les cas cliniques seront présentés à l'équipe technique non seulement en tant que résultats formels de la recherche et mais aussi au sein travail interdisciplinaire réalisé au cours de l'étude. Une telle présentation, prenant en compte l'écriture des cas cliniques, est aussi une preuve de l'application de la méthode psychanalytique pendant les consultations.

\section{Droit d'accès aux données et aux documents produits}

Toutes les familles auront un droit d'accès, si elles le souhaitent, aux données produites et aux synthèses des séances.

\section{Considérations légales et éthiques}

La recherche suivra des règles d'éthique et de conduite de l'Hospital de Clínicas de Porto Alegre, respectant les droits des patients à la non-divulgation des données sans consentement préalable.

\section{Références Bibliographiques}

ANSERMET, F. \& GIACOBINO, A. (2012) Autisme : à chacun son génome. Paris, Navarin / Le Champ freudien.

ARMSTRONG, L. (2014). Epigenetics. New York and London, Garland Science.

AVITAL, E. \& JABONKLA, E. (2000). Animal Traditions : Behavioural Inheritance in Evolution. Cambridge, Cambridge Press.

CORIAT, L. \& JERUSALINSKY, A. [1982]. Aspectos estruturais e instrumentais do desenvolvimento. In: Escritos da Criança. Porto Alegre, Centro Lydia Coriat, 1996.

ELIA, L. (1999) A Transferência na Pesquisa em Psicanálise: Lugar ou Excesso? In: Psicologia: Reflexão e Crítica, Volume 12, N. 3, Porto Alegre.

FIGUEIREDO, A.C. (1997). Vastas Confusões e Atendimentos Imperfeitos: A Clínica Psicanalítica no Ambulatório Público. Rio de Janeiro, Relume-Dumará.

FORBES, J. (2011). Desautorizando o sofrimento socialmente padronizado em pacientes afetados por doenças neuromusculares (Tese de doutorado). Programa de Neurologia da Faculdade de Medicina da Universidade de São Paulo, São Paulo.

FREUD, S. [1912]. Sobre a Dinâmica da Transferência. In: Obras Completas, Volume XII. Rio de Janeiro, IMAGO, 1976. 
FREUD, S [1912]. Recomendações aos médicos que exercem a psicanálise. In: Obras Completas, Volume XII. Rio de Janeiro, IMAGO, 1976.

FREUD S, [1914]. Sobre o narcisismo: uma introdução. In : Obras completas- Volume XIV. Rio de Janeiro, IMAGO, 1974.

GÜRKAN K. \& HAGERMAN R. (2012). Targeted treatments in autism and fragile X syndrome. Research in Autism Spectrum Disorders, 6:1311-1320.

HAGERMAN J. \& HAGERMAN P. (2002). Fragile X syndrome: diagnosis, treatment and research. Third edition. New York: The Johns Hopkins University Press.

HEARD E., Épigénétique et mémoire cellulaire. Leçons inaugurales du Collège de France (2013), Fayard.

HUI, J-J. (2011). Hippocampal neurochemistry is involved in the behavioural effects of neonatal maternal separation and their reversal by post-weaning environmental enrichment: A magnetic resonance study. In: Behavioural Brain Research, $\mathrm{N}^{\circ}$ 217, p. 122-127.

JERUSALINSKY, A. \& LAZNIK, M.C. (2011). Uma discussão com a neurociência. In: $O$ livro negro da psicopatologia contemporânea. Orgs: Jerusalinsky, A. \& Fendrik, S. São Paulo, Via Lettera.

LO BIANCO, A-C. Sobre as bases dos procedimentos investigativos em psicanálise. In: Psico-USF, Volume 8, N. 2, p. 115-123, Julho / Dezembro, 2003.

LUTZ, P.-E \& TURECKI, G. (2014). Dna methylation and childhood maltreatment: from animal models to human studies. In : Neuroscience, $\mathrm{N}^{\circ} 264$, p. 142-156.

MADEIRA M. (2015). Mundi-o: considerações sobre um caso de psicose. In: Revista Ágora, Volume 18, p.241-256.

MADEIRA M. e VARELA A. (2016). L'émergence de la parole chez l'enfant à la croisée de la médecine génétique et de la psychanalyse. In : Topique (Paris), nº135, p. 135-148. MANNONI M. (1964/1977). A criança retardada e sua mãe. São Paulo, Martins Fontes. MANNONI M. (1967/1999). A criança sua “doença” e os outros. São Paulo, Via Lettera. MANNONI M. (1979/2004). A primeira entrevista em psicanálise. Rio de Janeiro, Elsevier. MARTIN-BLANCO, A. et al. (2014). Association between methylation of the glucocorticoid receptor gene, childhood maltreatment, and clinical severity in borderline personality disorder. In : Journal of psychiatric research, $\mathrm{N}^{\circ} 57$, p. 34-40.

MONGET, P. \& VEITIA R. (2014). Introduction à la génétique moderne. Palaiseau, Éditions de l'École polytechnique. 
MONHONVAL, P. \& LOTSTRA, F. Transmission transgénérationnelle des traits acquis par l'épigénétique. In : Cahiers de psychologie clinique 2014/2 (n 43), p. 29-42. DOI 10.3917/cpc. 043.0029

MORETTO, M.L. (2001). O que pode um analista no hospital ? São Paulo, Casa do Psicólogo.

PERROUD, N. et al. (2013). Response to psychotherapy in borderline personality disorder and methylation status of the BDNF gene. In : Translational Psychiatry, $\mathrm{N}^{\circ} 3$, e207, 18.

RASKIN S. (2015). Genética e psicanálise: um encontro possível? In: Por uma (nova) psicopatologia da infância e da adolescência. Orgs: Kamers, M.; Mariotto, R.M. \& Voltolini, R. São Paulo, Escuta.

ROBERTS S, LESTER KJ, HUDSON et al. (2014). Serotonin transporter methylation and response to cognitive behaviour therapy in children with anxiety disorders. Transl Psychiatry, 4, e444. Doi: 10.1038/tp.2014.83

SCHECHTER, D. et al. (2015). Methylation of NR3C1 is related to maternal PTSD, parenting stress and maternal medial pre frontal cortical activity in response to child separation among mothers with histories of violence exposure. In: Frontiers in Psychology, 6:690. doi: 10.3389/fpsyg.2015.00690

THURMAN Angela, MCDUFFIE Andrea, HAGERMAN Randi et ABBEDUTO Leonard (2014). Psychiatric symptoms in boys with fragile X syndrome : a comparison with nonsyndromic autism spectrum disorder. Research in Developmental Disabilities $35: 1072-1086$.

VARELA, A. (2013) Psychanalyse et Médecine Génétique: essai d'articulation entre les différents champs du savoir à partir d'un travail sur le syndrome du chromosome $X$ fragile. Dissertação de mestrado, disponível em Biblioteca da Université Paris Diderot, Paris.

YEHUDA, R. et al. (2013) Epigenetic biomarkers as predictors and correlates of symptom improvement following psychotherapy in combat veterans with PTSD. In : Frontiers in psychiatric, Vol 4, $\mathrm{n}^{\circ} 118,01-14$.

ZIEGLER C, RICHTER J et al. (2016). MAOA gene hypomethylation in panic disorder reversibility of an epigenetic risk pattern by psychotherapy. Transl. Psychiatric, 6, e773. Doi: 10.1038/tp.2016.41. 